WILLIAM HONG

APLICAÇÃO DO MÉTODO DE ANÁLISE DE RISCO AO ESTUDO DO DESCARRILAMENTO

São Paulo

2011 


\section{WILLIAM HONG}

\section{APLICAÇÃO DO MÉTODO DE ANÁLISE DE RISCO AO ESTUDO DO DESCARRILAMENTO}

Dissertação apresentada à Escola

Politécnica da Universidade de São

Paulo para a obtenção do título de Mestre em Engenharia

Área de Concentração:

Engenharia Mecânica de Projeto de Fabricação

Orientador: Prof. Dr. Gilberto Francisco Martha de Souza

São Paulo 
Este exemplar foi revisado e alterado em relação à versão original, sob responsabilidade única do autor e com a anuência de seu orientador.

São Paulo, 25 de maio de 2011.

Assinatura do autor

Assinatura do orientador

\section{FICHA CATALOGRÁFICA}

Hong, William

Aplicação do método de análise de risco ao estudo do des carrilamento / W. Hong. -- ed.rev. -- São Paulo, 2011.

$174 \mathrm{p}$.

Dissertação (Mestrado) - Escola Politécnica da Universidade de São Paulo. Departamento de Engenharia Mecatrônica e de Sistemas Mecânicos.

1. Análise de risco 2. Dinâmica veicular 3. Ferrovias (Eficiência) 4. Material rodante (Confiabilidade) I. Universidade de São Paulo. Escola Politécnica. Departamento de Engenharia Mecatrônica e de Sistemas Mecânicos II. t. 


\section{DEDICATÓRIA}

Dedico este trabalho à minha família 


\section{AGRADECIMENTOS}

Aos meus pais e irmã pelo apoio e dedicação que sempre tiveram durante minha vida, me ajudando em todos os momentos.

Ao Prof. Dr. Gilberto Francisco Martha de Souza pela confiança depositada ao longo do trabalho e pela orientação acadêmica.

À Escola Politécnica da USP pela oportunidade de obtenção do título de mestre.

À Débora por todo o companheirismo.

Aos engenheiros Alexandre Facini e Fernando Guevara pelo apoio e incentivo neste projeto.

A todos os meus amigos que direta ou indiretamente contribuíram para este trabalho. 


\section{RESUMO}

Este trabalho propõe um método de análise de risco aplicada ao descarrilamento (incidente no qual a roda perde a sustentação provida pelo trilho, podendo ser causado por diversos aspectos como imperfeições na via, falhas no material rodante, obstáculos na via, entre outras que pode acarretar possíveis acidentes e perdas materiais e humanas) de forma a tornar mais seguro o transporte ferroviário, que atualmente não apresenta diminuição da taxa de ocorrência dos descarrilamentos, complementando assim as simulações computacionais e simulações dinâmicas que podem ser aplicadas ao estudo deste evento.

Risco pode ser definido como o potencial de perda resultante da exposição a um perigo, sendo relacionado à probabilidade de ocorrência de um evento ou combinação de eventos acarretando em um perigo e a conseqüência deste perigo. Este conceito pode ser utilizado para investigar e avaliar as incertezas associadas com um evento. Já Confiabilidade pode ser definida como a probabilidade de um item executar a sua função sob condições pré-definidas de uso e manutenção por um período de tempo específico.

Assim, considerando estes dois conceitos, será apresentada uma metodologia de análise de risco e confiabilidade para análise e discussão do descarrilamento, discorrendo sobre os possíveis parâmetros que podem causar este evento bem como propondo uma alternativa para avaliação da probabilidade de ocorrência do descarrilamento; desta forma permite guiar o gerenciamento da segurança quanto a este evento já que no Brasil não existe a figura da autoridade ferroviária, órgão máximo e responsável final pela regulamentação para a operação de um sistema ferroviário, que poderia determinar o processo que deve ser seguido para a garantia de segurança.

Os objetos de estudo serão veículos ferroviários e conseqüentemente os elementos de interface com este tipo de veículo, como por exemplo, os elementos de via.

Palavras-chave: análise de risco, confiabilidade, descarrilamento, veículo ferroviário. 


\begin{abstract}
This research proposes a risk analysis method applied to derailment event (characterized by the wheel overlap on the rail, which can be caused by many aspects: rail imperfections, rolling stock failures, obstacles etc and which can cause accidents, material and life loss) to increase the safety level on railway transport that actually does not present decrease of derailment rate. This method also complements computational and dynamic simulations, which can be applied to this event.
\end{abstract}

Risk can be defined as the potential loss due to a hazard exposure, also related with the probability of occurrence of an event or combinations of events leading to a hazard and the consequence of this hazard. This concept can be applied to investigate and to evaluate the uncertainties related with this event. Reliability can be defined as the probability of an item to perform its function under predefined use and maintenance conditions during a specific period of time.

Thus, considering these two concepts, it will be presented a risk and reliability analysis to study the derailment event, discoursing about the possible parameters that can cause this event and proposing alternatives to evaluate the derailment occurrence probability in order to guide safety management since a railway authority does not exist in Brazil (body with the overall accountability to a regulator for operation a railway system, that could determines the process to be followed to assure safety levels).

This research will cover railway vehicles and consequently the interface, for example, the railroad elements.

Keywords: risk analysis, reliability, derailment, railroad vehicle. 


\section{LISTA DE ILUSTRAÇÕES}

Figura 2.1 - Exemplo de Planilha de FMEA (Adaptado de MIL-STD-1629-A, 1984) ...8

Figura 2.2 - Porta lógica OU........................................................................

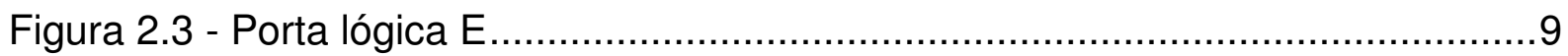

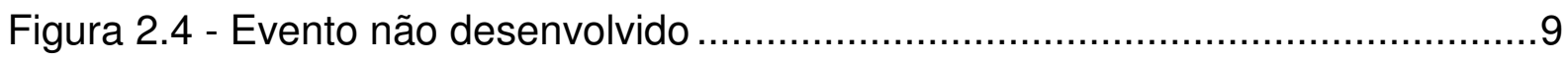

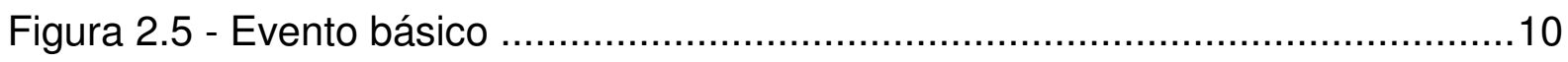

Figura 2.6 - Exemplo de comportamento da taxa de falha de um subsistema com componentes substituídos na ocorrência de falha (Adaptada de NPRD-95, 1995)...10

Figura 2.7 - Fluxograma do Método Probabilístico Condicionado Avançado ${ }^{1}$...........17

Figura 2.8 - Exemplo de diagrama de causa e conseqüência ...............................23

Figura 3.1 - Elementos de Via Permanente (SILVA, 2004) ..................................31

Figura 3.2 - Segregação no trilho (COLPAERT, 1959) ....................................32

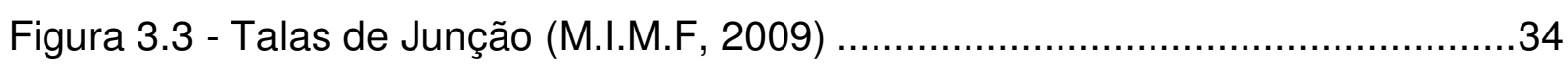

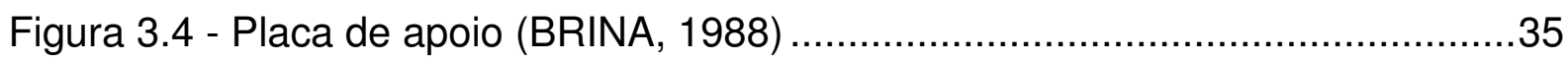

Figura 3.5 - Tirefonadora (LAUERMAN, 2008 apud ALL, 2002) ............................36

Figura 3.6 - Exemplo de Aparelho de Mudança de Via ..........................................37

Figura 3.7 - Aparelho de Mudança de Via (LAUERMAN, 2008 apud ALL, 2002)......37

Figura 3.8 - Modelo para Inscrição Limite (BRINA, 1988) .................................42

Figura 3.9 - Modelo do Avanço do Friso (Adaptado de BRINA, 1988) ....................42

Figura 3.10 - Modelo para Inscrição Livre (BRINA, 1988) ....................................44

Figura 3.11 - Modelo para Determinação de Superelevação Máxima (BRINA, 1988)

Figura 3.12 - Sistema de Guiagem de Veículos (BARBOSA, 1999) ......................49

Figura 3.13 - Truque (Adaptada de ALMEIDA, 2006) ......................................50

Figura 3.14 - Truque (Adaptada de PIRES, 2006) ..........................................50

Figura 3.15 - Suspensão Primária de Mola e Elastômero (CONSOLI, 2007)............51

Figura 3.16 - Suspensão secundária (Adaptado de CONSOLI, 2007 apud

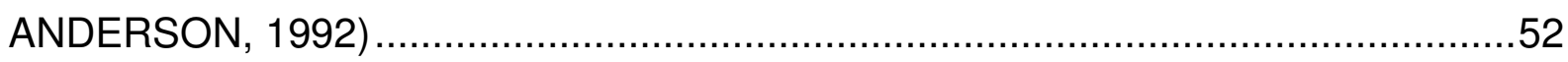

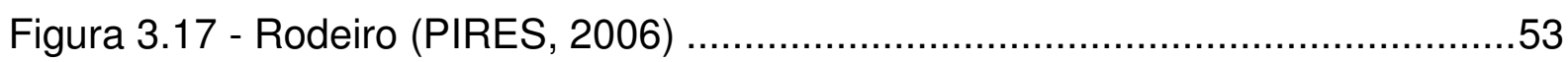

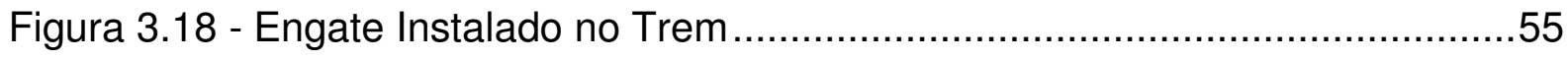

Figura 3.19 - Diagrama Funcional de um Trem de Passageiros (FACINI, 2007) ......57 
Figura 4.1 - Comportamento da taxa de acidentes dos trens em termos de quilometragem (Adaptado de RAILWAY SAFETY STATISTICS, 2005)

Figura 4.2 - Comportamento da taxa de acidentes dos trens em termos de passageiros transportados (Adaptado de RAILWAY SAFETY STATISTICS, 2005) .61 Figura 4.3 - Causas Sucintas do Descarrilamento em 2005 (RAILWAY SAFETY STATISTICS, 2005) .65

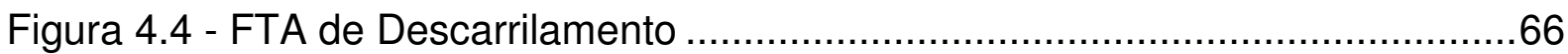

Figura 4.5 - Forças de Contato Para o Critério de Nadal (IWNICKY, 2006)..............71

Figura 4.6 - Exemplo de Curva do Efeito do Ângulo de Ataque no limite da relação L/V (IWNICKY, 2006) .71

Figura 4.7 - Referências Móveis e Fixas e Vetores de Força (BARBOSA, 2004) .....73

Figura 4.8 - Forças na Rotação do Trilho (IWNICKY, 2006) ..................................74

Figura 4.9 - Exemplo de Falso Contato entre Roda e Trilho (IWNICKY, 2006).........75

Figura 4.10 - Parâmetros Considerados na Equação (4.10) (IWNICKY, 2006) ........75

Figura 4.11 - Aumento da Dimensão da Bitola (IWNICKY, 2006) ………...............76

Figura 4.12 - Instabilidade Lateral do Veículo (ALMEIDA, 2006) ............................77

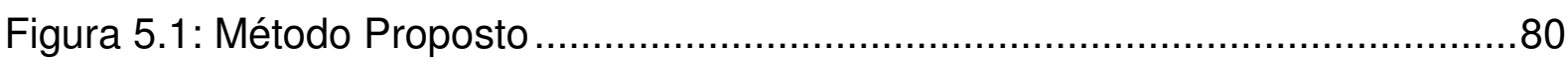

Figura 6.1 - Diagrama Causa Conseqüência - Descarrilamento ……………..........84

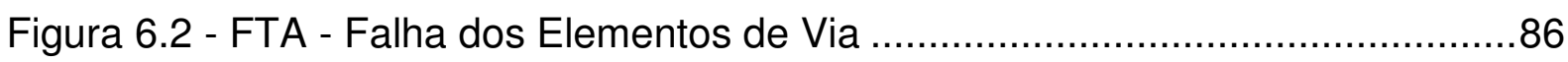

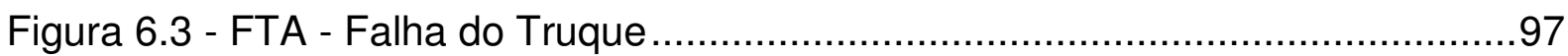

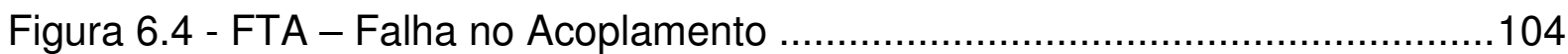

Figura 6.5 - FTA - Falha do Sistema de Tração e Frenagem …….........................110

Figura 7.1 - Princípio do Lubrificador de Flange de Roda (REBS, 2009) ................124

Figura 7.2 - Princípio de Funcionamento do Sistema de Lubrificação de Flange

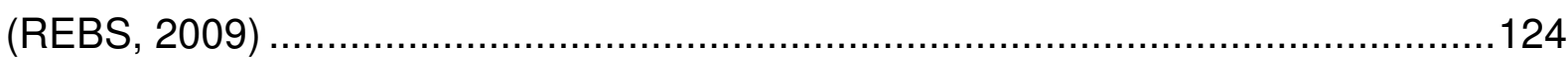

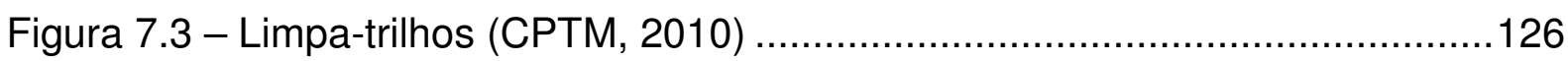

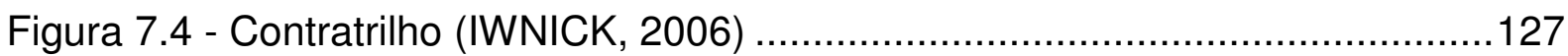

Figura 7.5 - Fluxograma de Monitoramento ………...........................................137

Figura ( A-1 ) - Parâmetros do perfil da roda definidos em norma (UIC 510 - 2, 2004)

Figura ( B-1 ) - Valores Limite das dimensões Eixo-furo (UIC 813 O, 2003) ...........161

Figura ( C-1 ) - Fluxograma Geral de Aprovação de um Veículo ferroviário Quanto

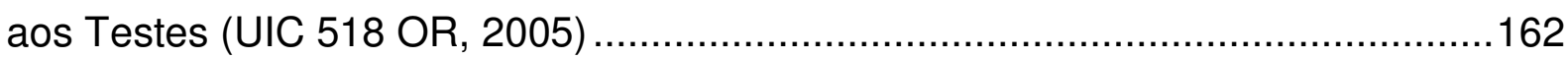

Figura ( D-1 ) - Trilho com regiões descarbonetadas (COLPAERT, 1959) ..............163 
Figura ( D-2 ) - Trilho com segregação, bolhas e fissura interna (COLPAERT, 1959) 163

Figura ( D-3 ) - Trilho com segregação e fissura (COLPAERT, 1959) ....................164

Figura ( D-4 ) - Trilho fissurado devido a trincas de fadiga (COLPAERT, 1959) .....164

Figura ( D-5 ) - Tirefão com segregação (COLPAERT, 1959) ...............................165

Figura ( D-6 ) - Tirefão com segregação (COLPAERT, 1959) ………...................165

Figura ( E-1 ) - Campos da referência (FMD, 1997) ..........................................166

Figura ( E-2 ) - Falhas referentes à roda (FMD-97, 1997) .................................166

Figura ( E-3 ) - Falhas referentes ao eixo (FMD-97, 1997) .................................167

Figura ( E-4 ) - Falhas referentes à mola (FMD-97, 1997) …............................168

Figura ( E-5 ) - Falhas referentes ao redutor (FMD-97, 1997) ..............................168

Figura ( E-6 ) - Falhas referentes às sapatas de freio (FMD-97, 1997) ..................169

Figura ( E-7 ) - Falhas referentes às sapatas de freio (FMD-97, 1997) ..................169

Figura ( E-8 ) - Falhas referentes ao cilindro de freio e ao mecanismo (FMD-97,

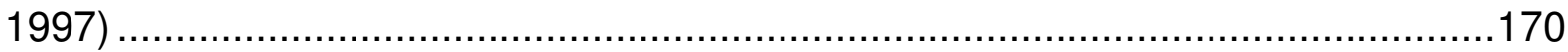

Figura ( E-9 ) - Falhas referentes ao trilho (FMD-97, 1997) …….......................170

Figura ( E-10 ) - Falhas referentes às talas de junção e fixações (FMD-97, 1997) 171 Figura ( F-1 )- Perfil de Roda UIC-ERRI para roda com diâmetro entre $1000 \mathrm{~mm}$ e $760 \mathrm{~mm}$ e altura de flange igual a $28 \mathrm{~mm}$ (UIC $510-2$ OR, 2004). 172 


\section{LISTA DE TABELAS}

Tabela 1.1 - Evolução do Transporte Regular Metropolitano ...................................1

Tabela 1.2 - Principais Investimentos das Concessionárias .....................................2

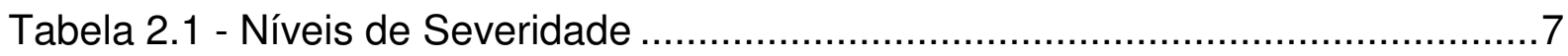

Tabela 2.2 - Variáveis Básicas e suas Funções Densidade de Probabilidade ..........20

Tabela 2.3 - Índices de Confiabilidade Obtidos na Validação do Código

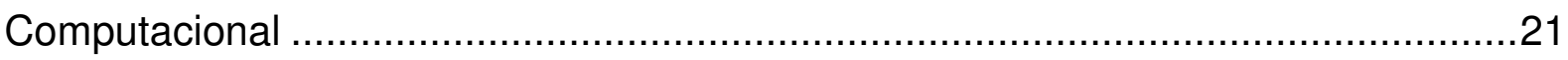

Tabela 2.4: Nível de Integridade de Segurança .................................................24

Tabela 2.5 - Freqüência de Ocorrência do Evento ................................................25

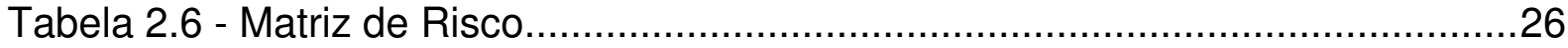

Tabela 2.7 - Ações a serem realizadas para cada categoria de risco ………...........26

Tabela 2.8 - Tabela de Multiplicadores para a Taxa de Falha................................27

Tabela 2.9 - Exemplos de Testes de Aceitação ……….............................................29

Tabela 3.1 - Tabela para Substituição e Inversão dos Trilhos....................................34

Tabela 3.2 - Comparativo entre Tipos de Dormentes.............................................38

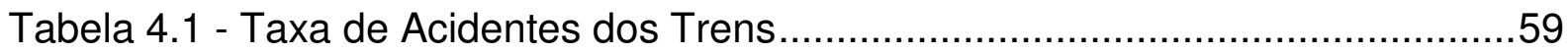

Tabela 4.2 - Sumário Histórico de Acidentes/Incidentes .......................................60

Tabela 4.3 - Causas do Descarrilamento em 2005 ..............................................62

Tabela 4.4 - Causas Sucintas do Descarrilamento em 2005 .................................65

Tabela 4.5 - Índice de Acidentes no Transporte de Carga ......................................67

Tabela 4.6 - Distribuição de Acidentes de acordo com os Critérios de

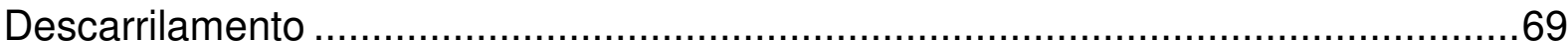

Tabela 6.1 - Elementos de Via - Modos de falha considerados e referências............87

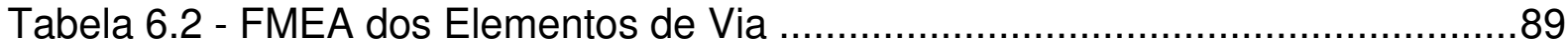

Tabela 6.3 - Sistema Truque - Modos de falha considerados e referências ..............98

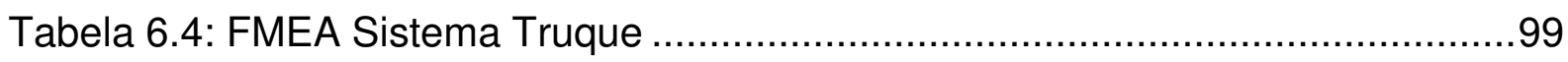

Tabela 6.5 - Sistema Acoplamento - Modos de falha considerados e referências .. 105

Tabela 6.6 - FMEA Sistema de Acoplamento....................................................106

Tabela 6.7 - Sistema de Tração e Frenagem - Modos de falha considerados e

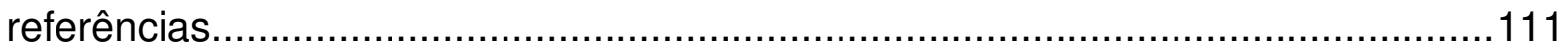

Tabela 6.8 - FMEA Sistema de Tração/Frenagem ………..............................114

Tabela 7.1 - Valores das variáveis no caso exemplo .............................................140 
Tabela 7.2 - Valor das probabilidade de falhas de acordo com diferentes

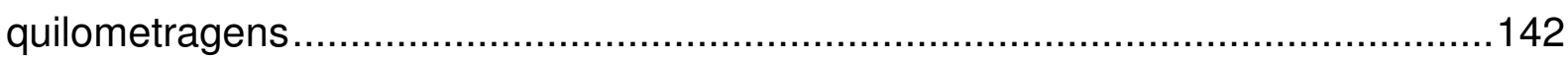

Tabela 7.3 - Valor do custo anual referente ao risco de descarrilamento ...............144

Tabela 7.4 - Valores das variáveis na análise de sensibilidade ............................145

Tabela 7.5 - Custo anual referente ao risco de descarrilamento para diferentes

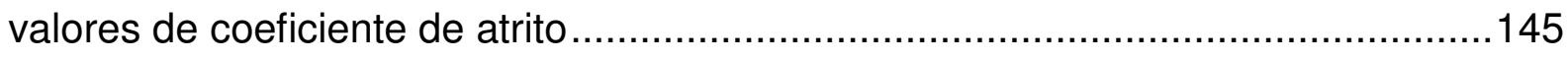

Tabela 7.6 - Custo anual referente ao risco de descarrilamento para diferentes

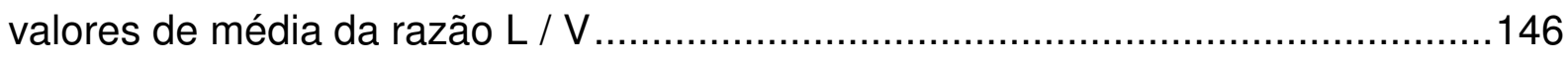

Tabela 7.7 - Custo anual referente ao risco de descarrilamento para diferentes valores de taxa de desgaste..........................................................................147 


\section{LISTA DE ABREVIATURAS E SÍMBOLOS}

ABNT Associação Brasileira de Normas Técnicas

AMV Aparelho de Mudança de Via

ANTT Agência Nacional de Transportes Terrestres

ASEP Programa de Avaliação de Seqüências de Acidentes - do inglês Accident Sequence Evaluation Program

ATP Proteção Automático do Trem - do inglês Automatic Train Protection

CPTM Companhia Paulista de Trens Metropolitanos

FMEA Análise de Modos e Efeitos de Falha - do inglês Failure Mode Effects Analysis

FMECA Análise de Modos e Efeitos de Falha Críticos - do inglês Failure Mode Effects and Critical Analysis

FPMK Falhas por Milhão de Quilômetros

FPMM Falhas por Milhão de Milhas

FRA Administração Federal das Ferrovias - do inglês Federal Railroad Administration

FTA Análise de Árvore de Falhas - do inglês Fault Tree Analysis

IBGE Instituto Brasileiro de Geografia e Estatística

MTBE Tempo Médio Entre Eventos - do inglês Mean Time Between Events

MTBF Tempo Médio Entre Falhas - do ingles Mean Time Between Failures

OAT Árvore de Ações do Operador - do inglês Operator Action Tree

OHA Análise de Perigos de Operação - do inglês Operating Hazard Analysis

RCM Manutenção Centrada em Confiabilidade - do inglês Reliability Centered Maintenance

Sev Severidade

SIL Nível de Integridade de Segurança - do inglês Safety Integrity Level

TCMS Sistema de Controle e Monitoramento do Trem - do inglês Train Control and Monitoring System

THERP Técnica para a Predição de Taxas de Erros Humanos - do inglês Technique for Human Error Rate Prediction

THR Taxa tolerável do perigo - do inglês Tolerable Hazard Rate 


\section{LISTA DE SÍMBOLOS}

Z Função do estado limite, também chamada de $\mathrm{g}(\mathrm{X})$

$x_{i} \quad$ Variável básica

$\mathrm{X} \quad$ Conjunto das variáveis $x_{1}, x_{2}, \ldots \ldots \ldots \ldots . ., x_{n}$ que descrevem o processo de colapso em estudo.

$\mathrm{X}^{*} \quad$ Conjunto das variáveis $x_{1}^{*}, x_{2}^{*}, \ldots \ldots \ldots \ldots, x_{n}^{*}$ que descrevem o ponto de linearização

$m_{z} \quad$ Valor esperado da função de estado limite $Z$

$m_{i} \quad$ Valor esperado da variável básica $x_{i}$

$\sigma_{z} \quad$ Desvio padrão da função de estado limite $Z$

$\sigma_{i} \quad$ Desvio padrão da variável $x_{i}$

$\mathrm{P}_{\mathrm{F}} \quad$ Probabilidade de colapso do sistema

$\beta \quad$ Índice de confiabilidade

$\alpha_{i} \quad$ Constante de proporcionalidade

$\Phi(\mathrm{x}) \quad$ Magnitude da função distribuição acumulada da distribuição normal reduzida, calculada no ponto " $x$ ".

$\mu_{x_{i}}^{N} \quad$ Média da distribuição normal equivalente em um determinado ponto de linearização

$F_{i}\left(X_{i}^{*}\right) \quad$ Magnitude da função distribuição acumulada da variável básica $x_{\mathrm{i}}$ calculada no ponto $\mathrm{x}_{\mathrm{i}}=X_{i}^{*}$;

$\sigma_{x_{i}}^{N} \quad$ Desvio padrão da distribuição normal equivalente em um determinado ponto de linearização

$f_{i}\left(X_{i}^{*}\right) \quad$ Magnitude da função densidade de probabilidade da variável básica $x_{\mathrm{i}}$ calculada no ponto $\mathrm{x}_{\mathrm{i}}=X_{i}^{*}$;

$\phi(a) \quad$ Magnitude da função densidade de probabilidade da distribuição normal reduzida

$g_{\Delta K}(x) \quad$ Função de desempenho para análise da vida em fadiga

$q_{i} \quad$ Dimensão inicial da trinca

$\mathrm{K}_{\mathrm{IC}} \quad$ Fator de intensificação crítica do material

$\Delta S \quad$ Flutuação de tensão.

$\mathrm{N} \quad$ Número de ciclos de carregamento 


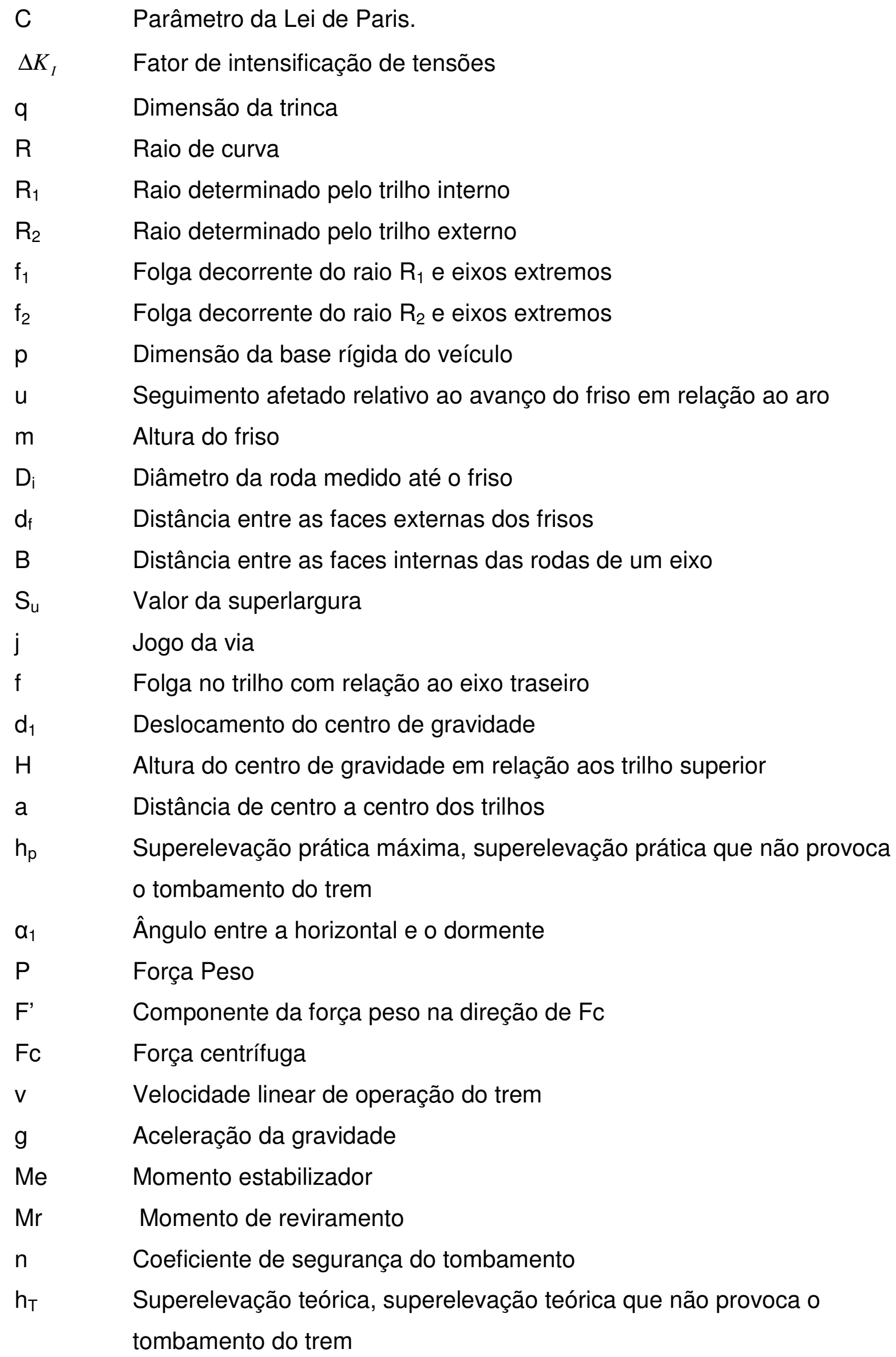




\begin{tabular}{|c|c|}
\hline$\gamma$ & Aceleração centrífuga \\
\hline L & Força lateral do contato \\
\hline V & Força vertical do contato \\
\hline $\mathrm{F} 2$ & Força de reação tangente a superfície de contato entre Flange e Boleto \\
\hline F3 & Força de reação normal a superfície de contato entre Flange e Boleto. \\
\hline$\delta$ & Ângulo de contato do flange com o boleto \\
\hline$\mu$ & Coeficiente de atrito entre roda e trilho \\
\hline$\psi$ & Ângulo entre $\vec{X}$ e $\vec{x}$ \\
\hline$\alpha$ & Ângulo entre o plano de contato da roda com o trilho e o eixo $\vec{Y}$ \\
\hline $\mathrm{T}$ & Força de Atrito \\
\hline$T_{x}$ & Componente da força T referente ao eixo $\vec{x}$ \\
\hline $\mathrm{T}_{\mathrm{w}}$ & Componente da força $T$ referente ao escorregamento rotacional \\
\hline $\mathrm{T}_{\mathrm{L}}$ & Componente da força $\mathrm{T}$ referente ao escorregamento lateral \\
\hline M & Momento torsor \\
\hline$d$ & $\begin{array}{l}\text { Distância horizontal entre o ponto de aplicação da força } V \text { e o ponto de } \\
\text { rotação do perfil do trilho }\end{array}$ \\
\hline $\mathrm{h}$ & $\begin{array}{l}\text { Distância vertical entre o ponto de aplicação da força } L \text { e o ponto de } \\
\text { rotação do perfil do trilho }\end{array}$ \\
\hline G & Bitola \\
\hline W & Largura da roda \\
\hline$f_{w}$ & Largura do flange \\
\hline S & Dimensão de segurança \\
\hline $\mathrm{t}$ & Tombamento angular do trilho \\
\hline $\mathrm{Yr}$ & $\begin{array}{l}\text { Valor em milímetros da coordenada horizontal dos pares coordenados } \\
\text { que determinam o perfil da roda UIC-ERRI para rodas com diâmetro } \\
\text { entre } 1000 \mathrm{~mm} \text { e } 760 \mathrm{~mm}\end{array}$ \\
\hline $\mathrm{Zr}$ & $\begin{array}{l}\text { Valor em milímetros da coordenada vertical dos pares coordenados que } \\
\text { determinam o perfil da roda UIC-ERRI para rodas com diâmetro entre } \\
1000 \mathrm{~mm} \text { e } 760 \mathrm{~mm}\end{array}$ \\
\hline $\mathrm{D}$ & Distância percorrida pelo material rodante \\
\hline $\mathrm{C}_{\mathrm{m}}$ & Custo referente à perda de material \\
\hline $\mathrm{C}_{\text {in }}$ & Custo referente a indenizações \\
\hline $\mathrm{C}_{\mathrm{mo}}$ & Custo de manutenção referente a mão de obra \\
\hline
\end{tabular}


$\mathrm{C}_{\mathrm{mm}} \quad$ Custo da manutenção referente a material

$\mathrm{C}_{\mathrm{a}} \quad$ Custo anual do risco

Q Quilometragem entre manutenções 


\section{ÍNDICE}

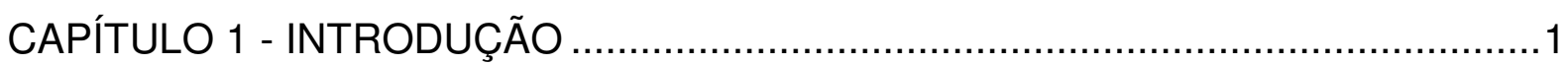

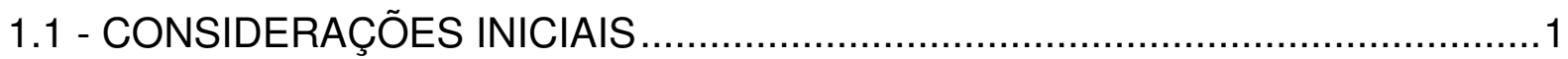

1.2 - OBJETIVO

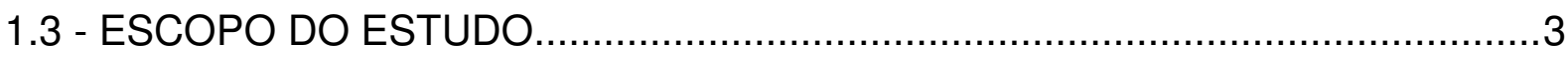

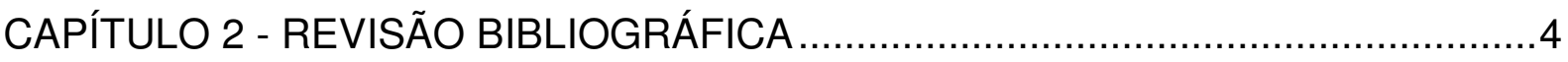

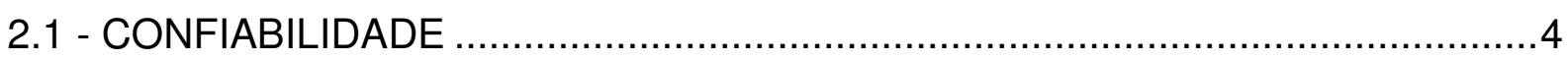

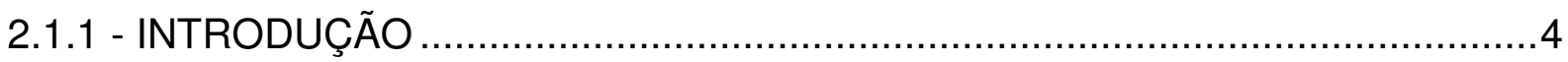

2.1.2 - ANÁLISE DE MODOS E EFEITOS DE FALHAS (FMEA) ..............................

2.1.3 - ANÁLISE POR ÁRVORE DE FALHAS (FTA) ….................................

2.1.4 - ANÁLISE DE CONFIABILIDADE POR SOLICITAÇÃO E RESISTÊNCIA .....11

2.1.4.1 - Fundamentos do Método Probabilístico Condicionado ……......................12

2.1.4.2 - Fundamentos do Método Probabilístico Condicionado Avançado ...............14

2.1.4.3 - Correção Aplicada às Variáveis Básicas...............................................18

2.1.4.4 - Código Computacional Baseado no Método Probabilístico Condicionado

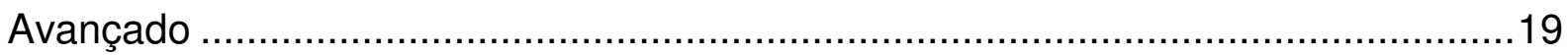

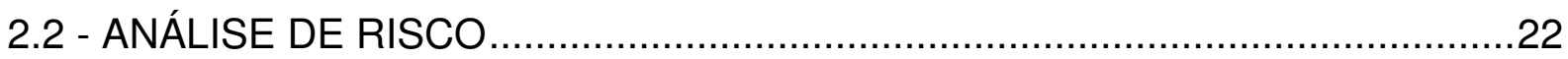

CAPÍTULO 3 - ELEMENTOS DO TRANSPORTE FERROVIÁRIO...........................30

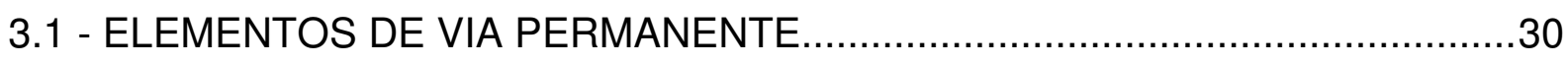

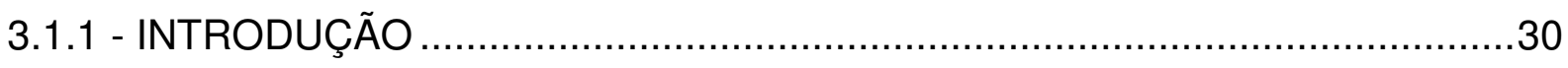

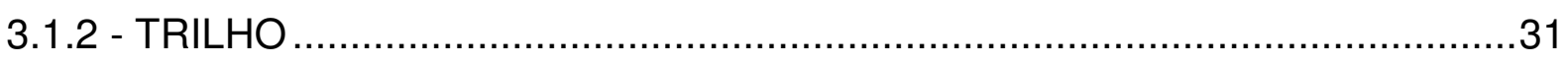

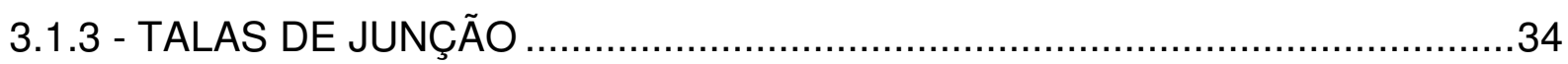

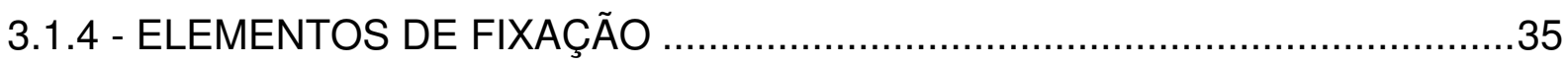

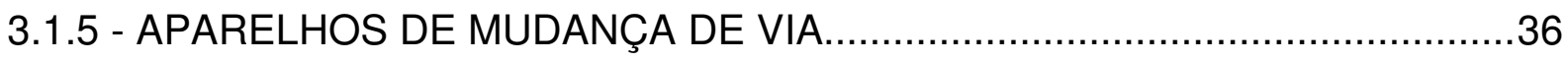

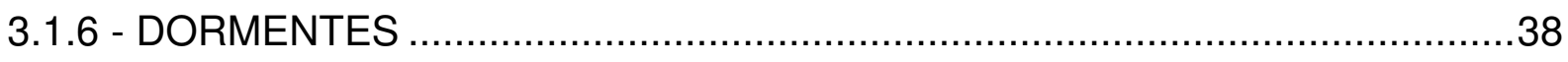

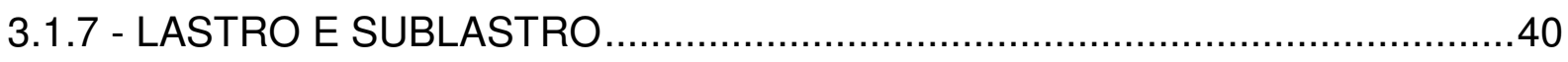

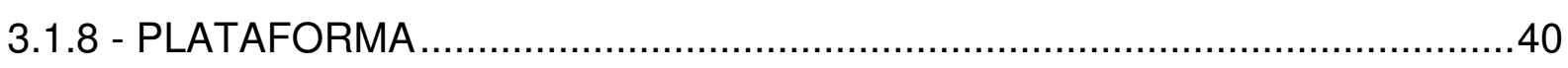

3.1.9 - CARACTERÍSTICAS GEOMÉTRICAS ................................................

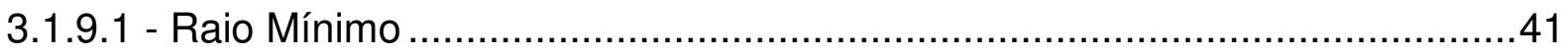

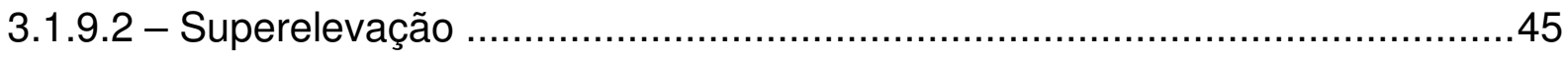

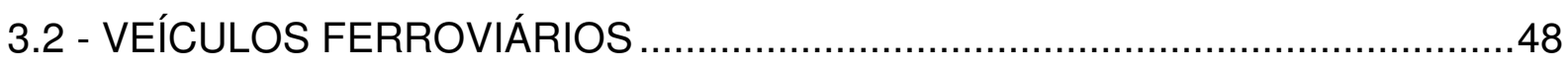

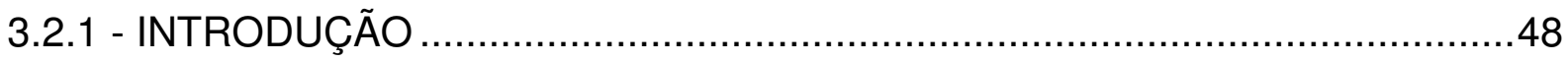




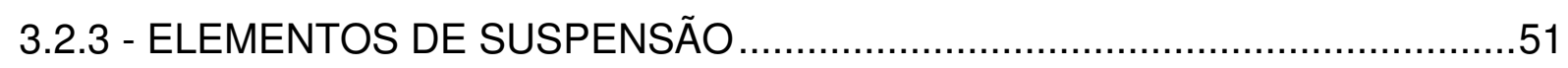

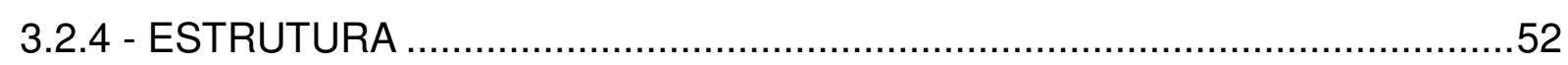

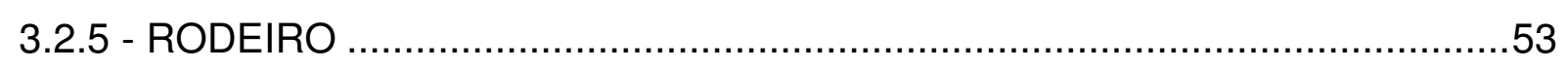

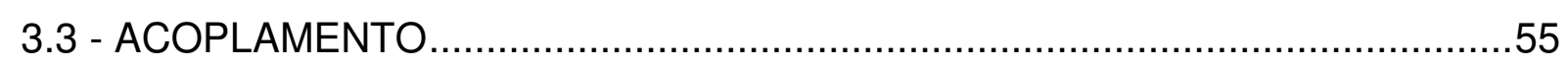

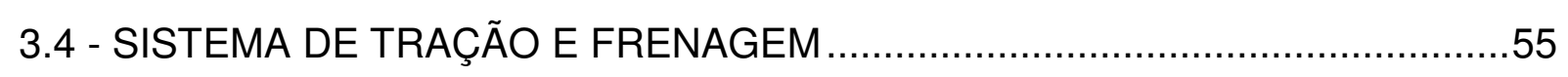

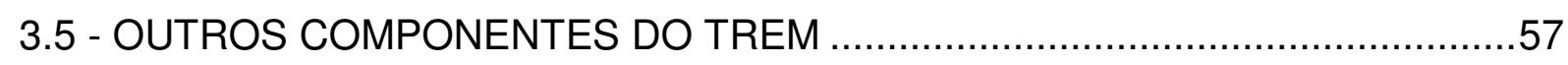

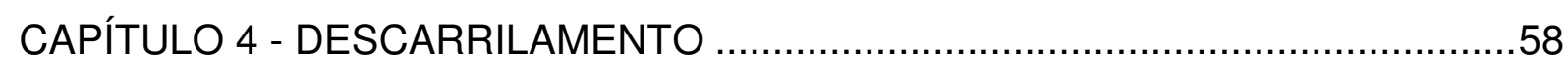

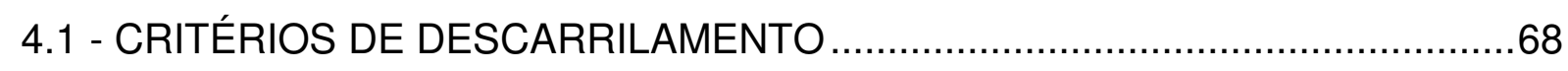

4.1.1 - SOBREPOSIÇÃO DO FLANGE DA RODA SOBRE O TRILHO …................69

4.1.2 - DIMENSÃO DO BITOLA E ROTAÇÃO DO TRILHO.....................................73

4.1.3 - DESCARRILAMENTO POR AUMENTO DA DIMENSÃO DA BITOLA ...........76

4.1.4 - INSTABILIDADE LATERAL DO VEÍCULO .................................................77

CAPÍTULO 5 - DESCRIÇÃO DO MÉTODO …....................................................78

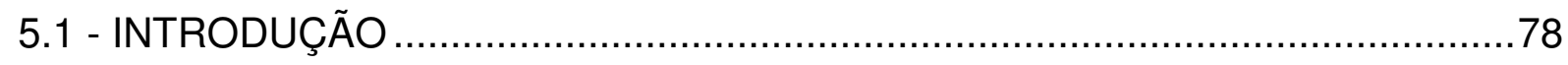

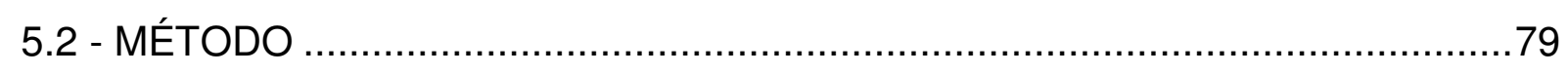

CAPÍTULO 6 - APLICAÇÃO DO MÉTODO: CASO-ESTUDO.................................83

6.1 - ANÁLISE DE CAUSA E CONSEQÜÊNCIA - DESCARRILAMENTO ................83

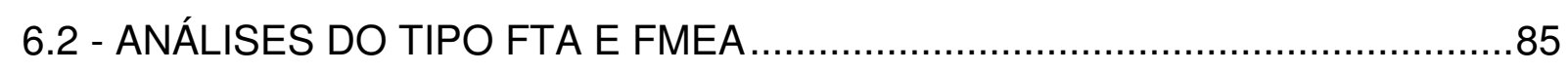

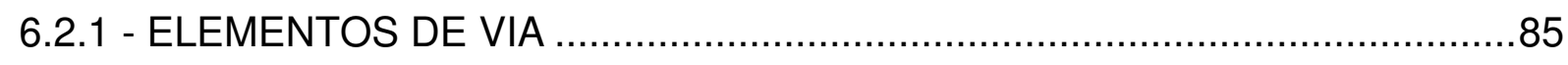

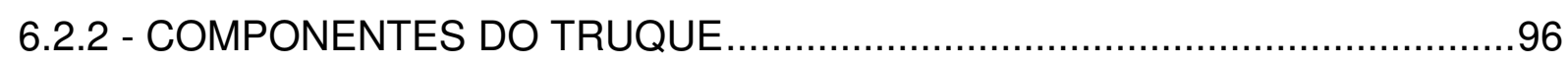

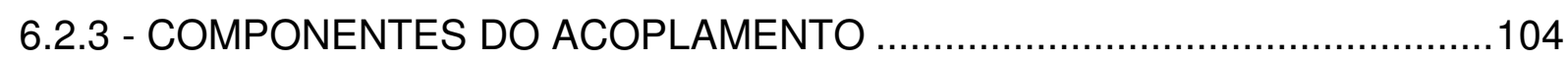

6.2.4 - COMPONENTES DO SISTEMA DE TRAÇÃO E FRENAGEM .....................109

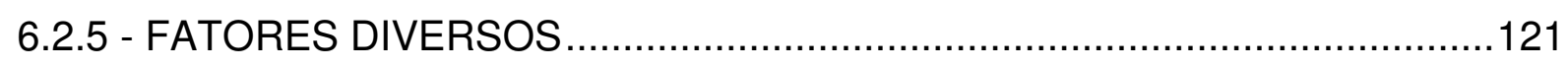

CAPÍTULO 7 - AÇÕES DE REDUÇÃO DO RISCO …............................................122

7.1 - AÇÕES PREVENTIVAS E PALIATIVAS DE PROJETO ...............................123

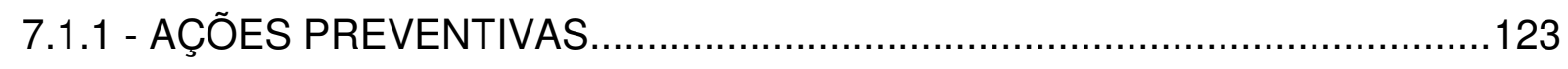

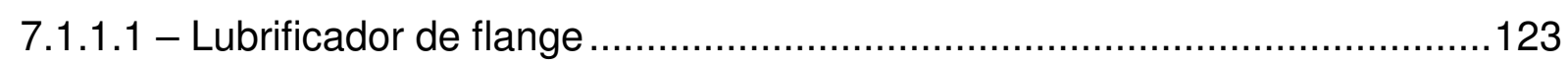

7.1.1.2 - Determinação da vida útil dos componentes ........................................125

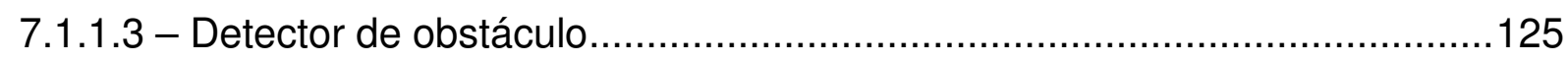

7.1.1.4 - Deflector de obstáculo - limpa-trilhos..................................................126

7.1.1.5 - Projeto que respeita os critérios de descarrilamento...............................126

7.1.1.6 - Instalação de contratrilhos em curvas acentuadas.................................127 
7.1.1.7 - Otimização da suspensão do truque e resistência do movimento de yaw do truque 127

7.1.1.8 - Inserção de monitoramento do sistema..............................................128

7.1.1.9 - Inserção de sistemas de proteção (ATP) .............................................129

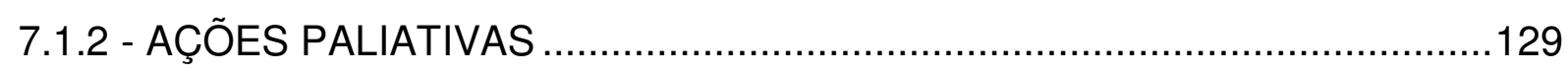

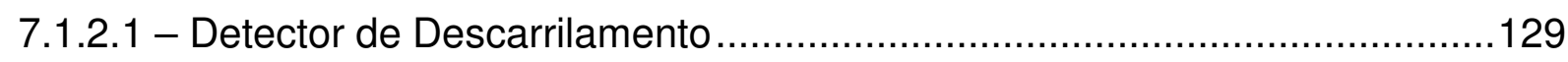

7.2 - AÇÕES PREVENTIVAS DE MANUFATURA ..............................................129

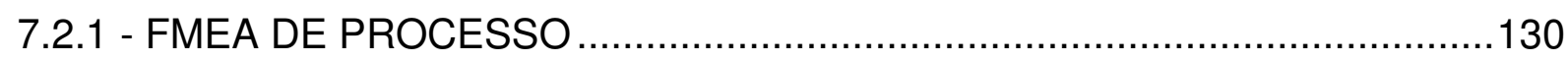

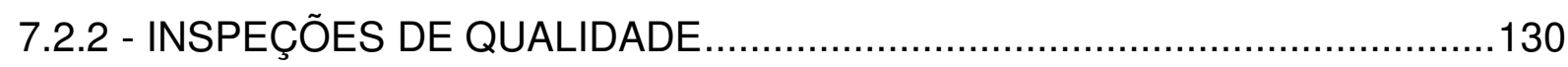

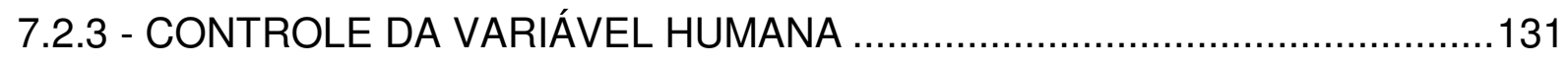

7.3 - AÇÕES DE PREVENTIVAS E PALIATIVAS DE OPERAÇÃO.........................131

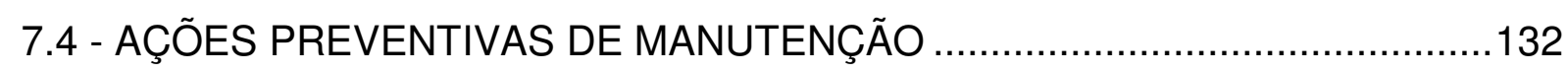

7.4.1 - MANUTENÇÃO CENTRADA EM CONFIABILIDADE ...............................132

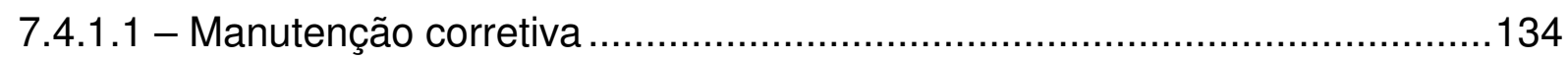

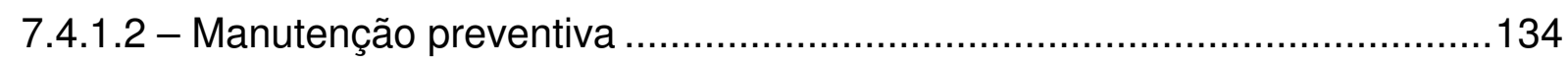

7.4.1.3 - Monitoramento das condições......................................................... 134

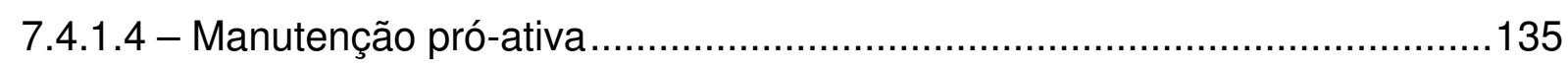

7.4.1.5 - Políticas de manutenção recomendadas...............................................135

7.4.2 - MONITORAMENTO DOS PARÂMETROS DE VIA.....................................135

7.4.3 - SISTEMA DE DIAGNÓSTICO DE FALHAS...........................................136

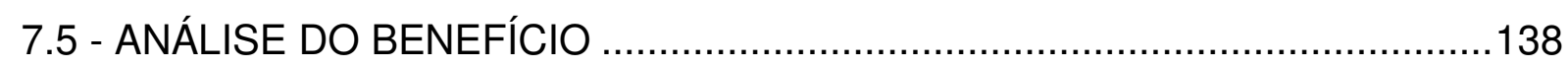

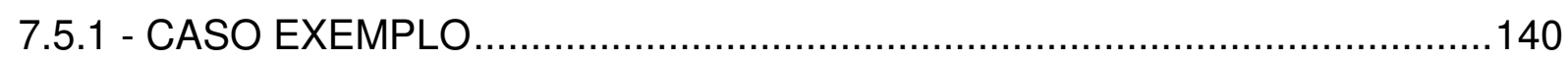

CAPÍTULO 8 - CONCLUSÕES E RECOMENDAÇÕES ......................................148

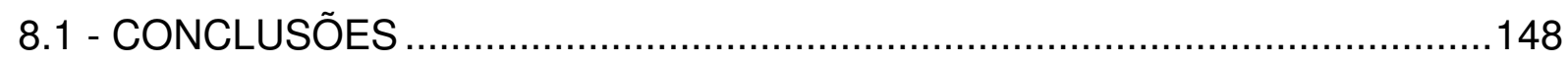

8.2 RECOMENDAÇÕES PARA TRABALHOS FUTUROS ....................................150

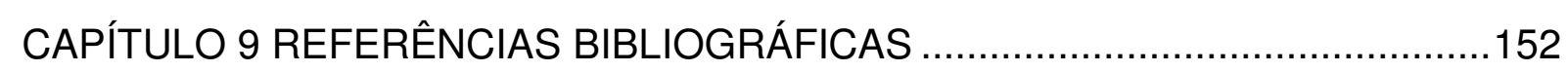

APÊNDICE A - EXEMPLO DE PARÂMETROS DIMENSIONAIS DA RODA ...........160

APÊNDICE B - TOLERÂNCIAS DAS DIMENSÕES EIXO-FURO...........................161

APÊNDICE C - APROVAÇÃO DE UM VEÍCULO FERROVIÁRIO QUANTO AOS

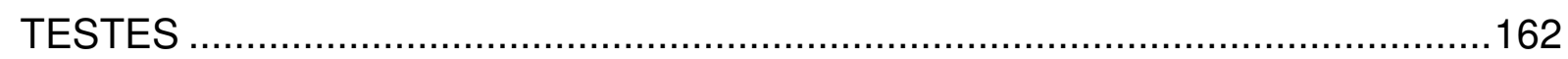

APÊNDICE D - HETEROGENEIDADES NO TRILHO E FIXAÇÃO ........................163

APÊNDICE E - MODOS DE FALHA SEGUNDO FMD-97 (1997) ..........................166

APÊNDICE F - EXEMPLO DE PERFIL DE RODA UIC-ERRI...............................172 


\section{CAPÍTULO 1 - INTRODUÇÃO}

\section{1- CONSIDERAÇÕES INICIAIS}

O transporte ferroviário vem se tornando cada vez mais importante e, segundo Almeida (2006), o desenvolvimento de uma ampla malha ferroviária pode permitir a ampliação do transporte de cargas e passageiros e o aumento da capacidade de escoamento da malha de transporte. Porém a crescente demanda do transporte ferroviário exige uma melhor análise da segurança e confiabilidade relacionada com a operação. Esta crescente demanda é indicada, por exemplo, na Tabela 1.1 que mostra um aumento considerável no número de passageiros transportados. Tomando como comparação os anos de 2001 e 2006, o número cresceu de 228,7 para 726,6 milhões de passageiros.

Tabela 1.1 - Evolução do Transporte Regular Metropolitano

\begin{tabular}{lcccccccc}
\hline EMPRESAS & $\mathbf{1 9 9 2}$ & $\mathbf{1 9 9 7}$ & $\mathbf{2 0 0 1}$ & $\mathbf{2 0 0 2}$ & $\mathbf{2 0 0 3}$ & $\mathbf{2 0 0 4}$ & $\mathbf{2 0 0 5}$ & $\mathbf{2 0 0 6}$ \\
\hline CBTU & 377,9 & 70,2 & 84,4 & 80 & 89,4 & 93 & 97 & 99,3 \\
TRENSURB & 31,9 & 31,5 & 39,6 & 41,3 & 44,5 & 48,9 & 48,3 & 45,8 \\
SUPERVIA & & & 104,7 & 114,9 & 125 & 125 & 128,3 & 139,2 \\
CENTRAL & - & - & - & - & - & 0,29 & 0,31 & 0,24 \\
METROFOR & - & - & - & 4,9 & 10,4 & 9,3 & 9,4 & 7,7 \\
CPTM & & & & 345,4 & 353,8 & 368,8 & 389,6 & 430,2 \\
CTS & - & - & - & - & - & - & - & 4,2
\end{tabular}

TOTAL \begin{tabular}{llllllll}
409,8 & 101,7 & 228,7 & 586,5 & 623,1 & 645,3 & 672,9 & 726,6 \\
\hline
\end{tabular}

Valores em milhões de passageiros

(ANTT, 2007)

O Brasil apresenta um crescimento no investimento no transporte ferroviário, como na infra-estrutura, na aquisição do novo material rodante e outros elementos relacionados tal como expõe a Tabela 1.2 obtida dos estudos da ANTT (2007). 
Tabela 1.2 - Principais Investimentos das Concessionárias

\begin{tabular}{|c|c|c|c|c|c|c|c|}
\hline CATEGORIA & 1997 & 2001 & 2002 & 2003 & 2004 & 2005 & 2006 \\
\hline $\begin{array}{l}\text { MATERIAL } \\
\text { RODANTE }\end{array}$ & 113 & 243,3 & 261,7 & 604,5 & $1.222,00$ & $2.012,00$ & $1.039,80$ \\
\hline INFRA-ESTRUTURA & 15,5 & 122,9 & 48,6 & 61 & 73 & 185,2 & 362,4 \\
\hline SUPERESTRUTURA & 64,3 & 328,8 & 173,5 & 184,3 & 364,3 & 679,3 & 674,4 \\
\hline $\begin{array}{l}\text { COMUNICAÇÃO E } \\
\text { SINALIZAÇÃO }\end{array}$ & 10,4 & 41,8 & 49,9 & 66,1 & 37,8 & 56,6 & 74 \\
\hline OUTROS & 149,8 & 73,6 & 92 & 156,2 & 192,5 & 259 & 308,3 \\
\hline TOTAL & 353 & 810,4 & 625,7 & $1.072,10$ & $1.889,60$ & $3.192,10$ & $2.458,90$ \\
\hline
\end{tabular}

Diante das evidências do crescimento do transporte ferroviário nacional, cresce a importância de avaliar e analisar a possibilidade de um cenário acidental que pode ser considerado crítico e que deve ser evitado como é o caso do descarrilamento.

\section{2- OBJETIVO}

O objetivo do trabalho é apresentar um método baseado nos conceitos de análise de risco e confiabilidade por meio das ferramentas como a análise de causa e consequência, a análise por árvores de falhas e a análise do tipo FMEA. Esta última procura identificar causas do possível descarrilamento e desta forma auxilia na proposição de ações de redução de risco que podem ser empregadas em sistemas antigos ou soluções que devem ter sua implementação garantida em sistemas novos para a diminuição da taxa de ocorrência deste evento.

O método também discute uma proposta para a análise da probabilidade de ocorrência do descarrilamento utilizando análise probabilística condicionada avançada, permitindo uma estimativa de custos dos riscos envolvidos. 


\section{3 - ESCOPO DO ESTUDO}

Este trabalho, que tem como foco a apresentação do método de análise de risco aplicado ao estudo do descarrilamento, primeiramente discute o método de análise a ser utilizado, abordando conceitos fundamentais de confiabilidade e algumas ferramentas para análise do descarrilamento do trem, como por exemplo, os diagramas de causa e conseqüência e as análises de FMEA e FTA.

Feita a descrição do método de análise, serão detalhados os elementos considerados na análise do evento de descarrilamento do trem, ou seja, são abordados de maneira sucinta os sistemas do material rodante e os elementos de via, podendo citar os truques, acoplamentos, trilhos, dormentes entre outros.

Discorre-se também neste trabalho sobre os índices de confiabilidade apresentados no cenário atual pelos diferentes critérios de descarrilamento que já foram desenvolvidos para entendimento do tema e apresentação do cenário atual.

As diversas ferramentas de análise serão aplicadas para o estudo do descarrilamento e, por fim, serão discutidas as ações de projeto e manufatura e políticas de manutenção desenvolvidas no decorrer da evolução ferroviária que podem ser consideradas para evitar o descarrilamento de modo a tornar este evento menos provável de ocorrer.

Adicionalmente, é proposto um método para a análise da probabilidade de ocorrência deste evento baseado no método probabilístico condicionado avançado, assim permitindo uma estimativa de custos dos riscos envolvidos. 


\section{CAPÍTULO 2 - REVISÃO BIBLIOGRÁFICA}

Neste capítulo são discutidos os conceitos de confiabilidade e as principais técnicas de análise bem como o conceito de análise de risco.

\section{1 - CONFIABILIDADE}

\subsection{1 - INTRODUÇÃO}

Pode-se definir confiabilidade, de acordo com Souza (1994) apud US Military Handbook (1970) como "a probabilidade de um item executar a sua função sob condições pré-definidas de uso e manutenção por um período de tempo específico". Em outras palavras, pode-se dizer que é a probabilidade de um item funcionar de maneira pré-determinada sob um período de tempo (uma determinada quilometragem, um número de ciclos etc) pré-determinado.

A confiabilidade empregada em engenharia de projetos surgiu entre 1939 e 1945 durante a Segunda Guerra Mundial para o desenvolvimento de sistemas de maior complexidade e que apresentassem uma menor probabilidade de falha durante o período de uso (VILLEMEUR, 1991). Após a guerra, os conceitos de confiabilidade puderam ser aplicados em outros ramos da engenharia que necessitavam uma predição da vida operacional, dos intervalos de manutenção, entre outras necessidades.

Atualmente, com os mercados cada vez mais exigentes quanto à qualidade de produtos e segurança, se faz necessária a análise da confiabilidade, que pode diminuir os custos e inconvenientes, aumentar a segurança para o consumidor e realizar o estudo da viabilidade de políticas de manutenção.

Para a análise de confiabilidade, é necessária a definição de diversas variáveis, como: 
- Clareza da função do equipamento, verificando a forma de utilização, a forma que pode falhar, as causas da falha e a conseqüência que esta falha pode acarretar;

- O meio ambiente do equipamento, por exemplo, o local em que o item é instalado, as formas em que ocorrerão a manutenção, os usuários e as instalações e

- O período de uso, determinando o tempo de uso e os ciclos de operação.

Para o objeto de estudo, ou seja, o material rodante, a função do equipamento é bastante clara, ou seja, o transporte de pessoas e objetos em uma condição segura. $O$ meio ambiente do equipamento pode ser previamente definido pelo conhecimento das condições de umidade, temperatura entre outros parâmetros ambientais em que o material rodante opera ou operará.

O período de uso é baseado na vida útil do material rodante (normalmente um período de 30 anos).

Três ferramentas que serão empregadas serão a análise de modos e efeitos de falha (FMEA), a análise por árvores de falhas (FTA) e análise de confiabilidade por solicitação e resistência (também conhecida como análise de confiabilidade estrutural).

\subsection{2 - ANÁLISE DE MODOS E EFEITOS DE FALHAS (FMEA)}

A análise de Modos e Efeitos de Falhas (FMEA) é um método qualitativo que analisa individualmente as falhas simples de um sistema e os efeitos e impactos que podem causar no mesmo, determinando assim como cada modo de falha afeta 0 funcionamento do objeto de estudo. Esta definição é apresentada por autores como Sundararajan (1991) e também por Villemeur (1991), sendo que esta ferramenta apresenta grande utilidade na identificação dos itens que podem causar 0 descarrilamento durante o transporte ferroviário de cargas e passageiros. 
A diferença entre FMECA e FMEA é que na análise FMECA (análise de modos e efeitos de falhas críticas) há uma análise quanto à probabilidade de ocorrência e severidade do efeito, desta forma se faz necessário o conhecimento da freqüência de ocorrência dos modos de falha para tal análise crítica. Assim, neste trabalho é utilizada a análise do tipo FMEA, já que a probabilidade de falha de cada componente varia de acordo com o tipo e condições de operação do veículo ferroviário.

A análise do tipo FMEA/FMECA tem como benefícios a possibilidade de identificação de deficiências de projeto possibilitando melhorias no mesmo e permitindo também a priorização quanto às ações de redução do risco estudado, porém por se tratar de uma análise de modo de falha simples, ou seja, cada modo de falha é considerado individualmente, combinações de falhas que podem gerar um evento não são identificadas (SUNDARARAJAN, 1991).

Existem diversos modelos de planilhas para a elaboração de FMEA. A norma MIL-STD-1629A (1984) apresenta um exemplo com os seguintes campos principais:

- Número identificador: neste campo é preenchido um número para facilitar a identificação para cada modo de falha de cada componente.

- Identificação funcional ou do item: o nome ou nomenclatura do item ou função do sistema que será analisado através dos seus modos de falha.

- Função: a função que o elemento desempenha, incluindo sua função propriamente dita, assim como sua relação com os demais elementos.

- Modos de falha e causas: os modos de falha são descritos neste campo. As causas mais prováveis associadas com este modo de falha também devem ser descritas. E, para garantir que uma completa análise seja realizada, cada modo de falha deve ser examinado pelas seguintes condições de falha:

- Operação prematura;

- Falha na operação em um tempo determinado;

- Operação intermitente;

- Falha de parada no tempo determinado;

- Falha de saída ou durante operação;

- Saída degradada ou degradação da capacidade nominal; 
- Outras condições de falha, quando aplacáveis baseadas nas características do sistema e requisitos de operação.

- Modo ou fase de operação: descrição sucinta do modo ou fase de operação no qual a falha ocorre.

- Efeito das falhas: o efeito causado pelas falhas analisadas. Estes efeitos podem ser analisados quanto aos diversos níveis em um sistema.

- Modo de detecção da falha: descrição do método utilizado para a detecção do modo de falha.

- Ação de gerenciamento: ações recomendadas para a mitigação ou eliminação dos efeitos.

- Severidade (Sev): classificação quanto à severidade dos efeitos. A classificação de severidade será realizada conforme Tabela 2.1.

- Notas: alguma informação que se julgue necessária.

Tabela 2.1 - Níveis de Severidade

\begin{tabular}{ccc}
\hline $\begin{array}{c}\text { Descrição da Severidade } \\
\text { do Perigo }\end{array}$ & $\begin{array}{c}\text { Categoria da } \\
\text { severidade do perigo }\end{array}$ & Conseqüência ao pessoal ou ambiente \\
\hline CATASTRÓFICO & I & $\begin{array}{r}\text { Fatalidade e/ou ferimentos múltiplos } \\
\text { severos e/ou danos maiores ao ambiente }\end{array}$ \\
CRÍTICO & II & $\begin{array}{r}\text { Fatalidade simples e/ou ferimentos severos } \\
\text { e/ou danos significativos ao ambiente }\end{array}$ \\
MARGINAL & III & Ferimentos menores e/ou ameaça \\
significativa ao ambiente
\end{tabular}

(EN 50126, 2000)

A Planilha padrão que será utilizada neste trabalho é apresentada na Figura 2.1 e foi adaptada da norma MIL-STD-1629A (1984). 


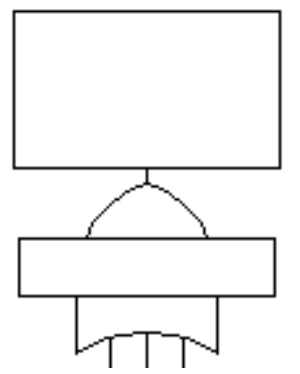

Figura 2.2 - Porta lógica OU

A porta lógica $E$, representada na Figura 2.3, indicada que a saída é verdadeira quando todas as entradas forem verdadeiras. Esta saída pode ser tanto o evento topo (evento indesejável em estudo) quanto um evento intermediário, sendo que são necessárias pelo menos duas entradas nesta porta (SUNDARARAJAN, 1991).

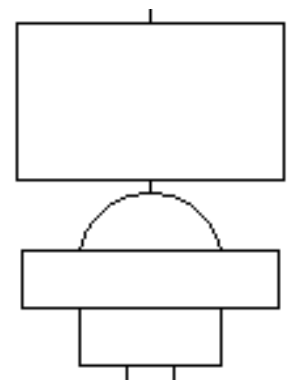

Figura 2.3 - Porta lógica E

O evento não desenvolvido, representado na Figura 2.4, indica um evento em que a análise mais detalhada não foi realizada, normalmente quando é considerada desnecessária ou não se possui informação suficiente no momento.

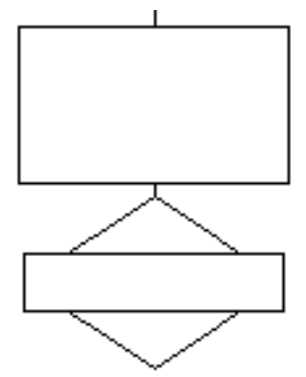

Figura 2.4 - Evento não desenvolvido

O evento básico, representado na Figura 2.5, é um evento que não pode mais ser desenvolvido em outros sub-níveis, ou seja, não pode ser subdividido. 


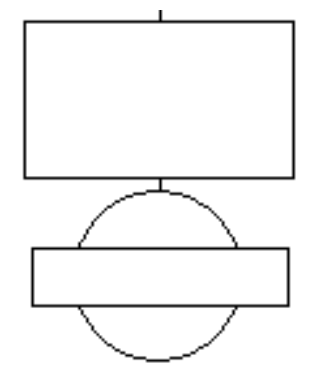

Figura 2.5 - Evento básico

Para o cálculo da probabilidade de falha do evento topo de uma árvore de falha e estimação das taxas de falha dos eventos básicos, pode-se, por exemplo, considerar o apresentado na NPRD-95 (1995). Assume-se como função que descreve o comportamento da confiabilidade do componente a distribuição exponencial. Esta hipótese é possível, ainda segundo a NPRD-95 (1995), se há a consideração de grandes intervalos de tempo (por exemplo a vida útil do material rodante superior a 30 anos) e se os componentes forem substituídos na ocorrência da falha. Esta estabilização da taxa de falha após um longo intervalo de tempo é apresentada na Figura 2.6, que indica um comportamento com taxa de falha variável no início da vida operacional, e que devido à substituição de componentes em diferentes momentos de operação, a taxa de falha do grupo de componentes acaba seguindo uma taxa de falha constante.

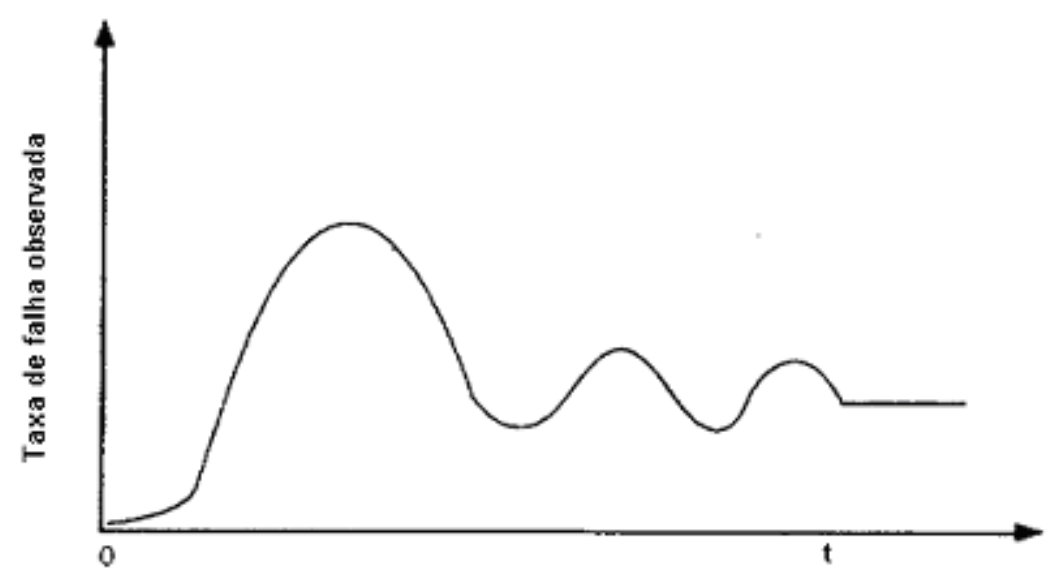

Figura 2.6 - Exemplo de comportamento da taxa de falha de um subsistema com componentes substituídos na ocorrência de falha (Adaptada de NPRD-95, 1995) 


\subsection{4 - ANÁLISE DE CONFIABILIDADE POR SOLICITAÇÃO E RESISTÊNCIA}

No campo da engenharia, as solicitações e resistências não apresentam valores exatos, variando ao longo da vida útil do sistema, afetando assim a possibilidade de operação sem falha do mesmo. Ou seja, os valores de solicitação e resistência não são pontuais, apresentando faixas de valores estatisticamente distribuídas.

Para determinação da probabilidade de falha pelo método de confiabilidade estrutural (também chamado de análise por solicitação e resistência), considera-se que a falha ocorre quando a solicitação é maior que a resistência (SOUZA, 1994).

Diversos métodos podem ser utilizados para a determinação da confiabilidade através da comparação entre solicitação e resistência, como por exemplo, o método de Monte Carlo. Segundo Souza (1994), foram desenvolvidos alguns métodos para a análise de confiabilidade baseada na comparação entre solicitação e resistência empregando-se aproximações e simplificações do modelo de análise, sendo estes modelos divididos em três níveis, de I a III.

O modelo de Nível I é chamado de Método Semi-Probabilístico e utiliza fatores de segurança parciais para as variáveis empregadas no modelo.

O modelo de Nível II, chamado de Método Probabilístico Condicionado, modela o problema através da formulação de uma função de estado limite que descreve o processo de colapso do sistema, assim, determinando a probabilidade desta função ser menor ou igual a zero, a chance desta ser inferior a zero indica a probabilidade de falha do sistema considerando que a mesma ocorre na posição indicada pelos modelos determinísticos. Além disso, as variáveis do problema são descritas através de funções densidade de probabilidade (SOUZA, 1994).

O modelo de Nível III, também chamado de Modelo Probabilístico Puro, calcula a probabilidade de colapso do sistema levando em conta todas as possíveis configurações de colapso que se tornam possíveis pela potencial variação das propriedades mecânicas e das dimensões do elemento estudado (SOUZA, 1994). 
Ainda segundo Souza (1994), na comparação destes três métodos, percebese que 0 de Nível I considera diversas simplificações que podem levar a um resultado insatisfatório quanto à probabilidade de falha. Já o de Nível III apresenta uma complexidade elevada em sua aplicação. Assim o método probabilístico condicionado, por ser um ponto de equilíbrio entre os dois outros métodos e por apresentar um bom resultado no cálculo da confiabilidade, é o utilizado neste trabalho.

\subsubsection{1- Fundamentos do Método Probabilístico Condicionado}

O Método Probabilístico Condicionado, ou método probabilístico de Nível II consiste basicamente na determinação da função do estado limite que descreve o processo, sendo esta função necessariamente linear (SOUZA, 1994).

Esta função pode ser descrita da seguinte forma:

$$
Z=g\left(x_{1}, x_{2}, \ldots \ldots \ldots \ldots, x_{n}\right)=g(X)
$$

Sendo $x_{1}, x_{2}, \ldots \ldots \ldots . . ., x_{n}$ as variáveis que descrevem o processo de colapso em estudo.

Porém, a função limite $Z$ do sistema nem sempre é linear, sendo necessária a linearização da função através de expansão em série de Taylor, selecionando-se os termos de $1^{\underline{a}}$ ordem, como indicado na equação (2.2) apresentada por Souza (1994):

$$
Z \cong g\left(X^{*}\right)+\sum_{i=1}^{n}\left(x_{i}-x_{i}^{*}\right) g_{i}^{\prime}\left(X^{*}\right)
$$

Sendo:

$$
\begin{aligned}
& X=\left(x_{1}, x_{2}, \ldots \ldots \ldots \ldots, x_{n}\right) \\
& X^{*}=\left(x_{1}^{*}, x_{2}^{*}, \ldots \ldots \ldots \ldots, x_{n}^{*}\right)
\end{aligned}
$$


$g_{i}^{\prime}\left(X^{*}\right)=\frac{\partial g}{\partial x_{i}}$

Após algumas manipulações algébricas, é obtida a equação (2.3):

$$
Z \cong g\left(X^{*}\right)-\sum_{i=1}^{n} x_{i}^{*} \cdot g_{i}^{\prime}\left(X^{*}\right)+\sum_{i=1}^{n} x_{i} \cdot g_{i}^{\prime}\left(X^{*}\right)
$$

$\mathrm{Ou}$

$$
Z \cong C_{0}+\sum_{i=1}^{n} C_{i} x_{i}
$$

Em que:

$$
\begin{gathered}
C_{0}=g\left(X^{*}\right)-\sum_{i=1}^{n} x_{i}^{*} \cdot g_{i}^{\prime}\left(X^{*}\right) \\
C_{i}=g_{i}^{\prime}\left(X^{*}\right)
\end{gathered}
$$

Através das propriedades de cálculo da média e variância de uma função de variáveis aleatórias, tem-se:

$$
\begin{gathered}
m_{z}=C_{0}+\sum_{i=1}^{n} C_{i} m_{i} \\
\sigma_{z}=\left[\sum_{i=1}^{n} C_{i}^{2} \sigma_{i}^{2}\right]^{\frac{1}{2}}
\end{gathered}
$$

Sendo:

$m_{z}$ : valor esperado da função de estado limite Z;

$\sigma_{z}$ : desvio padrão da função de estado limite Z;

$m_{i}$ : valor esperado da variável básica $\mathrm{x}_{\mathrm{i}}$;

$\sigma_{i}:$ desvio padrão da variável $x_{i}$;

$C_{i}=g_{i}^{\prime}\left(X^{*}\right) \operatorname{com} X^{*}=\left(m_{1}, m_{2}, \ldots \ldots \ldots \ldots . . . ., m_{n}\right)$. 
Com isso, obtido o valor da variável $Z$, tem-se o colapso quando $Z$ é menor ou igual a zero, caso contrário, não ocorre o colapso. Assim, pode-se determinar 0 índice de confiabilidade " $\beta$ ” expresso pela relação (2.9):

$$
\beta=\frac{m_{z}}{\sigma_{z}}
$$

Logo, tem-se a probabilidade de colapso do sistema através da função distribuição acumulada da distribuição normal reduzida calculada no ponto "- $\beta$ ":

$$
P_{F}=\Phi(-\beta)
$$

Segundo Souza (1994) um problema que se tem neste método é o fato de que o valor obtido depende do ponto escolhido para a linearização da função do estado limite $(Z)$, ou seja, quanto maior a distância deste ponto à superfície definida pela condição $Z=0$, maior o erro cometido no cálculo do índice de confiabilidade. E é devido a este erro que foi desenvolvido o método probabilístico condicionado avançado.

\subsubsection{2 - Fundamentos do Método Probabilístico Condicionado Avançado}

Neste método, de acordo com Souza (1994, p.43), "o ponto escolhido para a linearização da função do estado limite ( $Z$ ) deve ser tal que a probabilidade de falha na estrutura seja maximizada, sendo que o mesmo se encontra na curva definida por $Z=0 "$. O procedimento para a determinação do ponto de linearização é o seguinte:

a) Adotar um valor para o índice de confiabilidade $\beta$;

b) Adotar para todas as variáveis relevantes no sistema que $x_{i}^{*}=m_{i}$, onde $m_{i}$ é o valor esperado da variável básica $x_{i}$

c) Calcular $g_{i}^{\prime}\left(X^{*}\right)$ para as $\mathrm{n}$ variáveis básicas; 
d) Calcular o valor da constante de proporcionalidade $\alpha_{i}$ para as $n$ variáveis básicas sabendo-se que a função do estado limite é dada pela equação (2.3) ou (2.4) e o valor esperado da função é dado pelas equações (2.5), (2.6) e (2.7).

Assim, o desvio padrão da função do estado limite é calculado pela equação (2.8) e pela combinação linear dos desvios padrões das variáveis básicas envolvidas no problema, obtém-se a equação (2.11):

$$
\sigma_{z} \cong \sum_{i=1}^{n} \alpha_{i} \cdot g_{i}^{\prime}\left(X^{*}\right) \sigma_{i}
$$

Logo, a constante de proporcionalidade referente a cada variável é dada pela equação (2.12):

$$
\alpha_{i}=\frac{g_{i}^{\prime}\left(X^{*}\right) \sigma_{i}}{\left[\sum_{j=1}^{n}\left(g_{j}^{\prime}\left(X^{*}\right) \sigma_{j}\right)^{2}\right]^{\frac{1}{2}}}
$$

Onde:

$\sigma_{i}$ :Desvio padrão relacionado a cada variável básica

e) Calcular um novo ponto de linearização $X^{*}$, utilizando-se a seqüência de atividades abaixo indicadas:

Deduzindo-se o índice de confiabilidade através das expressões do item "d" e sabendo-se que o ponto de linearização deve estar em $Z=0$, tem-se a expressão (2.13):

$$
\beta=\frac{\sum_{i=1}^{n}\left(m_{i}-x_{i}^{*}\right) \cdot g_{i}^{\prime}\left(X^{*}\right)}{\sum_{i=1}^{n} \alpha_{i} g_{i}^{\prime}\left(X^{*}\right) \sigma_{i}}
$$

Manipulando os termos tem-se (2.14): 


$$
x_{i}^{*}=m_{i}-\alpha_{i} \cdot \beta \cdot \sigma_{i}
$$

f) Repetir os passos "c" a "e", até que o ponto de linearização se mantenha constante;

g) Calcular o valor da função do estado limite $Z=g\left(X^{*}\right)$, utilizando-se o ponto de linearização obtido no passo f;

h) Utilizar valores de $\beta$ e repetir os passos "c" a "h" até obter-se um valor nulo para a função de estado limite, ou seja, $Z=0$;

i) Determinar a probabilidade de colapso utilizando-se a relação:

$$
P_{F}=\Phi(-\beta)
$$

Sendo $\Phi(\mathrm{x})$ a função distribuição acumulada da distribuição normal reduzida.

Este algoritmo é apresentado no fluxograma indicado na Figura 2.7. 


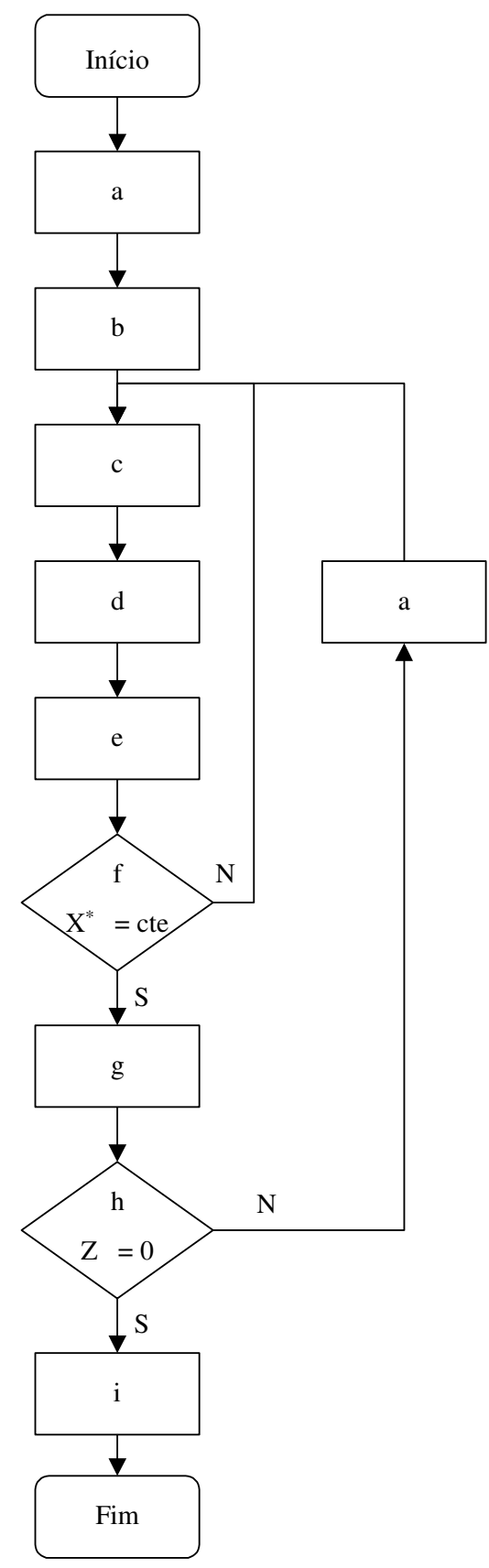

Figura 2.7 - Fluxograma do Método Probabilístico Condicionado Avançado ${ }^{1}$

Porém, este método apresenta certa restrição quanto ao cálculo da média e do desvio padrão para as variáveis básicas, necessitando de certas correções aplicadas às variáveis básicas que não são representadas por distribuições normais (SOUZA, 1994).

\footnotetext{
${ }^{1}$ As letras do fluxograma indicam a etapa do cálculo, N indica "não" e S indica "sim".
} 


\subsubsection{3 - Correção Aplicada às Variáveis Básicas}

O método descrito anteriormente apresenta restrição quanto às variáveis básicas que descrevem o problema. Quando estas não podem ser representadas por uma distribuição normal, são necessárias correções no cálculo da média e do desvio padrão destas variáveis.

Desta forma, segundo Souza (1994 apud RACKWITZ e FIESSLER, 1978), para o cálculo destas correções, é necessário determinar a média e o desvio padrão da distribuição normal equivalente no ponto de linearização através das expressões (2.15) e (2.16):

$$
\begin{gathered}
\mu_{x_{i}}^{N}=X_{i}^{*}-\Phi^{-1}\left[F_{i}\left(X_{i}^{*}\right)\right] \sigma_{x_{i}}^{N} \\
\sigma_{x_{i}}^{N}=\frac{\phi\left(\Phi\left[F_{i}\left(X_{i}^{*}\right)\right]\right)}{f_{i}\left(X_{i}^{*}\right)}
\end{gathered}
$$

\section{Em que:}

$\phi(a)$ é a magnitude da função densidade de probabilidade da distribuição normal reduzida;

$F_{i}\left(X_{i}^{*}\right)$ é a magnitude da função distribuição acumulada da variável básica $x_{i}$ calculada no ponto $\mathrm{x}_{\mathrm{i}}=X_{i}^{*}$;

$f_{i}\left(X_{i}^{*}\right)$ é a magnitude da função densidade de probabilidade da variável básica $\mathrm{x}_{\mathrm{i}}$ calculada no ponto $\mathrm{x}_{\mathrm{i}}=X_{i}^{*}$;

$\Phi(b)$ é a magnitude da função distribuição acumulada da distribuição normal reduzida, calculada no ponto $b$. 


\subsubsection{4 - Código Computacional Baseado no Método Probabilístico Condicionado Avançado}

O código computacional utilizado foi baseado no método probabilístico condicionado avançado apresentado nesta pesquisa e baseado nas pesquisas de Souza (2001). Foi elaborado em "Matlab 7.9.0" em sua versão R2009b e seguindo o fluxograma apresentado na Figura 2.7.

Para a verificação e validação da rotina computacional proposta, os resultados foram comparados com a pesquisa de Souza (2001) e a pesquisa de Souza (2001 apud HARRIS, 1995) para o mesmo caso exemplo utilizado pelas referências.

O exemplo baseou-se em uma chapa infinita com uma trinca central passante e submetida a tensões cíclicas de tração. A expressão considerada da função de desempenho para análise da vida em fadiga, conforme Souza (2001), é:

$$
g_{\Delta K}(x)=\frac{1}{\pi^{2}}\left(\frac{1}{q_{i}}-\frac{\pi \Delta S^{2}}{K_{I C}^{2}}\right)-N C \Delta S^{4}
$$

Onde:

qi é a dimensão inicial da trinca;

$\mathrm{K}_{\mathrm{IC}}$ é o fator de intensificação crítica do material;

$\Delta S$ é a flutuação de tensão;

$\mathrm{N}$ é o número de ciclos de carregamento;

C é o parâmetro da Lei de Paris.

Ainda, segundo Souza (2001 apud HARRIS, 1995), as funções utilizadas para as variáveis básicas bem como os parâmetros, médias e desvios padrões são dados na Tabela 2.2. 
Tabela 2.2 - Variáveis Básicas e suas Funções Densidade de Probabilidade

\begin{tabular}{|c|c|c|c|c|c|c|}
\hline $\begin{array}{l}\text { Variável } \\
\text { básica }\end{array}$ & Símbolo & $\begin{array}{c}\text { Tipo de } \\
\text { Distribuição }\end{array}$ & Função Densidade de probabilidade & Parâmetros & Média & $\begin{array}{l}\text { Desvio } \\
\text { Padrão }\end{array}$ \\
\hline $\begin{array}{c}\text { Dimensão } \\
\text { inicial da } \\
\text { trinca }\end{array}$ & $q_{i}$ & Exponencial & $f_{q}(q)=\frac{1}{\lambda} \exp \left(-\frac{q}{\lambda}\right)$ & $\lambda=0,02$ & 0,02 & 0,02 \\
\hline $\begin{array}{l}\text { Parâmetro da } \\
\text { lei de Paris }\end{array}$ & C & Lognormal & $f_{C}(c)=\frac{1}{\varepsilon c \sqrt{2 \pi}} \exp \left[-\frac{1}{2}\left(\frac{\ln (c)-\lambda_{c}}{\varepsilon}\right)^{2}\right]$ & $\begin{array}{l}\lambda_{C}=-20,73 \\
\varepsilon=0,50\end{array}$ & $1,13 \cdot 10^{-9}$ & $6,04 \cdot 10^{-10}$ \\
\hline $\begin{array}{l}\text { Flutuação de } \\
\text { tensão }\end{array}$ & $\Delta S$ & Normal & $f_{\Delta S}(\Delta S)=\frac{1}{\sigma \sqrt{2 \pi}} \exp \left[-\frac{1}{2}\left(\frac{\Delta S-\mu}{\sigma}\right)^{2}\right]$ & $\begin{array}{l}\mu=16 \\
\sigma=2\end{array}$ & 16,0 & 2,0 \\
\hline $\begin{array}{l}\text { Tenacidade à } \\
\text { fratura }\end{array}$ & $\mathrm{K}_{\mathrm{IC}}$ & Weibull & $f_{K_{I C}}\left(K_{I C}\right)=\frac{k}{w}\left(\frac{K_{I C}}{w}\right)^{k-1} \exp \left[-\left(\frac{K_{I C}}{w}\right)^{k}\right.$ & $\begin{array}{l}w=32,07 \\
k=7,0\end{array}$ & 30,0 & 5,037 \\
\hline
\end{tabular}

(SOUZA, 2001)

Com as funções densidade de probabilidade apresentadas na tabela, obtiveram-se os resultados indicados na Tabela 2.3 para o índice de confiabilidade, considerando a variação do número de ciclos de carregamento. 
Tabela 2.3 - Índices de Confiabilidade Obtidos na Validação do Código Computacional

\begin{tabular}{cccc}
\hline Número de ciclos & $\begin{array}{c}\text { Índice de } \\
\text { Confiabilidade } \\
\text { de carregamento } \\
\text { Souza (2001 apud } \\
\text { HARRIS, 1995) }\end{array}$ & $\begin{array}{c}\text { Índice de } \\
\text { Confiabilidade } \\
\text { Souza (2001) }\end{array}$ & $\begin{array}{c}\text { Índice de } \\
\text { Confiabilidade obtido } \\
\text { nesta pesquisa } \\
\text { (Set/2010) }\end{array}$ \\
\hline $2 \times 10^{3}$ & 3,72 & 3,59 & 3,76 \\
$3 \times 10^{3}$ & 3,54 & 3,58 & 3,32 \\
$4 \times 10^{3}$ & 3,12 & 3,22 & 3,02 \\
$5 \times 10^{3}$ & 2,84 & 2,84 & 2,79 \\
$6 \times 10^{3}$ & 2,58 & 2,59 & 2,60 \\
$7 \times 10^{3}$ & 2,46 & 2,43 & 2,44 \\
$8 \times 10^{3}$ & 2,29 & 2,30 & 2,31 \\
$9 \times 10^{3}$ & 2,09 & 2,18 & 2,19 \\
$1 \times 10^{4}$ & 2,06 & 2,08 & 2,09 \\
$2 \times 10^{4}$ & 1,44 & 1,42 & 1,43 \\
$3 \times 10^{4}$ & 1,04 & 1,05 & 1,06 \\
$4 \times 10^{4}$ & 0,77 & 0,81 & 0,81 \\
$5 \times 10^{4}$ & 0,58 & 0,62 & 0,63 \\
$6 \times 10^{4}$ & 0,47 & 0,46 & 0,48 \\
\hline
\end{tabular}

Os índices de confiabilidade obtidos estão próximos aos apresentados por Souza (2001) e Souza (2001 apud HARRIS, 1995), permitindo assim aplicar o código na computacional baseado no método probabilístico condicionado avançado desenvolvido para a análise de confiabilidade por solicitação e resistência. 


\section{2 - ANÁLISE DE RISCO}

Risco pode ser definido como o potencial de perda resultante da exposição a um perigo e este conceito de risco é utilizado para investigar e avaliar as incertezas associadas com um evento. De acordo com a norma IEC 62278 (2002), o risco está relacionado com dois conceitos:

- a probabilidade de ocorrência de um evento ou combinação de eventos acarretando em um perigo e

- a conseqüência deste perigo.

A análise de risco é executada considerando (IEC 62278, 2002):

- a descrição da metodologia;

- hipóteses, limitações e justificativas quanto ao uso da metodologia;

- identificação dos resultados estudo do perigo;

- estimativa do risco e nível de confiança;

- resultados de estudos;

- discussão sobre fonte de dados e

- referências.

Para tal pode ser utilizado o diagrama de causa e conseqüência. Seu objetivo é identificar nos fluxogramas disponíveis os perigos presentes. Este método desenvolvido na década de 70 (VILLEMEUR, 1991 apud NIELSEN, 1971) segue as seguintes etapas:

- Seleção do evento inicial: um evento crítico relacionado com a falha de componentes ou sistemas e que acarretam em conseqüências indesejadas.

- Identificação das causas do evento inicial: estas causas podem ser identificadas com auxílio de árvore de falhas (FTA) que foi apresentada no tópico 2.1.3.

- Identificação das conseqüências do evento inicial: neste estudo a conseqüência indesejada é o descarrilamento.

- Diagrama de causa e conseqüência e cortes mínimos: o diagrama de causa e conseqüência sumariza o evento inicial, as causas do evento e 
as conseqüências em figuras que facilitam o entendimento e permitem a identificação da mínima combinação de falhas que podem gerar 0 evento indesejado.

A Figura 2.8 apresenta um exemplo do diagrama de causa e conseqüência.

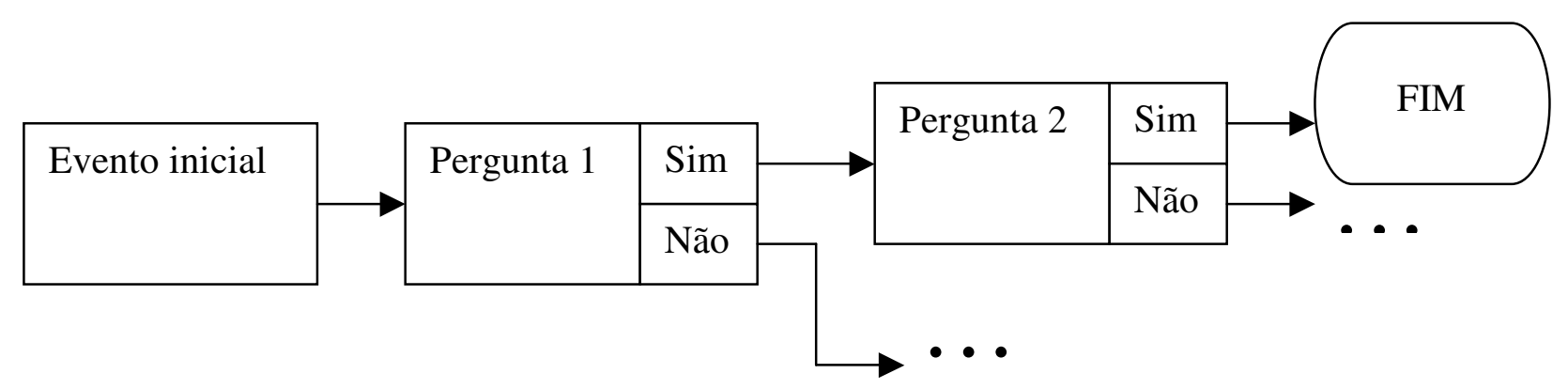

Figura 2.8 - Exemplo de diagrama de causa e conseqüência

Para a construção de uma matriz de risco, a norma IEC 62278 (2002) determina que "as categorias, seus números e a escala numérica devem ser definidas pela Autoridade Ferroviária, de forma apropriada para a aplicação considerada" ou seja, os valores de freqüência, severidades e aceitabilidade de cada combinação de freqüência com severidade devem ser determinados pela autoridade ferroviária. Ainda segundo a norma IEC 62278 (2002), a autoridade ferroviária é o órgão máximo e responsável final pela regulamentação para a operação de um sistema ferroviário.

A definição das tabelas de Severidade, Freqüência e Matriz de Risco consideraram os critérios estabelecidos nas normas IEC 62278 (2002) ou EN 50126 (2000) e também no "HAZARD ANALYSIS GUIDELINES FOR TRANSIT PROJECTS" elaborada pela Federal Transit Administration dos EUA (FEDERAL TRANSIT ADMINISTRATION, 2000), agência reguladora para segurança de transportes terrestres daquele país. Nesta definição de matriz de risco, a norma IEC 62278 (2002) ou EN 50126 (2000) apresenta seis classes de freqüência de ocorrência, porém não apresenta os valores numéricos, já o "HAZARD ANALYSIS GUIDELINES FOR TRANSIT PROJECTS" (FEDERAL TRANSIT ADMINISTRATION, 2000) apresenta apenas cinco classes de freqüência com os valores numéricos de MTBE. 
Para a freqüência "inacreditável", o valor numérico foi baseado na EN 50129 (2002) utilizando-se um valor de referência maior que o THR requerido para equipamentos com nível de integridade de segurança (SIL) 4, pois o mesmo apresenta o maior nível de segurança e a menor taxa tolerável de ocorrência de um evento não desejado.

O SIL é classificado em quatro diferentes categorias (de 1 a 4). A necessidade de diferentes níveis varia de acordo com a taxa tolerável de ocorrência de um determinado perigo. Esta taxa tolerável do perigo (THR) considera os riscos associados ao perigo, as conseqüências etc. O paralelo com esta taxa tolerável de perigo, segundo a norma EN 50129 (2002), é apresentado na Tabela 2.4.

\begin{tabular}{cc} 
Tabela 2.4: Nível de Integridade de Segurança \\
\hline THR por hora e por função & SIL \\
\hline $10^{-9} \leq \mathrm{THR}<10^{-8}$ & 4 \\
$10^{-8} \leq \mathrm{THR}<10^{-7}$ & 3 \\
$10^{-7} \leq \mathrm{THR}<10^{-6}$ & 2 \\
$10^{-6} \leq \mathrm{THR}<10^{-5}$ & 1 \\
\hline
\end{tabular}

Deve ser observado que para que o nível SIL desejável seja alcançado, a preocupação não é limitada apenas ao THR, mas também as seguintes condições devem ser consideradas:

- condições de gerenciamento da qualidade;

- condições de gerenciamento de segurança;

- condições técnicas de segurança e

- metas quantitativas de segurança.

Assim, pela combinação das freqüências de ocorrência (apresentada na Tabela 2.5) com o nível de severidade das conseqüências dos perigos (apresentada na Tabela 2.1) é construída a matriz de risco conforme Tabela 2.6. 
Tabela 2.5 - Freqüência de Ocorrência do Evento

\begin{tabular}{|c|c|c|c|}
\hline Categoria & Descrição & $\begin{array}{l}\text { Tempo Médio Entre Falhas } \\
\text { MTBE (h) }\end{array}$ & $\begin{array}{l}\text { Probabilidade de falha em } 1 \mathrm{~h} \\
\text { (considerando taxa de falha constante) }\end{array}$ \\
\hline Freqüente & $\begin{array}{c}\text { Susceptível que ocorra } \\
\text { freqüentemente. A situação } \\
\text { perigosa será experimentada } \\
\text { continuamente. }\end{array}$ & $\mathrm{MTBE}<1000$ & $F(t)>10^{-3}$ \\
\hline Provável & $\begin{array}{l}\text { Ocorrerá diversas vezes. } \\
\text { Espera-se que a situação } \\
\text { perigosa ocorra com } \\
\text { freqüência. }\end{array}$ & $100.000>$ MTBE $\geq 1.000$ & $10^{-3} \geq F(t)>10^{-5}$ \\
\hline Ocasional & $\begin{array}{c}\text { Susceptível de ocorrer } \\
\text { diversas vezes. Espera-se que } \\
\text { a situação perigosa ocorra } \\
\text { diversas vezes. }\end{array}$ & $\begin{array}{c}1.000 .000>\text { MTBE } \geq \\
100.000\end{array}$ & $10^{-5} \geq F(t)>10^{-6}$ \\
\hline Raro & $\begin{array}{l}\text { Susceptível de ocorrer alguma } \\
\text { vez no ciclo de vida do } \\
\text { sistema. Espera-se que a } \\
\text { situação perigosa ocorra com } \\
\text { razoável freqüência. }\end{array}$ & $\begin{array}{c}100.000 .000>\text { MTBE } \geq \\
1.000 .000\end{array}$ & $10^{-6} \geq F(t)>10^{-8}$ \\
\hline Improvável & $\begin{array}{l}\text { Improvável ocorrência mas } \\
\text { possível. Supõe-se que a } \\
\text { situação perigosa ocorra } \\
\text { excepcionalmente. }\end{array}$ & $\begin{array}{c}1.000 .000 .000 \geq \text { MTBE } \geq \\
100.000 .000\end{array}$ & $10^{-8} \geq F(t) \geq 10^{-9}$ \\
\hline Inacreditável & $\begin{array}{l}\text { Extremamente improvável de } \\
\text { ocorrer. Assume-se que a } \\
\text { situação perigosa não ocorre. }\end{array}$ & MTBE $>1.000 .000 .000$ & $\mathrm{~F}(\mathrm{t})<10^{-9}$ \\
\hline
\end{tabular}

(Adaptada de IEC 62278, 2002) 
Tabela 2.6 - Matriz de Risco

\begin{tabular}{|c|c|c|c|c|}
\hline Freqüência & \multicolumn{4}{|c|}{ Nível do Risco } \\
\hline Freqüente & Indesejável & Intolerável & Intolerável & Intolerável \\
\hline Provável & Aceitável & Indesejável & Intolerável & Intolerável \\
\hline Ocasional & Aceitável & Indesejável & Indesejável & Intolerável \\
\hline Raro & Desprezível & Aceitável & Indesejável & Indesejável \\
\hline Improvável & Desprezível & Desprezível & Aceitável & Aceitável \\
\hline Inacreditável & Desprezível & Desprezível & Desprezível & Desprezível \\
\hline \multirow{2}{*}{} & Insignificante & Marginal & Crítico & Catastrófico \\
\cline { 2 - 5 } & \multicolumn{4}{|c|}{ severidade } \\
\cline { 2 - 5 }
\end{tabular}

Pela matriz de risco, é demonstrada a relação entre confiabilidade e segurança (grande parte dos sistemas com maior confiabilidade apresentam maior segurança).

Os critérios de aceitação dos riscos apresentados pela norma IEC 62278 (2002) estão descritos na Tabela 2.7.

Tabela 2.7 - Ações a serem realizadas para cada categoria de risco

\begin{tabular}{|c|l|}
\hline Categoria do Risco & Ações a serem aplicadas para cada categoria \\
\hline Intolerável & Deve ser eliminado. \\
\hline Indesejável & $\begin{array}{l}\text { Só deve ser aceito quando a redução do risco é impossível e } \\
\text { com o consentimento da autoridade ferroviária ou o da } \\
\text { autoridade reguladora de segurança, como apropriado. }\end{array}$ \\
\hline Aceitável & $\begin{array}{l}\text { Aceitável com adequado controle e com o consentimento da } \\
\text { autoridade ferroviária. }\end{array}$ \\
\hline Desprezível & Aceitável com/sem o consentimento da autoridade ferroviária. \\
\hline (IEC 62278, 2002) &
\end{tabular}

Desta forma, considerando a severidade do evento "descarrilamento" como sendo uma severidade catastrófica (I), a probabilidade de falha ideal que se deseja alcançar é inferior ao valor de $10^{-9} \mathrm{em} 1$ hora. Este valor de probabilidade de falha é 
bastante baixo e considerando o valor de MTBE de 1.000.000.000 horas, seria de difícil comprovação em ensaios a eficácia da implementação de uma ação com base na confiabilidade do mesmo.

Segundo a norma NBR 9321 (1986) e considerando a taxa de falha constante, conforme apresentado em 2.1.3, para se realizar uma estimativa por ponto da taxa de falha de um determinado sistema, deve-se ter cuidado para que 0 tempo relevante de ensaio seja suficientemente grande em relação ao valor esperado de tempo médio até a falha. Caso contrário, a taxa de falha obtida deve ser aumentada, dependendo do intervalo de confiança e do número de falhas que ocorreram durante o ensaio (NBR 9321, 1986). Na Tabela 2.8, que apresenta um exemplo para fatores de multiplicação da taxa de falha de acordo com o limite de confiança desejado, pode-se verificar que para um maior intervalo de confiança deve-se aplicar um fator de multiplicação da taxa de falha obtida durante o ensaio visando o aumento de seu valor, além disso, este aumento é tanto maior quanto menor o número de falhas observadas.

Tabela 2.8 - Tabela de Multiplicadores para a Taxa de Falha

\begin{tabular}{cccc}
\hline Número de falhas & $\mathrm{M}(5 \%)$ & $\mathrm{M}(90 \%)$ & $\mathrm{M}(95 \%)$ \\
\hline 1 & 0,051 & 3,889 & 4,743 \\
2 & 0,177 & 2,662 & 3,147 \\
3 & 0,272 & 2,226 & 2,584 \\
4 & 0,341 & 1,997 & 2,288 \\
5 & 0,394 & 1,854 & 2,103 \\
10 & 0,521 & 1,54 & 1,695 \\
20 & 0,662 & 1,351 & 1,452 \\
60 & 0,8 & 1,184 & 1,237 \\
\hline
\end{tabular}

(NBR 9321, 1986)

No Brasil não existe a figura da autoridade ferroviária, desta forma, é comum transferir as responsabilidades de aceitação e definição da matriz de risco para as operadoras ou empresas que estão adquirindo o material rodante. 
Desta forma, é possível que esta empresa determine o tempo relevante acumulado de ensaio bem como os critérios de aceitação do risco residual.

Para o tempo relevante acumulado, a mesma pode se guiar pela norma IEC 61124 (2006) que estabelece diferentes planos para a comprovação da confiabilidade, como: teste seqüencial truncado, teste com término por tempo ou falha e teste combinado.

O teste seqüencial truncado é caracterizado por regras de aceitação, rejeição ou prorrogação do teste e permite menor tempo de teste para sistemas mais confiáveis, porém pode rejeitar mais rapidamente sistemas com alta taxa de falha prematura.

O teste de término por tempo ou falha é caracterizado por regras de aceitação ou rejeição quando o tempo máximo de teste for alcançado ou o número aceitável de falhas for excedido.

O teste combinado faz uso de uma linha de rejeição que considera um número constante de falhas, enquanto que a linha de aceitação é curva, desta forma itens com alta confiabilidade são aceitos de uma forma mais rápida enquanto itens com alta taxa de falha prematura não são rejeitados imediatamente.

A Tabela 2.9 é baseada na norma IEC 61124 (2006) e apresenta as características, as vantagens e desvantagens destes testes. 
Tabela 2.9 - Exemplos de Testes de Aceitação

\begin{tabular}{|c|c|c|c|c|}
\hline $\begin{array}{l}\text { Tipo de } \\
\text { teste }\end{array}$ & & Característica & Vantagens & Desvantagens \\
\hline $\begin{array}{l}\text { Seqüencial } \\
\text { truncado }\end{array}$ & 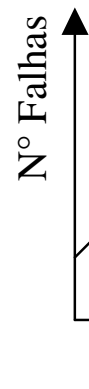 & $\int_{\text {Tembo }}$ & $\begin{array}{l}\text { Garante melhor eficiência } \\
\text { (menor tempo de teste) }\end{array}$ & $\begin{array}{l}\text { Complicado para se } \\
\text { administrar }\end{array}$ \\
\hline $\begin{array}{l}\text { Término por } \\
\text { tempo ou falha }\end{array}$ & 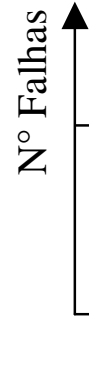 & $\underset{\text { Tempo }}{\stackrel{\text { Aceita }}{\longrightarrow}}$ & É de simples compreensão & $\begin{array}{c}\text { O tempo de teste é } \\
\text { maior considerando } \\
\text { itens muito } \\
\text { confiáveis e itens } \\
\text { pouco confiáveis. }\end{array}$ \\
\hline Combinado & 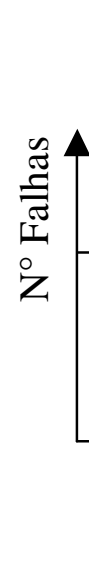 & $\underset{\text { Tempo }}{\longrightarrow}$ & $\begin{array}{l}\text { Combina as vantagens do } \\
\text { teste com término por } \\
\text { tempo ou falha e o teste } \\
\text { seqüencial truncado. Itens } \\
\text { mais confiáveis serão } \\
\text { aceitos com maior rapidez } \\
\text { e itens com muitas falhas } \\
\text { prematuras não serão } \\
\text { rejeitados precocemente } \\
\text { no teste }\end{array}$ & $\begin{array}{l}\text { Muito complicado } \\
\text { para se administrar }\end{array}$ \\
\hline
\end{tabular}




\section{CAPÍTULO 3 - ELEMENTOS DO TRANSPORTE FERROVIÁRIO}

Os elementos que são abordados neste capítulo são os elementos de via e os componentes e sistemas do material rodante. Os elementos de via serão apresentados no item 3.1 e podem ser caracterizados como todos os componentes que compõem as estruturas que guiam o movimento do trem bem como as estruturas que permitem a interface com o trem. Já o material rodante será apresentado em 3.2 e pode ser definido como todo veículo que apresenta a sua trajetória pré-estabelecida, caracterizado por um ou mais vagões interligados para o transporte de cargas e pessoas. A sua trajetória é limitada pelos elementos via que impedem a alteração da direção do veículo.

\section{1 - ELEMENTOS DE VIA PERMANENTE}

\subsection{1 - INTRODUÇÃO}

As primeiras locomotivas, segundo Almeida (2006), não possuíam rodas com flange, podendo utilizar estradas. Porém para a economia de material e melhora da dirigibilidade, criaram-se flanges para as rodas e aliando o movimento das locomotivas aos trilhos.

Os elementos de via podem ser caracterizados como todos os componentes que compõem as estruturas que guiam o movimento do trem bem como as estruturas que permitem a interface com o trem.

É necessária a análise dos elementos de via para a determinação do risco quanto ao descarrilamento do material rodante, já que os mesmos influenciam na operação e no possível descarrilamento.

A Figura 3.1 apresenta elementos de via que serão abordados neste estudo. 

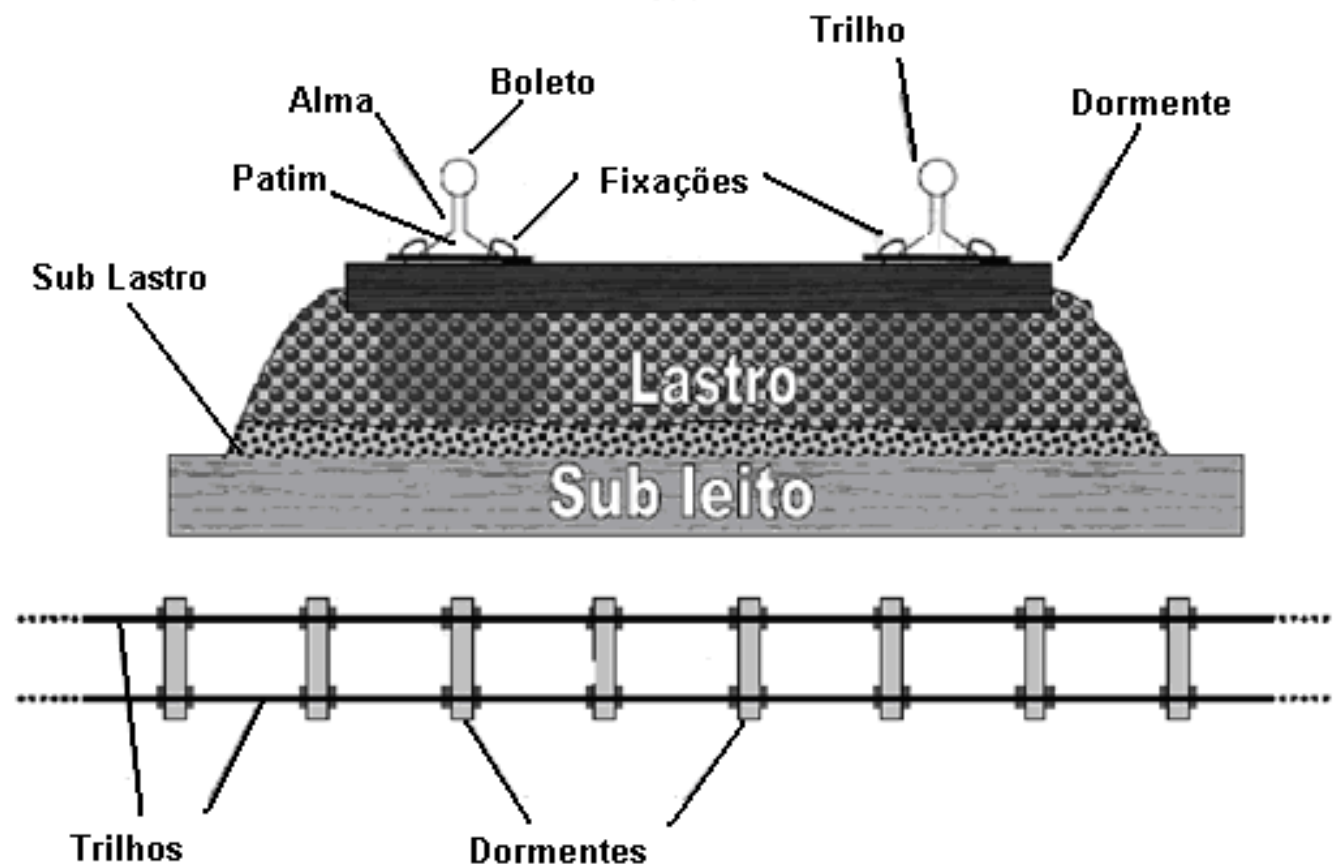

Figura 3.1 - Elementos de Via Permanente (SILVA, 2004)

\subsection{2 - TRILHO}

Os trilhos são os elementos de contato com a roda permitindo o contato metal-metal, servindo de sustentação para o material rodante e devendo apresentar perfil estável ao tombamento com alta resistência lateral, arestas arredondadas para diminuir a ação de tensões residuais e ter a sua vida útil respeitada (SILVA, 2004). Normalmente apresentam o perfil Vignole, que consiste em três áreas como mostra a Figura 3.1, o boleto que apresenta uma maior massa, favorecendo o momento de inércia, a alma que é dimensionada para garantir a resistência à flexão e o desgaste provocado pela corrosão atmosférica e o patim que é responsável por garantir a perpendicularidade do trilho.

As falhas que podem ocorrer nos trilhos são, segundo Brina (1988), separados em defeitos de fabricação e defeitos originados em serviço.

Os principais defeitos de fabricação, que podem afetar a segurança, são divididos em fenômenos chamados de vazio, segregações, inclusões e fissura transversais. 
O fenômeno de vazio ocorre durante o resfriamento do aço após a fabricação do trilho. O resfriamento causa a solidificação da região externa do trilho por estar em contato com o ar e por esta razão pode ocorrer um vazio devido à contração do material durante o resfriamento da região interna, assim ocorre uma diminuição da resistência do trilho (BRINA, 1988). Para evitar este defeito, é comum o uso de um massalote, ou seja, uma expansão deste trilho que é envolto de material mau condutor de calor. Esta expansão sofre o processo de "rechupe" e após o termino do resfriamento, o mesmo é descartado.

O fenômeno de segregação é causado pela presença de impurezas na liga de aço utilizado na fabricação, por exemplo, como ocorre na solidificação do metal líquido utilizado na fabricação do trilho, em que os elementos, como o enxofre, tornam-se menos solúveis e tendem a se agrupar na região central do trilho, já que esta região se solidifica depois quando comparada à região externa (COLPAERT, 1959). Desta forma, pode ocorrer alteração das propriedades mecânicas com falta de homogeneidade destas características, podendo apresentar qualidades mecânicas inferiores. A Figura 3.2 demonstra a disposição da segregação que freqüentemente se encontra nas seções de um trilho laminado e forjado.

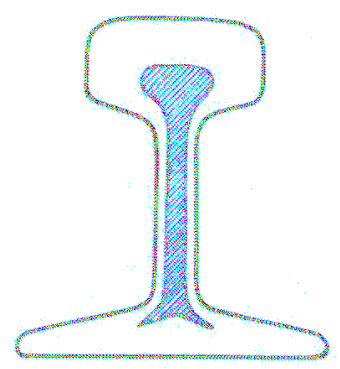

Figura 3.2 - Segregação no trilho (COLPAERT, 1959)

O fenômeno de inclusão não metálica é causado por elementos insolúveis ao aço como gases ou alguns óxidos, provocando desta forma a perda da homogeneidade e conseqüente qualidade inferior. Tal defeito pode ser evitado por uma desoxidação e práticas de lingoteamento convenientes (BRINA, 1988).

O defeito de fissuras transversais é causado por cavidades formadas no final da laminação e pode gerar fratura em operação. Para se evitar o risco provocado 
por este defeito, podem ser empregados equipamentos, como o detector de Sperry (BRINA, 1988), que utiliza corrente elétrica para a geração de campos magnéticos e para determinar a presença destas fissuras ou o Sonirail que se utiliza de sons para a detecção do defeito.

Alguns problemas relacionados com as heterogeneidades são apresentados no APÊNDICE D.

Os principais defeitos originados em serviço (BRINA, 1988) que podem afetar a segurança são divididos em:

- deformação das pontas que ocorre devido ao desnivelamento dos dormentes permitindo choques e flexões nas juntas;

- autotêmpera superficial, fenômeno no qual ocorre o aquecimento da superfície devido, por exemplo, à patinação das rodas e posterior resfriamento rápido, podendo causar assim fissuras ou fragilidade do material;

- escoamento do metal na superfície do boleto, que é uma deformação permanente devido, por exemplo, a choques e causando aumento da superfície do boleto;

- desgaste da alma e do patim por ação química, que é proveniente de produtos transportados ou da ação ambiente;

- desgaste do trilho por atrito, que ocorre devido às forças de atrito atuantes na movimentação do trem;

- fratura dos trilhos originadas em serviço, que pode ser causada pelas fissuras transversais ou fadiga do material.

De acordo com a Federal Railroad Administration (2006), a fratura dos trilhos é responsável por diversos acidentes, entre eles o descarrilamento. Além disso, o mesmo estudo ainda apresenta avaliação da resistência à fratura para trilhos fabricados com aço bainíticos e perlíticos bem como análise do crescimento da trinca pelo evento de fadiga. 
Para auxílio e facilitação da manutenção, existem indicações de limites de uso dos trilhos para o fenômeno de desgaste, como exemplo pode-se citar a que apresenta as ações nos trilhos que devem ser realizadas de acordo com o desgaste dos mesmos.

Tabela 3.1 - Tabela para Substituição e Inversão dos Trilhos

\begin{tabular}{|c|c|c|c|c|c|c|c|c|c|c|c|c|c|c|c|c|c|c|c|c|c|c|c|}
\hline \multicolumn{24}{|c|}{ TABELA PARA SUBSTITUIÇÃO / INVERSÃO DE TRILHOS TR-37 - Bitola Estreita, VMA de $30 \mathrm{Km} / \mathrm{h}$ e 20 tieixo } \\
\hline BOLETO & 63 & 62 & 61 & 60 & 59 & 58 & 57 & 58 & 55 & 54 & 53 & 52 & 51 & 50 & \begin{tabular}{|l|}
49 \\
\end{tabular} & \begin{tabular}{|l|l|}
48 \\
\end{tabular} & \begin{tabular}{|l|}
47 \\
\end{tabular} & 46 & 45 & \begin{tabular}{|l|l|}
44 & \\
\end{tabular} & 43 & 42 & 41 \\
\hline DESGASTE HORIZ. & 0 & 1 & 2 & 3 & 4 & 5 & 6 & 7 & 8 & 9 & 10 & 11 & 12 & 13 & 14 & 15 & 16 & 17 & 18 & 19 & 20 & 21 & 22 \\
\hline 1 & & & & & & & & & & & & & & & & & & & & & & & \\
\hline 2 & & & & & & & & - & & & E & & & & & & & & & & & & \\
\hline 3 & & & & & & & & & & & & & & & & & & & & & & & \\
\hline 4 & & & & & & & & & & & & & & & & & & E & ב & & - & 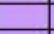 & \\
\hline 5 & & & & & & & & & & & & & & & & & & & & & & & \\
\hline 6 & & & & & & & & & & & & & & & & & & & & & & & \\
\hline 7 & & & & & & & & & & & & & & & & & & & & & & & \\
\hline 8 & & & & & & & & & & & & & & & & & & & & & & & \\
\hline 9 & & & & & & & & & & & & & & & & & & & & & & & \\
\hline 10 & & & & & & & & & & & & & & & & & & & & & & & \\
\hline 11 & & & & & & & & & & & & & & & & & & & & & & & \\
\hline 12 & & & & & & & & & & & & & & & & & & & & & & & \\
\hline 13 & & & & & & & & & & & & & & & & & & & & & & & \\
\hline 14 & & & & & & & & & & & & & & & 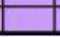 & - & 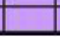 & - & 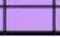 & & 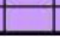 & & - \\
\hline & & & & & VERS & & & & & & & & & & 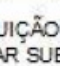 & BSTIT & TUIC & & fora de & a toler. & ância & & \\
\hline
\end{tabular}

(LAUERMAN, 2008 apud ALL, 2002)

\subsection{3 - TALAS DE JUNÇÃO}

As talas de junção são responsáveis pela união entre os trilhos. Estes elementos são montados na alma do trilho, podendo ter geometria tanto plana quanto angular, além de apresentar tamanhos variados como apresenta a Figura 3.3.
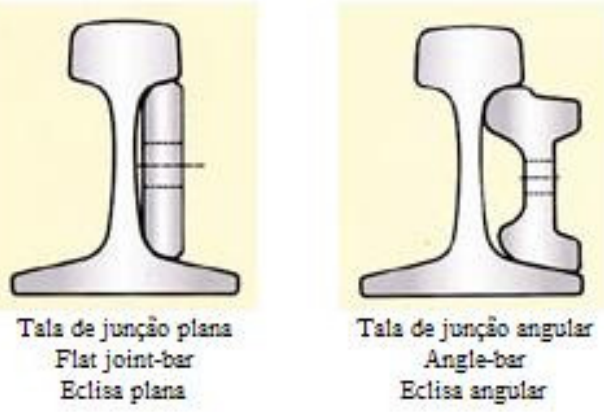

Figura 3.3 - Talas de Junção (M.I.M.F, 2009) 


\subsection{4 - ELEMENTOS DE FIXAÇÃO}

Os elementos de fixação são estruturas que garantem a fixação entre os trilhos e os dormentes. Estas fixações podem ser tanto rígidas quanto elásticas, que apresentam a vantagem de não afrouxar com as vibrações causadas pelos ciclos de operação. Pode-se citar como elementos de fixação: parafusos, arruelas, placas de apoio, pregos de linha, tirefões, grampos elásticos, fixações pandrol e retensores.

Os parafusos e arruelas são utilizados, por exemplo, para o aperto das talas de junção. Já as placas de apoio são utilizadas para aumentar a área do trilho no dormente e melhorar a distribuição da carga, aumentando a vida do dormente. A Figura 3.4 apresenta uma representação da placa de apoio.

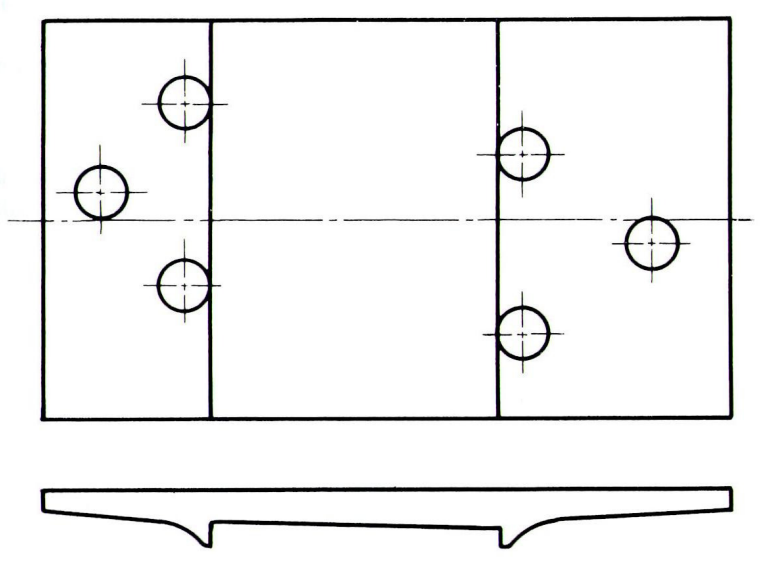

Figura 3.4 - Placa de apoio (BRINA, 1988)

O prego de linha é o tipo mais comum de fixação do trilho e é o menos eficiente quando comparado ao tirefão devido ao seu formato de cunha que tende a trincar o dormente. Já o tirefão apresenta seu corpo roscado e cabeça para permitir o uso de ferramentas para sua instalação. Um exemplo desta ferramenta é apresentada na Figura 3.5. Além disso, o APÊNDICE D apresenta-se figuras de problemas que podem ser encontrados em tirefões. 


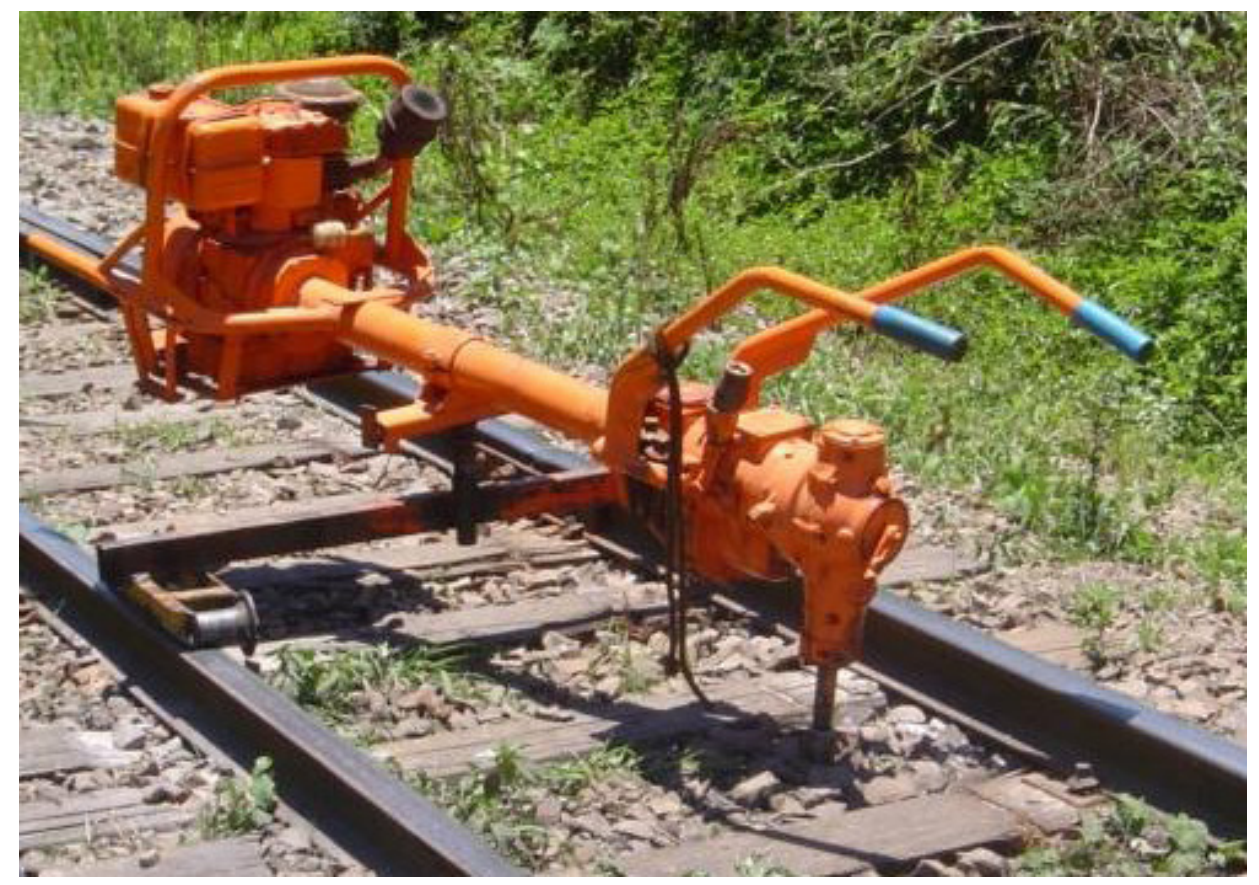

Figura 3.5 - Tirefonadora (LAUERMAN, 2008 apud ALL, 2002)

Outros elementos de fixação são os grampos elásticos, como as fixações pandrol, que são fixações elásticas e por esta razão apresentam menor afrouxamento quando comparados às rígidas. E por fim, os retensores que impedem o deslocamento dos trilhos na direção longitudinal.

Os elementos apresentados são utilizados na atualidade, por exemplo, a TRENSURB (2010) utiliza em seu trecho de via em superfície fixações elásticas nos dormentes de concreto e fixações com placa Pandrol e tirefões nos dormentes de madeira. Já a CPTM em dezembro de 2010, utilizava na estação Comandante Sampaio da linha 8 - Diamante fixações elásticas e na estação Lapa da linha 7 Rubi fazia uso de fixações pandrol e tirefões.

\subsection{5 - APARELHOS DE MUDANÇA DE VIA}

Os aparelhos de mudança de via (AMV) são dispositivos que permitem a alteração de rota do trem, uma vez que o trem não apresenta possibilidade de alteração de direção de operação própria. Na Figura 3.6 é apresentado um exemplo de aparelho de mudança de via. 


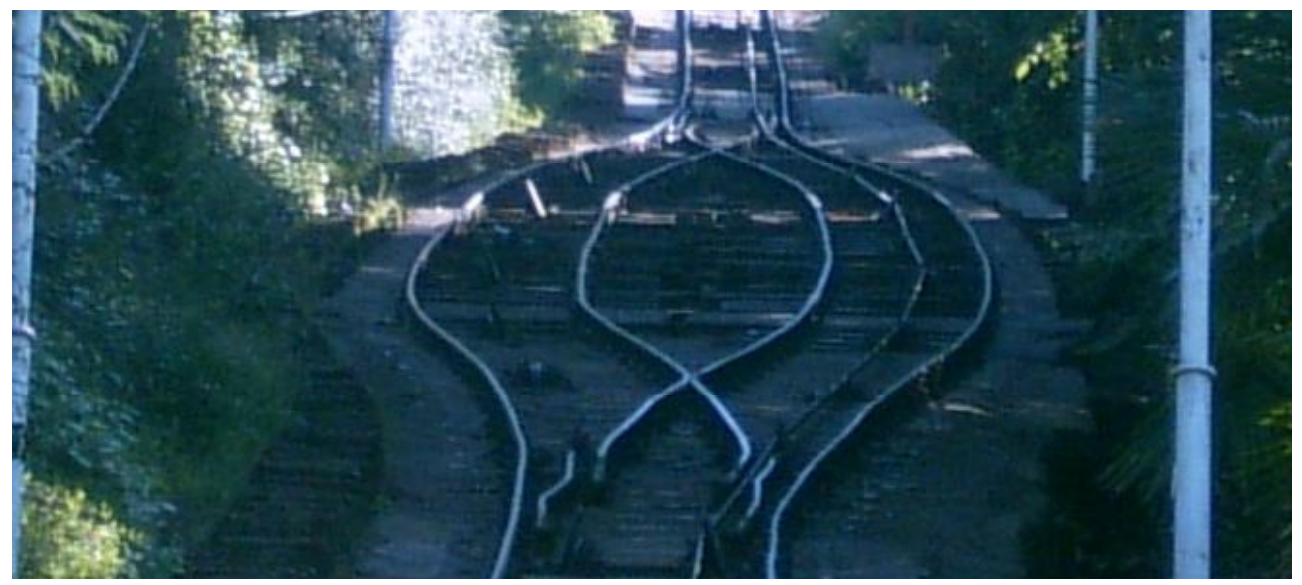

Figura 3.6 - Exemplo de Aparelho de Mudança de Via

Segundo (BRINA, 1988), os aparelhos de mudança de via podem ser classificados como: aparelhos de mudança de via comum, aparelhos de mudança de via especiais (giradores e carretões), triângulos de reversão, cruzamentos e párachoques.

As estruturas principais dos aparelhos de mudança de via comuns são:

- as agulhas, estruturas metálicas móveis e paralelas entre si permitindo a alteração da direção do movimento;

- as contra-agulhas, que servem de batente para as agulhas;

- os aparelhos de manobra, que permitem a movimentação das agulhas;

- os trilhos de ligação, que ligam as agulhas aos jacarés;

- os jacarés, partes principais dos aparelhos de mudança de via e apresentados na Figura $3.7 \mathrm{e}$

- os contratrilhos, instalados normalmente nos trilhos externos para evitar que os frisos das rodas se choquem com os jacarés.

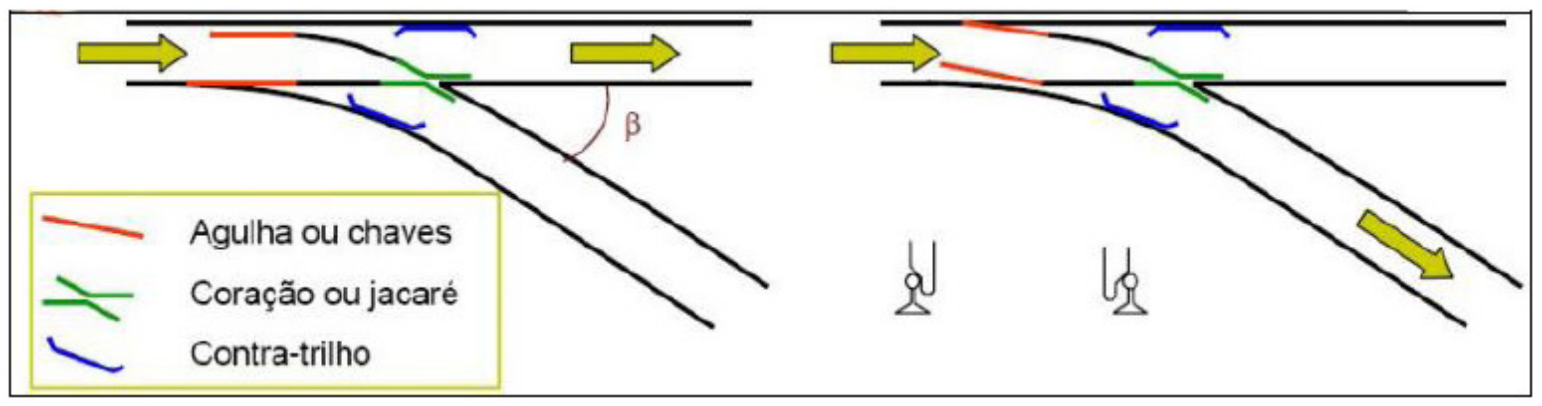

Figura 3.7 - Aparelho de Mudança de Via (LAUERMAN, 2008 apud ALL, 2002) 
Os aparelhos de mudança de via especiais são utilizados principalmente em áreas de manutenção, como oficinas, de forma a permitir, por exemplo, a mudança do sentido de operação (no caso dos giradores) e a mudança de veículos para diferentes vias (no caso de carretões).

Os triângulos de reversão são constituídos de desvios interligados de modo a alterar o sentido de operação do veículo ferroviário sem a necessidade do uso de giradores (que apresenta um maior preço de instalação). Já os pára-choques de via são instalados nas extremidades de via de modo a evitar o descarrilamento nas pontas dos desvios.

Por fim, os cruzadores permitem o cruzamento entre as duas vias férreas sem a necessidade de alteração do nível das mesmas. Vale ressaltar que este tipo de aparelho não pode ser utilizado em vias comerciais já que são inseguras para estas operações comerciais.

\subsection{6 - DORMENTES}

Os dormentes, segundo Silva (2004) e Brina (1988), apresentam como funções principais à distribuição da carga no lastro, garantir a bitola, garantir estabilidade e amortecer as vibrações. Existem diversos tipos de dormentes, sendo os principais os de concreto, os de madeira e os de aço. A Tabela 3.2 apresenta um comparativo entre estes três tipos de dormentes.

Tabela 3.2 - Comparativo entre Tipos de Dormentes

\begin{tabular}{lccc}
\hline & Concreto & Madeira & Aço \\
\hline Maior massa & $\mathrm{X}$ & & \\
Melhor isolamento & $\mathrm{X}$ & $\mathrm{X}$ & \\
Suportam supersolicitação & & $\mathrm{X}$ & $\mathrm{X}$ \\
Resistência a fungos & $\mathrm{X}$ & & $\mathrm{X}$ \\
Reciclável & & $\mathrm{X}$ & $\mathrm{X}$ \\
Facilidade de manuseio & & $\mathrm{X}$ & $\mathrm{X}$ \\
\hline
\end{tabular}


O uso de madeira para a fabricação de dormentes é comum por apresentar características importantes para os mesmos como menor massa quando comparado ao dormente de concreto, bom isolamento elétrico e a possibilidade de reciclagem. Porém, aliado a estas características desejáveis, a durabilidade deste material deve ser considerada, pois é influenciada pela qualidade do material, clima, drenagem da via, peso do trem, velocidade de operação e tratamentos químicos que a madeira recebe.

Os dormentes de aço podem apresentar diversos tipos de formato, sendo o mais comum a forma de $U$ invertido e é uma solução contra o inconveniente dos fungos que podem vir a atacar os dormentes de madeira. Porém, apresentam como inconvenientes o maior barulho em operação, a dificuldade de isolamento elétrico e maior rigidez com conseqüente possibilidade de afrouxamentos dos elementos de fixação (BRINA, 1988).

Os dormentes de concreto foram criados devido à escassez de boas madeiras para dormentes evitando assim o desflorestamento, porém apresentam como inconveniente a incapacidade de suportar supersolicitações, ocorrendo trincas e quebras com a operação dos trens. E para a resolução deste problema, algumas soluções foram propostas para os dormentes de concreto, como: dormentes de concreto protendido, dormentes mistos e dormentes poliblocos.

Os dormentes de concreto protendido apresentam protenção reforçada (introdução na estrutura do dormente de um estado prévio de tensões, melhorando a sua resistência quanto à ação de diversas solicitações) e região central com altura média mais espessa. Já os dormentes mistos são formados por dois blocos de concreto unidos por uma viga metálica, tentando unir as características do concreto (isolamento, resistência etc) e do metal (maior elasticidade quando comparado ao concerto). Por fim, os dormentes poliblocos apresentam três blocos de concreto unidos por fios de aço e material elástico. 


\subsection{7 - LASTRO E SUBLASTRO}

Os lastros são construídos para distribuir os esforços nos dormentes, permitir a manutenção do nivelamento da via e drenagem. Já o sublastro é construído com o intuito de impedir que ocorra a difusão de lama na direção vertical com sentido para cima.

Os principais modos de falha desta infra-estrutura, segundo Porto (1984), são: ruptura geral, deformação excessiva, contaminação do lastro pela presença de finos bombeados do sub-leito e ruptura do lastro. A ruptura geral é caracterizada pela ruptura da infra-estrutura podendo ocasionar deslocamento de material para o lado da via ou para a região entre os dormentes, sendo causado quando o subleito não consegue suportar as cargas do movimento do material rodante. Já a deformação excessiva é caracterizada quando a deformação atinge um limite em que a operação ferroviária não é viável economicamente.

Outro modo de falha, a contaminação do lastro pela presença de finos bombeados do sub-leito, é causada pela ruptura do solo em contato com o lastro ou sub-lastro, seguido de bombeamento da argila e remonte do material fino através do lastro, causando maior rigidez na via e aumentando a velocidade de deterioração da via. Por fim, a ruptura do lastro é causada pelo acúmulo de partículas finas produzidas pelo desgaste do lastro ou de algum outro depósito, impedindo a drenagem e podendo causar a formação de lama que facilita o deslocamento do lastro e pode causar a ruptura do mesmo. Neste caso, o dimensionamento das camadas para se evitar esta falha pode ser realizado através do uso de fatores de segurança.

\subsection{8 - PLATAFORMA}

A plataforma é o elemento que permite, por exemplo, a acomodação de passageiros e de carga. Ou seja, trata-se da interface entre o trem e as pessoas e a colocação de cargas. Dependendo das regiões, pode apresentar diferentes alturas e comprimentos. 


\subsection{9 - CARACTERÍSTICAS GEOMÉTRICAS}

As características geométricas da via são limitadas pela dinâmica do movimento do trem, já que esta dinâmica apresenta diversas peculiaridades, como por exemplo, o contato metal-metal que garante 0 atrito responsável pelo movimento, a restrição quanto às curvas devido ao truque (sistema que é detalhado no item 3.2.2) que apresenta estrutura rígida, a limitação de potência gerada pelo sistema de tração, entre outras. Por esta razão, faz-se importante apresentar as formas de determinação das limitações de via, sendo considerado como as duas principais limitações presentes na ferrovia o raio mínimo permitido e a superelevação.

\subsubsection{1 - Raio Mínimo}

O raio mínimo permitido é estabelecido por normas e autoridades ferroviárias. Este raio deve limitar o escorregamento entre o trilho e rodas e permitir a inscrição da base rígido dos truques do carro (SILVA, 2004). A existência desta restrição ocorre devido, em última análise, à inscrição dos veículos que se aproxima à de um retângulo com base rígida de inscrição igual à distância entre os eixos extremos (BRINA, 1988). Esta base rígida pode ser observada na Figura 3.8 e Figura 3.10.

De acordo com as dinâmicas dos veículos na via, o mesmo pode tomar algumas posições diferentes: a de inscrição limite ou obrigada e a inscrição livre ou normal.

No caso da inscrição limite, os frisos das rodas extremas estarão em permanente contato com o trilho aumentando a resistência da curva, facilitando o descarrilamento nesta situação; desta forma o dimensionamento da curva neste caso só seria aceito em trechos de velocidade reduzida, como pátios (BRINA, 1988). Alternativamente às normas que limitam o raio mínimo, é possível a estimativa da superlargura (excesso de distância em relação à bitola aplicada em curvas para facilitar a rodagem e a inscrição), considerando-se os parâmetros definidos na 
Figura 3.8 e o seguimento afetado relativo ao avanço do friso em relação ao aro definido na Figura 3.9. Nestas figuras considera-se:

R: raio da curva

$R_{1}$ : Raio determinado pelo trilho interno

$\mathrm{R}_{2}$ : Raio determinado pelo trilho externo

$f_{1}$ : folga decorrente do raio $R_{1}$ e eixos extremos

$f_{2}$ : folga decorrente do raio $R_{2}$ e eixos extremos

$\mathrm{p}$ : dimensão da base rígida do veículo

u: seguimento afetado relativo ao avanço do friso em relação ao aro

$\mathrm{m}$ : altura do friso

$D_{\mathrm{i}}$ : diâmetro da roda medido até o friso

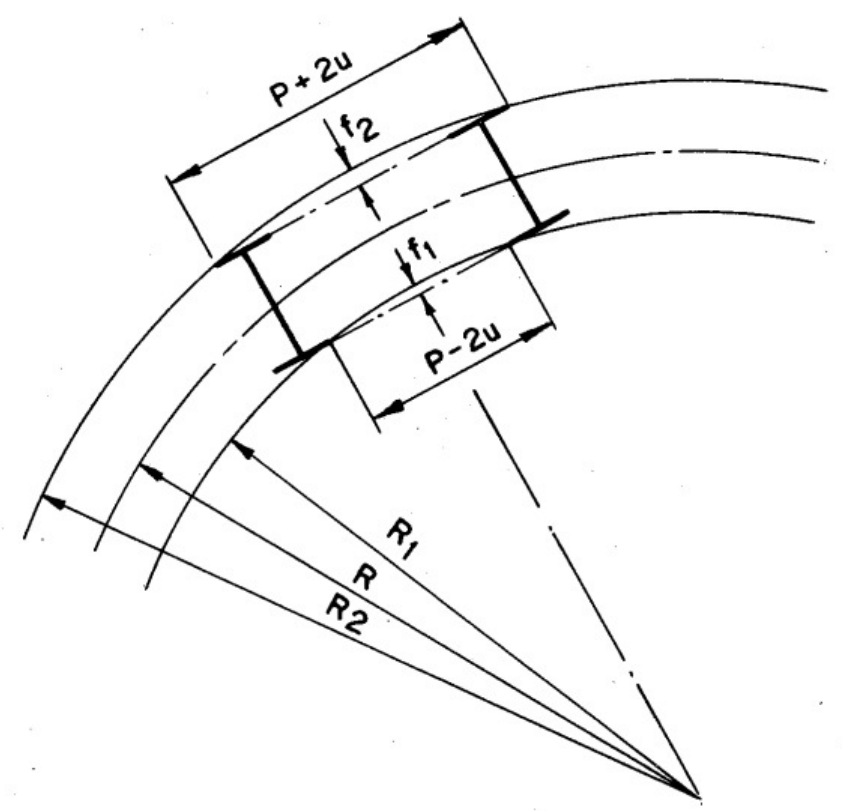

Figura 3.8 - Modelo para Inscrição Limite (BRINA, 1988)

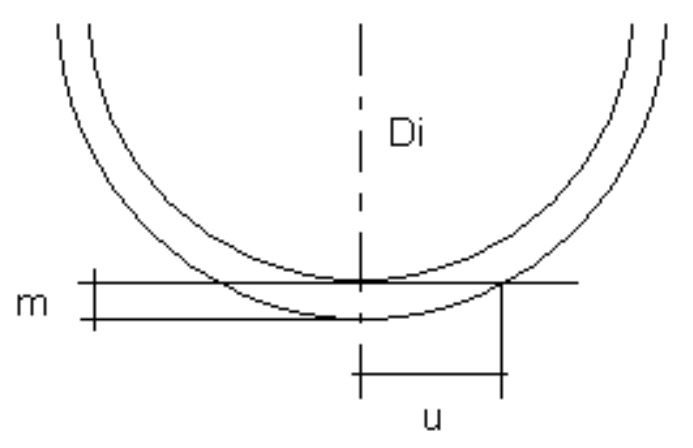

Figura 3.9 - Modelo do Avanço do Friso (Adaptado de BRINA, 1988) 
Considerando $d_{f}$ como a distância entre as faces externas dos frisos e $j o$ jogo da via, é obtida a equação (3.1) e (3.2):

$$
\begin{gathered}
d_{f}+f_{2}=f_{1}+B+S_{u} \\
B-d_{f}=j
\end{gathered}
$$

Por conseqüência o valor da superlargura $S_{u}$ :

$$
S_{u}=f_{2}-f_{1}-j
$$

Sabendo ainda que geometricamente tem-se (desconsiderando $f_{2}^{2}$ e $f_{1}^{2}$ frente a $2 \mathrm{R})$ :

$$
\begin{aligned}
& \left(\frac{p+2 u}{2}\right)^{2}=f_{2}\left(2 R_{2}-f_{2}\right)=2 R_{2} \cdot f_{2} \\
& \left(\frac{p-2 u}{2}\right)^{2}=f_{1}\left(2 R_{1}-f_{1}\right)=2 R_{1} \cdot f_{1}
\end{aligned}
$$

Tem-se assim através da manipulação de (3.3), (3.4) e (3.5):

$$
S_{u}=\frac{(p+2 u)^{2}}{8\left(R+\frac{B}{2}\right)}-\frac{(p-2 u)^{2}}{8\left(R-\frac{B}{2}\right)}-j
$$

Considerando ainda:

$$
u^{2}=d_{f} m
$$

é obtida a equação (3.8) da superlargura mínima, ou através de manipulações, do raio mínimo para que ocorra ao menos a inscrição limite. 


$$
S_{u}=\frac{p R \sqrt{d_{f} m}-\frac{p^{2} B}{8}-\frac{m B d_{f}}{2}}{R^{2}-\frac{B^{2}}{4}}-j
$$

No caso da inscrição livre, o eixo traseiro tomará a posição radial em que o mesmo ficará na direção do raio da curva (BRINA, 1976). Desta forma, considerando-se a Figura 3.10 sendo que $f$ é a folga no trilho com relação ao eixo traseiro:

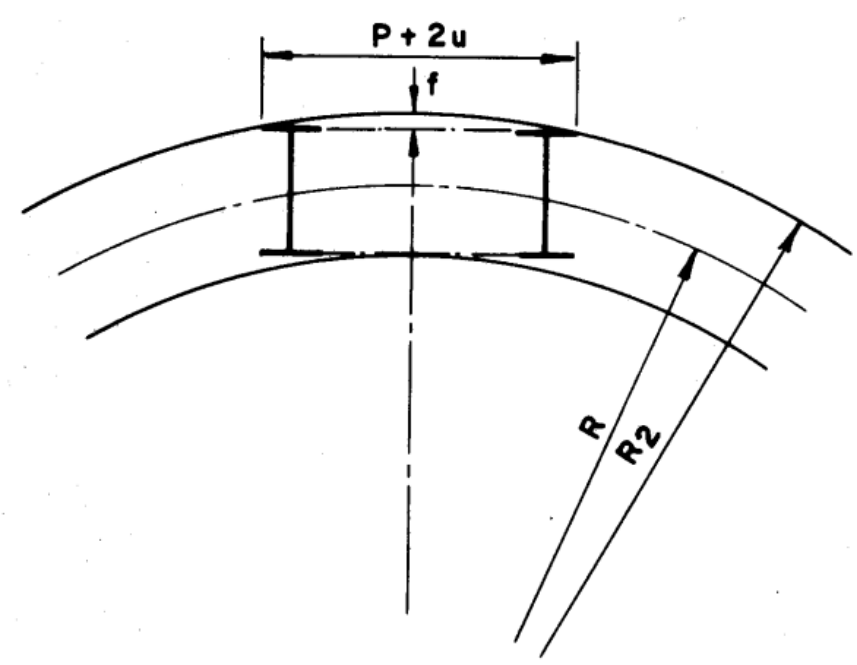

Figura 3.10 - Modelo para Inscrição Livre (BRINA, 1988)

A equação demonstrada por Brina (1976) para o raio mínimo é expressa por:

$$
f=\frac{p^{2}-2 p u}{2\left(R-\frac{B}{2}\right)}
$$

Através da equação (3.8) e (3.9, é possível estimar os raios mínimos, em que normalmente são aplicados fatores de segurança quanto a estes raios. A equação (3.8) refere-se à inscrição limite (que não deve ser utilizada em operações comerciais) e a equação (3.9 refere-se à inscrição livre. 


\subsubsection{2 - Superelevação}

A superelevação é utilizada no projeto de vias férreas com o intuito de diminuir o desgaste do contato metal-metal e o risco de descarrilamento, além de permitir um maior conforto ao passageiro. Assim, é possível o equacionamento da superelevação considerando o carregamento presente em um carro em curva de acordo com a Figura 3.11. Nesta figura considera-se:

$\mathrm{d}_{1}=$ deslocamento do centro de gravidade;

$\mathrm{H}=$ altura do centro de gravidade em relação ao trilho superior;

$\mathrm{a}=$ distância de centro a centro dos trilhos;

$h_{p}=$ superelevação máxima, ou seja, é a maior superelevação prática que não provoca o tombamento do trem;

$\alpha_{1}$ = ângulo entre a horizontal e o dormente;

$P$ é a força peso;

F' é a componente da força peso na direção de Fc e;

Fc é a força centrífuga resultante.

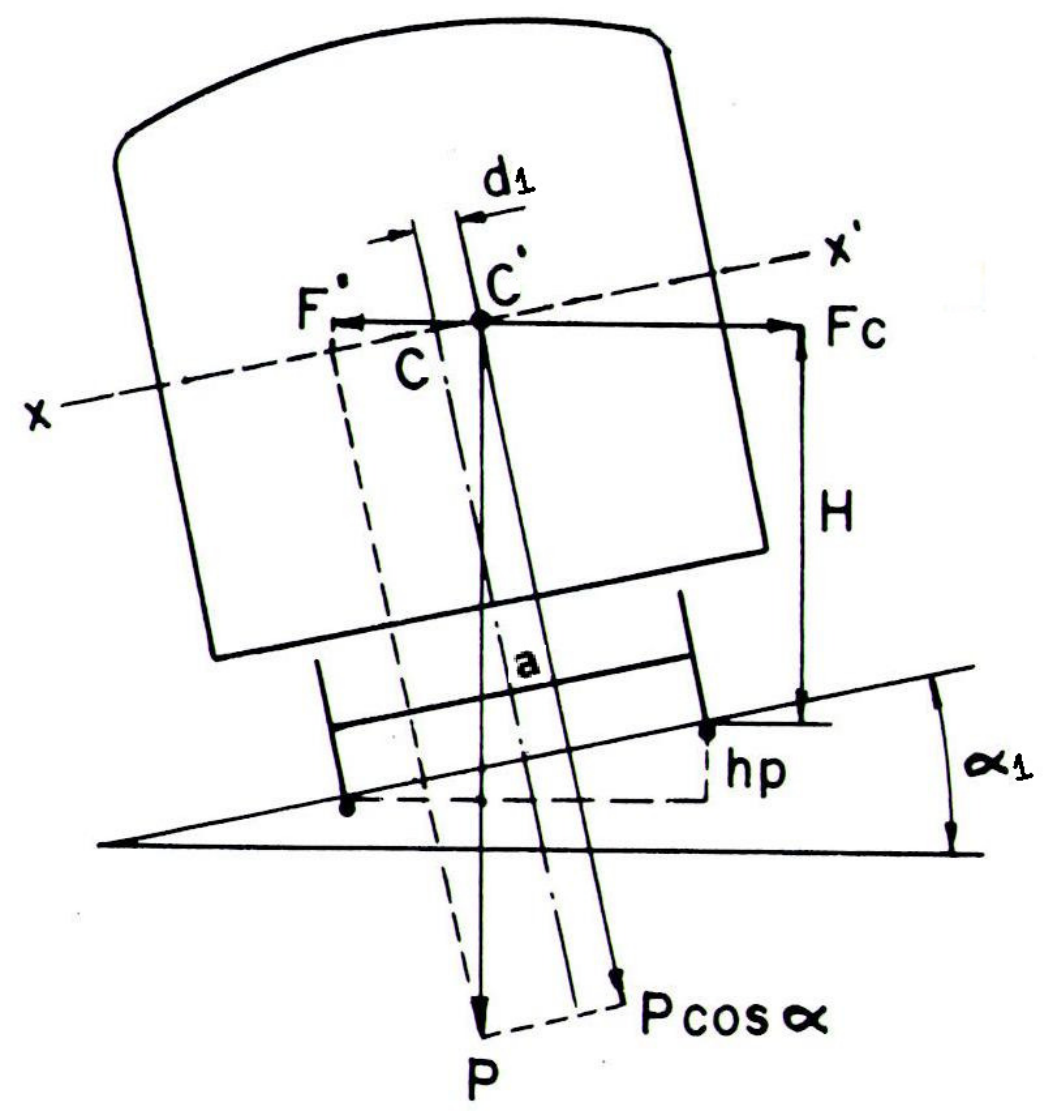

Figura 3.11 - Modelo para Determinação de Superelevação Máxima (BRINA, 1988) 
Na configuração apresentada na Figura 3.11, segundo Stopatto (1987) e Brina (1988), considerando uma velocidade do trem (v) e o raio da curva $(R)$, a força centrífuga resultante (Fc) é expressa por (3.10).

$$
F_{C}=\frac{P v^{2}}{g R}
$$

Além disso, durante o movimento surgem dois momentos, o momento estabilizador (Me) e o momento de reviramento (Mr). Considerando como ponto de referência o ponto de contato entre a roda e o trilho superior, têm-se as expressões (3.11) e (3.12).

$$
\begin{gathered}
M e=P \cdot \cos \alpha_{1}\left(\frac{a}{2}-d_{1}\right) \\
M r=\left(P \frac{h}{a}-\frac{P v^{2}}{g R}\right) H
\end{gathered}
$$

Assim, para ângulos pequenos de $\alpha_{1}$ é obtida a expressão (3.13).

$$
M e=P \cdot\left(\frac{a}{2}-d_{1}\right)
$$

Para que ocorra o equilíbrio, o momento de reviramento deve ser igual ao momento estabilizador. Vale ressaltar que são considerados coeficientes de segurança (n) para garantir que não ocorra o tombamento; portanto são obtidas as equações (3.14) e (3.15).

$$
\begin{gathered}
M e=n \cdot M r \\
h_{p}=\frac{a v^{2}}{g \cdot R}-\frac{a}{H \cdot n}\left(\frac{a}{2}-d_{1}\right)
\end{gathered}
$$


Outro critério que deve ser considerado na determinação da superelevação é o critério de conforto, ou seja, a aceleração centrífuga que uma pessoa pode suportar confortavelmente deve ser considerado. De acordo com experimentos, a aceleração centrífuga que uma pessoa pode suportar sem que sinta desconforto é $0,6 \mathrm{~m} / \mathrm{s}^{2}$ (BRINA, 1988). Assim, considerando um veículo percorrendo uma curva com raio de curvatura $R$, a expressão (3.15) é simplificada desconsiderando a parcela resultado da força peso na direção de Fc, logo é obtida a equação (3.16).

$$
h_{T}=\frac{a v^{2}}{g \cdot R}
$$

A aceleração centrífuga $\gamma$ pode ser expressa por $v^{2} / R$, causando assim uma parcela de superelevação conforme expressão (3.17):

$$
\Delta h=\frac{a \gamma}{g}
$$

Logo a equação (3.19) representa a superelevação de acordo com o critério de conforto.

$$
\begin{gathered}
\Delta h=h_{T}-h_{p} \\
h_{p}=\frac{a v^{2}}{g \cdot R}-\frac{a \gamma}{g}
\end{gathered}
$$

Assim, para a determinação da superelevação máxima, escolhe-se entre 0 maior valor que atenda às duas equações (3.15) e (3.19).

Além disso, de maneira análoga pode-se determinar a velocidade máxima de operação em cada curva. Já para a determinação da velocidade mínima, considerase que o tombamento pode ocorrer pelo trilho interno à curva, assim, utilizando-se um equacionamento semelhante pode-se determinar a velocidade mínima de operação de um trem em curva. 


\section{2 - VEÍCULOS FERROVIÁRIOS}

\subsection{1 - INTRODUÇÃO}

O veículo ferroviário ou material rodante é definido, segundo Almeida (2006) e Santos (2007), como todo veículo que apresenta a sua trajetória pré-estabelecida, caracterizado por um ou mais veículos interligados para o transporte de cargas e pessoas. A sua trajetória é limitada pelos elementos via que impedem a alteração da direção do veículo. Atualmente existem diversos tipos de veículos ferroviários, como: locomotivas, pendulares, metropolitanos, trens regionais, trens de alta velocidade e veículos leves sobre trilhos.

As locomotivas são os veículos que apresentam a possibilidade de movimentação autônoma, fornecendo possibilidade de movimento para os demais veículos a ela ligados, possuindo diversos tipos de propulsão, como por exemplo, a vapor, diesel e elétricas.

Os veículos leves sobre trilhos são veículos de menor massa quando comparados com os demais e operam mais comumente entre bairros e pequenas cidades.

Os trens metropolitanos são utilizados para o transporte de um grande número de pessoas e normalmente são utilizados em metrópoles e percorrem menores distâncias entre as estações quando comparados com os trens regionais.

Os trens regionais normalmente são os que apresentam maior massa quando comparados aos demais trens e apresentam a característica de ligar as regiões de subúrbio com as metrópoles.

Os trens de alta velocidade são trens utilizados para unir diferentes regiões que apresentam grandes distâncias entre si em um menor intervalo de tempo. Normalmente apresentam custo mais elevado para a sua utilização. 
Os trens pendulares são veículos guiados sobre trilhos que apresentam em seu movimento um sistema que aumenta o conforto através da inclinação dos veículos em regiões com maior sobreelevação permitindo também uma maior velocidade de operação dos mesmos em vias comuns (FACINI, 2007).

Pode-se ainda classificar os veículos ferroviários de acordo com o seu tipo de guiagem. Estes tipos são apresentados na Figura 3.12.

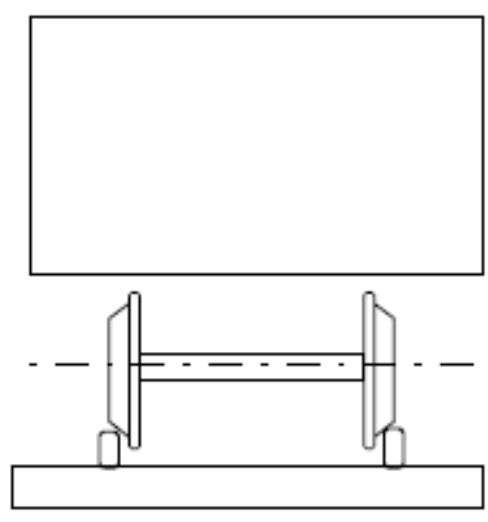

Veículo com

Roda Cônica

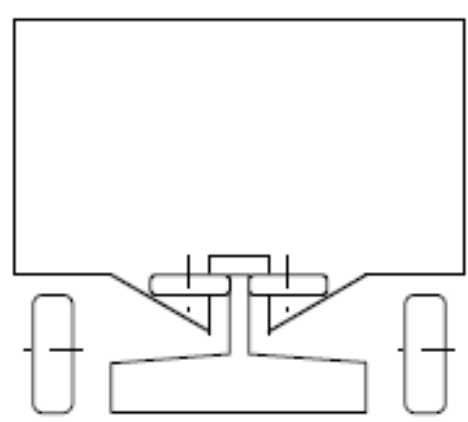

Veículo Pneumático com Guia Lateral

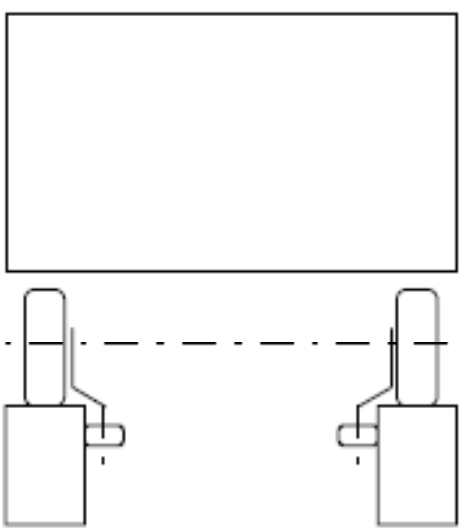

Veículo com Pneumático Guiado

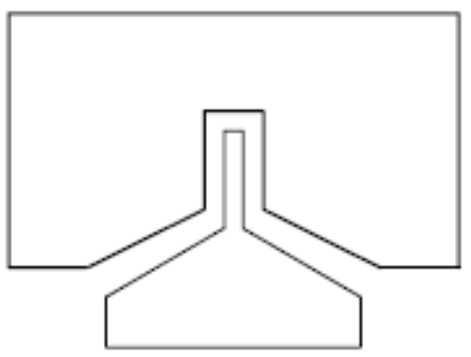

Veículo de Levitação Magnética

Figura 3.12 - Sistema de Guiagem de Veículos (BARBOSA, 1999)

No presente trabalho serão abordados apenas os veículos guiados por roda cônica como apresentado na Figura 3.12. 


\subsection{2 - TRUQUE}

O truque pode ser definido como a estrutura de sustentação do trem. É o elemento de contato com o trilho. Os seus componentes principais são: suspensão, estrutura e rodeiro. As figuras 3.13 e 3.14 apresentam estes componentes.

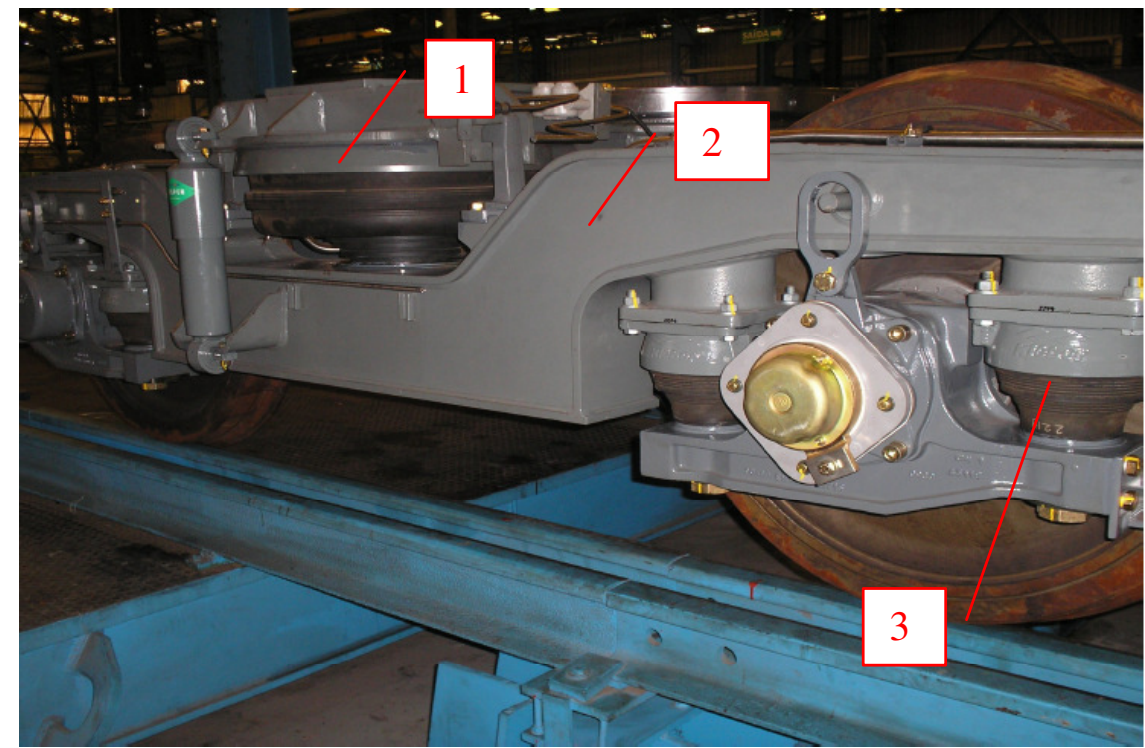

1 - Suspensão Secundária / 2 - Estrutura / 3 - Suspensão Primária

Figura 3.13 - Truque (Adaptada de ALMEIDA, 2006)

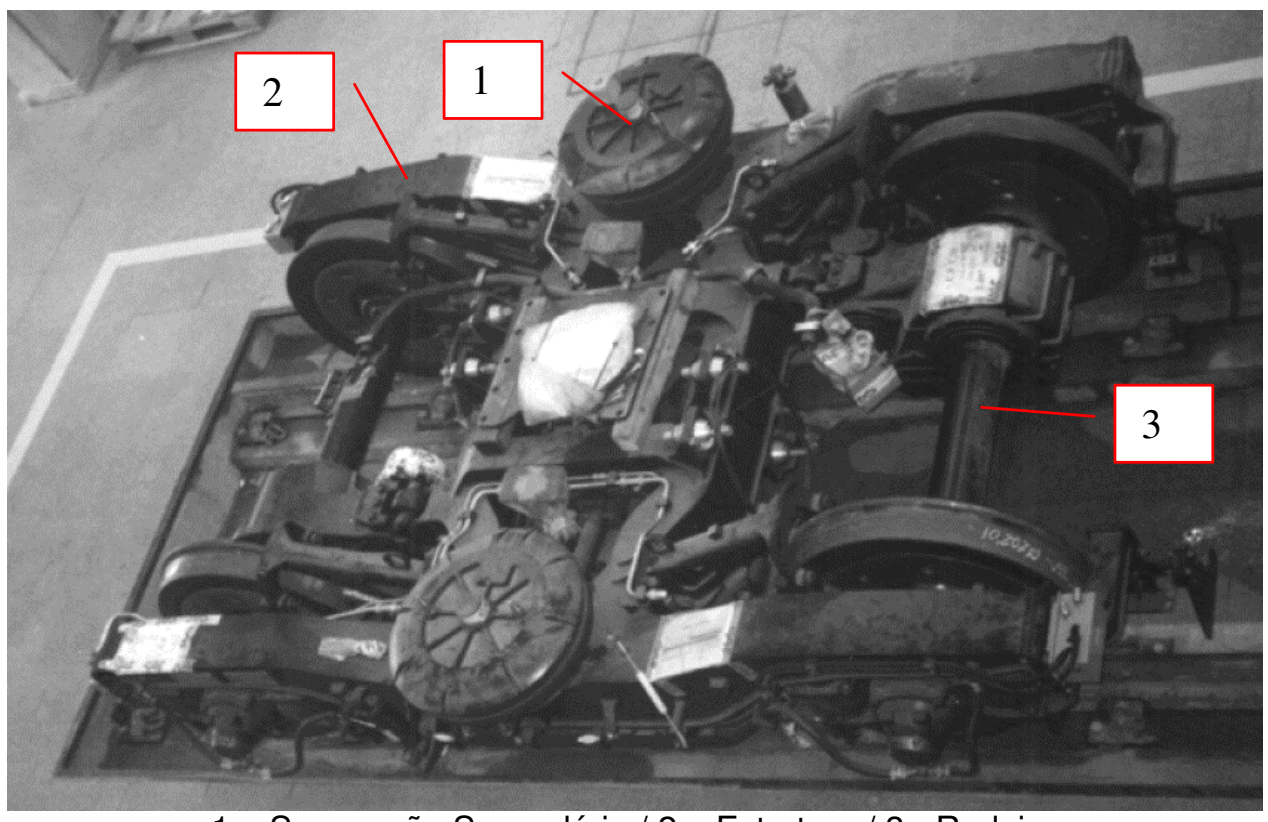

1 - Suspensão Secundária / 2 - Estrutura / 3 - Rodeiro

Figura 3.14 - Truque (Adaptada de PIRES, 2006) 


\subsection{3 - ELEMENTOS DE SUSPENSÃO}

A suspensão pode ser dividida em suspensão primária e suspensão secundária. A suspensão primária, segundo Consoli (2007), é "o primeiro filtro de vibração" servindo para diminuir a transmissão ao veículo das altas vibrações. Nos veículos ferroviários esta suspensão normalmente é construída com molas que isolam as vibrações causadas pelo contato roda trilho como mostra a Figura 3.15.

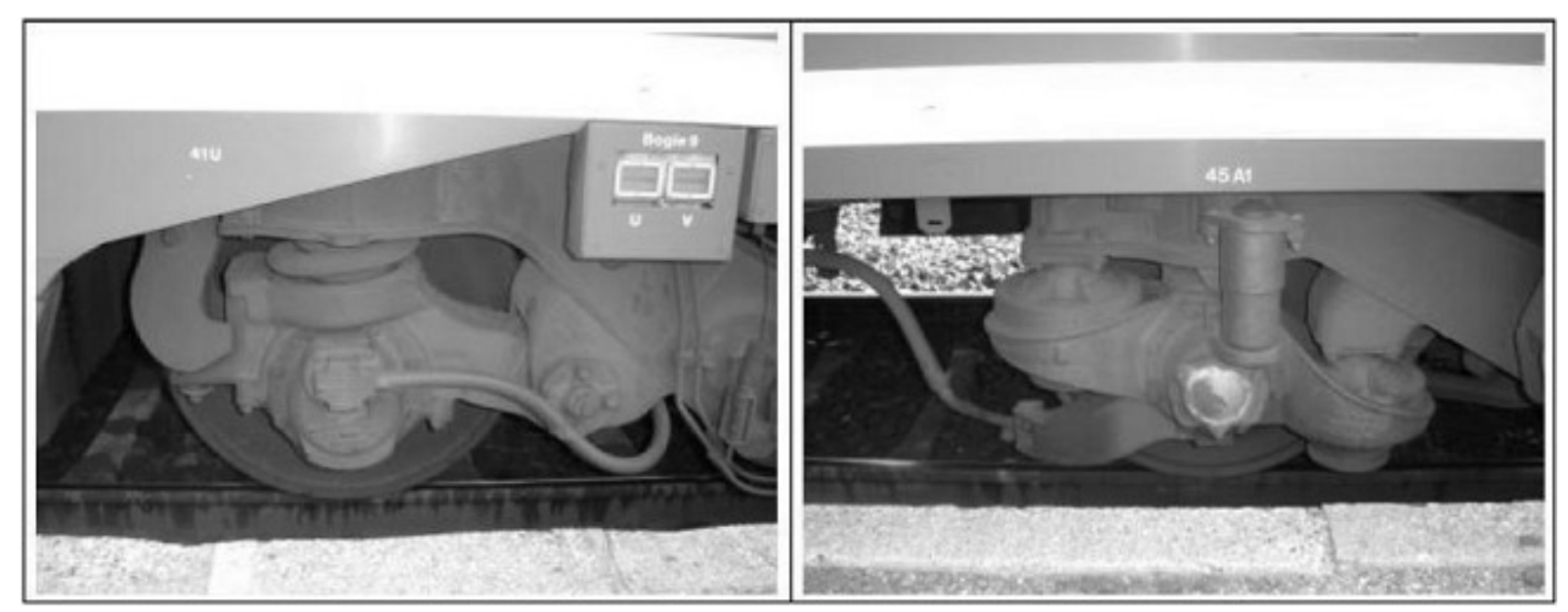

Figura 3.15 - Suspensão Primária de Mola e Elastômero (CONSOLI, 2007)

A suspensão secundária é normalmente construída utilizando molas pneumáticas e isola as vibrações de baixa freqüência provenientes da armação do truque, garantindo estabilidade de movimento e conforto aos passageiros (CONSOLI, 2007). A Figura 3.16 apresenta um exemplo de suspensão secundária. 


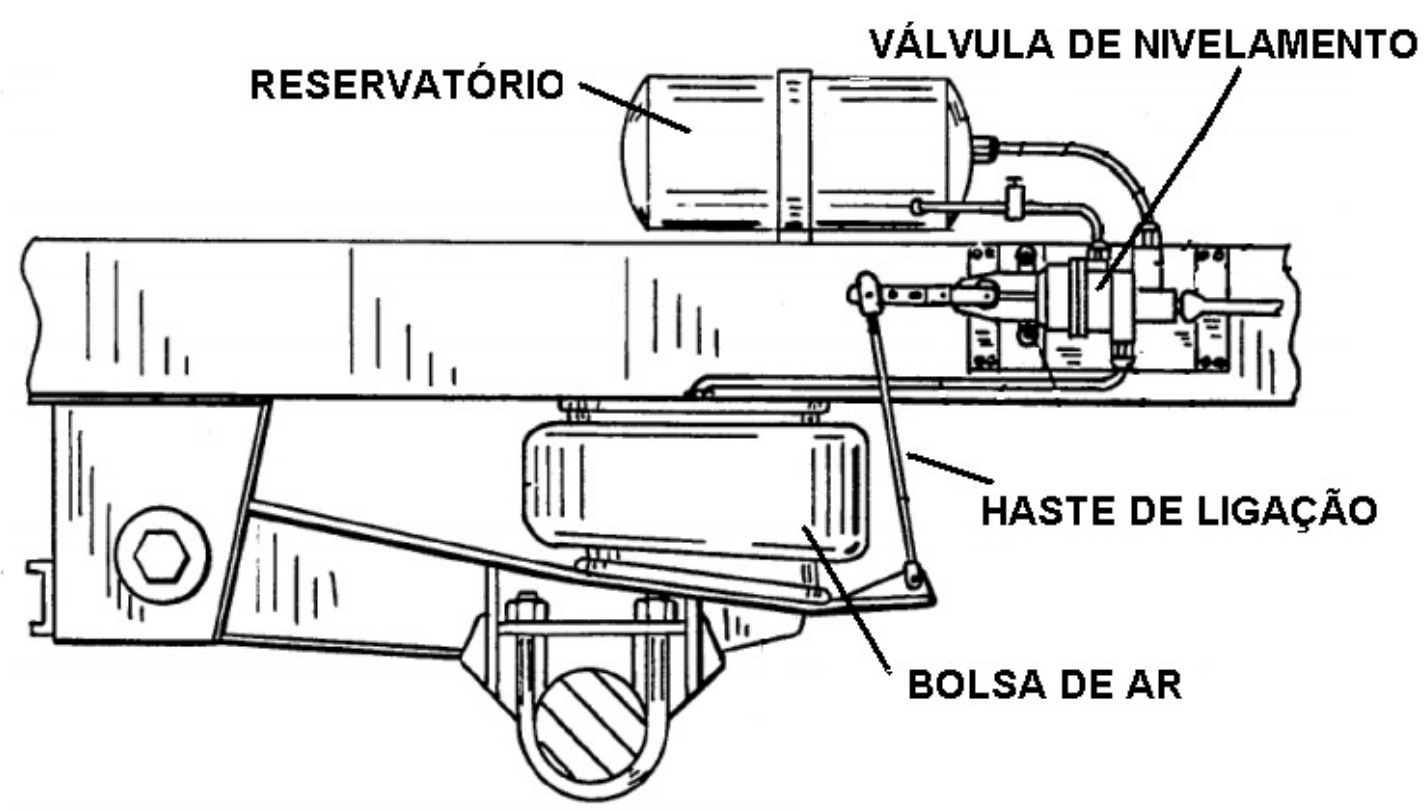

Figura 3.16 - Suspensão secundária (Adaptado de CONSOLI, 2007 apud ANDERSON, 1992)

Em conjunto com a suspensão secundária, normalmente são utilizadas válvulas de nivelamento, que proporcionam o nivelamento dos vagões do veículo. Estas válvulas em conjunto com as hastes de ligação permitem a passagem de ar para a bolsa quando a distância entre a estrutura do truque e a caixa/vagão diminuem. Esta diminuição é causada pelo aumento da carga naquela região; com este aumento, ocorre o aumento da pressão na bolsa de ar e conseqüentemente o nivelamento.

A suspensão secundária não é utilizada em trens de carga, já que o balanceamento dos vagões dos carros é feito na carga do vagão e as cargas não se movimentam, diferentemente dos trens de passageiros em que as cargas são dinâmicas e este nivelamento e compensação do centro de massa deve ser realizado.

\subsection{4 - ESTRUTURA}

A estrutura do truque garante a fixação de todos os outros elementos, podendo ser de aço ou alumínio, sendo este componente de difícil fabricação devido ao seu tamanho elevado e necessidade de controle de fabricação para se evitar 
problemas como trincas e requerendo, por exemplo, soldadores experientes e certificados ou máquinas de custo elevado para tal. Além disso, esta estrutura é de difícil inspeção devido a localização no veículo ferroviário e o seu tamanho elevado como pode ser observado nas figuras 3.13 e 3.14 .

\subsection{5 - RODEIRO}

A estrutura formada pelo eixo, rodas e caixa de rolamentos recebe o nome de rodeiro. A Figura 3.17 apresenta um exemplo desse tipo de montagem.

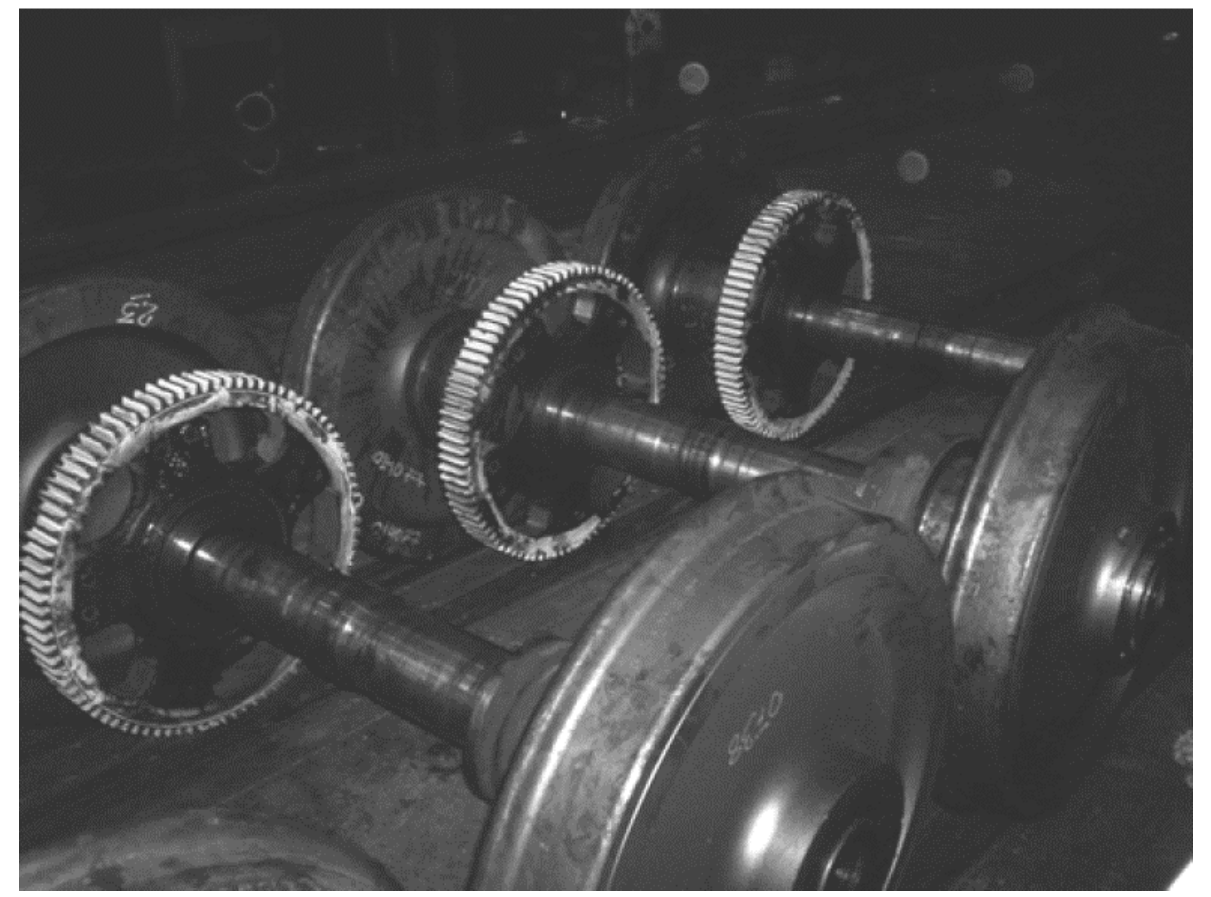

Figura 3.17 - Rodeiro (PIRES, 2006)

Em truques motores, a caixa de engrenagens também é atribuída ao rodeiro, porém neste trabalho a análise da caixa de engrenagens é realizada no sistema de tração porque a mesma altera a transmissão de velocidade de rotação do motor de tração. Já o perfil da roda é importante na dirigibilidade do material rodante, podendo afetar também a taxa de desgaste do trilho e da roda, ou seja, segundo Almeida (2006), ao se mudar o raio dos pontos de contato e o ângulo de conicidade das rodas no contato, as forças tangencias também mudam. Este fator influencia no descarrilamento, como será apresentado na seção 4.1. 
Nesta dissertação, serão estudadas rodas com perfil cônico que melhoram o auto-direcionamento do rodeiro. Além disso, apresentam frisos que limitam 0 movimento do rodeiro. Existindo normativas que determinam a geometria da roda, como por exemplo a norma UIC 510 - 2 OR (2004) intitulada Trailing stock: wheels and wheelsets. Conditions concerning the use of wheels of various diameters que trata perfis de roda de $300 \mathrm{~mm}$ a $1.000 \mathrm{~mm}$ apresentando também o carregamento permitido no eixo. Um exemplo dos parâmetros geométricos do perfil da roda é apresentado no APÊNDICE A.

Segundo a norma UIC 510 -2 OR (2004) existem especificações para o tipo de material a ser utilizado para a fabricação das rodas e também tratamentos especiais dependendo do uso. Outros aspectos abordados pela norma são os parâmetros quanto às dimensões da roda que devem ser respeitados para a operação segura do mesmo. A mesma menciona que rodas padrões (com diâmetros nominais maiores ou iguais a $840 \mathrm{~mm}$ ) não necessitam de regulamentações especiais para a determinação de seus diâmetros. Para diâmetros nominais menores que 840 mm, são definidos parâmetros para os ângulos de ataque e forças laterais.

Normas como a UIC 813 O (2003) definem tolerâncias (por exemplo, as tolerâncias entre os eixos e furos apresentados no APÊNDICE B) e parâmetros de prensagem do conjunto eixo-roda presentes no material rodante. Para o rodeiro, segundo esta norma, são definidas as características mecânicas deste item, a resistência elétrica (não deve exceder 0,01 $\Omega$ ), desbalanceamento, dimensões e ações de manufatura (como indicação do número serial, data de aceitação, marca de inspeção etc). Ademais, são apresentados os métodos de manufatura, parâmetros, inspeções dos componentes, inspeções da produção, inspeções das características dos rodeiros e conclusões das inspeções a serem realizadas, forma de entrega, forma em que deve ser fornecida a garantia e requerendo ao final um certificado quanto aos requisitos da especificação técnica. 


\section{3 - ACOPLAMENTO}

O acoplamento ou engate é a estrutura de ligação entre os carros /vagões. Estes elementos sofrem forças decorrentes da movimentação do trem (tração, compressão, torção, flexão). Usualmente existem dois tipos de acoplamentos, os automáticos e os não automáticos. Os automáticos apresentam dispositivos para que o acoplamento seja realizado de forma remota; para tal, faz-se o uso de circuito elétricos e/ou pneumáticos que podem acionar dispositivos de união e/ou separação dos acoplamentos. Já os não automáticos não apresentam estes dispositivos sendo que a união e separação devem ser feitas manualmente com dispositivos de fixação como, por exemplo, parafusos.

A Figura 3.18 contempla um exemplo de engate automático.

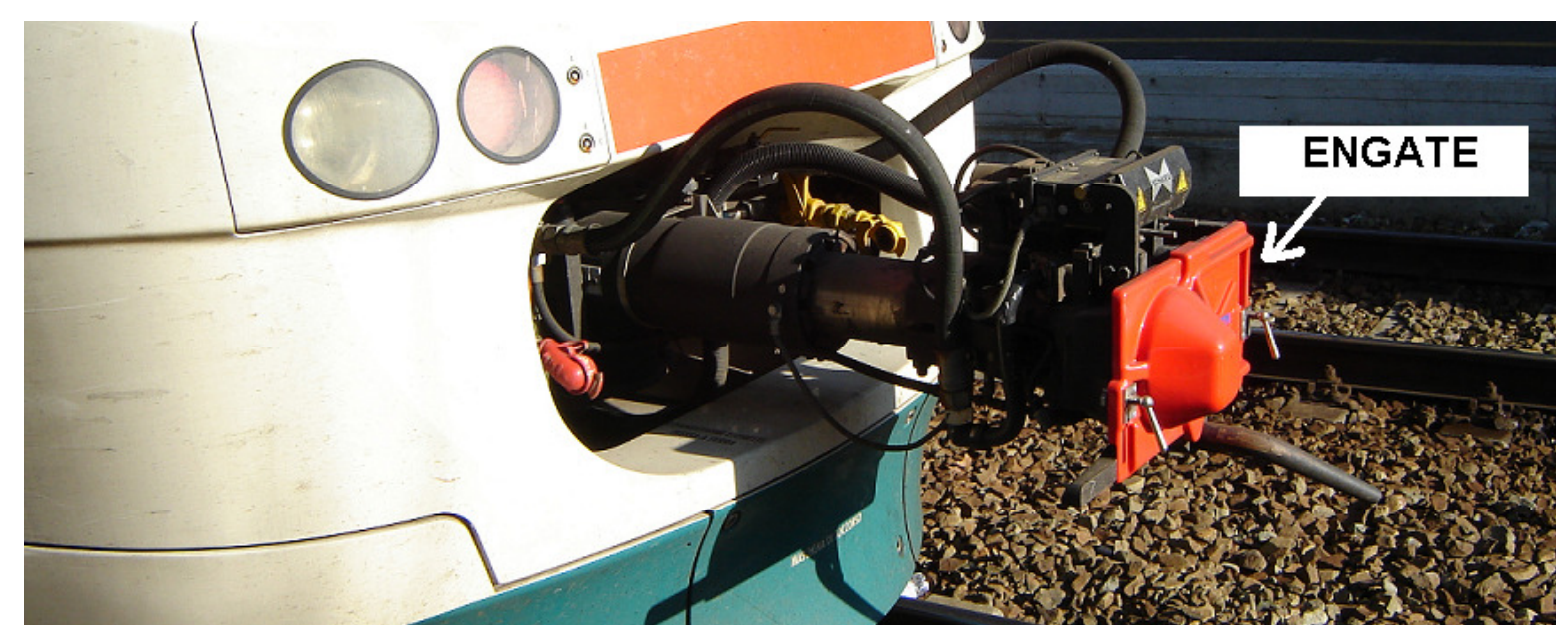

Figura 3.18 - Engate Instalado no Trem

\section{4 - SISTEMA DE TRAÇÃO E FRENAGEM}

O sistema de tração é responsável pelo fornecimento de energia para o movimento do trem. Pode ser decomposto pelo sistema de atuação (motor / redutor) e pelo sistema de controle e comando (sensores, controladores de velocidade etc). Já o sistema de freio é aquele que retira energia cinética do trem, podendo ter atuação tanto elétrica como pneumática. 
A atuação elétrica retira a energia cinética e devolve para a linha de alimentação ou dissipa a mesma através de energia térmica. Porém a atuação pneumática segue o princípio similar ao do automóvel com frenagem por atrito.

Normas como a UIC 544-1 OR (2004), UIC 544-2 OR (1983), UIC 541-1 OR (2003), UIC 541-3 OR (2004), UIC 541-4 OR (2004) e UIC 541-5 OR (2006) apresentam diversos aspectos que devem ser considerados durante o projeto e fabricação do sistema de freio do material rodante. Alguns aspectos principais descritos são:

- dimensões e características dos encanamentos de freio;

- características de torneiras e válvulas;

- características de acionamento do freio de emergência;

- tipos de pastilhas de freio e suas aplicações;

- características e sinalizações de aplicação de freio de emergência;

- requisitos para sistemas de auto-ajuste de freio;

- requisitos para o freio eletro pneumático;

- aspectos dos dispositivos elétricos de controle de freio;

- testes que podem ser aplicados e aprovação;

- avaliação do desempenho de frenagem para diferentes velocidades de operação e veículos;

- características de frenagem elétrica. 


\section{5 - OUTROS COMPONENTES DO TREM}

Alguns sistemas do trem são apresentados na Figura 3.19.

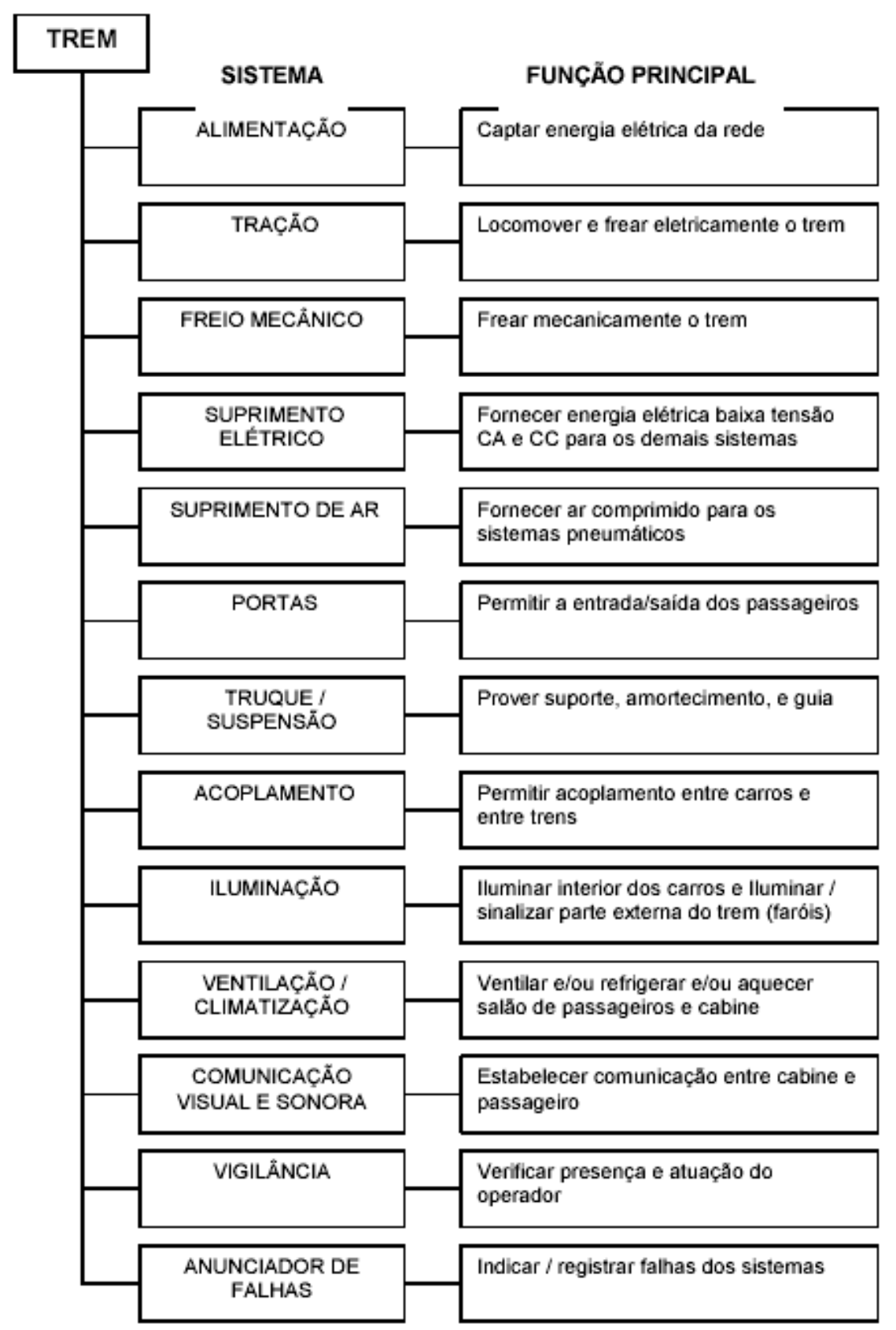

Figura 3.19 - Diagrama Funcional de um Trem de Passageiros (FACINI, 2007) 


\section{CAPÍTULO 4 - DESCARRILAMENTO}

O descarrilamento pode ser definido, segundo Iwnicky (2006), como o incidente no qual a roda perde a sustentação provida pelo trilho, podendo ser classificados como internos (quando a roda se movimenta para dentro da região determinada pelos trilho) ou externos (quando a roda se movimenta para fora da região determinada pelos trilho). É ainda possível classificar o descarrilamento quanto ao impacto, ou seja, se ocorreu em apenas em um rodeiro, se ocorreu em um truque ou se ocorreu no vagão inteiro.

Diversos fatores ou combinação de fatores podem causar este evento e uma estimativa das taxas de ocorrência do descarrilamento é apresentada na Tabela 4.1. Os valores desta tabela foram calculados com base na Tabela 4.2, que é um sumário de acidentes ou incidentes relacionados ao transporte ferroviário extraído do banco de dados de Railway Safety Statistics (2005). 
Tabela 4.1 - Taxa de Acidentes dos Trens

\begin{tabular}{|c|c|c|c|c|c|c|c|c|}
\hline$\stackrel{\circ}{\frac{1}{4}}$ & 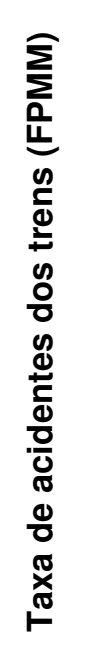 & 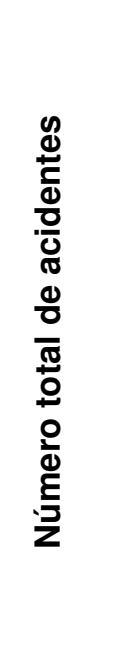 & 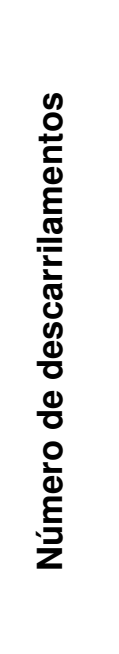 & 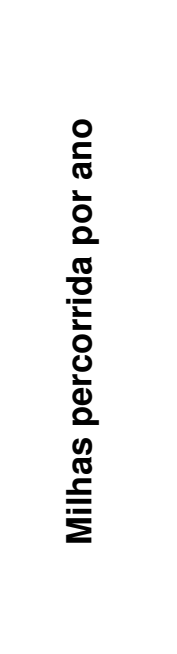 & 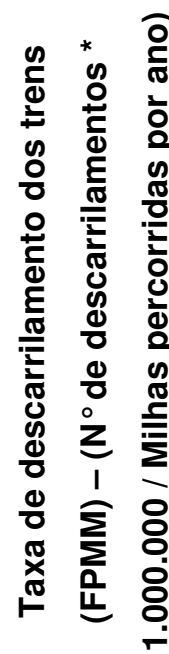 & 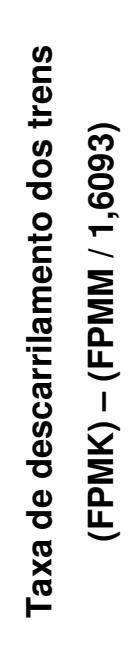 & 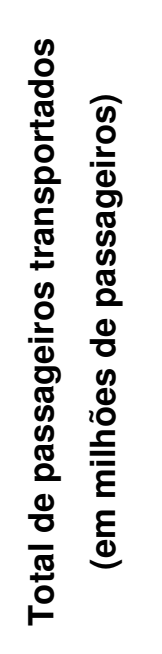 & 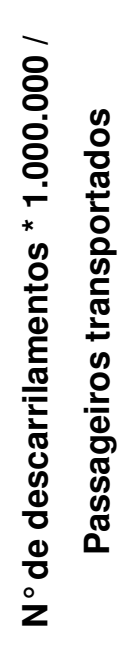 \\
\hline 1994 & 3,82 & 2.504 & 1.825 & $6,55 \times 10^{8}$ & 2,78 & 1,73 & 393,600 & 4,64 \\
\hline 1995 & 3,67 & 2.459 & 1.742 & $6,70 \times 10^{8}$ & 2,60 & 1,62 & 385,827 & 4,51 \\
\hline 1996 & 3,64 & 2.443 & 1.816 & $6,71 \times 10^{8}$ & 2,71 & 1,68 & 397,394 & 4,57 \\
\hline 1997 & 6,54 & 2.397 & 1.741 & $3,67 \times 10^{8}$ & 4,75 & 2,95 & 408,619 & 4,26 \\
\hline 1998 & 6,77 & 2.575 & 1.757 & $3,80 \times 10^{8}$ & 4,62 & 2,87 & 439,958 & 3,99 \\
\hline 1999 & 3,89 & 2.768 & 1.961 & $7,12 \times 10^{8}$ & 2,76 & 1,71 & 464,885 & 4,22 \\
\hline 2000 & 4,13 & 2.983 & 2.112 & $7,22 \times 10^{8}$ & 2,92 & 1,82 & 501,750 & 4,21 \\
\hline 2001 & 4,25 & 3.023 & 2.234 & $7,11 \times 10^{8}$ & 3,14 & 1,95 & 517,249 & 4,32 \\
\hline 2002 & 3,76 & 2.738 & 1.989 & $7,28 \times 10^{8}$ & 2,73 & 1,70 & 503,930 & 3,95 \\
\hline 2003 & 4,05 & 3.011 & 2.126 & $7,43 \times 10^{8}$ & 2,86 & 1,78 & 494,229 & 4,30 \\
\hline 2004 & 4,38 & 3.373 & 2.427 & $7,70 \times 10^{8}$ & 3,15 & 1,96 & 513,291 & 4,73 \\
\hline 2005 & 4,08 & 3.223 & 2.280 & $7,90 \times 10^{8}$ & 2,89 & 1,79 & 522,498 & 4,36 \\
\hline
\end{tabular}


Tabela 4.2 - Sumário Histórico de Acidentes/Incidentes

\begin{tabular}{|c|c|c|c|c|c|c|c|c|c|c|c|c|}
\hline Categoria & 1994 & 1995 & 1996 & 1997 & 1998 & 1999 & 2000 & 2001 & 2002 & 2003 & 2004 & 2005 \\
\hline \multicolumn{13}{|c|}{ TOTAL GERAL } \\
\hline Acidentes / incidentes & 22465 & 19591 & 17690 & 16698 & 16501 & 16776 & 16919 & 16086 & 14403 & 14330 & 14467 & 13957 \\
\hline $\begin{array}{l}\text { Taxa de incidentes (Total } \\
\text { de acidentes ou incidentes } \\
* 1.000 .000) /(\text { milhagem } \\
\text { total dos trens) }\end{array}$ & 19,14 & 16,60 & 15,05 & 14,14 & 13,78 & 13,72 & 13,94 & 13,56 & 12,18 & 11,99 & 11,77 & 11,00 \\
\hline Mortes & 1226 & 1146 & 1039 & 1063 & 1008 & 932 & 937 & 971 & 951 & 868 & 897 & 888 \\
\hline Condições não fatais & 16812 & 14440 & 12558 & 11767 & 11459 & 11700 & 11643 & 10985 & 11103 & 9220 & 9108 & 9162 \\
\hline \multicolumn{13}{|c|}{ ACIDENTES COM TRENS } \\
\hline $\begin{array}{l}\text { Taxa de acidentes (Total } \\
\text { acidentes }{ }^{*} 1000000 / \\
\text { milhagem total dos trens) }\end{array}$ & 3,82 & 3,67 & 3,64 & 3,54 & 3,77 & 3,89 & 4,13 & 4,25 & 3,76 & 4,05 & 4,38 & 4,08 \\
\hline Número Total & 2504 & 2459 & 2443 & 2397 & 2575 & 2768 & 2983 & 3023 & 2738 & 3011 & 3373 & 3223 \\
\hline Mortes & 12 & 14 & 25 & 17 & 4 & 9 & 10 & 6 & 15 & 4 & 13 & 33 \\
\hline Feridos & 262 & 294 & 281 & 183 & 129 & 130 & 275 & 310 & 1884 & 228 & 306 & 734 \\
\hline Colisão & 240 & 235 & 205 & 202 & 168 & 205 & 238 & 220 & 192 & 198 & 237 & 269 \\
\hline Descarrilamento & 1825 & 1742 & 1816 & 1741 & 1757 & 1961 & 2112 & 2234 & 1989 & 2126 & 2427 & 2280 \\
\hline Causado pela via & 911 & 856 & 905 & 879 & 900 & 995 & 1035 & 1121 & 941 & 972 & 1044 & 1074 \\
\hline $\begin{array}{l}\text { Taxa de acidentes } \\
\text { causada pela via }\end{array}$ & 1,39 & 1,28 & 1,35 & 1,3 & 1,32 & 1,4 & 1,43 & 1,58 & 1,29 & 1,31 & 1,36 & 1,36 \\
\hline Causada por fator humano & 911 & 944 & 783 & 855 & 971 & 1031 & 1147 & 1035 & 1050 & 1224 & 1354 & 1249 \\
\hline Causada por equipamento & 293 & 279 & 318 & 271 & 307 & 321 & 372 & 427 & 367 & 362 & 427 & 365 \\
\hline Causada por sinalização & 36 & 27 & 49 & 39 & 38 & 49 & 70 & 42 & 50 & 58 & 69 & 63 \\
\hline $\begin{array}{l}\text { Dano aos equipamentos } \\
\text { (milhões \$) }\end{array}$ & 124850 & 134766 & 160908 & 152092 & 162561 & 164654 & 169172 & 200752 & 173982 & 198492 & 224634 & 222153 \\
\hline Dano à via (milhões \$) & 43899 & 54458 & 51407 & 58637 & 71337 & 80435 & 94040 & 113713 & 92550 & 99392 & 100290 & 113589 \\
\hline $\begin{array}{l}\text { Passageiros transportados } \\
\text { (em milhões) }\end{array}$ & 393,600 & 385,827 & 397,394 & 408,619 & 439,958 & 464,885 & 501,750 & 517,249 & 503,930 & 494,229 & 513,291 & 522,498 \\
\hline
\end{tabular}


A Figura 4.1 apresenta o comportamento da taxa de acidentes e de descarrilamento dos trens, demonstrando que não há uma diminuição destes valores ao longo do tempo. Desta forma o presente trabalho tem importância no auxilio da diminuição da taxa de descarrilamento, evento este que pode ter como conseqüências o ferimento e morte de passageiros bem como perdas relacionadas a danos na via, no material rodante, na carga transportada, no meio ambiente etc.

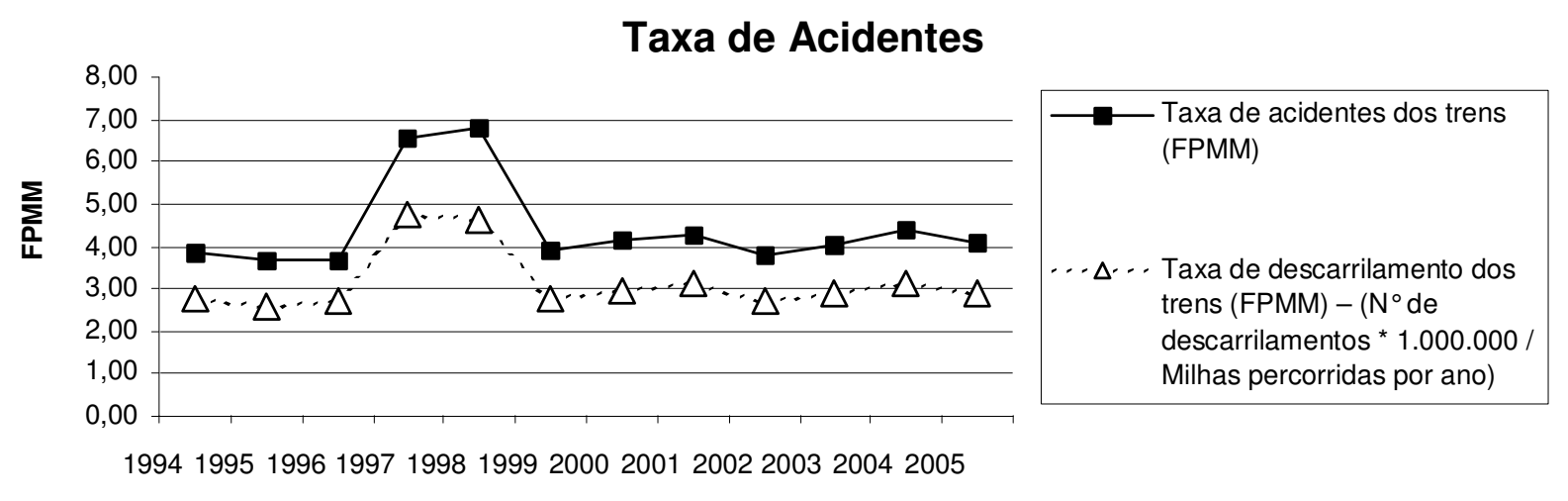

Ano

Figura 4.1 - Comportamento da taxa de acidentes dos trens em termos de quilometragem (Adaptado de RAILWAY SAFETY STATISTICS, 2005)

É possível também representar a taxa de acidentes considerando o número de passageiros transportados. Nesta representação, conforme Figura 4.2, também é perceptível que não há uma diminuição destes valores ao longo dos anos, ou seja, estes mantêm-se aproximadamente constante.

Taxa de Acidentes

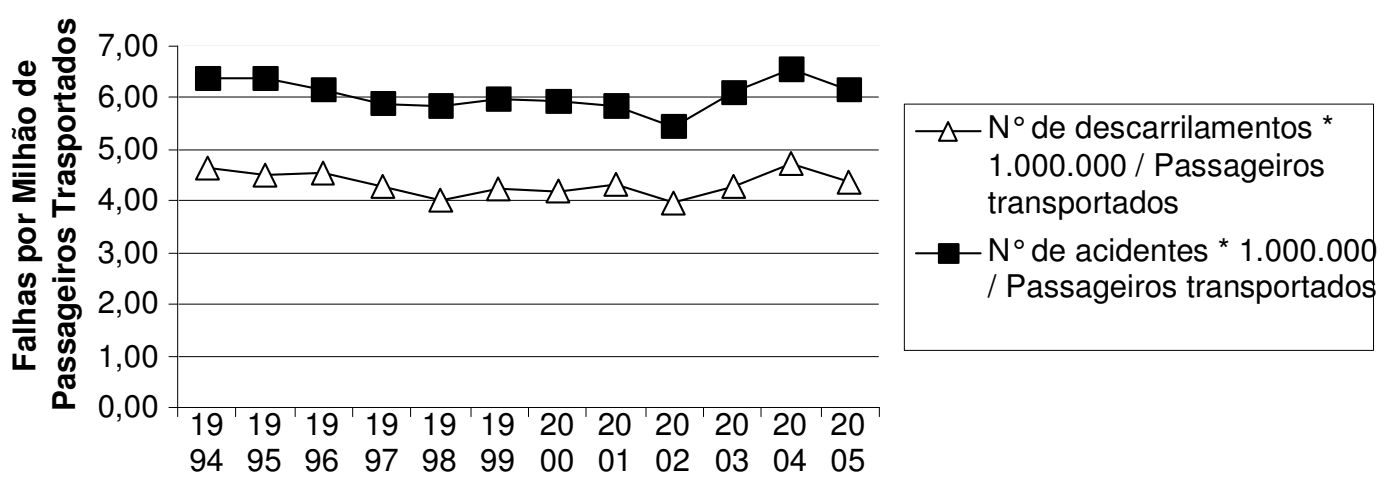

Ano

Figura 4.2 - Comportamento da taxa de acidentes dos trens em termos de passageiros transportados (Adaptado de RAILWAY SAFETY STATISTICS, 2005) 
A taxa de falha por cada tipo de causa pode ser obtida de Railway Safety Statistics (2005) e é relacionada na Tabela 4.3.

Tabela 4.3 - Causas do Descarrilamento em 2005

continua

\begin{tabular}{|c|c|c|c|c|}
\hline Causa & $\begin{array}{l}\mathrm{N}^{\circ} \text { de } \\
\text { Ocorrências }\end{array}$ & $\begin{array}{l}\text { Taxa de } \\
\text { Falha } \\
\text { (FPMM) }\end{array}$ & $\begin{array}{l}\text { Taxa de } \\
\text { Falha } \\
\text { (FPMK) }\end{array}$ & Comentário \\
\hline Geometria da via & 399 & 0,505 & 0,314 & $\begin{array}{l}\text { Classificada como falha da via, neste caso } \\
\text { devido à falha da geometria da via, } \\
\text { podendo ser por projeto, instalação ou } \\
\text { manutenção. }\end{array}$ \\
\hline $\begin{array}{l}\text { Trilho, talas de junção, } \\
\text { dispositivos de fixação }\end{array}$ & 381 & 0,482 & 0,300 & $\begin{array}{c}\text { Classificada como falha da via, neste caso } \\
\text { devido a falhas das fixações. }\end{array}$ \\
\hline $\begin{array}{l}\text { Uso de Aparelhos de } \\
\text { mudança }\end{array}$ & 237 & 0,300 & 0,186 & $\begin{array}{l}\text { Classificada como falha humana por erro de } \\
\text { no uso do AMV. }\end{array}$ \\
\hline $\begin{array}{l}\text { Jacarés, aparelhos de } \\
\text { mudança de via, } \\
\text { equipamentos de via }\end{array}$ & 199 & 0,252 & 0,157 & $\begin{array}{l}\text { Classificada como falha da via, neste caso } \\
\text { devido a aparelhos de mudança de via. }\end{array}$ \\
\hline Regras de mudança & 177 & 0,224 & 0,139 & $\begin{array}{c}\text { Classificada como falha humana por erro } \\
\text { durante mudanças de via ou determinação } \\
\text { errada das regras. }\end{array}$ \\
\hline $\begin{array}{c}\text { Condições } \\
\text { operacionais não } \\
\text { usuais }\end{array}$ & 147 & 0,186 & 0,116 & $\begin{array}{c}\text { Classificada como falha causada por razões } \\
\text { diversas. }\end{array}$ \\
\hline $\begin{array}{c}\text { Manobras do veículo } \\
\text { ferroviário }\end{array}$ & 121 & 0,153 & 0,095 & $\begin{array}{l}\text { Classificada como falha humana por } \\
\text { manobra do veículo ferroviário. }\end{array}$ \\
\hline Outras causas & 75 & 0,095 & 0,059 & $\begin{array}{c}\text { Classificada como falha causada por razões } \\
\text { diversas. }\end{array}$ \\
\hline Truque & 64 & 0,081 & 0,050 & $\begin{array}{c}\text { Classificada como falha do material } \\
\text { rodante, neste caso devido a alguma falha } \\
\text { do truque em geral. }\end{array}$ \\
\hline Rodas & 61 & 0,077 & 0,048 & $\begin{array}{c}\text { Classificada como falha do material } \\
\text { rodante, neste caso devido a alguma falha } \\
\text { das rodas do truque. }\end{array}$ \\
\hline
\end{tabular}


continuação

\begin{tabular}{|c|c|c|c|c|}
\hline Causa & $\begin{array}{c}\mathrm{N}^{\circ} \mathrm{de} \\
\text { Ocorrências }\end{array}$ & $\begin{array}{l}\text { Taxa de } \\
\text { Falha } \\
\text { (FPMM) }\end{array}$ & $\begin{array}{l}\text { Taxa de } \\
\text { Falha } \\
\text { (FPMK) }\end{array}$ & Comentário \\
\hline Eixo e rolamentos & 52 & 0,066 & 0,041 & $\begin{array}{l}\text { Classificada como falha do material } \\
\text { rodante, neste caso devido a alguma falha } \\
\text { dos eixos ou ao rolamentos do truque, } \\
\text { como por exemplo travamento. }\end{array}$ \\
\hline Velocidade & 45 & 0,057 & 0,035 & $\begin{array}{l}\text { Classificada como falha humana por erro de } \\
\text { aplicação de operação por maior ou menor } \\
\text { demanda de tração. }\end{array}$ \\
\hline Uso dos Freios & 43 & 0,054 & 0,034 & $\begin{array}{l}\text { Classificada como falha humana por erro de } \\
\text { aplicação de freio (maior demanda ou } \\
\text { menor demanda). Ou seja, devido a maior } \\
\text { velocidade de operação em determinado } \\
\text { trecho ou a maior aplicação de freio. }\end{array}$ \\
\hline Condições ambientais & 37 & 0,047 & 0,029 & $\begin{array}{c}\text { Classificada como falha causada por razões } \\
\text { diversas, neste caso por condições } \\
\text { ambientais adversas. }\end{array}$ \\
\hline $\begin{array}{l}\text { Processos de } \\
\text { carregamento }\end{array}$ & 37 & 0,047 & 0,029 & $\begin{array}{l}\text { Classificada como falha causada por razões } \\
\text { diversas, neste caso por falhas no } \\
\text { carregamento da carga causando } \\
\text { desequilíbrio no trem. }\end{array}$ \\
\hline Acoplamento & 33 & 0,042 & 0,026 & $\begin{array}{l}\text { Classificada como falha do material } \\
\text { rodante, neste caso devido a alguma falha } \\
\text { do sistema de acoplamento. }\end{array}$ \\
\hline Assentamento da via & 32 & 0,041 & 0,025 & $\begin{array}{l}\text { Classificada como falha da via, neste caso } \\
\text { devido a falha de assentamento, por } \\
\text { exemplo, falha no lastro ou sublastro. }\end{array}$ \\
\hline Freios & 26 & 0,033 & 0,020 & $\begin{array}{l}\text { Classificada como falha do material } \\
\text { rodante, neste caso devido a alguma falha } \\
\text { de freios (maior ou menor demanda). }\end{array}$ \\
\hline Falha de sinalização & 25 & 0,032 & 0,020 & Classificada como falha de sinalização. \\
\hline Estrutura & 20 & 0,025 & 0,016 & $\begin{array}{c}\text { Classificada como falha do material } \\
\text { rodante, neste caso devido a alguma falha } \\
\text { da estrutura do trem, como por exemplo, a } \\
\text { do truque. }\end{array}$ \\
\hline
\end{tabular}


conclusão

\begin{tabular}{|c|c|c|c|c|}
\hline Causa & $\begin{array}{l}\mathrm{N}^{\circ} \mathrm{de} \\
\text { Ocorrências }\end{array}$ & $\begin{array}{l}\text { Taxa de } \\
\text { Falha } \\
\text { (FPMM) }\end{array}$ & $\begin{array}{l}\text { Taxa de } \\
\text { Falha } \\
\text { (FPMK) }\end{array}$ & Comentário \\
\hline $\begin{array}{c}\text { Falha de identificação } \\
\text { de sinalização fixa de } \\
\text { via e comunicação de } \\
\text { rádio }\end{array}$ & 19 & 0,024 & 0,015 & $\begin{array}{c}\text { Classificada como falha humana causada } \\
\text { por erro de operação na visualização e } \\
\text { compreensão da sinalização e } \\
\text { comunicação. }\end{array}$ \\
\hline $\begin{array}{c}\text { Miscelânea de Fatores } \\
\text { Humanos }\end{array}$ & 15 & 0,019 & 0,012 & Classificada como falha humana. \\
\hline Portas & 14 & 0,018 & 0,011 & $\begin{array}{l}\text { Esta taxa de falha será considerada como } \\
\text { participante do material rodante, mas julga- } \\
\text { se que a classificação quanto ao } \\
\text { componente (portas) não esteja } \\
\text { corretamente classificada (a causa desta } \\
\text { incoerência é abordada após a tabela). }\end{array}$ \\
\hline Outros defeitos de via & 13 & 0,016 & 0,010 & $\begin{array}{l}\text { Classificada como falha dos elementos de } \\
\text { via. }\end{array}$ \\
\hline Locomotivas & 4 & 0,005 & 0,003 & $\begin{array}{l}\text { Falha atribuída a locomotiva e classificada } \\
\text { como falha do material rodante. }\end{array}$ \\
\hline $\begin{array}{l}\text { Falha das autoridade } \\
\text { de via }\end{array}$ & 3 & 0,004 & 0,002 & $\begin{array}{l}\text { Falha classificada como falha humana, } \\
\text { sendo relacionada com o erro de } \\
\text { autorizações de movimentação. }\end{array}$ \\
\hline $\begin{array}{c}\text { Condições físicas dos } \\
\text { empregados }\end{array}$ & 1 & 0,001 & 0,001 & Classificada como falha humana. \\
\hline Total & 2280 & 2,886 & 1,793 & $\begin{array}{c}\text { Mesmos valores apresentados na Tabela } \\
4.1 .\end{array}$ \\
\hline
\end{tabular}

(RAILWAY SAFETY STATISTICS, 2005)

O uso de bancos de dados deve ser avaliado com cuidado, pois os mesmos podem ser baseados em registros cadastrados com pouco critério a respeito da real causa do descarrilamento, ou ser registrado por pessoas inexperientes quanto ao trato dessas informações. Além disso, durante um evento descarrilamento, os componentes causadores deste evento podem ser destruídos ou comprometidos devido aos estragos que $\mathrm{o}$ acidente pode causar, dificultando assim a real identificação do item que gerou o mesmo. 
Em suma, as falhas do descarrilamento podem ser agrupadas segundo Tabela 4.4 e Figura 4.3.

Tabela 4.4 - Causas Sucintas do Descarrilamento em 2005

\begin{tabular}{lccc}
\hline Causa & $\begin{array}{c}\text { Número de } \\
\text { Falha }\end{array}$ & $\begin{array}{c}\text { Taxa de } \\
\text { Falha } \\
\text { (FPMM) }\end{array}$ & $\begin{array}{c}\text { Taxa de } \\
\text { Falha } \\
\text { (FPMK) }\end{array}$ \\
\hline Fatores Humanos & 661 & 0,837 & 0,520 \\
Sinalização & 25 & 0,032 & 0,020 \\
Defeitos de Via & 1024 & 1,296 & 0,805 \\
Falha Mecânica ou elétrica do Material Rodante & 274 & 0,347 & 0,216 \\
Diversas & 296 & 0,375 & 0,233 \\
Total & 2280 & 2,886 & 1,794 \\
\hline
\end{tabular}

(RAILWAY SAFETY STATISTICS, 2005)

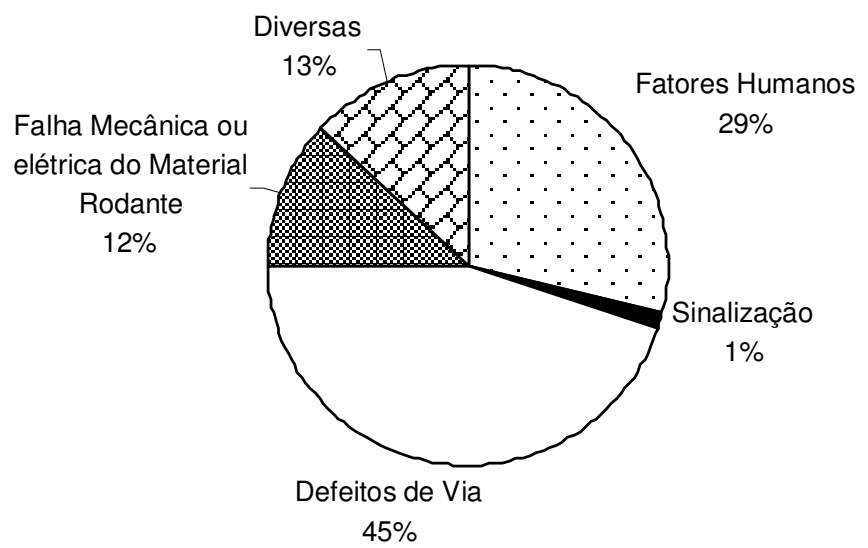

Figura 4.3 - Causas Sucintas do Descarrilamento em 2005 (RAILWAY SAFETY STATISTICS, 2005)

Nesta dissertação não são tratadas as falhas humanas, pois o foco do estudo está nas falhas decorrentes dos elementos de via ou do material rodante. Além disso, a metodologia apresentada neste trabalho não seria totalmente aplicável a análise da confiabilidade humana. Para esta análise humana utilizam-se metodologias como a técnica para a predição de taxas de erros humanos (THERP), programa de avaliação de seqüências de acidentes (ASEP), árvores de ações do operador (OAT) entre outras, sendo portanto diferentes das utilizadas neste estudo. 
Estas causas podem ainda ser agrupadas no diagrama de árvore de falhas estabelecido na Figura 4.4. Nesta figura, as taxas de falhas ( $r$ ) estão estabelecidas em falhas por milhas.

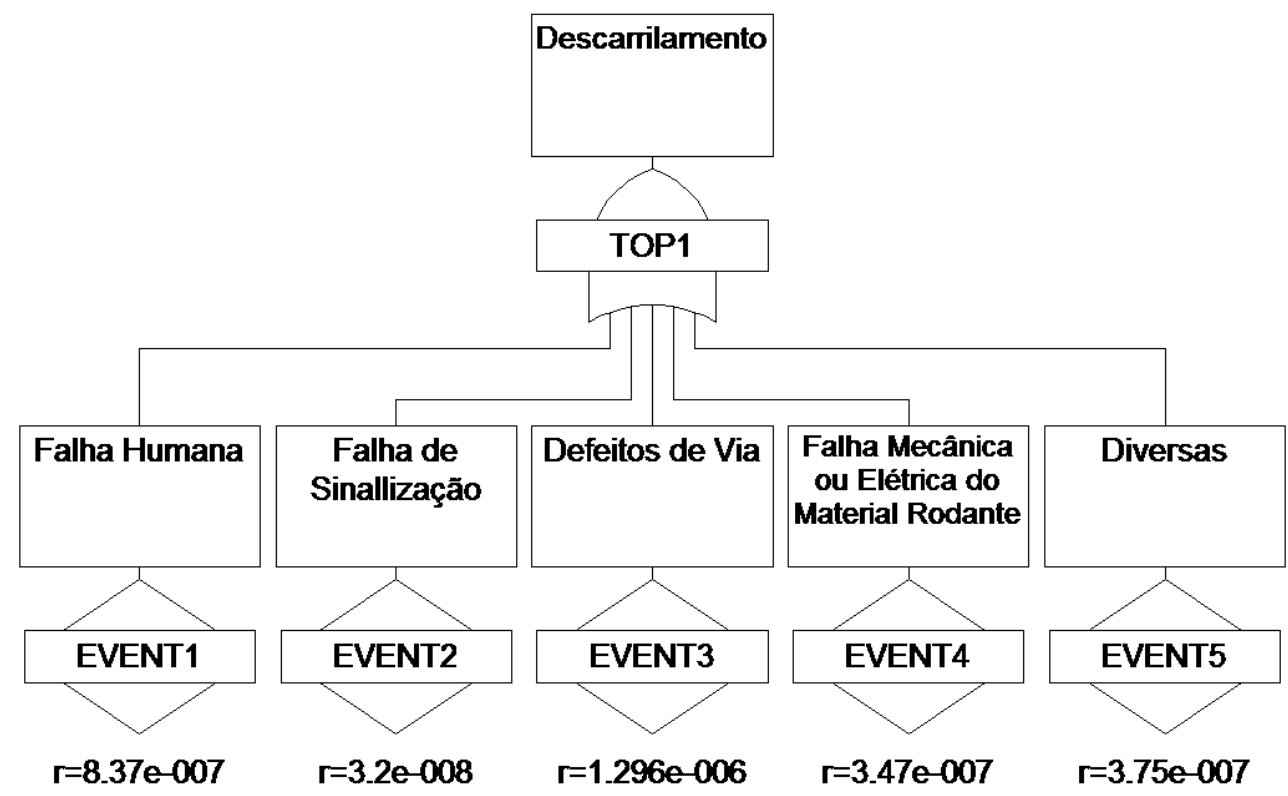

Figura 4.4 - FTA de Descarrilamento

Corroborando com as discussões dos principais causadores do descarrilamento, Wagner (2004) dividiu os causadores do descarrilamento nos seguintes grupos:

- falha de projeto, componente ou manutenção;

- falha de carregamento, fluidos transportados que podem causar desbalanceamento ou incertezas não consideradas no carregamento;

- dinâmica de interação entre a via e o veículo;

- critérios de descarrilamento atendidos que serão apresentados no 4.1;

- dinâmica do trem como impacto, vibrações e forças não previstos;

- fatores humanos como erro de operação;

- combinação destes fatores.

Os fatores humanos podem ser divididos em falha de operação e falha de manutenção. Já a falha de operação (como por exemplo, no balanceamento e distribuição dos fluídos transportados) não é objeto de análise deste trabalho. 
Ademais, as falhas de carregamento e as dinâmicas do trem como impacto, vibrações e forças não previstos podem ser agrupados na falha de projeto (deficiência na determinação de variáveis) ou manutenção já que estas falhas devem ser previstas durante o projeto do sistema (considerando as possíveis incertezas nos parâmetros) e evitadas durante a manutenção através do controle e verificação de alterações, portanto a classificação quanto às causas pode também ser resumida em: critérios de descarrilamento, dinâmica de interação entre o veículo e a via, falha de projeto e manutenção de componentes e a combinação destes fatores.

No cenário nacional, a Agência Nacional de Transportes Terrestres (ANTT) apresenta estudo quanto ao número de acidentes no transporte de carga descrito na Tabela 4.5. Observa-se que ocorre uma ausência de detalhamento dos dados quando comparados, por exemplo, ao cenário americano, que apresenta as prováveis causas dos acidentes. Uma das hipóteses que pode explicar esta carência é a inexistência da figura de autoridade ferroviária conforme discutido no item 2.2.

Tabela 4.5 - Índice de Acidentes no Transporte de Carga

\begin{tabular}{lcccccccc}
\hline CONCESSIONÁRIAS & $\mathbf{1 9 9 2}$ & $\mathbf{1 9 9 7}$ & $\mathbf{2 0 0 1}$ & $\mathbf{2 0 0 2}$ & $\mathbf{2 0 0 3}$ & $\mathbf{2 0 0 4}$ & $\mathbf{2 0 0 5}$ & $\mathbf{2 0 0 6}$ \\
\hline NOVOESTE & 87 & 178 & 145 & 125 & 151 & 188 & 302,3 & 299,1 \\
FCA & 134 & 103 & 83 & 78 & 67 & 43 & 26,2 & 20,9 \\
MRS & 80 & 60 & 28 & 25 & 23 & 16 & 8,5 & 7,3 \\
FTC & 158 & 116 & 12 & 13 & 13 & 13 & 10 & 10,2 \\
ALL & 89 & 110 & 41 & 23 & 19 & 15 & 16,2 & 13,8 \\
FERROESTE/FERROPAR & $\mathrm{Nd}$ & $\mathrm{Nd}$ & 27 & 6 & 3 & 5 & 0 & 0 \\
EFVM & 58 & 39 & 24 & 25 & 15 & 10 & 10,5 & 5,8 \\
EFC & 29 & 25 & 9 & 13 & 6 & 6 & 5,2 & 7,4 \\
CFN & 149 & 139 & 262 & 284 & 307 & 354 & 328,1 & 149,7 \\
FERROBAN & $\mathrm{Nd}$ & $\mathrm{Nd}$ & 63 & 42 & 27 & 33 & 24,8 & 33,7 \\
FERRONORTE & $\mathrm{Nd}$ & $\mathrm{Nd}$ & 7 & 19 & 7 & 10 & 84,6 & 68,5 \\
\hline Acidentes por milhão de trens $\mathrm{x} \mathrm{km}$ & & & & & & & \\
\hline \multicolumn{2}{c}{ (ANTT, 2007) } & & & & & & &
\end{tabular}


Nesta dissertação, por haver uma maior riqueza de dados da Railway Safety Statistics (2005), a mesma será utilizada ao invés de dados da ANTT. Esta opção pode causar uma perda de aderência quanto às informações apresentadas, pois o banco de dados utilizado pode não refletir o cenário brasileiro das causas dos acidentes e das causas dos descarrilamentos. Entretanto, o uso deste banco de dados americano é válido já que o mesmo apresenta maior detalhamento quanto às causas do descarrilamento e indica de formas gerais os principais causadores do evento (diferentemente da referência brasileira), além disso, o foco desta dissertação não é o valor da taxa de ocorrência do descarrilamento, pois este trabalho tem como objetivo a aplicação do método de análise de risco a um acidente ferroviário.

A seguir serão apresentados alguns critérios de descarrilamento, porém pela metodologia adotada, o foco principal da análise será a aplicação da metodologia de análise de risco aplicada aos componentes e sistemas tanto do material rodante quanto da via.

\section{1 - CRITÉRIOS DE DESCARRILAMENTO}

Diversos autores como Iwnicky (2006), Wagner (2004) e Almeida (2006) abordam critérios de descarrilamento em seus estudos. Os critérios apresentados neste trabalho são os mesmos considerados por Iwnicky (2006), que aborda o descarrilamento por falha de parâmetros do contato roda e trilho, e são:

- descarrilamento por sobreposição do flange da roda sobre o trilho, que é um critério relacionado ao descarrilamento externo;

- descarrilamento por dimensão indevida da bitola e rolamento do trilho, que é um critério relacionado ao descarrilamento interno;

- descarrilamento causado por Aumento da Bitola, que é um critério relacionado ao descarrilamento interno;

- descarrilamento por Instabilidade Lateral do Veículo, que está relacionado tanto ao descarrilamento interno quanto externo. 
A distribuição dos incidentes ocorridos relacionados com os critérios acima é apresentada na Tabela 4.6 (IWNICKY, 2006).

Tabela 4.6 - Distribuição de Acidentes de acordo com os Critérios de Descarrilamento

\begin{tabular}{|c|c|c|c|c|c|c|c|}
\hline$\underset{\frac{O}{c}}{\frac{1}{4}}$ & 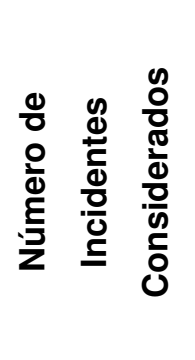 & 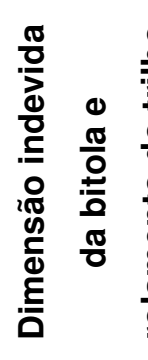 & 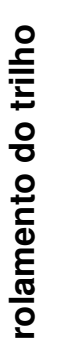 & $\begin{array}{l}\frac{\pi}{0} \\
\frac{0}{0} \\
\frac{\pi}{8} \\
0 \\
\frac{0}{8} \\
\frac{0}{0} \\
\frac{5}{3}\end{array}$ & 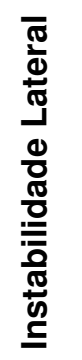 & 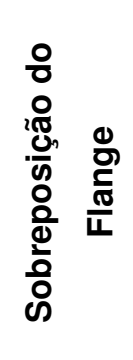 & 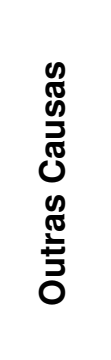 \\
\hline 2000 & 3193 & 295 & & 46 & 7 & 13 & 985 \\
\hline 1999 & 2924 & 234 & & 52 & 6 & 18 & 914 \\
\hline 1998 & 2745 & 189 & & 54 & 3 & 6 & 770 \\
\hline Soma & 9972 & 718 & & 152 & 16 & 37 & 2669 \\
\hline
\end{tabular}

Considerando os quatro critérios que serão estudados, a Tabela 4.6 apresenta como maior causador do descarrilamento a dimensão indevida da bitola e rotação do trilho. Conforme será discutido em 4.1.2, às dinâmicas de interação entre - veículo ferroviário e a via estão relacionadas com estes critérios de descarrilamento, sendo que esta dinâmica acaba sendo afetada por falha nos fatores de via, do material rodante, por fatores humanos (por exemplo falha de manutenção), entre outros. Estas causas também foram apresentadas na Tabela 4.3.

\subsection{1 - SOBREPOSIÇÃO DO FLANGE DA RODA SOBRE O TRILHO}

O descarrilamento por sobreposição do flange é um critério que considera a razão entre a força horizontal e a força vertical. Estas forças surgem devido ao contato que ocorre entre a roda e o trilho (IWNICKY, 2006). A quantificação da razão para a geração de uma instabilidade não será realizada nesta dissertação. 
A elevada força lateral é atribuída ao grande ângulo de ataque e distribuição irregular das massas do truque. Este fenômeno é determinado principalmente pelo raio de curvatura, o perfil da roda e trilho, as características da suspensão do truque e da velocidade do veículo. A definição para que ocorra a sobreposição do flange baseado no critério de Nadal é estabelecida através da relação L/V, ou seja, a relação entre a força lateral e a força vertical.

O critério de Nadal é equacionado a seguir baseado na relação L/V:

- Considerando a Figura 4.5 que representa as forças $L$ (força horizontal de contato), V (força vertical de contato), F3 (força de reação normal a superfície de contato) e F2 (força de reação tangente a superfície de contato).

- Estas forças são equacionadas nas equações (4.1) e (4.2):

$$
\begin{aligned}
& F_{3}=V \cos \delta+L \operatorname{sen} \delta=V\left(\cos \delta+\frac{L}{V} \operatorname{sen} \delta\right) \\
& \left\{\begin{array}{crr}
F_{2}=V \operatorname{sen} \delta-L \cos \delta=V\left(\operatorname{sen} \delta-\frac{L}{V} \cos \delta\right) & \text { quando } & (V \operatorname{sen} \delta-L \cos \delta)<\mu \cdot F_{3} \\
F_{2}=\mu \cdot F_{3} & \text { quando } & (V \operatorname{sen} \delta-L \cos \delta) \geq \mu \cdot F_{3}
\end{array}\right.
\end{aligned}
$$

- Assim, é obtida a equação (4.3) para a relação L/V:

$$
\frac{L}{V}=\frac{\tan \delta-\frac{F_{2}}{F_{3}}}{1+\frac{F_{2}}{F_{3}} \tan \delta}
$$

- A relação de $\mathrm{Nadal}$ foi proposta considerando a relação $F_{2} / F_{3}=\mu$, obtendo-se assim a expressão (4.4).

$$
\frac{L}{V}=\frac{\tan \delta-\mu}{1+\mu \tan \delta}
$$




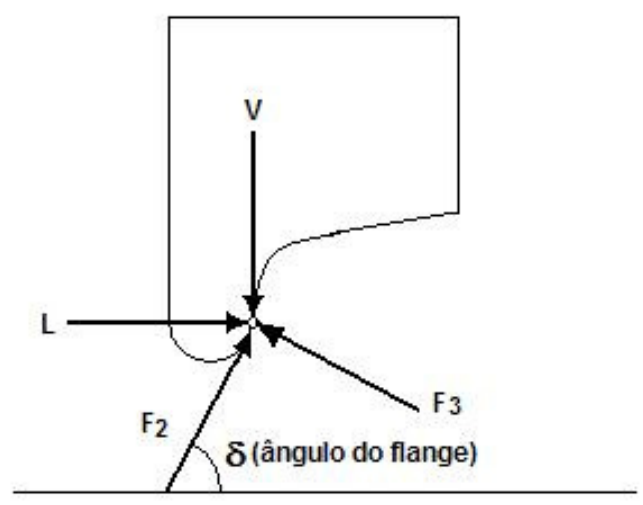

Figura 4.5 - Forças de Contato Para o Critério de Nadal (IWNICKY, 2006)

Neste critério, o descarrilamento depende do ângulo de contato do flange com o boleto $\delta$ e do coeficiente de atrito entre roda e trilho $\mu$. Ou seja, quando a relação L/V resultar em um valor menor que o determinado pela equação (4.4), o descarrilamento não ocorre. Porém, este critério de Nadal é eficiente para grandes ângulos de ataque e é bastante conservativo para pequenos ângulos de ataque. A quantificação da magnitude do ângulo de ataque é realizada pelo levantamento de curvas que dependem das características do veículo. Um exemplo desta curva é apresentado na Figura 4.6.

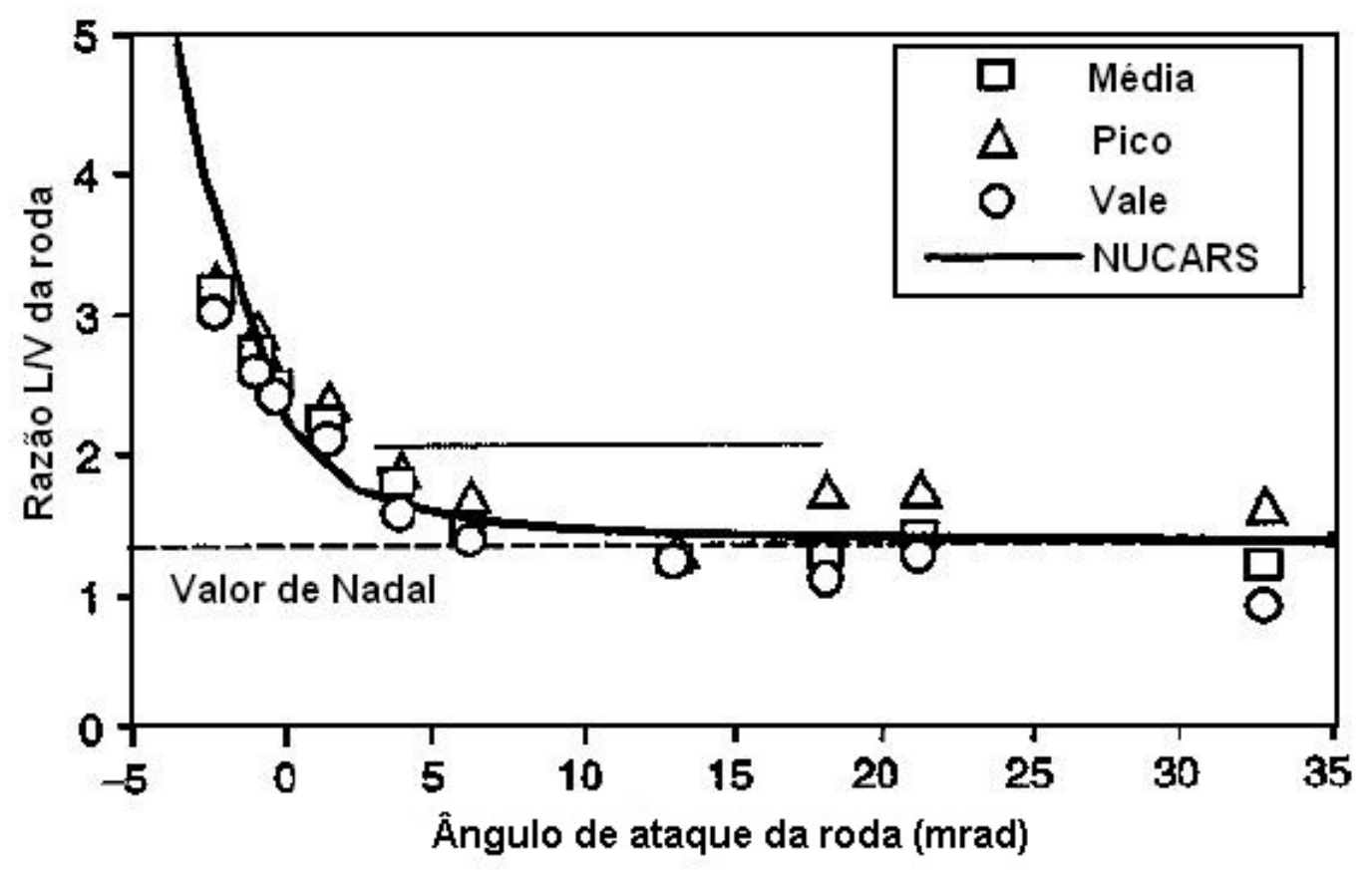

Figura 4.6 - Exemplo de Curva do Efeito do Ângulo de Ataque no limite da relação L/V (IWNICKY, 2006) 
Outros critérios para a sobreposição do flange já foram estabelecidos, como por exemplo, o critério de Weinstock, critério de FRA entre outros. Para o problema de sobreposição do flange, Barbosa (2004) e Barbosa (2005) propuseram um critério de segurança quanto ao descarrilamento considerando as forças de contato em uma abordagem em 3 dimensões devido à limitação que o critério de Nadal apresenta (ser bastante conservativo e funcionar bem apenas com grandes ângulos de ataque e grandes coeficientes de atrito).

A formulação do problema foi baseada na definição de uma referência móvel ortonormal $O \vec{X} \vec{Y} \vec{Z}$ conforme a Figura 4.7. Nesta referência, $\vec{X}$ está alinhado com o vetor velocidade e o plano determinado por $\vec{Y} \vec{Z}$ contém o centro da curva. Outra referência $c \vec{x} \vec{y} \vec{z}$ apresenta a origem $c$ no ponto de contato da roda com o trilho, 0 plano $\vec{y} \vec{z}$ sendo vertical e paralelo ao eixo e o eixo $\vec{z}$ perpendicular ao plano de contato. Quando ocorre o movimento do rodeiro, a rotação em torno do eixo $\vec{Z}$ causa um ângulo $\psi$ entre $\vec{X}$ e $\vec{x}$. Já a rotação em torno de $\vec{x}$ causa o ângulo $\alpha$ entre o plano de contato da roda com o trilho e o eixo $\vec{Y}$.

Este critério é apresentado na equação (4.5):

$$
\frac{L}{V}=\frac{A \mu-B \tan \alpha}{B+A \mu \tan \alpha}
$$

A equação (4.5) é complementada por (4.6) e (4.7).

$$
\begin{gathered}
A=k_{x} \operatorname{sen} \psi+\left(1+k_{y}\right) \cos \psi \quad B=\sqrt{k_{x}^{2}+1+2 k_{y}+k_{y}^{2}} \\
k_{x}=\frac{T_{x}}{T_{L}} \quad k_{y}=\frac{T_{\omega}}{T_{L}}
\end{gathered}
$$


$T_{x}$ é a componente da força de atrito $T$ no eixo $\vec{x}, T_{\mathrm{w}}$ é a componente da força $T$ referente ao escorregamento rotacional e $T_{L}$ é a componente da força $T$ referente ao escorregamento lateral.
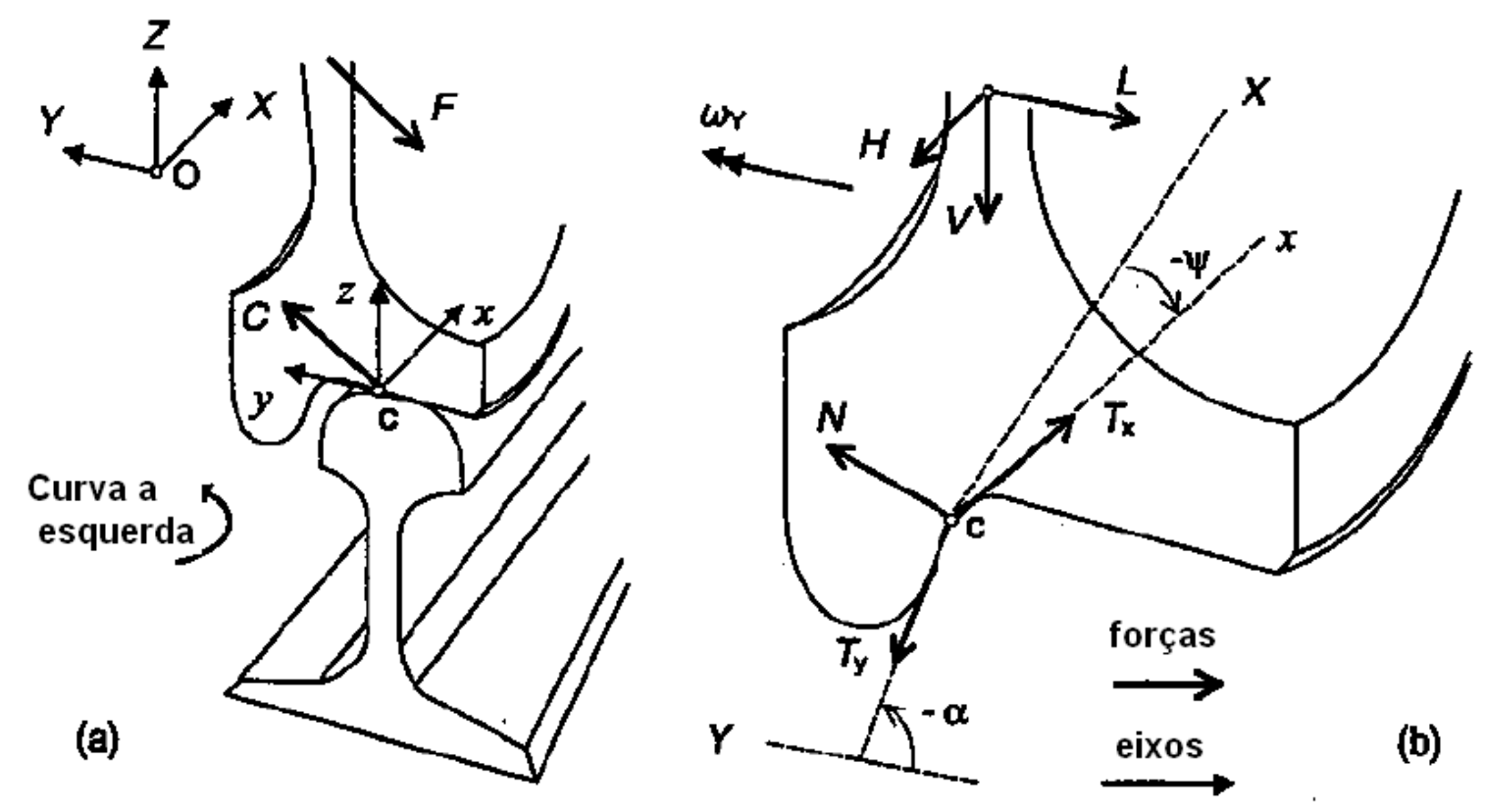

Figura 4.7 - Referências Móveis e Fixas e Vetores de Força (BARBOSA, 2004)

\subsection{2 - DIMENSÃO DO BITOLA E ROTAÇÃO DO TRILHO}

Os descarrilamentos por bitola indevida e rotação do trilho ocorrem devido às deflexões do trilho ou à distância indevida entre os trilhos quando comparado à bitola. Isso pode ser causado pelas forças laterais que ocorrem ou por erros de projeto e/ou manutenção.

Existem diversos critérios definidos para o descarrilamento por bitola indevida e por rotação do trilho. Os critérios que serão apresentados são o critério apresentado em Iwnicky (2006) apud AAR (1993), o critério da dimensão da bitola e o de desgaste irregular do perfil. Para a rotação do trilho, o critério apresentado no capítulo XI do AAR é estabelecido empregando também a relação $L / V$; nele é assumido que $\mathrm{o}$ trilho apresenta rotação causada pelas forças de contato. $O$ momento torsor, considerando a Figura 4.8, é expresso na equação (4.8):

$$
M=V d-L h
$$


No equilíbrio, o momento pode ser aproximado a zero. Logo é obtida a equação (4.9).

$$
\frac{L}{V}=\frac{d}{h}
$$

Assim, o descarrilamento ocorre quando o valor da relação L/V é maior que o valor da relação $d / h$.

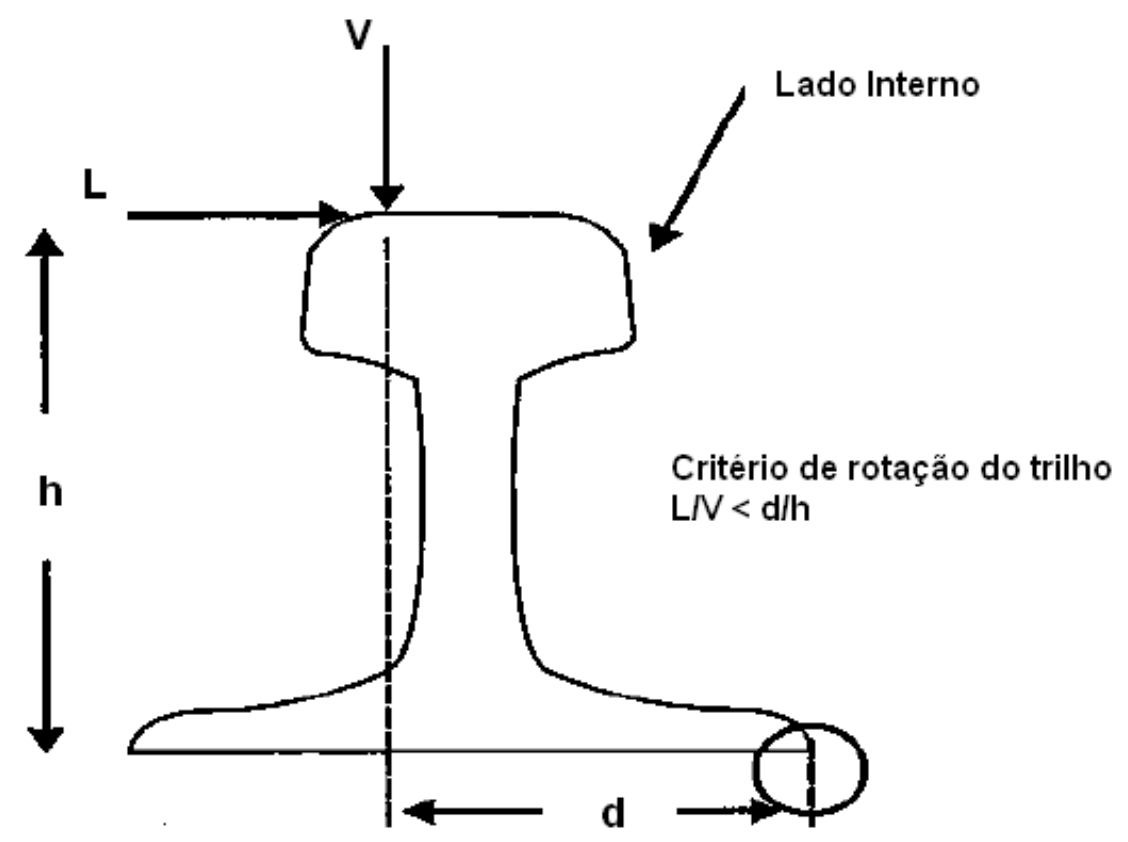

Figura 4.8 - Forças na Rotação do Trilho (IWNICKY, 2006)

O critério de desgaste irregular do perfil da roda é definido como a diferença radial entre a extremidade do perfil da roda e a região central da mesma. Neste caso, como mostrado na Figura 4.9, ocorre um contato indevido entre a roda e trilho, causando um momento torsor indevido e podendo também causar rotação do trilho. 


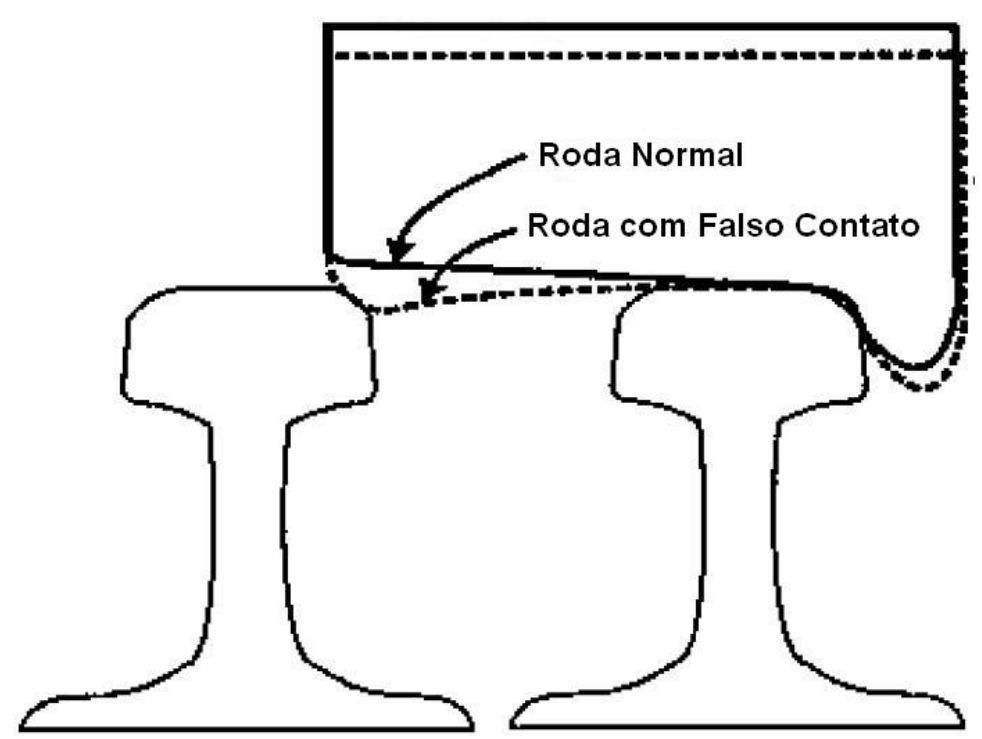

Figura 4.9 - Exemplo de Falso Contato entre Roda e Trilho (IWNICKY, 2006)

O critério da dimensão da bitola está apresentado na equação (4.10).

$$
G \geq B+W+f_{w}
$$

sendo $G, B, W$ e $f_{w}$ apresentados na Figura 4.10.

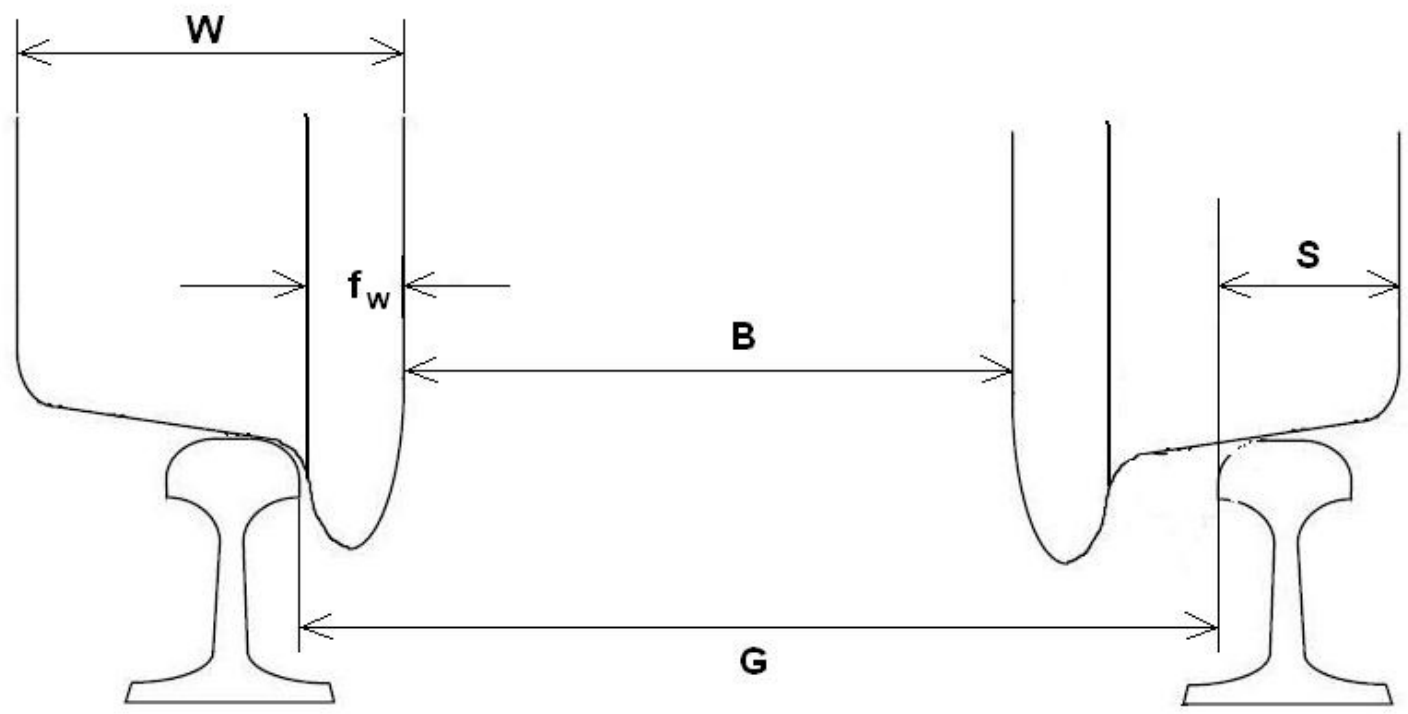

Figura 4.10 - Parâmetros Considerados na Equação (4.10) (IWNICKY, 2006) 
Neste caso, é atribuída uma dimensão de segurança S para que este critério não seja atendido e não provoque descarrilamento. Esta dimensão é expressa pela equação (4.11).

$$
\left(B+W+f_{w}\right)-G>S
$$

Ademais, combinando os critérios apresentados por Iwnicky (2006) conforme descritos nesta seção, pode-se relacionar a equação (4.11) e o tombamento angular do trilho (t) causado pela rotação do trilho, adicionando-se uma parcela nesta equação conforme (4.12).

$$
\left(B+W+f_{w}\right)-(G+t)>S
$$

\subsection{3 - DESCARRILAMENTO POR AUMENTO DA DIMENSÃO DA BITOLA}

O descarrilamento causado pelo aumento da dimensão da bitola é causado pelo aumento gradual desta distância devido à falha de componentes de via (podendo ser relacionados com a qualidade dos dormentes, falha nas fixações e desgaste do trilho). Este aumento da bitola é causado principalmente pela baixa resistência dos elementos de via. A Figura 4.11 ilustra este tipo de aumento da distância da bitola.

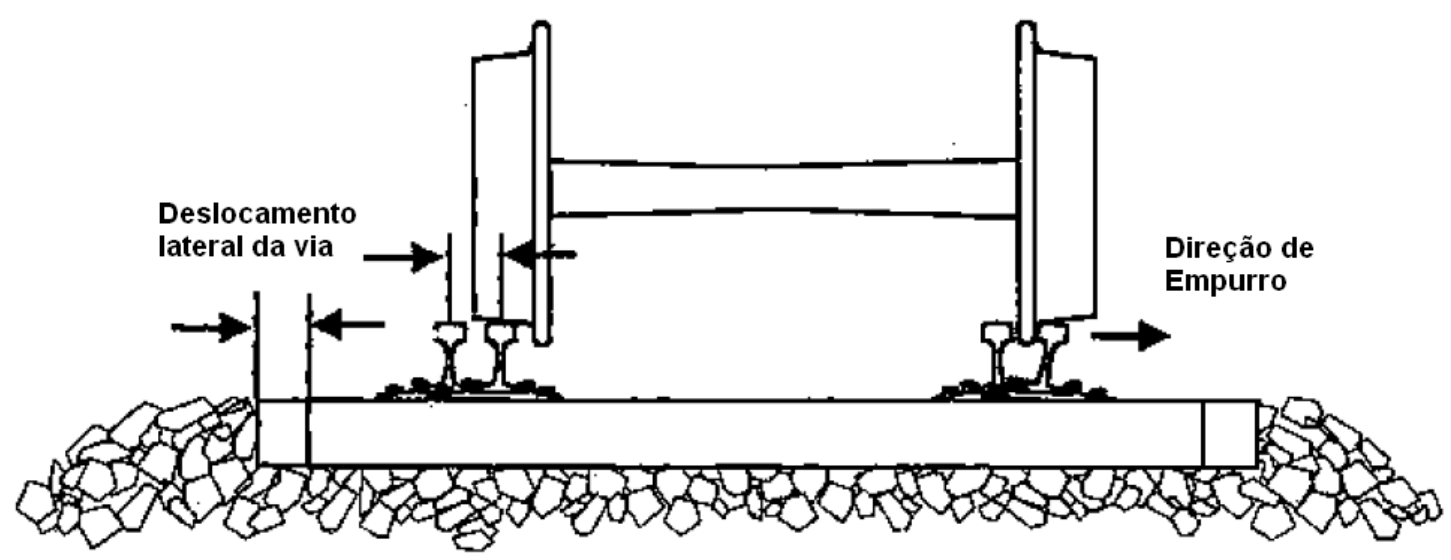

Figura 4.11 - Aumento da Dimensão da Bitola (IWNICKY, 2006) 


\subsection{4 - INSTABILIDADE LATERAL DO VEÍCULO}

A instabilidade lateral do veículo é causada pelo desalinhamento do eixo em relação à via, e devido ao perfil cônico da roda, este movimento acaba seguindo um perfil senoidal, desta forma, caso seja elevado, pode causar o descarrilamento. Este fenômeno também é conhecido como hunting, caracterizado pela variação em torno da linha central de equilíbrio.

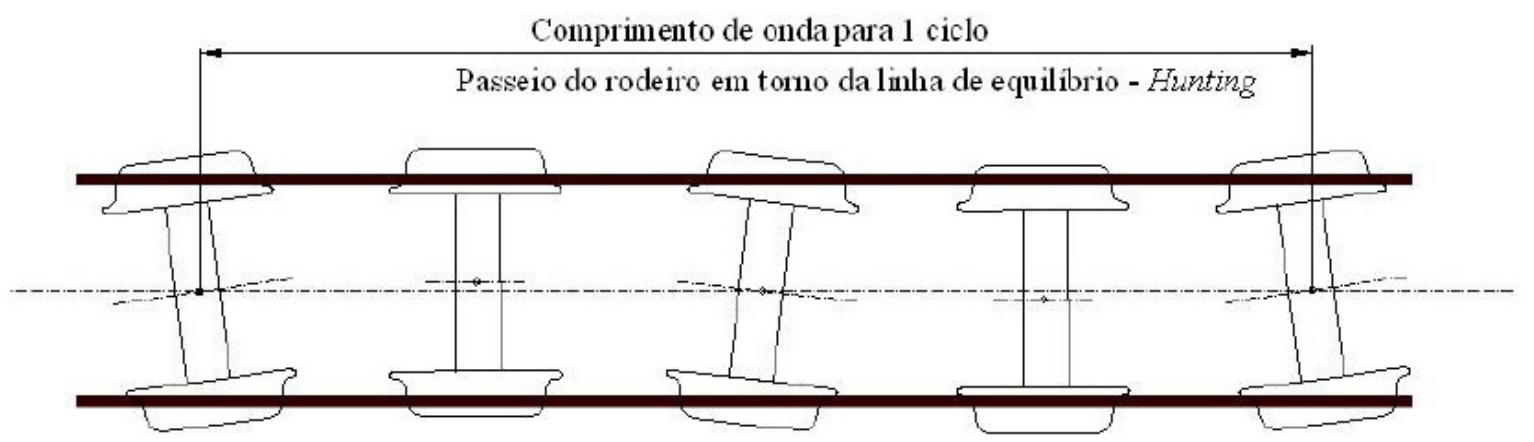

Figura 4.12 - Instabilidade Lateral do Veículo (ALMEIDA, 2006)

Tal fenômeno normalmente ocorre em veículos leves e depende de parâmetros de via e do veículo, como por exemplo, a massa do veículo, momento de inércia do rodeiro, rigidez da suspensão primária, raio de rolamento das rodas, conicidade, bitola da via e rigidez do contato. 


\section{CAPÍTULO 5 - DESCRIÇÃO DO MÉTODO}

\section{1- INTRODUÇÃO}

As simulações computacionais são uma importante ferramenta da engenharia para prever os comportamentos e reações dos sistemas. Estas simulações são aplicadas desde a década de 80 . Porém, o comportamento dinâmico em simulações operacionais, dependendo do número de variáveis que o modelo em estudo apresenta, pode apresentar um custo operacional grande, o que encarece o valor da simulação e pode tornar este tipo de ferramenta pouco viável em licitações de aquisição de sistema ferroviários que apresentam como primeira escolha a oferta do menor preço.

Uma alternativa para estas simulações computacionais é a simulação real do sistema. Esta simulação de operação pode ser realizada tanto na via original em que o sistema operará ou em uma via propriamente construída para esta simulação. Este tipo de alternativa é requerida em diversas especificações técnicas de operadoras de transporte ferroviário, sendo realizados através de equipamentos no veículo e na via como sensores, por exemplo, acelerômetros, esforcímetros etc.

Algumas normas podem ser aplicadas para realizar a da operação, por exemplo, para a simulação de via, segundo Iwnicki (2006), é possível utilizar o Capítulo XI do Manual of Standard and Recommended Practices (que foi aprovado pela Association of American Railroads). Neste documento são estabelecidas as condições de testes que incluem:

- hunting (instabilidade lateral do veiculo);

- curva constante;

- espiral;

- giro;

- pitch;

- yaw, swaye

- curva em movimento. 
A norma UIC 518 OR estabelece as diretrizes dos testes a serem realizados na dinâmica do movimento em termos de segurança, fadiga da via e comportamento quanto ao movimento. O processo de aprovação de um veiculo ferroviário, segundo esta norma, é apresentado no APÊNDICE C.

Conforme discutido em 2.2, no Brasil não existe a figura da autoridade ferroviária, órgão máximo e responsável final pela regulamentação para a operação de um sistema ferroviário (IEC 62278, 2002), desta forma, é comum transferir as responsabilidades de aceitação para as empresas que estão adquirindo o material rodante. Ademais, cada empresa que adquire o material rodante ou cada empresa que é responsável pela operação dos mesmos pode definir seus próprios critérios de aceitação quando da ausência desta figura ferroviária.

Para tal, normas como EN 50126 (2000), MIL-STD-882C (1993) e IEC 62278 (2002) baseada na norma EN 50126, apresentam formas de gerenciamento e condução de estudos de segurança que podem ser considerados, cabendo à autoridade ferroviária estipular se as mesmas serão aceitas.

Desta forma, é proposto um método de análise de risco aplicada ao descarrilamento que complementa as simulações computacionais e simulações dinâmicas de forma a tornar mais seguro o transporte ferroviário que não apresenta diminuição da taxa de descarrilamentos conforme demonstrado em Figura 4.1. Esta metodologia é apresentada no item 5.2.

\section{2 - MÉTODO}

O método de análise de risco ora proposto, aplicado ao descarrilamento, considera as seguintes etapas: entendimento do problema e identificação dos elementos sob análise, análise de causa e conseqüência, elaboração de FTA, elaboração de FMECA e proposta de cálculo da probabilidade de ocorrência do evento. O fluxograma que descreve este método é apresentado na Figura 5.1. 


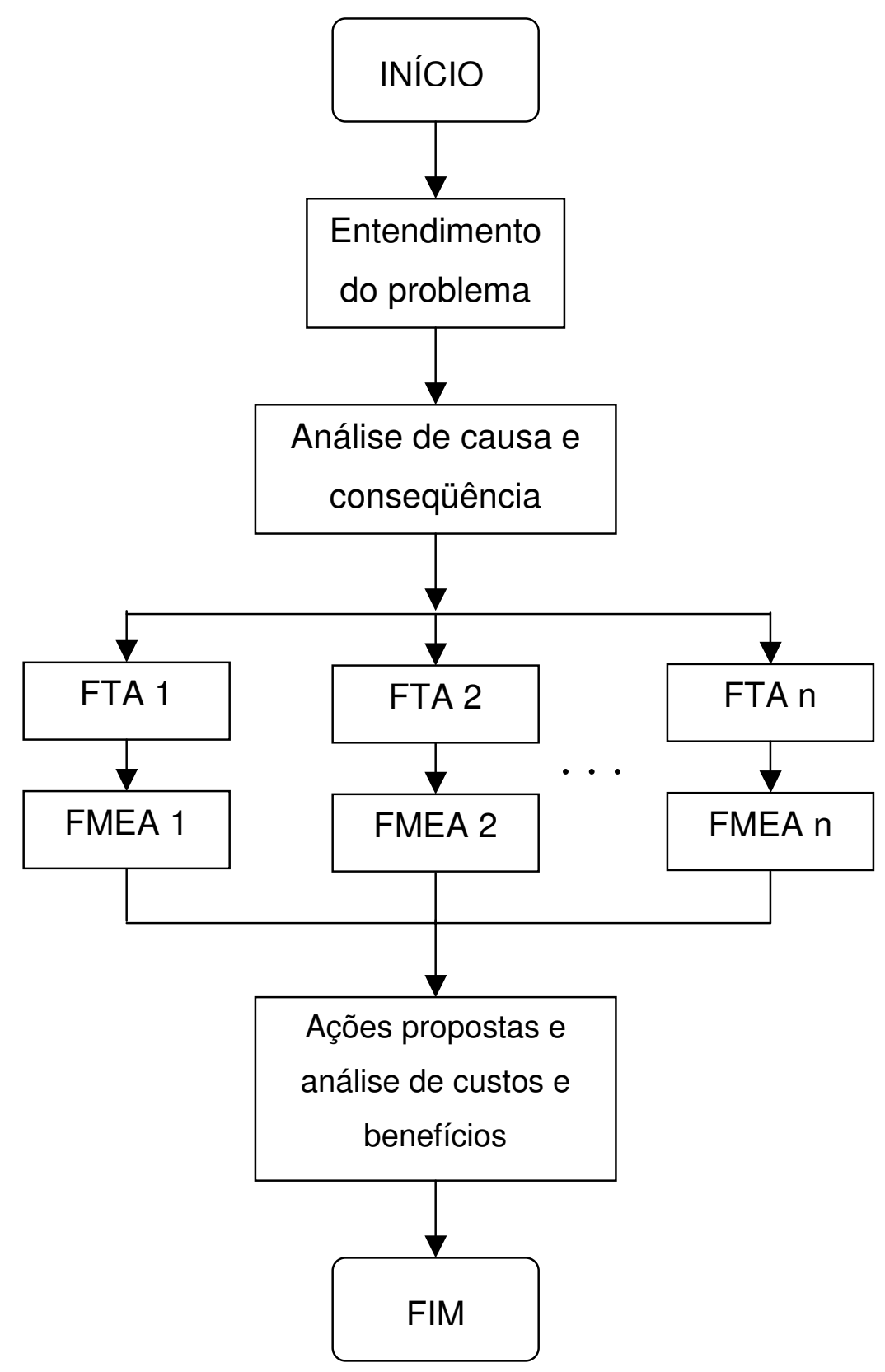

Figura 5.1: Método Proposto

O entendimento do problema e identificação dos elementos sob análise se fazem necessários pois conforme já apresentado em 2.1.1, a confiabilidade é a probabilidade de um item executar a sua função sob condições pré-definidas de uso e manutenção por um período de tempo específico; ou seja, para o estudo da confiabilidade é necessário o entendimento das funções do sistema bem como os mecanismos que podem causar a falha (no caso o descarrilamento) do mesmo. Esta 
discussão sobre o problema foi realizada no CAPÍTULO 4, em que se discorre sobre a definição de descarrilamento, as taxas de falha que o transporte ferroviário apresenta no cenário atual, componentes participantes do perigo, bem como diferentes critérios de descarrilamento já desenvolvidos.

A análise de causa e conseqüência (realizada no item 6.1.), cuja definição e explicação se encontram no item 2.2, tem por objetivo identificar nos fluxogramas disponíveis os perigos presentes, ou seja, através da compilação em um formato visual os eventos que podem influenciar na ocorrência do perigo estudado e para detalhamento destes eventos, faz-se uso primeiramente da análise do tipo FTA para sintetizar de maneira simples os fatores que causam o evento e após esta análise, utiliza-se a FMEA para obtenção dos mecanismos de falhas que geram estes fatores.

A elaboração e análise por árvore de falhas (FTA), cujos conceitos foram abordados em 2.1.3, visa auxiliar a análise de causa e conseqüência e permitir uma rápida identificação visual dos eventos que causam o evento topo analisado, identificar em um nível mais detalhado as causas do evento e permitir a familiarização do estudo do descarrilamento. O FTA é construído no item 6.2.

As análises dos modos e efeitos de falha (FMEA), cujos conceitos foram abordados em 2.1.2, tem por objetivo complementar as análises de causa e conseqüência e as análises por árvore de falhas de forma a permitir além da identificação dos componentes que podem vir a causar o descarrilamento, possibilitar a identificação dos modos de falha destes componentes, as possíveis causas destes modos de falha, os efeitos dos mesmos no sistema e os possíveis modos de detecção e ações de gerenciamento para as falhas. Ou seja, é uma análise que possibilita um maior detalhamento quanto ao problema. Estas análises são realizadas no item 6.2.

A elaboração de análises do tipo FMEA com posterior análise do tipo FTA não foi realizada (optando-se pela ordem inversa) pois teve-se como objetivo através da FTA primeiramente a definição dos eventos que seriam abordados na FMEA. 
Ao final, é proposto um método de cálculo da probabilidade de falha de um componente baseado no método probabilístico condicionado avançado, conforme os conceitos apresentados no item 11. Este método é um ponto de equilíbrio entre o método semi probabilístico (que utiliza fatores de segurança parciais para as variáveis empregadas no modelo) e o método probabilístico puro (que considera todas as possíveis configurações de colapso). Esta aplicação do método é realizada no item 7.5. Desta forma é possível avaliar o custo e o benefício em termos de confiabilidade de uma solução proposta. 


\section{CAPÍTULO 6 - APLICAÇÃO DO MÉTODO: CASO-ESTUDO}

\section{1 - ANÁLISE DE CAUSA E CONSEQÜÊNCIA - DESCARRILAMENTO}

Diferentemente da abordagem em que são estudados os critérios de descarrilamento e a determinação quantitativa das forças e parâmetros para se investigar a ocorrência ou não de um descarrilamento, esta dissertação discutirá o problema de descarrilamento por análise de risco pelo método de análise de causa e conseqüência. O diagrama de causa e conseqüência é apresentado na Figura 6.1.

Esta análise, apesar de não apresentar os valores quantitativos dos parâmetros como, por exemplo, pelo critério de Nadal, apresentará os itens que contribuem para o descarrilamento e os métodos de prevenção propondo assim uma abordagem com foco nos componentes e não na dinâmica de operação.

Esta abordagem apresenta limitações quanto à dificuldade da determinação quantitativa de variáveis que indicariam o descarrilamento, porém é eficiente para avaliação dos componentes que influenciam neste evento uma vez que identifica através de análises do tipo FTA e do FMEA. Neste diagrama, divide-se a análise em dois principais ramos: análise do material rodante e análise dos elementos de via.

As análises de cada subsistema apresentado no diagrama de causa e conseqüência na Figura 6.1 são realizadas no item 6.2. 


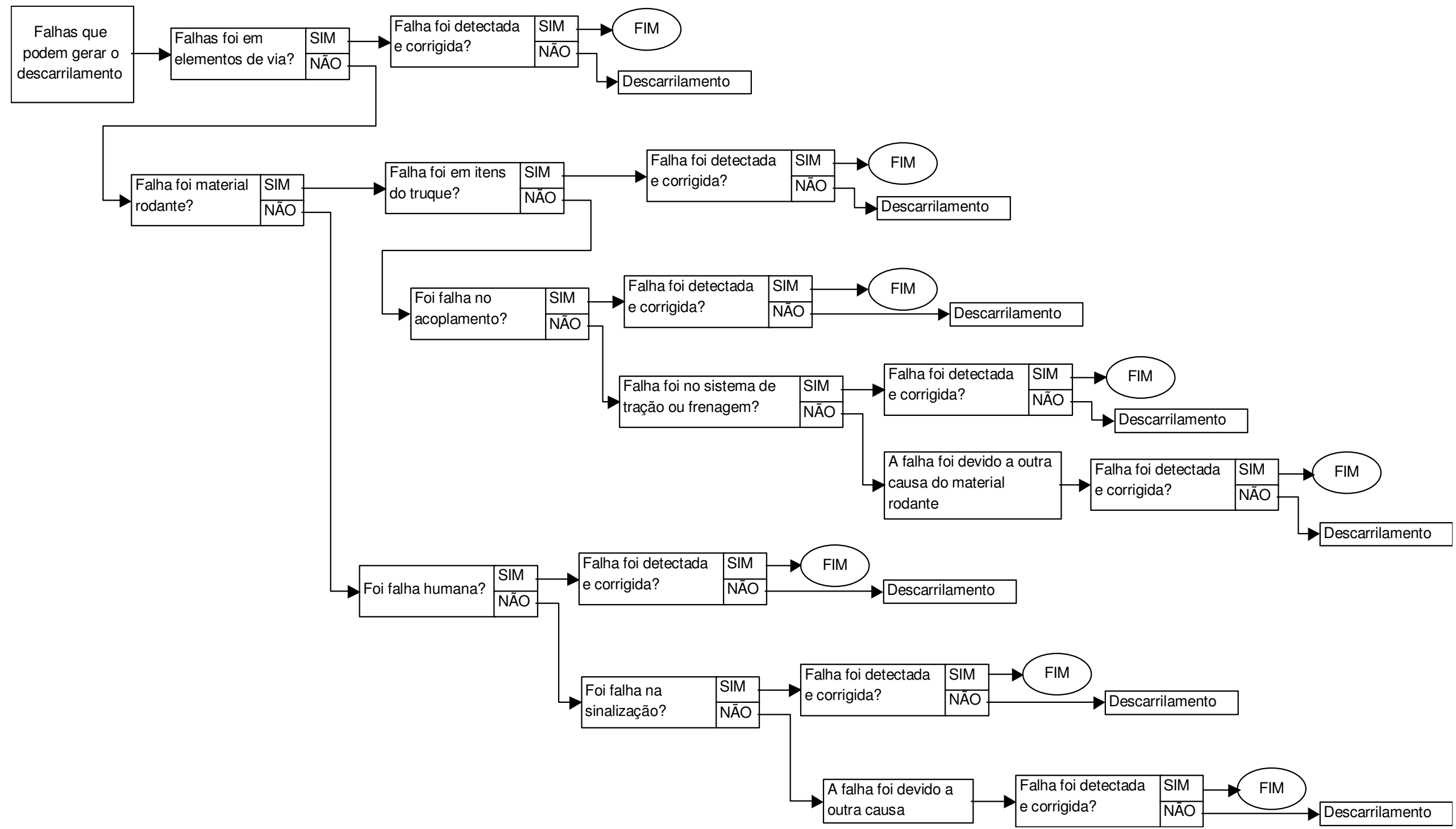

Figura 6.1 - Diagrama Causa Conseqüência - Descarrilamento 
O diagrama de causa e conseqüência iniciou com as falhas que podem gerar um descarrilamento, separando primeiramente em falhas da via e em falhas dos demais componentes. Através de perguntas cujas respostas devem ser "sim" ou "não", é elaborado o mesmo, sendo que a primeira pergunta está relacionado com a via que participa com $45 \%$ das causas do descarrilamento conforme Figura 4.3.

Caso haja uma resposta negativa quanto ao descarrilamento decorrente dos elementos de via, é questionado se a causa é proveniente do material rodante, sendo detalhados os diferentes sistemas que contribuem para o descarrilamento, e em caso negativo quanto ao material rodante, é questionado quanto às falhas humanas e de sinalização.

\section{2 - ANÁLISES DO TIPO FTA E FMEA}

Os eventos indicados no digrama de causa e conseqüência da Figura 6.1 são apresentados nesta seção. Além das análises do tipo FTA, são apresentadas também, para uma análise mais completa do problema envolvido, análises do tipo FMEA para compreensão do problema. Nestas análises são abordadas apenas as falhas que apresentam maior probabilidade de estarem relacionadas ao descarrilamento.

\subsection{1 - ELEMENTOS DE VIA}

A árvore de falhas referente aos elementos de via está apresentada na Figura 6.2. Nesta figura são representadas as combinações de falhas referentes aos elementos de via que podem geram um descarrilamento. 


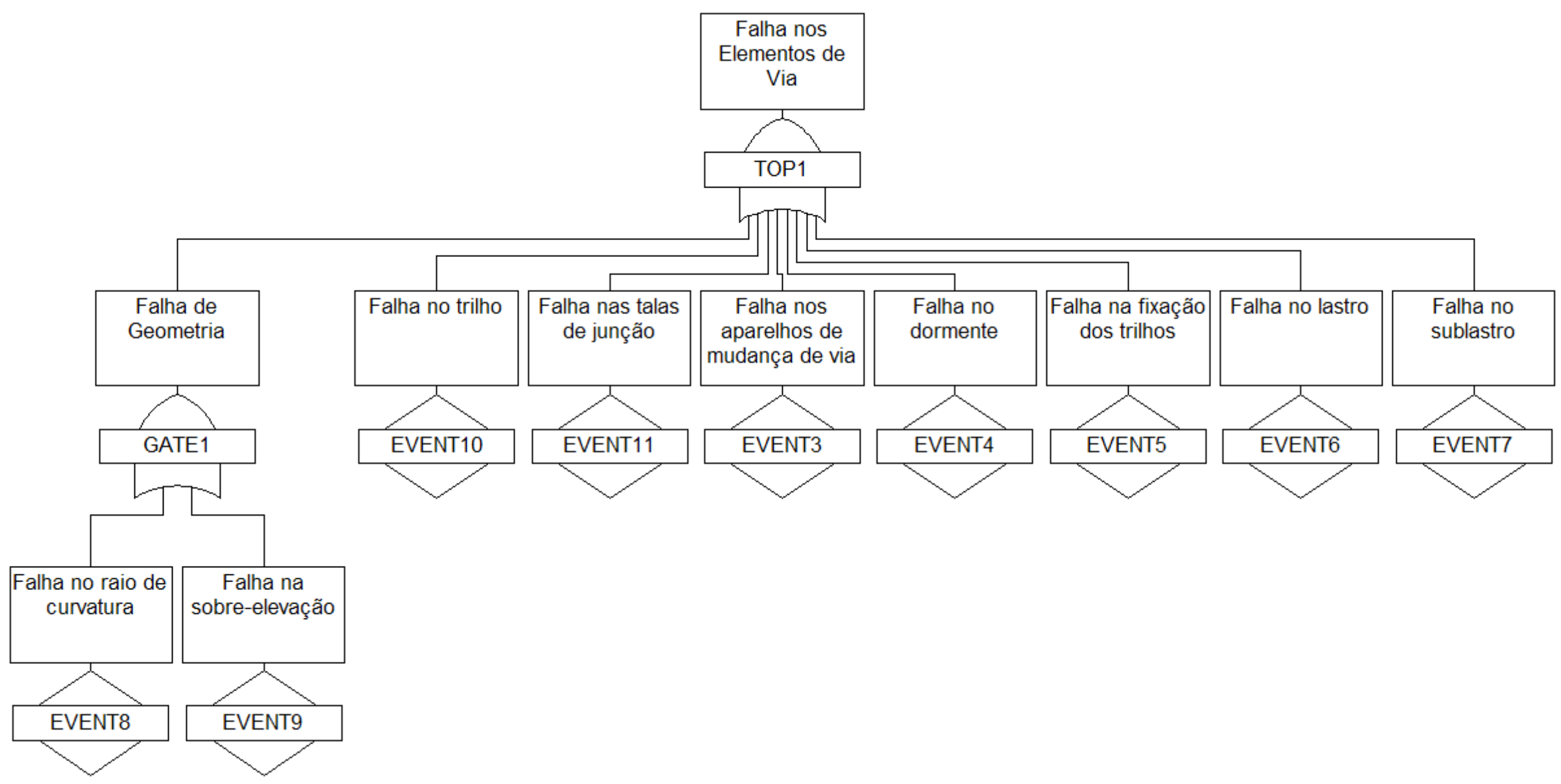

Figura 6.2 - FTA - Falha dos Elementos de Via 
A Tabela 6.1.apresenta os modos de falha para cada item/componente, com uma descrição de cada modo de falha e da fonte de referência que foi obtido o respectivo modo de falha.

A fonte de referência mais utilizada para os modos de falha foi a FMD-97 (1997). No APÊNDICE E são apresentados os trechos deste banco de dados referentes a componentes descritos nesta tabela. Além disso, uma parte das referências os modos de falha foram provenientes de hipóteses e outras da referência Reliability Toolkit (1995). Há ainda uma parte proveniente do trabalho de Porto (1984). Os modos de falha considerados e suas fontes são apresentados na Tabela 6.1.

Como ressalva, não foram considerados todos os modos de falha apresentados por Porto (1984) conforme descrito no item 3.1.7 pois, de acordo com o julgamento, os demais modos de falha não influenciam o descarrilamento.

É importante observar que para vias que não apresentam talas de junção dos trilhos, ou seja, os trilhos não apresentam emendas aparentes, os modos de falha considerados neste trabalho são os mesmos dos trilhos com junções aparentes.

Tabela 6.1 - Elementos de Via - Modos de falha considerados e referências

continua

\begin{tabular}{|c|c|c|c|c|}
\hline Item & Função & Modo de Falha & Descrição & FONTE \\
\hline Trilho & $\begin{array}{l}\text { Elemento de contato } \\
\text { entre a roda causando o } \\
\text { contato metal-metal. } \\
\text { Serve de sustentação } \\
\text { para o material rodante }\end{array}$ & Quebrado & $\begin{array}{c}\text { Trilho quebrado ou com danos } \\
\text { estruturais com possíveis causas } \\
\text { descritas em } 3.1 .2\end{array}$ & $\begin{array}{l}\text { FMD-97 } \\
(1997)\end{array}$ \\
\hline \multirow{3}{*}{$\begin{array}{l}\text { Aparelho de } \\
\text { mudança de } \\
\text { via }\end{array}$} & \multirow{3}{*}{$\begin{array}{l}\text { Permitir a alteração de } \\
\text { rota do trem }\end{array}$} & $\begin{array}{l}\text { Mudança } \\
\text { incompleta }\end{array}$ & $\begin{array}{c}\text { Falha que ocorre quando há } \\
\text { demanda para mudança, porém o } \\
\text { AMV se movimenta, mas não até } \\
\text { a sua posição final correta }\end{array}$ & Hipótese \\
\hline & & $\begin{array}{l}\text { Perda das } \\
\text { características } \\
\text { geométricas }\end{array}$ & $\begin{array}{l}\text { Falha caracterizada pela } \\
\text { alteração geométrica do } \\
\text { componente de forma a causar } \\
\text { descontinuidades na via }\end{array}$ & Hipótese \\
\hline & & Posição errada & $\begin{array}{c}\text { Deslocamento indevido do } \\
\text { aparelho de mudança de via sem } \\
\text { uma demanda efetiva do } \\
\text { dispositivo de controle ou não } \\
\text { alteração da posição quando } \\
\text { demandado }\end{array}$ & Hipótese \\
\hline
\end{tabular}


conclusão

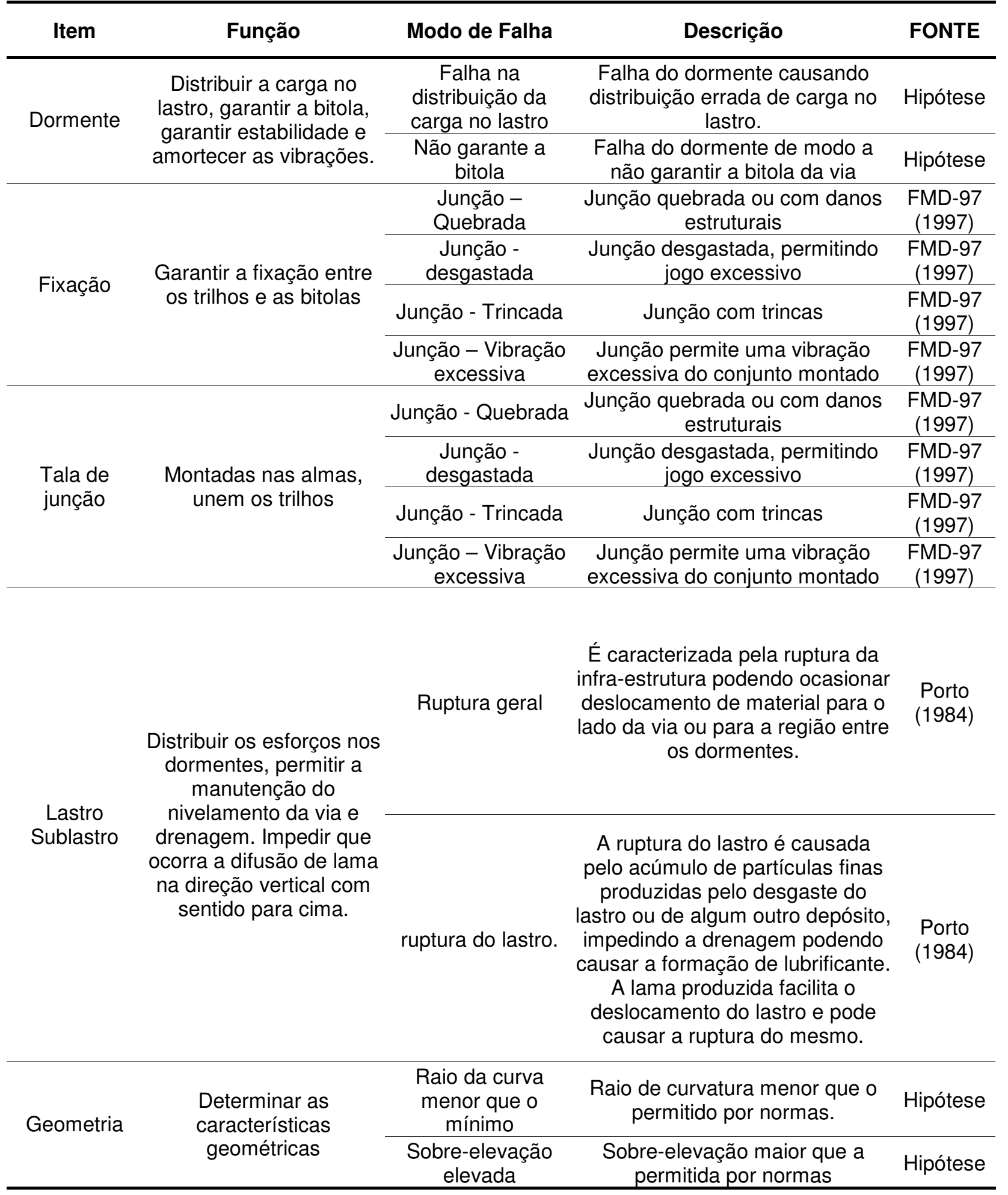

A Tabela 6.2 apresenta a implementação da análise do tipo FMEA para os elementos de via. 
Tabela 6.2 - FMEA dos Elementos de Via

continua

\begin{tabular}{|c|c|c|c|c|c|c|c|c|c|c|c|c|}
\hline \multicolumn{13}{|c|}{ Sistema: Elementos de Via } \\
\hline \multirow{2}{*}{ ID } & \multirow{2}{*}{ Item } & \multirow{2}{*}{ Função } & \multirow{2}{*}{$\begin{array}{l}\text { Modo de } \\
\text { Falha }\end{array}$} & \multirow{2}{*}{ Causas prováveis } & \multirow{2}{*}{$\begin{array}{c}\text { Modo } \\
\text { Operacional }\end{array}$} & \multicolumn{3}{|c|}{ Efeito das Falhas } & \multirow{2}{*}{ Modo de Detecção } & \multirow{2}{*}{ Ação de Gerenciamento } & \multirow{2}{*}{ Sev } & \multirow{2}{*}{ Notas } \\
\hline & & & & & & Item & Sistema & Trem & & & & \\
\hline$\stackrel{\frac{\pi}{1}}{\sum^{4}}$ & & 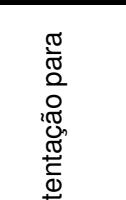 & & $\begin{array}{l}\text { Erro de } \\
\text { especificação de } \\
\text { projeto }\end{array}$ & & & 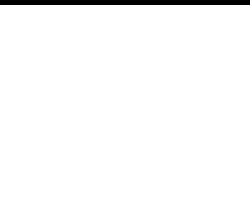 & & $\begin{array}{l}\text { Simulação do } \\
\text { movimento. } \\
\text { Testes operacionais. } \\
\text { Simulações } \\
\text { computacionais. }\end{array}$ & $\begin{array}{c}\text { Este item deve ser } \\
\text { inspecionado em controle } \\
\text { de qualidade. } \\
\text { Estudos e testes para a } \\
\text { averiguação da dinâmica } \\
\text { do movimento. }\end{array}$ & 1 & \\
\hline$\sum_{i}^{\infty}$ & & 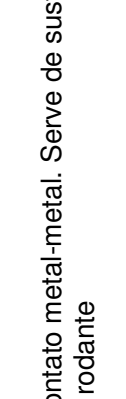 & & $\begin{array}{l}\text { Erro de manufatura } \\
\text { (vazio, segregações, } \\
\text { inclusões e fissura } \\
\text { transversais) }\end{array}$ & & & $\begin{array}{l}\text { Aumento da bitola } \\
\text { ou rotação do }\end{array}$ & $\begin{array}{c}\text { Pode ocorrer } \\
\text { descarrilamento } \\
\text { pela } \\
\text { descontinuidade do }\end{array}$ & $\begin{array}{l}\text { Controle de } \\
\text { qualidade dos itens. } \\
\text { Inspeção em } \\
\text { manutenção }\end{array}$ & $\begin{array}{c}\text { Este item deve ser } \\
\text { inspecionado em controle } \\
\text { de qualidade e inspeções } \\
\text { durante manufatura } \\
\text { Deve haver correto } \\
\text { controle do processo, por } \\
\text { exemplo utilizando-se } \\
\text { massalotes para evitar o } \\
\text { fenômeno de vazio ou } \\
\text { uso de material } \\
\text { adequado para evitar a } \\
\text { segregação. } \\
\end{array}$ & 1 & \\
\hline 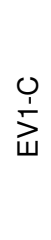 & $\underset{\underline{\underline{F}}}{\stackrel{c}{F}}$ & 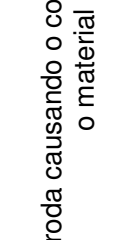 & Quebrado & Erro de montagem & movimento & função & $\begin{array}{l}\text { trilho. } \\
\text { Descontinuidade } \\
\text { dos trilhos }\end{array}$ & $\begin{array}{c}\text { trilho. } \\
\text { Possível } \\
\text { descarrilamento por } \\
\text { aumento da bitola } \\
\text { ou rotação do trilho. }\end{array}$ & $\begin{array}{l}\text { Testes operacionais } \\
\text { Inspeções de } \\
\text { qualidade }\end{array}$ & $\begin{array}{l}\text { Inspeção em controle de } \\
\text { qualidade. } \\
\text { Estudos e testes. }\end{array}$ & 1 & \\
\hline$\frac{0}{\sum^{\prime}}$ & & 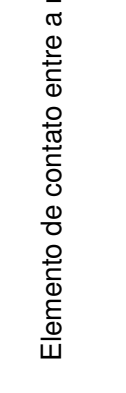 & & $\begin{array}{l}\text { Erro de manutenção } \\
\text { (deformação das } \\
\text { pontas, autotêmpera } \\
\text { superficial, } \\
\text { escoamento do } \\
\text { metal na superfície } \\
\text { do boleto, desgaste } \\
\text { da ação e do patim } \\
\text { por ação química, } \\
\text { desgaste dos trilhos } \\
\text { por atrito e fratura } \\
\text { dos trilhos) }\end{array}$ & & & & & $\begin{array}{l}\text { Inspeção em } \\
\text { manutenção }\end{array}$ & $\begin{array}{l}\text { Este item deve ser } \\
\text { inspecionado em } \\
\text { manutenção. } \\
\text { O manual deve } \\
\text { contemplar este item e os } \\
\text { funcionários devem } \\
\text { receber correto } \\
\text { treinamento para a } \\
\text { atividade }\end{array}$ & 1 & \\
\hline
\end{tabular}


continuação

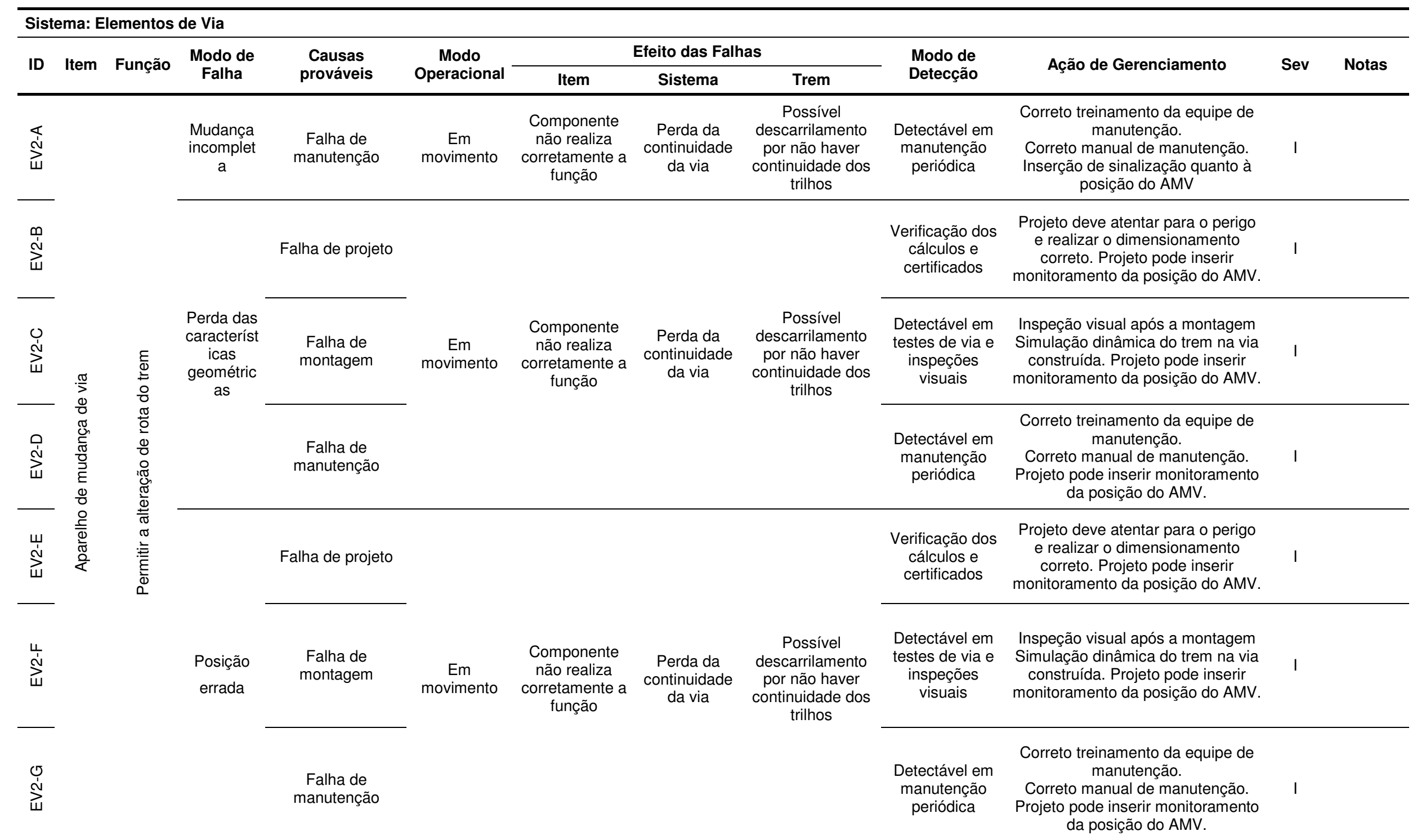


continuação

\begin{tabular}{|c|c|c|c|c|c|c|c|c|c|c|c|c|}
\hline \multicolumn{13}{|c|}{ Sistema: Elementos de Via } \\
\hline \multirow{2}{*}{ ID } & \multirow{2}{*}{ Item } & \multirow{2}{*}{ Função } & \multirow{2}{*}{$\begin{array}{l}\text { Modo de } \\
\text { Falha }\end{array}$} & \multirow{2}{*}{$\begin{array}{l}\text { Causas } \\
\text { prováveis }\end{array}$} & \multirow{2}{*}{$\begin{array}{c}\text { Modo } \\
\text { Operacional }\end{array}$} & \multicolumn{3}{|c|}{ Efeito das Falhas } & \multirow{2}{*}{$\begin{array}{l}\text { Modo de } \\
\text { Detecção }\end{array}$} & \multirow{2}{*}{ Ação de Gerenciamento } & \multirow{2}{*}{ Sev } & \multirow{2}{*}{ Notas } \\
\hline & & & & & & Item & Sistema & Trem & & & & \\
\hline 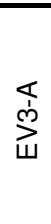 & \multirow{7}{*}{ 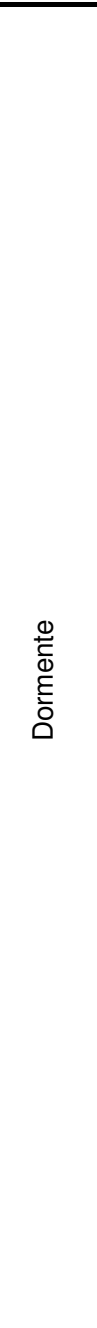 } & \multirow{7}{*}{ 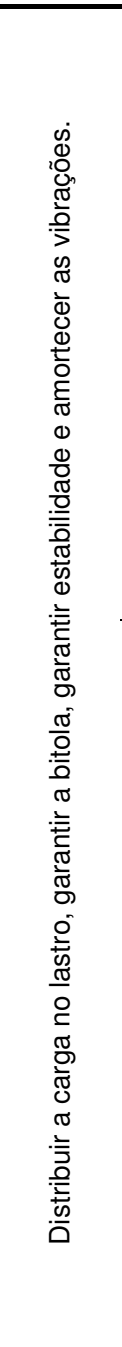 } & \multirow{3}{*}{$\begin{array}{c}\text { Falha na } \\
\text { distribuiçã } \\
\text { o da carga } \\
\text { no lastro }\end{array}$} & $\begin{array}{l}\text { Erro de } \\
\text { especificação de } \\
\text { projeto }\end{array}$ & \multirow{3}{*}{$\begin{array}{c}\text { Em } \\
\text { movimento }\end{array}$} & \multirow{3}{*}{$\begin{array}{l}\text { Componente } \\
\text { não realiza } \\
\text { corretamente a } \\
\quad \text { função }\end{array}$} & \multirow{3}{*}{$\begin{array}{c}\text { Possível } \\
\text { desnivelament } \\
\text { o da via }\end{array}$} & \multirow{3}{*}{$\begin{array}{c}\text { Pode ocorrer o } \\
\text { descarrilamento } \\
\text { devido ao desnível e } \\
\text { devido a isso, } \\
\text { desnivelamento da } \\
\text { via ou instabilidade } \\
\text { no movimento }\end{array}$} & $\begin{array}{l}\text { Simulação do } \\
\text { movimento. } \\
\text { Testes } \\
\text { operacionais. } \\
\text { Simulações } \\
\text { computacionais }\end{array}$ & $\begin{array}{l}\text { Estudos e testes para a } \\
\text { averiguação da dinâmica do } \\
\text { movimento. }\end{array}$ & 1 & \\
\hline$\stackrel{m}{m}^{m}$ & & & & $\begin{array}{l}\text { Erro de } \\
\text { manufatura ou } \\
\text { montagem }\end{array}$ & & & & & $\begin{array}{l}\text { Simulação do } \\
\text { movimento. } \\
\text { Testes } \\
\text { operacionais. } \\
\text { Inspeções de } \\
\text { qualidade }\end{array}$ & $\begin{array}{c}\text { Este item deve ser } \\
\text { inspecionado em controle } \\
\text { de qualidade. } \\
\text { Estudos e testes para a } \\
\text { averiguação da dinâmica do } \\
\text { movimento. }\end{array}$ & 1 & \\
\hline 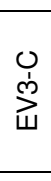 & & & & $\begin{array}{c}\text { Erro de } \\
\text { manutenção }\end{array}$ & & & & & $\begin{array}{l}\text { Inspeção em } \\
\text { manutenção }\end{array}$ & $\begin{array}{l}\text { Este item deve ser } \\
\text { inspecionado em } \\
\text { manutenção. Deve haver } \\
\text { manual com informações } \\
\text { claras. }\end{array}$ & 1 & \\
\hline \multirow[t]{2}{*}{ ले } & & & \multirow{4}{*}{$\begin{array}{l}\text { Não } \\
\text { garante a } \\
\text { bitola }\end{array}$} & $\begin{array}{l}\text { Erro de } \\
\text { especificação de } \\
\text { projeto }\end{array}$ & \multirow{4}{*}{$\begin{array}{c}\text { Em } \\
\text { movimento }\end{array}$} & \multirow{4}{*}{$\begin{array}{l}\text { Componente } \\
\text { não realiza } \\
\text { corretamente a } \\
\text { função }\end{array}$} & \multirow{4}{*}{$\begin{array}{c}\text { Possível } \\
\text { desnivelament } \\
\text { o da via }\end{array}$} & \multirow{4}{*}{$\begin{array}{c}\text { Pode ocorrer o } \\
\text { descarrilamento } \\
\text { devido ao desnível e } \\
\text { devido a isso, } \\
\text { desnivelamento da } \\
\text { via ou instabilidade } \\
\text { no movimento }\end{array}$} & $\begin{array}{l}\text { Simulação do } \\
\text { movimento. } \\
\text { Testes } \\
\text { operacionais. } \\
\text { Simulações } \\
\text { computacionais }\end{array}$ & $\begin{array}{l}\text { Estudos e testes para a } \\
\text { averiguação da dinâmica do } \\
\text { movimento. }\end{array}$ & 1 & \\
\hline & & & & & & & & & & & & \\
\hline 峁 & & & & $\begin{array}{l}\text { Erro de } \\
\text { manufatura ou } \\
\text { montagem }\end{array}$ & & & & & $\begin{array}{l}\text { Simulação do } \\
\text { movimento. } \\
\text { Testes } \\
\text { operacionais. } \\
\text { Inspeções de } \\
\text { qualidade }\end{array}$ & $\begin{array}{c}\text { Este item deve ser } \\
\text { inspecionado em controle } \\
\text { de qualidade. } \\
\text { Estudos e testes para a } \\
\text { averiguação da dinâmica do } \\
\text { movimento. }\end{array}$ & 1 & \\
\hline 岁 & & & & $\begin{array}{c}\text { Erro de } \\
\text { manutenção }\end{array}$ & & & & & $\begin{array}{l}\text { Inspeção em } \\
\text { manutenção }\end{array}$ & $\begin{array}{c}\text { Este item deve ser } \\
\text { inspecionado em } \\
\text { manutenção. Deve haver } \\
\text { manual com informações } \\
\text { claras. }\end{array}$ & 1 & \\
\hline
\end{tabular}


continuação

\begin{tabular}{|c|c|c|c|c|c|c|c|c|c|c|c|c|}
\hline \multicolumn{13}{|c|}{ Sistema: Elementos de Via } \\
\hline \multirow{2}{*}{ ID } & \multirow{2}{*}{ Item } & \multirow{2}{*}{ Função } & \multirow{2}{*}{$\begin{array}{l}\text { Modo de } \\
\text { Falha }\end{array}$} & \multirow{2}{*}{$\begin{array}{l}\text { Causas } \\
\text { prováveis }\end{array}$} & \multirow{2}{*}{$\begin{array}{c}\text { Modo } \\
\text { Operacional }\end{array}$} & \multicolumn{3}{|c|}{ Efeito das Falhas } & \multirow{2}{*}{$\begin{array}{l}\text { Modo de } \\
\text { Detecção }\end{array}$} & \multirow{2}{*}{ Ação de Gerenciamento } & \multirow{2}{*}{ Sev } & \multirow{2}{*}{ Notas } \\
\hline & & & & & & Item & Sistema & Trem & & & & \\
\hline 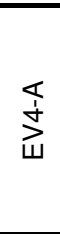 & & & 1 - Junção & $\begin{array}{l}\text { Erro de } \\
\text { especificação de } \\
\text { projeto }\end{array}$ & & & Aumento da & $\begin{array}{c}\text { Possível } \\
\text { descarrilamento }\end{array}$ & $\begin{array}{c}\text { Simulação do } \\
\text { movimento. } \\
\text { Testes } \\
\text { operacionais. } \\
\text { Simulações } \\
\text { computacionais }\end{array}$ & $\begin{array}{c}\text { Estudos e testes para a } \\
\text { averiguação da dinâmica do } \\
\text { movimento. } \\
\text { Pedido de certificados, por } \\
\text { exemplo, dos materiais } \\
\text { utilizados. }\end{array}$ & 1 & \\
\hline 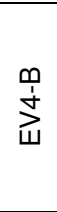 & & $\frac{\mathbb{\pi}}{\pi}$ & $\begin{array}{l}2 \text { - Junção } \\
\text { - Trincada }\end{array}$ & $\begin{array}{l}\text { Erro de } \\
\text { manufatura ou } \\
\text { montagem }\end{array}$ & $\begin{array}{c}\text { Em } \\
\text { movimento }\end{array}$ & $\begin{array}{l}\text { Componente } \\
\text { não fixa o trilho } \\
\text { pelo período } \\
\text { determinado }\end{array}$ & $\begin{array}{l}\text { bitola ou } \\
\text { quando em } \\
\text { diversos itens } \\
\text { rotação do } \\
\text { trilho }\end{array}$ & $\begin{array}{l}\text { por aumento do } \\
\text { tamanho da bitola } \\
\text { ou por rotação do } \\
\text { trilho e aumento } \\
\text { da bitola }\end{array}$ & $\begin{array}{l}\text { Simulação do } \\
\text { movimento. } \\
\text { Testes } \\
\text { operacionais. } \\
\text { Inspeções de } \\
\text { qualidade }\end{array}$ & $\begin{array}{c}\text { Este item deve ser inspecionado } \\
\text { em controle de qualidade. } \\
\text { Estudos e testes para a } \\
\text { averiguação da dinâmica do } \\
\text { movimento. }\end{array}$ & 1 & \\
\hline 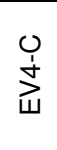 & & $\begin{array}{l}0 \\
\text { :0 } \\
0 \\
0 \\
0 \\
0 \\
0 \\
0\end{array}$ & & $\begin{array}{c}\text { Erro de } \\
\text { manutenção }\end{array}$ & & & & & $\begin{array}{l}\text { Inspeção em } \\
\text { manutenção }\end{array}$ & $\begin{array}{c}\text { Este item deve ser inspecionado } \\
\text { em manutenção. } \\
\text { Deve haver manual com } \\
\text { informações claras. }\end{array}$ & 1 & \\
\hline 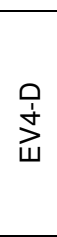 & 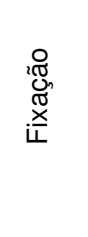 & 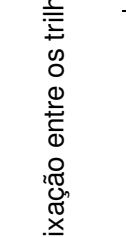 & $\begin{array}{l}\text { Junção - } \\
\text { desgastad } \\
\text { a }\end{array}$ & $\begin{array}{l}\text { Erro de } \\
\text { especificação de } \\
\text { projeto }\end{array}$ & $\begin{array}{c}\text { Em } \\
\text { movimento }\end{array}$ & $\begin{array}{l}\text { Componente } \\
\text { não fixa o trilho } \\
\text { pelo período }\end{array}$ & $\begin{array}{l}\text { Aumento da } \\
\text { bitola ou } \\
\text { quando em } \\
\text { diversos itens }\end{array}$ & $\begin{array}{c}\text { Possível } \\
\text { descarrilamento } \\
\text { por aumento do } \\
\text { tamanho da bitola }\end{array}$ & $\begin{array}{l}\text { Simulação do } \\
\text { movimento. } \\
\text { Testes } \\
\text { operacionais. } \\
\text { Simulações } \\
\text { computacionais } \\
\end{array}$ & $\begin{array}{c}\text { Estudos e testes para a } \\
\text { averiguação da dinâmica do } \\
\text { movimento. } \\
\text { Pedido de certificados, por } \\
\text { exemplo, dos materiais } \\
\text { utilizados. }\end{array}$ & 1 & \\
\hline 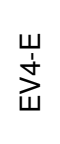 & & 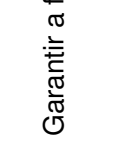 & & $\begin{array}{c}\text { Erro de } \\
\text { manutenção }\end{array}$ & & erminado & $\begin{array}{l}\text { rotação do } \\
\text { trilho }\end{array}$ & $\begin{array}{l}\text { trilho e aumento } \\
\text { da bitola }\end{array}$ & $\begin{array}{l}\text { Inspeção em } \\
\text { manutenção }\end{array}$ & $\begin{array}{l}\text { Este item deve ser inspecionado } \\
\text { em manutenção. } \\
\text { Deve haver manual com } \\
\text { informações claras. }\end{array}$ & 1 & \\
\hline 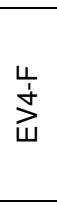 & & & $\begin{array}{l}\text { Junção - } \\
\text { Vibração }\end{array}$ & $\begin{array}{l}\text { Erro de } \\
\text { montagem }\end{array}$ & Em & $\begin{array}{l}\text { Componente } \\
\text { não fixa o trilho }\end{array}$ & $\begin{array}{l}\text { Aumento da } \\
\text { bitola ou } \\
\text { quando em }\end{array}$ & $\begin{array}{c}\text { Possível } \\
\text { descarrilamento } \\
\text { por aumento do } \\
\text { tamanho da bitola }\end{array}$ & $\begin{array}{l}\text { Simulação do } \\
\text { movimento. } \\
\text { Testes } \\
\text { operacionais. } \\
\text { Inspeções de } \\
\text { qualidade } \\
\end{array}$ & $\begin{array}{c}\text { Este item deve ser inspecionado } \\
\text { em controle de qualidade. } \\
\text { Estudos e testes para a } \\
\text { averiguação da dinâmica do } \\
\text { movimento. }\end{array}$ & 1 & \\
\hline$\stackrel{\substack{+⿱ 亠 䒑 十}}{\stackrel{4}{4}}$ & & & excessiva & $\begin{array}{c}\text { Erro de } \\
\text { manutenção }\end{array}$ & 0 & $\begin{array}{l}\text { pelo periodo } \\
\text { determinado }\end{array}$ & $\begin{array}{l}\text { diversos itens } \\
\text { rotação do } \\
\text { trilho }\end{array}$ & $\begin{array}{l}\text { ou por rotação do } \\
\text { trilho e aumento } \\
\text { da bitola }\end{array}$ & $\begin{array}{l}\text { Inspeção em } \\
\text { manutenção }\end{array}$ & $\begin{array}{l}\text { Este item deve ser inspecionado } \\
\text { em manutenção. Deve haver } \\
\text { manual com informações claras. }\end{array}$ & I & \\
\hline
\end{tabular}


continuação

\begin{tabular}{|c|c|c|c|c|c|c|c|c|c|c|c|c|}
\hline \multicolumn{13}{|c|}{ Sistema: Elementos de Via } \\
\hline \multirow{2}{*}{ ID } & \multirow{2}{*}{ Item } & \multirow{2}{*}{ Função } & \multirow{2}{*}{$\begin{array}{l}\text { Modo de } \\
\text { Falha }\end{array}$} & \multirow{2}{*}{$\begin{array}{l}\text { Causas } \\
\text { prováveis }\end{array}$} & \multirow{2}{*}{$\begin{array}{c}\text { Modo } \\
\text { Operacional }\end{array}$} & \multicolumn{3}{|c|}{ Efeito das Falhas } & \multirow{2}{*}{$\begin{array}{l}\text { Modo de } \\
\text { Detecção }\end{array}$} & \multirow{2}{*}{ Ação de Gerenciamento } & \multirow{2}{*}{ Sev } & \multirow{2}{*}{ Notas } \\
\hline & & & & & & Item & Sistema & Trem & & & & \\
\hline 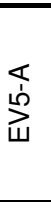 & \multirow{7}{*}{ 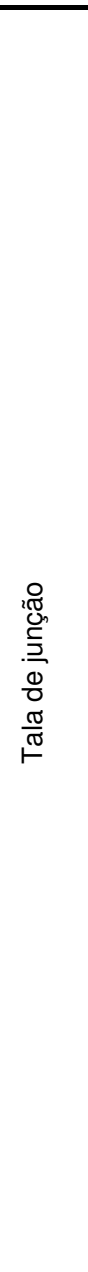 } & \multirow{7}{*}{ 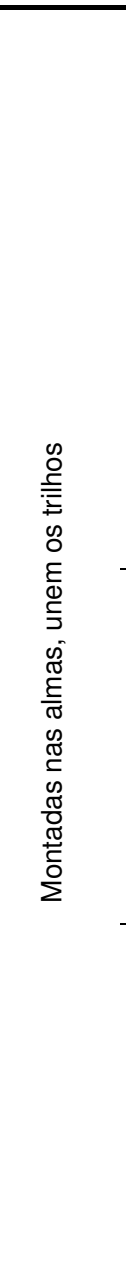 } & \multirow{3}{*}{$\begin{array}{l}1 \text { - Junção } \\
\overline{\text { Quebrada }} \\
2 \text { - Junção } \\
\text { - Trincada }\end{array}$} & $\begin{array}{l}\text { Erro de } \\
\text { especificação de } \\
\text { projeto }\end{array}$ & \multirow{3}{*}{$\begin{array}{c}\text { Em } \\
\text { movimento }\end{array}$} & \multirow{3}{*}{$\begin{array}{l}\text { Componente } \\
\text { não une os } \\
\text { trilhos pelo } \\
\text { período } \\
\text { determinado }\end{array}$} & \multirow{3}{*}{$\begin{array}{l}\text { Aumento da } \\
\text { bitola ou } \\
\text { quando em } \\
\text { diversos } \\
\text { itens rotação } \\
\text { do trilho. } \\
\text { Pode causar } \\
\text { descontinuid } \\
\text { ade do trilho }\end{array}$} & \multirow{3}{*}{$\begin{array}{c}\text { Pode ocorrer } \\
\text { descarrilamento } \\
\text { pela } \\
\text { descontinuidade do } \\
\text { trilho. } \\
\text { Possível } \\
\text { descarrilamento por } \\
\text { aumento da bitola } \\
\text { ou rotação do trilho. }\end{array}$} & $\begin{array}{l}\text { Simulação do } \\
\text { movimento. } \\
\text { Testes } \\
\text { operacionais. } \\
\text { Simulações } \\
\text { computacionais. }\end{array}$ & $\begin{array}{c}\text { Estudos e testes para a } \\
\text { averiguação da dinâmica do } \\
\text { movimento. } \\
\text { Pedido de certificados, por } \\
\text { exemplo, dos materiais } \\
\text { utilizados. }\end{array}$ & 1 & \\
\hline 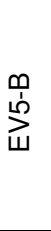 & & & & $\begin{array}{l}\text { Erro de } \\
\text { manufatura ou } \\
\text { montagem }\end{array}$ & & & & & $\begin{array}{l}\text { Simulação do } \\
\text { movimento. } \\
\text { Testes } \\
\text { operacionais. } \\
\text { Inspeções de } \\
\text { qualidade }\end{array}$ & $\begin{array}{l}\text { Este item deve ser inspecionado } \\
\text { em controle de qualidade. } \\
\text { Estudos e testes para a } \\
\text { averiguação da dinâmica do } \\
\text { movimento. }\end{array}$ & 1 & \\
\hline$\underbrace{0}_{\text {U }}$ & & & & $\begin{array}{c}\text { Erro de } \\
\text { manutenção }\end{array}$ & & & & & $\begin{array}{l}\text { Inspeção em } \\
\text { manutenção }\end{array}$ & $\begin{array}{l}\text { Este item deve ser inspecionado } \\
\text { em manutenção. Deve haver } \\
\text { manual com informações claras. }\end{array}$ & 1 & \\
\hline 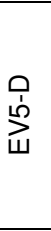 & & & \multirow[t]{2}{*}{$\begin{array}{l}\text { Junção - } \\
\text { desgastad } \\
\text { a }\end{array}$} & $\begin{array}{l}\text { Erro de } \\
\text { especificação de } \\
\text { projeto }\end{array}$ & \multirow[t]{2}{*}{$\begin{array}{c}\text { Em } \\
\text { movimento }\end{array}$} & \multirow[t]{2}{*}{$\begin{array}{l}\text { Componente } \\
\text { não une os } \\
\text { trilhos pelo } \\
\text { período } \\
\text { determinado }\end{array}$} & \multirow{2}{*}{$\begin{array}{l}\text { Aumento da } \\
\text { bitola ou } \\
\text { quando em } \\
\text { diversos } \\
\text { itens rotação } \\
\text { do trilho. } \\
\text { Pode causar } \\
\text { descontinuid } \\
\text { ade do trilho }\end{array}$} & \multirow{2}{*}{$\begin{array}{c}\text { Pode ocorrer } \\
\text { descarrilamento } \\
\text { pela } \\
\text { descontinuidade do } \\
\text { trilho. } \\
\text { Possível } \\
\text { descarrilamento por } \\
\text { aumento da bitola } \\
\text { ou rotação do trilho. }\end{array}$} & $\begin{array}{l}\text { Simulação do } \\
\text { movimento. } \\
\text { Testes } \\
\text { operacionais. } \\
\text { Simulações } \\
\text { computacionais. }\end{array}$ & $\begin{array}{l}\text { Estudos e testes para a } \\
\text { averiguação da dinâmica do } \\
\text { movimento. } \\
\text { Pedido de certificados, por } \\
\text { exemplo, dos materiais } \\
\text { utilizados. }\end{array}$ & 1 & \\
\hline 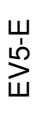 & & & & $\begin{array}{l}\text { Erro de } \\
\text { manutenção }\end{array}$ & & & & & $\begin{array}{l}\text { Inspeção em } \\
\text { manutenção }\end{array}$ & $\begin{array}{l}\text { Este item deve ser inspecionado } \\
\text { em manutenção. Deve haver } \\
\text { manual com informações claras. }\end{array}$ & 1 & \\
\hline 㭊 & & & \multirow{2}{*}{$\begin{array}{l}\text { Junção - } \\
\text { Vibração } \\
\text { excessiva }\end{array}$} & $\begin{array}{l}\text { Erro de } \\
\text { montagem }\end{array}$ & $\begin{array}{c}\text { Em } \\
\text { movimento }\end{array}$ & \multirow{2}{*}{$\begin{array}{l}\text { Componente } \\
\text { não une os } \\
\text { trilhos pelo } \\
\text { período } \\
\text { determinado }\end{array}$} & \multirow{2}{*}{$\begin{array}{l}\text { Aumento da } \\
\text { bitola ou } \\
\text { quando em } \\
\text { diversos } \\
\text { itens rotação } \\
\text { do trilho. } \\
\text { Pode causar } \\
\text { descontinuid } \\
\text { ade do trilho }\end{array}$} & \multirow{2}{*}{$\begin{array}{c}\text { Pode ocorrer } \\
\text { descarrilamento } \\
\text { pela } \\
\text { descontinuidade do } \\
\text { trilho. } \\
\text { Possível } \\
\text { descarrilamento por } \\
\text { aumento da bitola } \\
\text { ou rotação do trilho. }\end{array}$} & $\begin{array}{l}\text { Simulação do } \\
\text { movimento. } \\
\text { Testes } \\
\text { operacionais. } \\
\text { Inspeções de } \\
\text { qualidade } \\
\end{array}$ & $\begin{array}{l}\text { Este item deve ser inspecionado } \\
\text { em controle de qualidade. } \\
\text { Estudos e testes para a } \\
\text { averiguação da dinâmica do } \\
\text { movimento. }\end{array}$ & I & \\
\hline 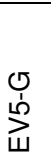 & & & & $\begin{array}{c}\text { Erro de } \\
\text { manutenção }\end{array}$ & & & & & $\begin{array}{l}\text { Inspeção em } \\
\text { manutenção }\end{array}$ & $\begin{array}{l}\text { Este item deve ser inspecionado } \\
\text { em manutenção. Deve haver } \\
\text { manual com informações claras. }\end{array}$ & 1 & \\
\hline
\end{tabular}


continuação

\begin{tabular}{|c|c|c|c|c|c|c|c|c|c|c|c|c|}
\hline \multicolumn{13}{|c|}{ Sistema: Elementos de Via } \\
\hline \multirow{2}{*}{ ID } & \multirow{2}{*}{ Item } & \multirow{2}{*}{ Função } & \multirow{2}{*}{$\begin{array}{l}\text { Modo de } \\
\text { Falha }\end{array}$} & \multirow{2}{*}{$\begin{array}{l}\text { Causas } \\
\text { prováveis }\end{array}$} & \multirow{2}{*}{$\begin{array}{c}\text { Modo } \\
\text { Operacional }\end{array}$} & \multicolumn{3}{|c|}{ Efeito das Falhas } & \multirow{2}{*}{$\begin{array}{l}\text { Modo de } \\
\text { Detecção }\end{array}$} & \multirow{2}{*}{ Ação de Gerenciamento } & \multirow{2}{*}{ Sev } & \multirow{2}{*}{ Notas } \\
\hline & & & & & & Item & Sistema & Trem & & & & \\
\hline 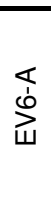 & \multirow{6}{*}{ 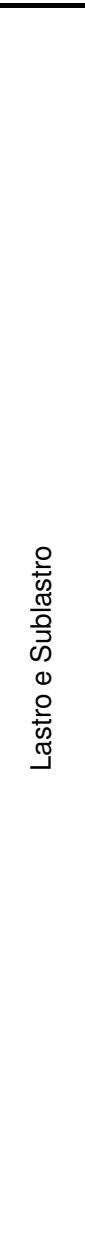 } & \multirow{6}{*}{ 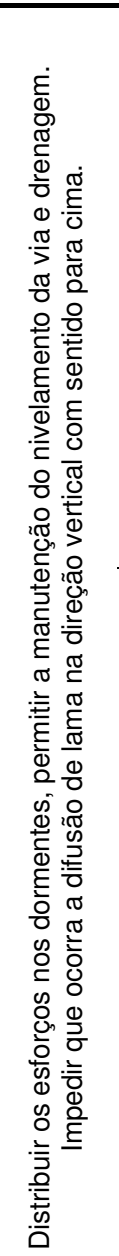 } & \multirow{3}{*}{$\begin{array}{l}\text { Ruptura } \\
\text { geral }\end{array}$} & $\begin{array}{l}\text { Uso de material } \\
\text { de qualidade ruim }\end{array}$ & \multirow{3}{*}{$\begin{array}{c}\text { Em } \\
\text { movimento }\end{array}$} & \multirow{3}{*}{$\begin{array}{l}\text { Pode ocorrer } \\
\text { deslocamento } \\
\text { do material } \\
\text { para o lado da } \\
\text { via ou para a } \\
\text { região entre os } \\
\text { dormentes }\end{array}$} & \multirow{3}{*}{$\begin{array}{l}\text { Desnível } \\
\text { na via }\end{array}$} & \multirow{3}{*}{$\begin{array}{c}\text { Pode ocorrer o } \\
\text { descarrilamento } \\
\text { devido ao desnível e } \\
\text { descontinuidade da } \\
\text { via causando } \\
\text { instabilidade no } \\
\text { movimento }\end{array}$} & $\begin{array}{l}\text { Controle de } \\
\text { qualidade dos } \\
\text { itens. } \\
\text { Inspeção em } \\
\text { manutenção }\end{array}$ & $\begin{array}{l}\text { Exigência de certificados de qualidade } \\
\text { e correto definição de processos e } \\
\text { parâmetros. }\end{array}$ & 1 & \\
\hline$\sum_{\text {ய }}^{\infty}$ & & & & $\begin{array}{l}\text { Erro de } \\
\text { especificação de } \\
\text { projeto }\end{array}$ & & & & & $\begin{array}{l}\text { Simulação do } \\
\text { movimento. } \\
\text { Testes } \\
\text { operacionais. }\end{array}$ & $\begin{array}{l}\text { Este item deve ser inspecionado em } \\
\text { controle de qualidade } \\
\text { Estudos e testes para a averiguação } \\
\text { da dinâmica do movimento. }\end{array}$ & 1 & \\
\hline 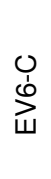 & & & & $\begin{array}{l}\text { Erro de } \\
\text { construção ou } \\
\text { manutenção }\end{array}$ & & & & & $\begin{array}{l}\text { Testes } \\
\text { operacionais. } \\
\text { Inspeções em } \\
\text { manutenção }\end{array}$ & $\begin{array}{l}\text { Este item deve ser inspecionado em } \\
\text { controle de qualidade e manutenção } \\
\text { Estudos e testes para a averiguação } \\
\text { da dinâmica do movimento. }\end{array}$ & I & \\
\hline$\sum_{\text {iे }}^{0}$ & & & \multirow{3}{*}{$\begin{array}{l}\text { ruptura do } \\
\text { lastro. }\end{array}$} & $\begin{array}{l}\text { Uso de material } \\
\text { de má qualidade }\end{array}$ & \multirow{3}{*}{$\begin{array}{l}\text { Em } \\
\text { movimento }\end{array}$} & \multirow{3}{*}{$\begin{array}{l}\text { Acúmulo de } \\
\text { partículas finas } \\
\text { produzidas } \\
\text { pelo desgaste } \\
\text { do lastro ou de } \\
\text { algum outro } \\
\text { depósito, } \\
\text { impedindo a } \\
\text { drenagem } \\
\text { podendo } \\
\text { causar a } \\
\text { formação de } \\
\text { lubrificante. }\end{array}$} & \multirow{3}{*}{$\begin{array}{l}\text { Desnível } \\
\text { na via }\end{array}$} & \multirow{3}{*}{$\begin{array}{c}\text { Pode ocorrer o } \\
\text { descarrilamento } \\
\text { devido ao desnível e } \\
\text { descontinuidade da } \\
\text { via causando } \\
\text { instabilidade no } \\
\text { movimento }\end{array}$} & $\begin{array}{l}\text { Controle de } \\
\text { qualidade dos } \\
\text { itens. } \\
\text { Inspeção em } \\
\text { manutenção }\end{array}$ & $\begin{array}{l}\text { Este item deve ser inspecionado em } \\
\text { controle de qualidade e manutenção }\end{array}$ & 1 & \\
\hline 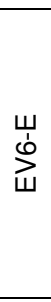 & & & & $\begin{array}{l}\text { Erro de } \\
\text { especificação de } \\
\text { projeto }\end{array}$ & & & & & $\begin{array}{l}\text { Simulação do } \\
\text { movimento. } \\
\text { Testes } \\
\text { operacionais. } \\
\text { Inspeções em } \\
\text { manutenção }\end{array}$ & $\begin{array}{l}\text { Neste caso, o dimensionamento das } \\
\text { camadas para se evitar esta falha } \\
\text { pode ser realizado através do uso de } \\
\text { fatores de segurança ou através da } \\
\text { confiabilidade estrutural. } \\
\text { Este item deve ser inspecionado em } \\
\text { controle de qualidade e manutenção } \\
\text { Estudos e testes para a averiguação } \\
\text { da dinâmica do movimento. }\end{array}$ & 1 & \\
\hline 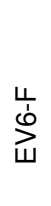 & & & & $\begin{array}{l}\text { Erro de } \\
\text { construção ou } \\
\text { manutenção }\end{array}$ & & & & & $\begin{array}{l}\text { Simulação do } \\
\text { movimento. } \\
\text { Testes } \\
\text { operacionais. } \\
\text { Inspeções em } \\
\text { manutenção }\end{array}$ & $\begin{array}{l}\text { Este item deve ser inspecionado em } \\
\text { controle de qualidade e manutençãã } \\
\text { Estudos e testes para a averiguação } \\
\text { da dinâmica do movimento. }\end{array}$ & I & \\
\hline
\end{tabular}


conclusão

\begin{tabular}{|c|c|c|c|c|c|c|c|c|c|c|c|c|}
\hline \multicolumn{13}{|c|}{ Sistema: Elementos de Via } \\
\hline \multirow{2}{*}{ ID } & \multirow{2}{*}{ Item } & \multirow{2}{*}{ Função } & \multirow{2}{*}{$\begin{array}{l}\text { Modo de } \\
\text { Falha }\end{array}$} & \multirow{2}{*}{$\begin{array}{l}\text { Causas } \\
\text { prováveis }\end{array}$} & \multirow{2}{*}{$\begin{array}{c}\text { Modo } \\
\text { Operacional }\end{array}$} & \multicolumn{3}{|c|}{ Efeito das Falhas } & \multirow{2}{*}{$\begin{array}{l}\text { Modo de } \\
\text { Detecção }\end{array}$} & \multirow{2}{*}{ Ação de Gerenciamento } & \multirow{2}{*}{ Sev } & \multirow{2}{*}{ Notas } \\
\hline & & & & & & Item & Sistema & Trem & & & & \\
\hline$\frac{⿱ 亠}{1}$ & \multirow{4}{*}{ 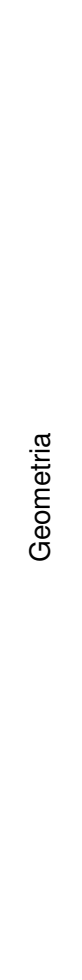 } & \multirow{4}{*}{ 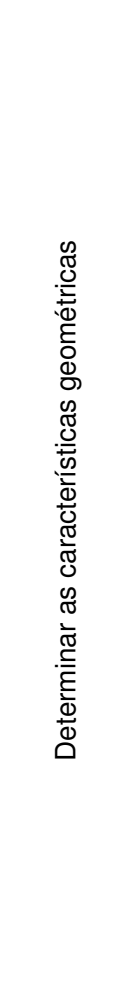 } & \multirow{2}{*}{$\begin{array}{l}\text { Raio da } \\
\text { curva } \\
\text { menor } \\
\text { que o } \\
\text { mínimo }\end{array}$} & $\begin{array}{l}\text { Erro de } \\
\text { especificação de } \\
\text { projeto }\end{array}$ & $\begin{array}{c}\text { Em } \\
\text { movimento }\end{array}$ & \multirow[t]{2}{*}{-} & \multirow{2}{*}{$\begin{array}{c}\text { Não limita o } \\
\text { escorregament } \\
\text { o entre o trilho } \\
\text { e rodas. } \\
\text { Pode permitir a } \\
\text { inscrição da } \\
\text { base rígido dos } \\
\text { truques do } \\
\text { carro. }\end{array}$} & \multirow{2}{*}{$\begin{array}{l}\text { Possível } \\
\text { descarrilamento por } \\
\text { sobreposição do } \\
\text { flange }\end{array}$} & $\begin{array}{l}\text { Simulação do } \\
\text { movimento. } \\
\text { Testes } \\
\text { operacionais. } \\
\text { Simulações } \\
\text { computacionais. }\end{array}$ & $\begin{array}{l}\text { Estudos e testes para a } \\
\text { averiguação da dinâmica do } \\
\text { movimento. }\end{array}$ & 1 & \multirow{2}{*}{$\begin{array}{c}\text { Apesar da } \\
\text { geometria não } \\
\text { se tratar de um } \\
\text { elemento de } \\
\text { via, por poder } \\
\text { apresentar } \\
\text { falhas que } \\
\text { causam o } \\
\text { descarrilament } \\
\text { o, é abordado } \\
\text { no FMEA } \\
\text { também }\end{array}$} \\
\hline$\stackrel{\substack{1 \\
⿱}}{\text { m }}$ & & & & $\begin{array}{l}\text { Erro de } \\
\text { montagem }\end{array}$ & $\begin{array}{c}\text { Em } \\
\text { movimento }\end{array}$ & & & & $\begin{array}{l}\text { Controle de } \\
\text { qualidade dos } \\
\text { itens. } \\
\text { Testes } \\
\text { operacionais. }\end{array}$ & $\begin{array}{c}\text { Este item deve ser } \\
\text { inspecionado em controle } \\
\text { de qualidade. } \\
\text { Estudos e testes para a } \\
\text { averiguação da dinâmica do } \\
\text { movimento. }\end{array}$ & 1 & \\
\hline 足 & & & \multirow{2}{*}{$\begin{array}{l}\text { Sobre- } \\
\text { elevação } \\
\text { elevada }\end{array}$} & $\begin{array}{l}\text { Erro de } \\
\text { especificação de } \\
\text { projeto }\end{array}$ & $\begin{array}{c}\text { Em } \\
\text { movimento }\end{array}$ & \multirow{2}{*}{-} & \multirow{2}{*}{$\begin{array}{l}\text { Maior momento } \\
\text { instabilizador }\end{array}$} & \multirow{2}{*}{$\begin{array}{c}\text { Maior probabilidade } \\
\text { de descarrilamento } \\
\text { devido ao } \\
\text { tombamento do trem }\end{array}$} & $\begin{array}{l}\text { Simulação do } \\
\text { movimento. } \\
\text { Testes } \\
\text { operacionais. } \\
\text { Simulações } \\
\text { computacionais. }\end{array}$ & $\begin{array}{l}\text { Estudos e testes para a } \\
\text { averiguação da dinâmica do } \\
\text { movimento. }\end{array}$ & 1 & \multirow{2}{*}{$\begin{array}{c}\text { Apesar da } \\
\text { geometria não } \\
\text { se tratar de um } \\
\text { elemento de } \\
\text { via, por poder } \\
\text { apresentar } \\
\text { falhas que } \\
\text { causam o } \\
\text { descarrilament } \\
\text { o, é abordado } \\
\text { no FMEA } \\
\text { também }\end{array}$} \\
\hline$\stackrel{0}{\stackrel{2}{1}}$ & & & & $\begin{array}{l}\text { Erro de } \\
\text { montagem }\end{array}$ & $\begin{array}{c}\text { Em } \\
\text { movimento }\end{array}$ & & & & $\begin{array}{l}\text { Controle de } \\
\text { qualidade dos } \\
\text { itens. } \\
\text { Testes } \\
\text { operacionais. }\end{array}$ & $\begin{array}{c}\text { Este item deve ser } \\
\text { inspecionado em controle } \\
\text { de qualidade. } \\
\text { Estudos e testes para a } \\
\text { averiguação da dinâmica do } \\
\text { movimento. }\end{array}$ & 1 & \\
\hline
\end{tabular}


Em suma, as ações de gerenciamento recomendadas na Tabela 6.2 são:

- projeto que respeita os critérios de descarrilamento (item 4.1) bem como os devidos fatores de segurança, que podem ser calculados pelo método probabilístico condicionado avançado (item 2.1.4.2);

- estudos e testes para a averiguação da dinâmica do movimento (mais detalhes já apresentados em 5.1);

- correta determinação do processo de fabricação, por exemplo utilizando-se massalotes para evitar o fenômeno de vazio ou uso de material adequado para evitar a segregação ou ainda utilizar a ferramenta intitulada FMECA de processo conforme discussão em 7.2.1;

- inspeção durante a manufatura, podendo ser realizadas pelo controle de qualidade dos componentes fabricados bem como a exigência de certificados disponibilizados pelos fornecedores quanto à qualidade de produto fabricado (mais detalhes em 7.2.2);

- correta manutenção dos sistemas e componentes, fornecendo treinamento às equipes de manutenção e documentação coerente e clara para esta atividade, sendo que para tal pode-se seguir a manutenção centrada em confiabilidade conforme item 7.4.1;

- inserção de sinalização e intertravamento quanto à posição dos aparelhos de via.

\subsection{2 - COMPONENTES DO TRUQUE}

A árvore de falhas referente ao sistema truque está apresentada na Figura 6.3. Nesta figura são representadas as combinações de falhas referentes ao truque que podem geram um descarrilamento. 


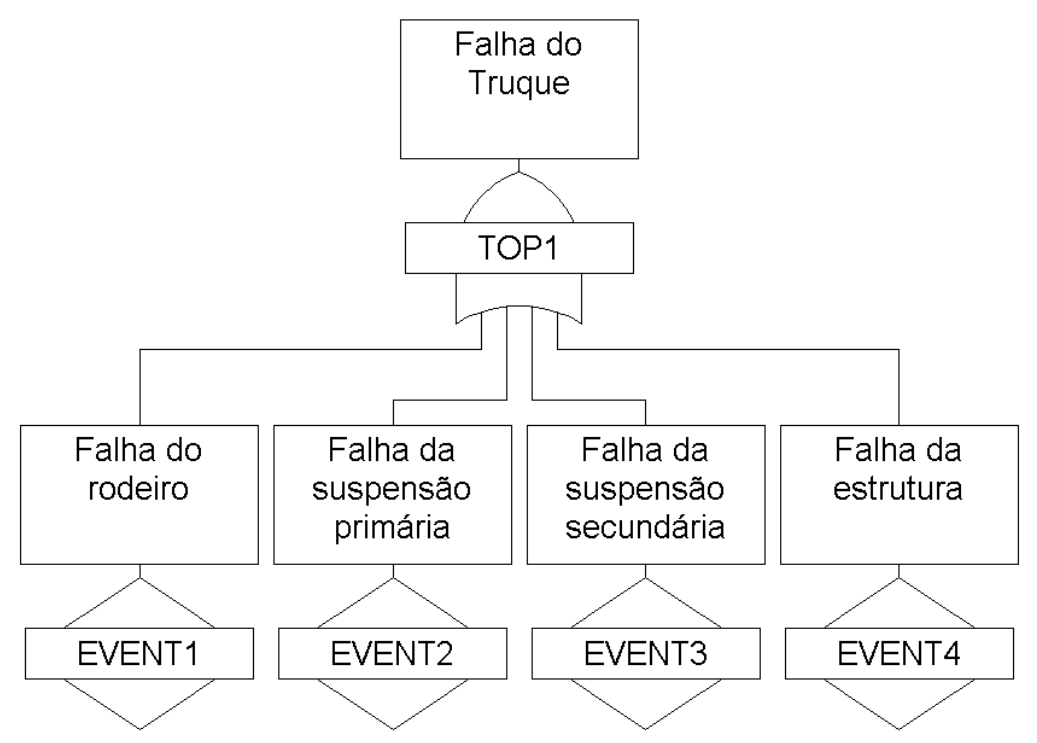

Figura 6.3 - FTA - Falha do Truque

Elaborada a árvore de falha, deve ser implementada a análise do tipo FMEA. Para esta implementação foram considerados diversos modos de falha, sendo que a referência mais utilizada para os mesmos foi a FMD-97 (1997). No APÊNDICE E são apresentados os trechos deste banco de dados referentes a componentes descritos nesta tabela. Além disso, alguns modos de falha apresentados na referência foram agrupados de acordo com o julgamento realizado e explicado no referido anexo. Uma parte das referências dos modos de falha foi proveniente de hipóteses e outras da Reliability Toolkit (1995). Já o modo de falha da suspensão primária e secundária foi simplificada para os modos de falha de uma mola.

A Tabela 6.3 apresenta os modos de falha para cada item/componente, contemplando também uma descrição de cada modo de falha e da fonte de referência que foi obtido o respectivo modo de falha. 
Tabela 6.3 - Sistema Truque - Modos de falha considerados e referências

\begin{tabular}{|c|c|c|c|c|}
\hline Item & Função & Modo de Falha & Descrição & FONTE \\
\hline \multirow{8}{*}{ Rodeiro } & \multirow{8}{*}{$\begin{array}{l}\text { Movimentar o } \\
\text { trem através } \\
\text { da sua rotação } \\
\text { em torno do } \\
\text { eixo axial }\end{array}$} & Quebra da roda & $\begin{array}{l}\text { Ruptura estrutural da roda devido } \\
\text { à quebra do componente ou } \\
\text { trincas que podem comprometer o } \\
\text { componente. }\end{array}$ & $\begin{array}{l}\text { FMD-97 } \\
(1997)\end{array}$ \\
\hline & & $\begin{array}{l}\text { Roda - alteração da } \\
\text { geometria }\end{array}$ & Alteração da geometria da roda & $\begin{array}{l}\text { FMD-97 } \\
(1997)\end{array}$ \\
\hline & & $\begin{array}{l}\text { eixo - marcado / } \\
\text { arranhado }\end{array}$ & $\begin{array}{l}\text { Eixo marcado (podendo ser } \\
\text { marcas de grande profundidade) } \\
\text { ou arranhado de modo a poder } \\
\text { causar ruptura ou travamento do } \\
\text { eixo }\end{array}$ & $\begin{array}{l}\text { FMD-97 } \\
(1997)\end{array}$ \\
\hline & & eixo - distorcido & Alteração da geometria & $\begin{array}{l}\text { FMD-97 } \\
(1997)\end{array}$ \\
\hline & & $\begin{array}{l}\text { eixo - dano } \\
\text { mecânico }\end{array}$ & Eixo com danos & $\begin{array}{l}\text { FMD-97 } \\
(1997)\end{array}$ \\
\hline & & rolamento - travado & $\begin{array}{l}\text { Rolamento não permite ou dificulta } \\
\text { a rotação }\end{array}$ & $\begin{array}{l}\text { Reliability } \\
\text { Toolkit } \\
\text { (1995) }\end{array}$ \\
\hline & & $\begin{array}{l}\text { rolamento - folga } \\
\text { excessiva }\end{array}$ & $\begin{array}{l}\text { Rolamento com jogo ou folga } \\
\text { excessiva }\end{array}$ & $\begin{array}{l}\text { Reliability } \\
\text { Toolkit } \\
\text { (1995) }\end{array}$ \\
\hline & & $\begin{array}{l}\text { Rolamento - } \\
\text { contaminado }\end{array}$ & $\begin{array}{l}\text { Lubrificação do rolamento } \\
\text { contaminado, podendo causar } \\
\text { aquecimento e travamento }\end{array}$ & $\begin{array}{l}\text { Reliability } \\
\text { Toolkit } \\
\text { (1995) }\end{array}$ \\
\hline \multirow{5}{*}{$\begin{array}{l}\text { Suspensão } \\
\text { Primária e } \\
\text { Secundária }\end{array}$} & \multirow{5}{*}{$\begin{array}{l}\text { Filtrar as } \\
\text { primeiras } \\
\text { vibrações } \\
\text { Isolar as } \\
\text { vibrações de } \\
\text { baixa } \\
\text { freqüência } \\
\text { provenientes } \\
\text { da armação do } \\
\text { truque }\end{array}$} & Mola - quebra & Quebra ou dano severo a mola & $\begin{array}{l}\text { FMD-97 } \\
(1997)\end{array}$ \\
\hline & & $\begin{array}{l}\text { mola - inoperante } \\
\text { por enfraquecimento }\end{array}$ & $\begin{array}{l}\text { Mola inoperante devido a } \\
\text { travamento da mesma, jogo } \\
\text { excessivo. }\end{array}$ & $\begin{array}{l}\text { FMD-97 } \\
(1997)\end{array}$ \\
\hline & & mola - marcada & Mola marcada em sua superfície & $\begin{array}{l}\text { FMD-97 } \\
(1997)\end{array}$ \\
\hline & & $\begin{array}{l}\text { mola - uso além da } \\
\text { vida útil }\end{array}$ & $\begin{array}{l}\text { Mola desgastada por uso além da } \\
\text { vida útil ou em condições mais } \\
\text { severas. }\end{array}$ & $\begin{array}{l}\text { FMD-97 } \\
(1997)\end{array}$ \\
\hline & & mola - corroída & $\begin{array}{l}\text { Mola corroída devido ao indevido } \\
\text { ambiente exposto }\end{array}$ & $\begin{array}{l}\text { FMD-97 } \\
(1997)\end{array}$ \\
\hline \multirow[t]{2}{*}{ Estrutura } & \multirow{2}{*}{$\begin{array}{l}\text { Fixar todos os } \\
\text { outros } \\
\text { elementos do } \\
\text { truque }\end{array}$} & Ruptura Estrutural & $\begin{array}{l}\text { Ruptura estrutural devido à quebra } \\
\text { do componente por sobrecarga ou } \\
\text { propagação de trincas que podem } \\
\text { comprometer o componente. }\end{array}$ & Hipótese \\
\hline & & $\begin{array}{l}\text { Mudança de } \\
\text { geometria }\end{array}$ & $\begin{array}{l}\text { Alteração da geometria da } \\
\text { estrutura }\end{array}$ & Hipótese \\
\hline
\end{tabular}

A Tabela 6.4 refere-se a análise do tipo FMEA para os sistema Truque. 
Tabela 6.4: FMEA Sistema Truque

continua

\begin{tabular}{|c|c|c|c|c|c|c|c|c|c|c|c|c|}
\hline \multicolumn{13}{|c|}{ Sistema: Truque } \\
\hline \multirow{2}{*}{ ID } & \multirow{2}{*}{ Item } & \multirow{2}{*}{ Função } & \multirow{2}{*}{$\begin{array}{l}\text { Modo de } \\
\text { Falha }\end{array}$} & \multirow{2}{*}{$\begin{array}{l}\text { Causas } \\
\text { prováveis }\end{array}$} & \multirow{2}{*}{$\begin{array}{c}\text { Modo } \\
\text { Operacional }\end{array}$} & \multicolumn{3}{|c|}{ Efeito das Falhas } & \multirow{2}{*}{ Modo de Detecção } & \multirow{2}{*}{ Ação de Gerenciamento } & \multirow{2}{*}{ Sev } & \multirow{2}{*}{ Notas } \\
\hline & & & & & & Item & Sistema & Trem & & & & \\
\hline$\frac{\mathbb{r}}{\stackrel{I}{r}}$ & \multirow{6}{*}{$\begin{array}{l}\frac{.0}{\overline{0}} \\
\frac{0}{0} \\
\check{\Upsilon}\end{array}$} & \multirow{6}{*}{ 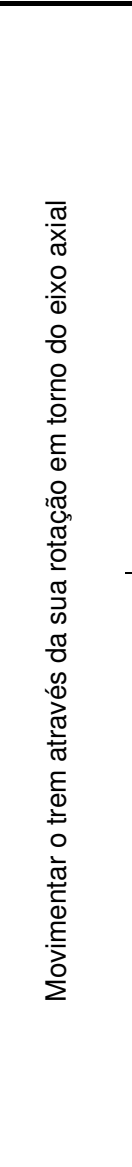 } & \multirow{3}{*}{$\begin{array}{l}\text { Quebra da } \\
\text { roda }\end{array}$} & $\begin{array}{l}\text { Falha de } \\
\text { projeto }\end{array}$ & \multirow{3}{*}{$\begin{array}{c}\text { Em } \\
\text { movimento }\end{array}$} & \multirow{3}{*}{$\begin{array}{c}\text { Rodeiro } \\
\text { sem } 1 \\
\text { roda }\end{array}$} & \multirow{3}{*}{$\begin{array}{c}\text { Truque } \\
\text { comprometido }\end{array}$} & \multirow{3}{*}{$\begin{array}{c}\text { Pode ocorrer } \\
\text { descarrilamento } \\
\text { devido a queda de } \\
\text { componente na via } \\
\text { ou causar a rotação } \\
\text { indevida da caixa } \\
\text { com conseqüente } \\
\text { desbalanceamento } \\
\text { e descarrilamento }\end{array}$} & $\begin{array}{c}\text { Detectável por medições } \\
\text { dos parâmetros de projeto e } \\
\text { por verificação dos } \\
\text { certificados e cálculos de } \\
\text { projeto. }\end{array}$ & $\begin{array}{l}\text { O projeto deve dimensionar a } \\
\text { correta força de prensagem das } \\
\text { rodas (dimensionando a } \\
\text { interferência). Durante montagem } \\
\text { deve haver respeito aos } \\
\text { parâmetros definidos em projeto. }\end{array}$ & I & \\
\hline 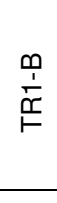 & & & & $\begin{array}{l}\text { Falha de } \\
\text { manufatura }\end{array}$ & & & & & $\begin{array}{c}\text { Detectável por inspeção } \\
\text { periódica ou durante } \\
\text { inspeção de qualidade de } \\
\text { fabricação se houverem } \\
\text { trincas superficiais ou por } \\
\text { ultra-som. } \\
\end{array}$ & $\begin{array}{l}\text { Inspeção de qualidade de } \\
\text { fabricação do elemento e } \\
\text { inspeções periódicas da } \\
\text { manufatura. }\end{array}$ & I & \\
\hline$\frac{0}{\frac{1}{x}}$ & & & & $\begin{array}{l}\text { Falha na } \\
\text { manutenção }\end{array}$ & & & & & $\begin{array}{l}\text { Detectável por inspeção } \\
\text { periódica se houverem } \\
\text { trincas superficiais ou por } \\
\text { ultra-som. }\end{array}$ & $\begin{array}{l}\text { Deve ser verificado em inspeções } \\
\text { periódicas. } \\
\text { O manual de manutenção deve } \\
\text { contemplar a correta manutenção } \\
\text { do truque. }\end{array}$ & I & \\
\hline $\begin{array}{l}\stackrel{\mathbb{i}}{\tilde{\sim}} \\
\stackrel{\check{F}}{\vdash}\end{array}$ & & & \multirow{3}{*}{$\begin{array}{l}\text { Roda - } \\
\text { alteração da } \\
\text { geometria }\end{array}$} & $\begin{array}{l}\text { Falha de } \\
\text { projeto }\end{array}$ & \multirow{3}{*}{$\begin{array}{c}\text { Em } \\
\text { movimento }\end{array}$} & \multirow{3}{*}{$\begin{array}{l}\text { Alteração } \\
\text { das } \\
\text { característ } \\
\text { icas } \\
\text { geométric } \\
\text { as da roda } \\
\text { (exemplo: } \\
\text { deformaçã } \\
\text { o) }\end{array}$} & \multirow{3}{*}{$\begin{array}{l}\text { Movimentação } \\
\text { irregular do } \\
\text { truque, } \\
\text { vibração e } \\
\text { alteração das } \\
\text { características } \\
\text { dinâmicas }\end{array}$} & \multirow{3}{*}{$\begin{array}{c}\text { Pode ocorrer } \\
\text { sobreposição do } \\
\text { flange e/ou } \\
\text { instabilidade lateral } \\
\text { do veículo e } \\
\text { possível } \\
\text { descarrilamento }\end{array}$} & $\begin{array}{c}\text { Detectável por medições } \\
\text { dos parâmetros de projeto e } \\
\text { por verificação dos } \\
\text { certificados e cálculos de } \\
\text { projeto. }\end{array}$ & $\begin{array}{l}\text { O projeto deve seguir as normas } \\
\text { aplicáveis para perfil de roda. } \\
\text { Durante fabricação deve haver } \\
\text { respeito aos parâmetros definidos } \\
\text { em projeto. }\end{array}$ & I & \\
\hline $\begin{array}{l}\stackrel{m}{1} \\
\tilde{\sim} \\
\stackrel{\sim}{\vdash}\end{array}$ & & & & $\begin{array}{l}\text { Falha de } \\
\text { manufatura }\end{array}$ & & & & & $\begin{array}{l}\text { Detectável por inspeção } \\
\text { periódica ou durante } \\
\text { inspeção de qualidade de } \\
\text { fabricação. }\end{array}$ & $\begin{array}{l}\text { Inspeção de qualidade de } \\
\text { fabricação do elemento e } \\
\text { inspeções periódicas da } \\
\text { manufatura. }\end{array}$ & I & \\
\hline $\begin{array}{l}u \\
\stackrel{\sim}{\sim} \\
\stackrel{\sim}{\vdash}\end{array}$ & & & & $\begin{array}{l}\text { Falha na } \\
\text { manutenção }\end{array}$ & & & & & $\begin{array}{l}\text { Ruído em operação. } \\
\text { Calo na roda. } \\
\text { Detectável também em } \\
\text { inspeções periódicas. }\end{array}$ & $\begin{array}{c}\text { Deve ser verificado em inspeções } \\
\text { periódicas. } \\
\text { O manual de manutenção deve } \\
\text { contemplar a correta manutenção } \\
\text { do truque. }\end{array}$ & I & \\
\hline
\end{tabular}


continuação

\begin{tabular}{|c|c|c|c|c|c|c|c|c|c|c|c|c|}
\hline \multicolumn{13}{|c|}{ Sistema: Truque } \\
\hline \multirow{2}{*}{ ID } & \multirow{2}{*}{ Item } & \multirow{2}{*}{ Função } & \multirow{2}{*}{ Modo de Falha } & \multirow{2}{*}{$\begin{array}{l}\text { Causas } \\
\text { prováveis }\end{array}$} & \multirow{2}{*}{$\begin{array}{c}\text { Modo } \\
\text { Operacional }\end{array}$} & \multicolumn{3}{|c|}{ Efeito das Falhas } & \multirow{2}{*}{ Modo de Detecção } & \multirow{2}{*}{ Ação de Gerenciamento } & \multirow{2}{*}{ Sev } & \multirow{2}{*}{ Notas } \\
\hline & & & & & & Item & Sistema & Trem & & & & \\
\hline $\begin{array}{l}\stackrel{\leftarrow}{\infty} \\
\stackrel{\Upsilon}{F} \\
\vdash\end{array}$ & & & & $\begin{array}{l}\text { Falha de } \\
\text { projeto }\end{array}$ & & & & & $\begin{array}{l}\text { Detectável por } \\
\text { verificação dos } \\
\text { certificados e cálculos } \\
\text { de projeto }\end{array}$ & $\begin{array}{l}\text { O projeto deve considerar as } \\
\text { corretas solicitações que o trem } \\
\text { escolhendo corretamente o } \\
\text { material, processo de fabricação } \\
\text { e dimensões. }\end{array}$ & 1 & \\
\hline 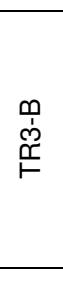 & & 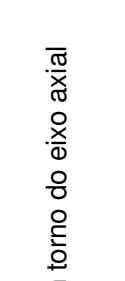 & $\begin{array}{l}\text { eixo - marcado / } \\
\text { arranhado (que } \\
\text { possa levar a } \\
\text { ruptura/ dano } \\
\text { mecânico severo) } \\
\text { eixo - dano } \\
\text { mecânico }\end{array}$ & $\begin{array}{l}\text { Falha de } \\
\text { manufatura }\end{array}$ & $\begin{array}{l}\text { Em } \\
\text { movimento }\end{array}$ & $\begin{array}{l}\text { Caso seja } \\
\text { apenas marcas } \\
\text { leves não há } \\
\text { efeito. Em caso } \\
\text { de marcas } \\
\text { mais profundas } \\
\text { ou dano } \\
\text { mecânico } \\
\text { severo, ocorre }\end{array}$ & $\begin{array}{c}\text { Truque } \\
\text { comprometido }\end{array}$ & $\begin{array}{c}\text { Pode ocorrer } \\
\text { descarrilamento } \\
\text { devido à queda de } \\
\text { componente na via } \\
\text { ou causar a rotação } \\
\text { indevida da caixa } \\
\text { com conseqüente } \\
\text { desbalanceamento }\end{array}$ & $\begin{array}{c}\text { Detectável por } \\
\text { inspeção periódica ou } \\
\text { durante inspeção de } \\
\text { qualidade de } \\
\text { fabricação se } \\
\text { houverem trincas } \\
\text { superficiais ou por } \\
\text { ultra-som }\end{array}$ & $\begin{array}{l}\text { Inspeção de qualidade de } \\
\text { fabricação do elemento e } \\
\text { inspeções periódicas da } \\
\text { manufatura }\end{array}$ & 1 & \\
\hline 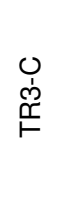 & $\frac{.}{\frac{0}{0}}$ & 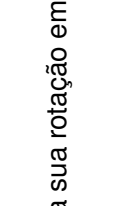 & & $\begin{array}{c}\text { Falha } \\
\text { causada por } \\
\text { uso indevido }\end{array}$ & & ruptura do eixo. & & e descarrilamento & $\begin{array}{l}\text { Detectável por } \\
\text { inspeção periódica se } \\
\text { houverem trincas } \\
\text { superficiais ou por } \\
\text { ultra-som }\end{array}$ & $\begin{array}{l}\text { Deve ser verificado em } \\
\text { inspeções periódicas. } \\
\text { O manuual de manutenção deve } \\
\text { contemplar a correta } \\
\text { manutenção do truque }\end{array}$ & 1 & \\
\hline $\begin{array}{l}\stackrel{\leftarrow}{\dot{i}} \\
\mathbb{I} \\
\stackrel{F}{F}\end{array}$ & & 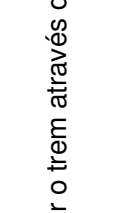 & & $\begin{array}{l}\text { Falha de } \\
\text { projeto }\end{array}$ & & & Movimentação & Pode ocorrer & $\begin{array}{c}\text { Detectável por } \\
\text { medições dos } \\
\text { parâmetros de projeto } \\
\text { e por verificação dos } \\
\text { certificados e cálculos } \\
\text { de projeto } \\
\end{array}$ & $\begin{array}{l}\text { O projeto deve dimensionar } \\
\text { corretamente considerando os } \\
\text { parâmetros de operação. } \\
\text { Durante fabricação deve haver } \\
\text { respeito aos parâmetros } \\
\text { definidos em projeto. }\end{array}$ & 1 & \\
\hline 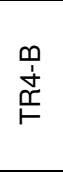 & & 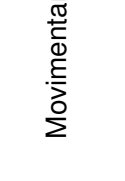 & eixo - distorcido & $\begin{array}{l}\text { Falha de } \\
\text { manufatura }\end{array}$ & $\begin{array}{c}\text { Em } \\
\text { movimento }\end{array}$ & $\begin{array}{l}\text { Alteraçao das } \\
\text { características } \\
\text { geométricas } \\
\text { (exemplo: } \\
\text { deformação) }\end{array}$ & $\begin{array}{l}\text { Irregular do } \\
\text { truque, } \\
\text { vibração e } \\
\text { alteração das } \\
\text { características } \\
\text { dinâmicas }\end{array}$ & $\begin{array}{l}\text { sobreposiçao do } \\
\text { flange elou } \\
\text { instabilidade lateral } \\
\text { do veículo e } \\
\text { possível } \\
\text { descarrilamento }\end{array}$ & $\begin{array}{l}\text { Detectável por } \\
\text { inspeção periódica ou } \\
\text { durante inspeção de } \\
\text { qualidade de } \\
\text { fabricação }\end{array}$ & $\begin{array}{l}\text { Inspeção de qualidade de } \\
\text { fabricação do elemento e } \\
\text { inspeções periódicas da } \\
\text { manufatura }\end{array}$ & 1 & \\
\hline $\begin{array}{l}\text { U } \\
\dot{y} \\
\mathbb{1} \\
\vdash\end{array}$ & & & & $\begin{array}{c}\text { Falha } \\
\text { causada por } \\
\text { uso indevido }\end{array}$ & & & & & $\begin{array}{c}\text { Detectável em } \\
\text { inspeções periódicas }\end{array}$ & $\begin{array}{c}\text { Deve ser verificado em } \\
\text { inspeções periódicas. } \\
\text { O manual de manutenção deve } \\
\text { contemplar a correta } \\
\text { manutenção do truque }\end{array}$ & 1 & \\
\hline
\end{tabular}


continuação

\begin{tabular}{|c|c|c|c|c|c|c|c|c|c|c|c|c|}
\hline \multicolumn{13}{|c|}{ Sistema: Truque } \\
\hline \multirow{2}{*}{ ID } & \multirow{2}{*}{ Item } & \multirow{2}{*}{ Função } & \multirow{2}{*}{$\begin{array}{l}\text { Modo de } \\
\text { Falha }\end{array}$} & \multirow{2}{*}{$\begin{array}{l}\text { Causas } \\
\text { prováveis }\end{array}$} & \multirow{2}{*}{$\begin{array}{c}\text { Modo } \\
\text { Operacional }\end{array}$} & \multicolumn{3}{|c|}{ Efeito das Falhas } & \multirow{2}{*}{ Modo de Detecção } & \multirow{2}{*}{ Ação de Gerenciamento } & \multirow{2}{*}{ Sev } & \multirow{2}{*}{ Notas } \\
\hline & & & & & & Item & Sistema & Trem & & & & \\
\hline $\begin{array}{l}\mathbb{1} \\
\text { 定 } \\
\stackrel{\sim}{F}\end{array}$ & \multirow{6}{*}{\begin{tabular}{l}
$\frac{.}{\overline{1}}$ \\
$\frac{0}{0}$ \\
\hdashline
\end{tabular}} & \multirow{6}{*}{ 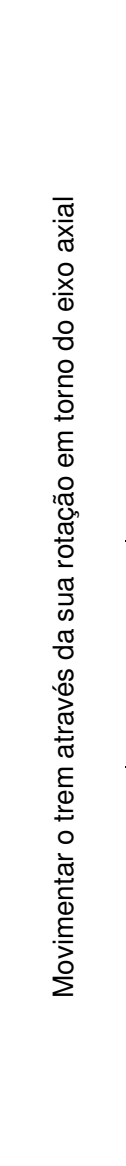 } & \multirow{3}{*}{$\begin{array}{l}\text { rolamento - } \\
\text { travado }\end{array}$} & $\begin{array}{l}\text { Falta de } \\
\text { lubrificação }\end{array}$ & \multirow{3}{*}{$\begin{array}{c}\text { Em } \\
\text { movimento }\end{array}$} & \multirow{3}{*}{$\begin{array}{l}\text { Bloqueio do } \\
\text { rolamento }\end{array}$} & \multirow{3}{*}{$\begin{array}{l}\text { Rodeiro não } \\
\text { se } \\
\text { movimenta }\end{array}$} & \multirow{3}{*}{$\begin{array}{l}\text { Em princípio maior } \\
\text { atrito no eixo com } \\
\text { possível } \\
\text { descarrilamento por } \\
\text { possível } \\
\text { sobreposição do } \\
\text { flange ou } \\
\text { instabilidade lateral }\end{array}$} & $\begin{array}{l}\text { Ruído em operação. } \\
\text { Calo na roda. } \\
\text { Lubrificante com alterações } \\
\text { das características. }\end{array}$ & $\begin{array}{l}\text { Correta Lubrificação dos } \\
\text { rolamentos } \\
\text { Definição dos intervalos de } \\
\text { manutenção }\end{array}$ & I & \\
\hline 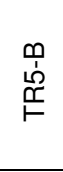 & & & & $\begin{array}{c}\text { Desgaste } \\
\text { indevido / falha de } \\
\text { manutenção }\end{array}$ & & & & & $\begin{array}{l}\text { Ruído em operação. } \\
\text { Calo na roda. } \\
\text { Lubrificante com alterações } \\
\text { das características. }\end{array}$ & $\begin{array}{l}\text { Definir e inspecionar em } \\
\text { corretos períodos de } \\
\text { manutenção }\end{array}$ & I & \\
\hline 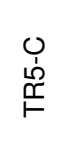 & & & & $\begin{array}{l}\text { Mudança de } \\
\text { Geometria por } \\
\text { solicitações } \\
\text { adversas }\end{array}$ & & & & & $\begin{array}{l}\text { Ruído em operação. } \\
\text { Calo na roda. } \\
\text { Lubrificante com alterações } \\
\text { das características. }\end{array}$ & $\begin{array}{l}\text { Correto cálculo das } \\
\text { solicitações sofridas pelo } \\
\text { rolamento }\end{array}$ & I & \\
\hline $\begin{array}{l}\mathbb{1} \\
\dot{\phi} \\
\underline{q}\end{array}$ & & & $\begin{array}{l}\text { rolamento - } \\
\text { folga } \\
\text { excessiva }\end{array}$ & $\begin{array}{c}\text { Desgaste } \\
\text { indevido / falha de } \\
\text { manutenção }\end{array}$ & $\begin{array}{c}\text { Em } \\
\text { movimento }\end{array}$ & $\begin{array}{l}\text { Rolamento } \\
\text { com jogo ou } \\
\text { folga } \\
\text { excessiva }\end{array}$ & $\begin{array}{l}\text { Rolamento } \\
\text { permite } \\
\text { maior } \\
\text { vibração e } \\
\text { movimento } \\
\text { indevido do } \\
\text { eixo } \\
\end{array}$ & $\begin{array}{c}\text { Pode ocorrer } \\
\text { sobreposição do } \\
\text { flange e/ou } \\
\text { instabilidade lateral } \\
\text { do veículo e } \\
\text { possível } \\
\text { descarrilamento } \\
\end{array}$ & $\begin{array}{l}\text { Alteração das } \\
\text { características } \\
\text { operacionais. } \\
\text { Verificável também em } \\
\text { inspeções periódicas. }\end{array}$ & $\begin{array}{l}\text { Definir e inspecionar em } \\
\text { corretos períodos de } \\
\text { manutenção }\end{array}$ & I & \\
\hline 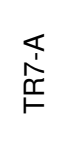 & & & & $\begin{array}{l}\text { Lubrificação } \\
\text { indevida }\end{array}$ & & & & $\begin{array}{l}\text { Em princípio maior } \\
\text { atrito no eixo com }\end{array}$ & $\begin{array}{l}\text { Ruído em operação. } \\
\text { Calo na roda. } \\
\text { Lubrificante com alterações } \\
\text { das características. }\end{array}$ & $\begin{array}{l}\text { Correta Lubrificação dos } \\
\text { rolamentos } \\
\text { Definição dos intervalos de } \\
\text { manutenção }\end{array}$ & I & \\
\hline 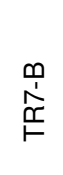 & & & & $\begin{array}{c}\text { Ambiente adverso } \\
\text { quando } \\
\text { comparado ao } \\
\text { projeto }\end{array}$ & movimento & & movimenta & $\begin{array}{c}\text { possivel } \\
\text { sobreposição do } \\
\text { flange ou } \\
\text { instabilidade lateral }\end{array}$ & $\begin{array}{l}\text { Ruído em operação } \\
\text { Calo na roda } \\
\text { Lubrificante com alterações } \\
\text { das características }\end{array}$ & $\begin{array}{l}\text { Correta determinação do } \\
\text { ambiente de operação do } \\
\text { trem }\end{array}$ & I & \\
\hline
\end{tabular}


continuação

\begin{tabular}{|c|c|c|c|c|c|c|c|c|c|c|c|c|}
\hline \multicolumn{13}{|c|}{ Sistema: Truque } \\
\hline \multirow{2}{*}{ ID } & \multirow{2}{*}{ Item } & \multirow{2}{*}{ Função } & \multirow{2}{*}{ Modo de Falha } & \multirow{2}{*}{$\begin{array}{l}\text { Causas } \\
\text { prováveis }\end{array}$} & \multirow{2}{*}{$\begin{array}{c}\text { Modo } \\
\text { Operacional }\end{array}$} & \multicolumn{3}{|c|}{ Efeito das Falhas } & \multirow{2}{*}{ Modo de Detecção } & \multirow{2}{*}{ Ação de Gerenciamento } & \multirow{2}{*}{ Sev } & \multirow{2}{*}{ Notas } \\
\hline & & & & & & Item & Sistema & Trem & & & & \\
\hline $\begin{array}{l}\mathbb{x} \\
0 \\
\dddot{1} \\
⺊\end{array}$ & \multirow{7}{*}{ 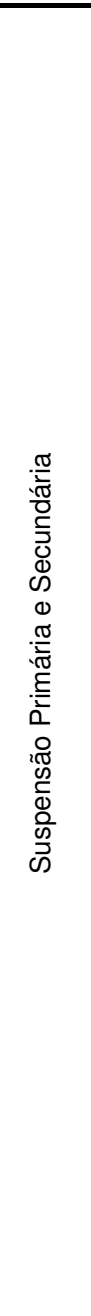 } & \multirow{7}{*}{ 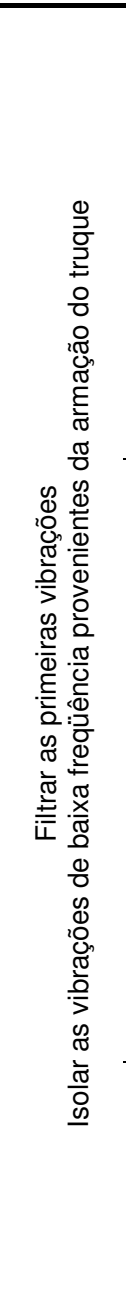 } & \multirow{3}{*}{$\begin{array}{l}\text { Mola - quebra } \\
\text { Mola - marcada } \\
\text { (podendo } \\
\text { ocasionar quebra } \\
\text { pela } \\
\text { concentração de } \\
\text { tensão) } \\
\text { Mola corroída } \\
\text { podendo ocorrer } \\
\text { ruptura }\end{array}$} & $\begin{array}{l}\text { Falha de } \\
\text { projeto }\end{array}$ & \multirow{3}{*}{$\begin{array}{l}\text { Em } \\
\text { movimento }\end{array}$} & \multirow{3}{*}{$\begin{array}{l}\text { Ruptura } \\
\text { estrutural }\end{array}$} & \multirow{3}{*}{$\begin{array}{c}\text { Pode ocorrer a } \\
\text { diminuição da } \\
\text { distância entre o } \\
\text { eixo e estrutura } \\
\text { do truque }\end{array}$} & \multirow{3}{*}{$\begin{array}{c}\text { Pode ocorrer } \\
\text { descarrilamento por } \\
\text { rotação indevida da } \\
\text { caixa, causando } \\
\text { desbalanceamento } \\
\text { severo e } \\
\text { sobreposição do } \\
\text { flange por } \\
\text { distribuição irregular } \\
\text { das massas }\end{array}$} & $\begin{array}{c}\text { Detectável por medições } \\
\text { dos parâmetros de projeto e } \\
\text { por verificação dos } \\
\text { certificados e cálculos de } \\
\text { projeto }\end{array}$ & $\begin{array}{c}\text { Correto dimensionamento } \\
\text { com relação às condições } \\
\text { climáticas de operação } \\
\text { Respeito à vida útil dos } \\
\text { elementos }\end{array}$ & 1 & \\
\hline 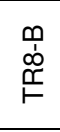 & & & & $\begin{array}{l}\text { Falha de } \\
\text { manufatura }\end{array}$ & & & & & $\begin{array}{c}\text { Detectável por inspeção } \\
\text { periódica ou durante } \\
\text { inspeção de qualidade de } \\
\text { fabricação } \\
\end{array}$ & $\begin{array}{l}\text { Inspeção de qualidade e } \\
\text { inspeções periódicas da } \\
\text { manufatura }\end{array}$ & 1 & \\
\hline $\begin{array}{l}\text { O } \\
\infty \\
\stackrel{1}{F} \\
\stackrel{F}{F}\end{array}$ & & & & $\begin{array}{c}\text { Condições } \\
\text { ambientais } \\
\text { adversas ou } \\
\text { manutenção } \\
\text { deficiente }\end{array}$ & & & & & $\begin{array}{l}\text { Detectável por inspeção } \\
\text { periódica }\end{array}$ & $\begin{array}{c}\text { Respeito à vida útil dos } \\
\text { elementos e verificação em } \\
\text { inspeções periódicas. } \\
\text { O manual deve contemplar } \\
\text { este item. }\end{array}$ & 1 & \\
\hline $\begin{array}{l}\mathbb{1} \\
\infty \\
\dddot{F} \\
\vdash\end{array}$ & & & \multirow{3}{*}{$\begin{array}{l}\text { mola - inoperante } \\
\text { por } \\
\text { enfraquecimento } \\
\text { mola - corroída }\end{array}$} & $\begin{array}{l}\text { Falha de } \\
\text { projeto }\end{array}$ & \multirow{3}{*}{$\begin{array}{l}\text { Em } \\
\text { movimento }\end{array}$} & \multirow{3}{*}{$\begin{array}{l}\text { Suspensão } \\
\text { apresenta } \\
\text { rigidez } \\
\text { alterada }\end{array}$} & \multirow{3}{*}{$\begin{array}{l}\text { Menor absorção } \\
\text { de vibração do } \\
\text { trem }\end{array}$} & \multirow{3}{*}{$\begin{array}{c}\text { Pode ocorrer } \\
\text { descarrilamento por } \\
\text { rotação indevida da } \\
\text { caixa e } \\
\text { desbalanceamento } \\
\text { e sobreposição do } \\
\text { flange por } \\
\text { distribuição irregular } \\
\text { das massas ou } \\
\text { instabilidade lateral }\end{array}$} & $\begin{array}{c}\text { Detectável por medições } \\
\text { dos parâmetros de projeto e } \\
\text { por verificação dos } \\
\text { certificados e cálculos de } \\
\text { projeto } \\
\end{array}$ & $\begin{array}{c}\text { Correto dimensionamento } \\
\text { com relação às condições } \\
\text { climáticas de operação, } \\
\text { características de material } \\
\text { etc. }\end{array}$ & 1 & \\
\hline $\begin{array}{l}\mathscr{\infty} \\
\text { ó } \\
\stackrel{\sim}{F}\end{array}$ & & & & $\begin{array}{l}\text { Falha de } \\
\text { manufatura }\end{array}$ & & & & & $\begin{array}{c}\text { Pode-se considerar não } \\
\text { detectável caso a alteração } \\
\text { não seja visual (apenas } \\
\text { propriedades mecânicas) } \\
\text { Caso seja visual (como a } \\
\text { distância entre espiras), } \\
\text { pode-se detectar em } \\
\text { manutenção }\end{array}$ & $\begin{array}{l}\text { Inspeção de qualidade e } \\
\text { inspecõos periódicas. } \\
\text { Exigência de certificados } \\
\text { dos materiais e em caso de } \\
\text { dúvida, realização de } \\
\text { ensaios. }\end{array}$ & 1 & \\
\hline 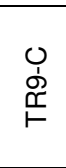 & & & & $\begin{array}{c}\text { Condições } \\
\text { ambientais } \\
\text { adversas ou } \\
\text { manutenção } \\
\text { deficiente }\end{array}$ & & & & & $\begin{array}{l}\text { Detectável por inspeção } \\
\text { periódica }\end{array}$ & $\begin{array}{c}\text { Respeito à vida útil dos } \\
\text { elementos e verificação em } \\
\text { inspeções periódicas. } \\
\text { O manual deve contemplar } \\
\text { este item. }\end{array}$ & 1 & \\
\hline 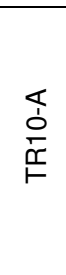 & & & $\begin{array}{l}\text { mola - uso além } \\
\text { da vida útil }\end{array}$ & $\begin{array}{l}\text { Falha de } \\
\text { manutenção } \\
\text { ou manual }\end{array}$ & $\begin{array}{c}\text { Em } \\
\text { movimento }\end{array}$ & $\begin{array}{l}\text { Suspensão } \\
\text { apresenta } \\
\text { rigidez } \\
\text { alterada ou } \\
\text { pode romper }\end{array}$ & $\begin{array}{c}\text { Pode ocorrer a } \\
\text { diminuição da } \\
\text { distância entre o } \\
\text { eixo e estrutura } \\
\text { do truque ou } \\
\text { menor absorção } \\
\text { de vibração do } \\
\text { trem }\end{array}$ & $\begin{array}{c}\text { Pode ocorrer } \\
\text { descarrilamento } \\
\text { devido a } \\
\text { enfraquecimento ou } \\
\text { quebra da } \\
\text { suspensão }\end{array}$ & $\begin{array}{l}\text { Detectável por inspeção } \\
\text { periódica }\end{array}$ & $\begin{array}{l}\text { O manual deve apresentar } \\
\text { a correta vida útil do } \\
\text { componente e este manual } \\
\text { deve ser seguido. }\end{array}$ & 1 & \\
\hline
\end{tabular}


conclusão

\begin{tabular}{|c|c|c|c|c|c|c|c|c|c|c|c|c|}
\hline \multicolumn{13}{|c|}{ Sistema: Truque } \\
\hline \multirow{2}{*}{ ID } & \multirow{2}{*}{ Item } & \multirow{2}{*}{ Função } & \multirow{2}{*}{ Modo de Falha } & \multirow{2}{*}{$\begin{array}{l}\text { Causas } \\
\text { prováveis }\end{array}$} & \multirow{2}{*}{$\begin{array}{c}\text { Modo } \\
\text { Operacional }\end{array}$} & \multicolumn{3}{|c|}{ Efeito das Falhas } & \multirow{2}{*}{ Modo de Detecção } & \multirow{2}{*}{ Ação de Gerenciamento } & \multirow{2}{*}{ Sev } & \multirow{2}{*}{ Notas } \\
\hline & & & & & & Item & Sistema & Trem & & & & \\
\hline$\frac{\mathbb{r}}{\frac{1}{\tilde{r}}}$ & \multirow{6}{*}{ 莺 } & \multirow{6}{*}{ 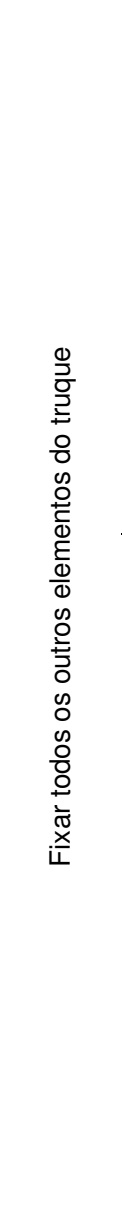 } & \multirow{3}{*}{ Ruptura Estrutural } & $\begin{array}{l}\text { Falha de } \\
\text { projeto }\end{array}$ & \multirow{3}{*}{$\begin{array}{l}\text { Em } \\
\text { movimento }\end{array}$} & \multirow{3}{*}{$\begin{array}{l}\text { Perda dos } \\
\text { parâmetros } \\
\text { geométricos }\end{array}$} & \multirow{3}{*}{$\begin{array}{c}\text { Truque } \\
\text { comprometido }\end{array}$} & \multirow{3}{*}{$\begin{array}{c}\text { Pode ocorrer } \\
\text { descarrilamento por } \\
\text { queda de } \\
\text { componente na via } \\
\text { ou causar a rotação } \\
\text { indevida da caixa, } \\
\text { desbalanceamento } \\
\text { e descarrilamento }\end{array}$} & $\begin{array}{l}\text { Detectável por medições } \\
\text { dos parâmetros de projeto e } \\
\text { por verificação dos } \\
\text { certificados e cálculos de } \\
\text { projeto }\end{array}$ & $\begin{array}{c}\text { O projeto deve } \\
\text { dimensionar } \\
\text { corretamente o truque }\end{array}$ & 1 & \\
\hline$\frac{\stackrel{m}{\frac{1}{\sigma}}}{\stackrel{\underline{x}}{F}}$ & & & & $\begin{array}{l}\text { Falha de } \\
\text { manufatura }\end{array}$ & & & & & $\begin{array}{l}\text { Detectável por inspeção } \\
\text { periódica ou durante } \\
\text { inspeção de qualidade de } \\
\text { fabricação }\end{array}$ & $\begin{array}{l}\text { Inspeção de qualidade e } \\
\text { inspeções periódicas na } \\
\text { manufatura }\end{array}$ & 1 & \\
\hline$\underset{\substack{1 \\
\frac{1}{\mathscr{I}}}}{\stackrel{1}{r}}$ & & & & $\begin{array}{l}\text { Falha de } \\
\text { manutenção }\end{array}$ & & & & & $\begin{array}{l}\text { Detectável por inspeção } \\
\text { periódica se houverem } \\
\text { trincas superficiais ou por } \\
\text { ultra-som }\end{array}$ & $\begin{array}{l}\text { Deve ser verificado em } \\
\text { inspeções periódicas. } \\
\text { O manual de } \\
\text { manutenção deve } \\
\text { contemplar a correta } \\
\text { manutenção do truque }\end{array}$ & I & \\
\hline 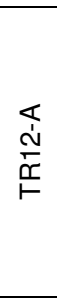 & & & \multirow{3}{*}{$\begin{array}{l}\text { Mudança de } \\
\text { geometria }\end{array}$} & $\begin{array}{l}\text { Falha de } \\
\text { projeto }\end{array}$ & \multirow{3}{*}{$\begin{array}{l}\text { Em } \\
\text { movimento }\end{array}$} & \multirow{3}{*}{$\begin{array}{l}\text { Alteração das } \\
\text { características } \\
\text { geométricas } \\
\text { (exemplo: } \\
\text { deformação) }\end{array}$} & \multirow{3}{*}{$\begin{array}{l}\text { Movimentação } \\
\text { irregular do } \\
\text { truque, } \\
\text { vibração e } \\
\text { alteração das } \\
\text { características } \\
\text { dinâmicas }\end{array}$} & \multirow{3}{*}{$\begin{array}{c}\text { Pode ocorrer } \\
\text { sobreposição do } \\
\text { flange e/ou } \\
\text { instabilidade lateral } \\
\text { do veículo e } \\
\text { possível } \\
\text { descarrilamento }\end{array}$} & $\begin{array}{l}\text { Detectável por medições } \\
\text { dos parâmetros de projeto e } \\
\text { por verificação dos } \\
\text { certificados e cálculos de } \\
\text { projeto }\end{array}$ & $\begin{array}{c}\text { O projeto deve } \\
\text { dimensionar } \\
\text { corretamente } \\
\text { considerando os } \\
\text { parâmetros de operação. } \\
\text { Durante fabricação deve } \\
\text { haver respeito aos } \\
\text { parâmetros definidos em } \\
\text { projeto. }\end{array}$ & 1 & \\
\hline 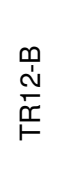 & & & & $\begin{array}{l}\text { Falha de } \\
\text { manufatura }\end{array}$ & & & & & $\begin{array}{l}\text { Detectável por inspeção } \\
\text { periódica ou durante } \\
\text { inspeção de qualidade de } \\
\text { fabricação }\end{array}$ & $\begin{array}{l}\text { Inspeção de qualidade de } \\
\text { fabricação do elemento e } \\
\text { inspeções periódicas da } \\
\text { manufatura }\end{array}$ & 1 & \\
\hline $\begin{array}{c}\stackrel{\bigcup}{N} \\
\stackrel{\mathbb{M}}{F}\end{array}$ & & & & $\begin{array}{l}\text { Falha de } \\
\text { manutenção }\end{array}$ & & & & & $\begin{array}{l}\text { Detectável em inspeções } \\
\text { periódicas }\end{array}$ & $\begin{array}{l}\text { Deve ser verificado em } \\
\text { inspeções periódicas. } \\
\text { O manual de } \\
\text { manutenção deve } \\
\text { contemplar a correta } \\
\text { manutenção do truque }\end{array}$ & 1 & \\
\hline
\end{tabular}


Em suma, as ações de gerenciamento recomendadas na Tabela 6.4 são:

- correta manutenção dos sistemas e componentes, fornecendo treinamento às equipes de manutenção e documentação coerente e clara para esta atividade, sendo que para tal pode-se seguir a manutenção centrada em confiabilidade conforme item 7.4.1;

- o projeto deve dimensionar a correta força de prensagem das rodas (dimensionando a interferência). Durante montagem deve haver respeito aos parâmetros definidos em projeto.

- inspeção durante a manufatura, podendo ser realizadas pelo controle de qualidade dos componentes fabricados, bem como a exigência de certificados disponibilizados pelos fornecedores e ensaios quanto à qualidade de produto fabricado (mais detalhes em 7.2.2);

- o projeto deve considerar as corretas solicitações que o trem sofrerá, escolhendo corretamente o material, processo de fabricação e dimensões, dimensionamento, ambiente de operação e aplicando as normas cabíveis.

- durante operação, devem ser seguidas as restrições operacionais, de ambiente de operação, vidas úteis e de solicitações permitidas.

\subsection{3- COMPONENTES DO ACOPLAMENTO}

A árvore de falhas referente ao sistema acoplamento está apresentada na Figura 6.4. Nesta figura são representadas as combinações de falhas referentes ao acoplamento que podem geram um descarrilamento.

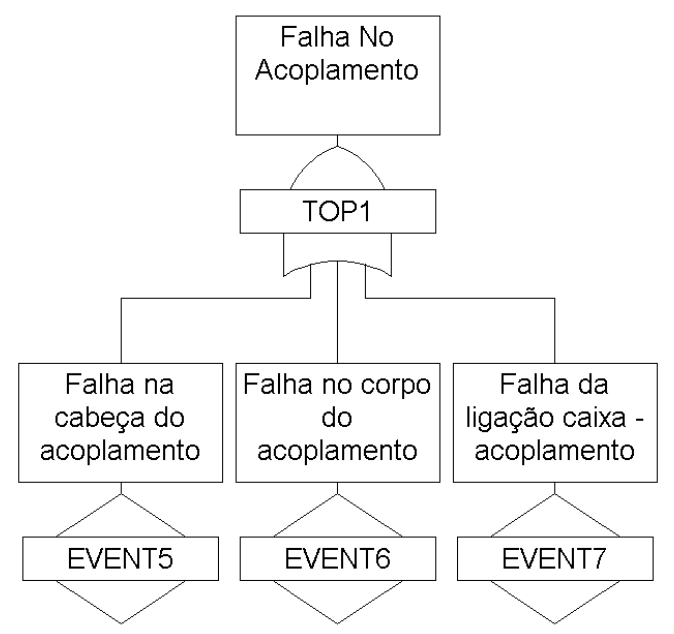

Figura 6.4 - FTA - Falha no Acoplamento 
A Tabela 6.5 apresenta os modos de falha para cada item/componente, apresentando também uma descrição de cada modo de falha e da fonte de referência que foi obtido o respectivo modo de falha. No caso do acoplamento, os modos de falha foram todos provenientes de hipóteses.

Tabela 6.5 - Sistema Acoplamento - Modos de falha considerados e referências

\begin{tabular}{|c|c|c|c|c|}
\hline Item & Função & Modo de Falha & Descrição & FONTE \\
\hline $\begin{array}{l}\text { Cabeça do } \\
\text { Acoplamento }\end{array}$ & $\begin{array}{l}\text { Permitir o engate } \\
\text { entre os carros ou } \\
\text { trens }\end{array}$ & $\begin{array}{l}\text { Desacoplamento } \\
\text { indevido }\end{array}$ & $\begin{array}{l}\text { Desacoplamento indevido entre } \\
\text { carros ou trens }\end{array}$ & Hipótese \\
\hline $\begin{array}{l}\text { Cabeça do } \\
\text { Acoplamento }\end{array}$ & $\begin{array}{l}\text { Permitir o engate } \\
\text { entre os carros ou } \\
\text { trens }\end{array}$ & Queda na via & $\begin{array}{l}\text { Queda do elemento na via } \\
\text { acarretando em obstáculo na } \\
\text { mesma e possibilidade de } \\
\text { descarrilamento }\end{array}$ & Hipótese \\
\hline $\begin{array}{l}\text { Corpo do } \\
\text { Acoplamento }\end{array}$ & $\begin{array}{l}\text { Fornecer a distância } \\
\text { necessária entre os } \\
\text { carros ou trens para } \\
\text { evitar colisões }\end{array}$ & $\begin{array}{l}\text { Desacoplamento } \\
\text { indevido }\end{array}$ & $\begin{array}{l}\text { Desacoplamento indevido entre } \\
\text { carros ou trens }\end{array}$ & Hipótese \\
\hline $\begin{array}{l}\text { Corpo do } \\
\text { Acoplamento }\end{array}$ & $\begin{array}{l}\text { Fornecer a distância } \\
\text { necessária entre os } \\
\text { carros ou trens para } \\
\text { evitar colisões }\end{array}$ & Queda na via & $\begin{array}{l}\text { Queda do elemento na via } \\
\text { acarretando em obstáculo na } \\
\text { mesma e possibilidade de } \\
\text { descarrilamento }\end{array}$ & Hipótese \\
\hline $\begin{array}{l}\text { Ligação da Caixa- } \\
\text { acoplamento }\end{array}$ & $\begin{array}{l}\text { Fixar o acoplamento à } \\
\text { caixa, }\end{array}$ & $\begin{array}{l}\text { Desacoplamento } \\
\text { indevido }\end{array}$ & $\begin{array}{l}\text { Desacoplamento indevido entre } \\
\text { carros ou trens }\end{array}$ & Hipótese \\
\hline $\begin{array}{l}\text { Ligação da Caixa- } \\
\text { acoplamento }\end{array}$ & $\begin{array}{l}\text { Fixar o acoplamento à } \\
\text { caixa, }\end{array}$ & Queda na via & $\begin{array}{l}\text { Queda do elemento na via } \\
\text { acarretando em obstáculo na } \\
\text { mesma e possibilidade de } \\
\text { descarrilamento }\end{array}$ & Hipótese \\
\hline
\end{tabular}

A Tabela 6.6 apresenta a análise do tipo FMEA para o sistema de acoplamento. 
Tabela 6.6 - FMEA Sistema de Acoplamento

continua

\begin{tabular}{|c|c|c|c|c|c|c|c|c|c|c|c|c|}
\hline \multicolumn{13}{|c|}{ Sistema: Acoplamento } \\
\hline \multirow{2}{*}{ ID } & \multirow{2}{*}{ Item } & \multirow{2}{*}{ Função } & \multirow{2}{*}{ Modo de Falha } & \multirow{2}{*}{$\begin{array}{l}\text { Causas } \\
\text { prováveis }\end{array}$} & \multirow{2}{*}{$\begin{array}{c}\text { Modo } \\
\text { Operacional }\end{array}$} & \multicolumn{3}{|c|}{ Efeito das Falhas } & \multirow{2}{*}{$\begin{array}{l}\text { Modo de } \\
\text { Detecção }\end{array}$} & \multirow{2}{*}{$\begin{array}{c}\text { Ação de } \\
\text { Gerenciamento }\end{array}$} & \multirow{2}{*}{ Sev } & \multirow{2}{*}{ Notas } \\
\hline & & & & & & Item & Sistema & Trem & & & & \\
\hline$\frac{⿱}{1}$ & & & & $\begin{array}{l}\text { Falha no } \\
\text { projeto }\end{array}$ & & & & & $\begin{array}{l}\text { Inspeção visual } \\
\text { ou testes de } \\
\text { desempenho }\end{array}$ & $\begin{array}{c}\text { Correto } \\
\text { dimensionamento do } \\
\text { engate. } \\
\text { Teste de acoplamento } \\
\text { antes da entrada em } \\
\text { operação de cada } \\
\text { trem. }\end{array}$ & 1 & \\
\hline 产 & & & & $\begin{array}{l}\text { Falha de } \\
\text { manufatura }\end{array}$ & & $\begin{array}{c}1- \\
\text { Desacoplamento }\end{array}$ & & $\begin{array}{l}\text { Pode ocorrer } \\
\text { descarrilamento }\end{array}$ & $\begin{array}{l}\text { Inspeção visual } \\
\text { ou testes de } \\
\text { desempenho }\end{array}$ & $\begin{array}{l}\text { Teste de acoplamento } \\
\text { antes da entrada em } \\
\text { operação de cada } \\
\text { trem. }\end{array}$ & 1 & \\
\hline 产 & $\begin{array}{l}\text { Cabeça do } \\
\text { Acoplamento }\end{array}$ & $\begin{array}{l}\text { Permitir o } \\
\text { engate entre } \\
\text { os carros ou } \\
\text { trens }\end{array}$ & $\begin{array}{c}1 \text { - } \\
\begin{array}{c}\text { Desacoplamento } \\
\text { indevido }\end{array} \\
\text { 2- Queda na via }\end{array}$ & $\begin{array}{l}\text { Falha de } \\
\text { montagem }\end{array}$ & $\begin{array}{c}\text { Em } \\
\text { Movimento }\end{array}$ & $\begin{array}{l}\text { de um engate } \\
\text { com o outro } \\
2 \text { - Cabeça do } \\
\text { acoplamento } \\
\text { perde sua fixação } \\
\text { com o restante } \\
\text { do acoplamento }\end{array}$ & $\begin{array}{l}\text { Acoplamento } \\
\text { perde a sua } \\
\text { função }\end{array}$ & $\begin{array}{c}\text { por queda de } \\
\text { componente na } \\
\text { via ou excesso } \\
\text { de velocidade } \\
\text { causando } \\
\text { sobreposição do } \\
\text { flange e possível } \\
\text { descarrilamento }\end{array}$ & $\begin{array}{l}\text { Inspeção visual } \\
\text { ou testes de } \\
\text { desempenho }\end{array}$ & $\begin{array}{c}\text { Correto } \\
\text { dimensionamento do } \\
\text { engate. } \\
\text { Teste de acoplamento } \\
\text { antes da entrada em } \\
\text { operação de cada } \\
\text { trem. } \\
\text { Inspeção por parte do } \\
\text { controle de qualidade. }\end{array}$ & 1 & \\
\hline 足 & & & & $\begin{array}{l}\text { Falha de } \\
\text { manutenção }\end{array}$ & & & & & $\begin{array}{l}\text { Detectável em } \\
\text { inspeções } \\
\text { periódicas }\end{array}$ & $\begin{array}{l}\text { Manual deve conter } \\
\text { informações corretas e } \\
\text { precisas bem como } \\
\text { treinamento aos } \\
\text { funcionários da } \\
\text { manutenção. }\end{array}$ & 1 & \\
\hline
\end{tabular}


continuação

\begin{tabular}{|c|c|c|c|c|c|c|c|c|c|c|c|c|}
\hline \multicolumn{13}{|c|}{ Sistema: Acoplamento } \\
\hline \multirow{2}{*}{ ID } & \multirow{2}{*}{ Item } & \multirow{2}{*}{ Função } & \multirow{2}{*}{ Modo de Falha } & \multirow{2}{*}{$\begin{array}{l}\text { Causas } \\
\text { prováveis }\end{array}$} & \multirow{2}{*}{$\begin{array}{c}\text { Modo } \\
\text { Operacional }\end{array}$} & \multicolumn{3}{|c|}{ Efeito das Falhas } & \multirow{2}{*}{$\begin{array}{l}\text { Modo de } \\
\text { Detecção }\end{array}$} & \multirow{2}{*}{$\begin{array}{c}\text { Ação de } \\
\text { Gerenciamento }\end{array}$} & \multirow{2}{*}{ Sev } & \multirow{2}{*}{ Notas } \\
\hline & & & & & & Item & Sistema & Trem & & & & \\
\hline 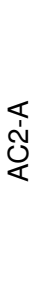 & \multirow{5}{*}{$\begin{array}{c}\text { Corpo do } \\
\text { Acoplamento }\end{array}$} & \multirow{5}{*}{$\begin{array}{l}\text { Fornecer a } \\
\text { distância } \\
\text { necessária } \\
\text { entre os } \\
\text { carros ou } \\
\text { trens para } \\
\text { evitar } \\
\text { colisões }\end{array}$} & \multirow{5}{*}{$\begin{array}{l}1- \\
\begin{array}{l}\text { Desacoplamento } \\
\text { indevido }\end{array} \\
\text { 2- Queda na via }\end{array}$} & $\begin{array}{l}\text { Falha no } \\
\text { projeto }\end{array}$ & \multirow{5}{*}{$\begin{array}{c}\text { Em } \\
\text { Movimento }\end{array}$} & \multirow{5}{*}{$\begin{array}{l}1- \\
\text { Desacoplamento } \\
\text { de um engate } \\
\text { com o outro } \\
2 \text { - Corpo do } \\
\text { acoplamento } \\
\text { perde sua fixação } \\
\text { com o restante } \\
\text { do acoplamento }\end{array}$} & \multirow{5}{*}{$\begin{array}{l}\text { Acoplamento } \\
\text { perde a sua } \\
\text { função }\end{array}$} & \multirow{5}{*}{$\begin{array}{l}\text { Pode ocorrer } \\
\text { descarrilamento } \\
\text { por queda de } \\
\text { componente na } \\
\text { via ou excesso } \\
\text { de velocidade } \\
\text { causando } \\
\text { sobreposição do } \\
\text { flange e possível } \\
\text { descarrilamento }\end{array}$} & $\begin{array}{c}\text { Inspeção } \\
\text { visual ou } \\
\text { testes de } \\
\text { desempenho }\end{array}$ & $\begin{array}{c}\text { Correto } \\
\text { dimensionamento } \\
\text { do engate. } \\
\text { Teste de } \\
\text { acoplamento antes } \\
\text { da entrada em } \\
\text { operação de cada } \\
\text { trem. }\end{array}$ & I & \\
\hline $\begin{array}{l}\stackrel{m}{1} \\
\dot{\sim} \\
\dot{\alpha}\end{array}$ & & & & $\begin{array}{l}\text { Falha de } \\
\text { manufatura }\end{array}$ & & & & & $\begin{array}{l}\text { Inspeção } \\
\text { visual ou } \\
\text { testes de }\end{array}$ & $\begin{array}{c}\text { Teste de } \\
\text { acoplamento antes } \\
\text { da entrada em }\end{array}$ & 1 & \\
\hline & & & & & & & & & & trem. & & \\
\hline 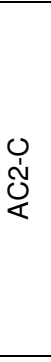 & & & & $\begin{array}{l}\text { Falha de } \\
\text { montagem }\end{array}$ & & & & & $\begin{array}{c}\text { Inspeção } \\
\text { visual ou } \\
\text { testes de } \\
\text { desempenho }\end{array}$ & $\begin{array}{c}\text { Correto } \\
\text { dimensionamento } \\
\text { do engate. } \\
\text { Teste de } \\
\text { acoplamento antes } \\
\text { da entrada em } \\
\text { operação de cada } \\
\text { trem. } \\
\text { Inspeção por parte } \\
\text { do controle de } \\
\text { qualidade. }\end{array}$ & I & \\
\hline 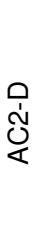 & & & & $\begin{array}{l}\text { Falha de } \\
\text { manutenção }\end{array}$ & & & & & $\begin{array}{l}\text { Detectável } \\
\text { em } \\
\text { inspeções } \\
\text { periódicas }\end{array}$ & $\begin{array}{l}\text { Manual deve conter } \\
\text { informações } \\
\text { corretas e precisas } \\
\text { bem como } \\
\text { treinamento aos } \\
\text { funcionários da } \\
\text { manutenção. }\end{array}$ & I & \\
\hline
\end{tabular}


conclusão

\begin{tabular}{|c|c|c|c|c|c|c|c|c|c|c|c|c|}
\hline \multicolumn{13}{|c|}{ Sistema: Acoplamento } \\
\hline \multirow{2}{*}{ ID } & \multirow{2}{*}{ Item } & \multirow{2}{*}{ Função } & \multirow{2}{*}{ Modo de Falha } & \multirow{2}{*}{$\begin{array}{l}\text { Causas } \\
\text { prováveis }\end{array}$} & \multirow{2}{*}{$\begin{array}{c}\text { Modo } \\
\text { Operacional }\end{array}$} & \multicolumn{3}{|c|}{ Efeito das Falhas } & \multirow{2}{*}{$\begin{array}{l}\text { Modo de } \\
\text { Detecção }\end{array}$} & \multirow{2}{*}{$\begin{array}{l}\text { Ação de } \\
\text { Gerenciamento }\end{array}$} & \multirow{2}{*}{ Sev } & \multirow{2}{*}{ Notas } \\
\hline & & & & & & Item & Sistema & Trem & & & & \\
\hline 感 & & & & $\begin{array}{l}\text { Falha no } \\
\text { projeto }\end{array}$ & & & & & $\begin{array}{l}\text { Inspeção visual } \\
\text { ou testes de } \\
\text { desempenho }\end{array}$ & $\begin{array}{c}\text { Correto } \\
\text { dimensionamento } \\
\text { do engate. } \\
\text { Teste de } \\
\text { acoplamento antes } \\
\text { da entrada em } \\
\text { operação de cada } \\
\text { trem. } \\
\end{array}$ & 1 & \\
\hline 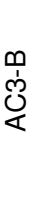 & & & & $\begin{array}{l}\text { Falha de } \\
\text { manufatura }\end{array}$ & & $\begin{array}{c}1- \\
\text { Desacoplamento } \\
\text { de uma caixa }\end{array}$ & & $\begin{array}{l}\text { Pode ocorrer } \\
\text { descarrilamento }\end{array}$ & $\begin{array}{l}\text { Inspeção visual } \\
\text { ou testes de } \\
\text { desempenho }\end{array}$ & $\begin{array}{c}\text { Teste de } \\
\text { acoplamento antes } \\
\text { da entrada em } \\
\text { operação de cada } \\
\text { trem. }\end{array}$ & 1 & \\
\hline 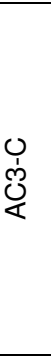 & $\begin{array}{l}\text { Ligação da } \\
\text { Caixa- } \\
\text { acoplamento }\end{array}$ & $\begin{array}{c}\text { Fixar o } \\
\text { acoplamento } \\
\text { à caixa, }\end{array}$ & $\begin{array}{c}1 \text { - } \\
\begin{array}{c}\text { Desacoplamento } \\
\text { indevido }\end{array} \\
\text { 2- Queda na via }\end{array}$ & $\begin{array}{l}\text { Falha de } \\
\text { montagem }\end{array}$ & $\begin{array}{c}\text { Em } \\
\text { Movimento }\end{array}$ & $\begin{array}{c}\text { com outra } \\
2 \text { - Ligação da } \\
\text { caixa com } \\
\text { acoplamento } \\
\text { perde sua fixação } \\
\text { com o restante } \\
\text { do acoplamento e } \\
\text { caixa }\end{array}$ & $\begin{array}{l}\text { Acoplamento } \\
\text { perde a sua } \\
\text { função }\end{array}$ & $\begin{array}{c}\text { por queda de } \\
\text { componente na } \\
\text { via ou excesso } \\
\text { de velocidade } \\
\text { causando } \\
\text { sobreposição do } \\
\text { flange e possível } \\
\text { descarrilamento }\end{array}$ & $\begin{array}{l}\text { Inspeção visual } \\
\text { ou testes de } \\
\text { desempenho }\end{array}$ & $\begin{array}{c}\text { Correto } \\
\text { dimensionamento } \\
\text { do engate. } \\
\text { Teste de } \\
\text { acoplamento antes } \\
\text { da entrada em } \\
\text { operação de cada } \\
\text { trem. } \\
\text { Inspeção por parte } \\
\text { do controle de } \\
\text { qualidade. }\end{array}$ & 1 & \\
\hline 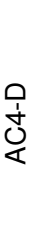 & & & & $\begin{array}{c}\text { Falha de } \\
\text { manutenção }\end{array}$ & & & & & $\begin{array}{l}\text { Detectável em } \\
\text { inspeções } \\
\text { periódicas }\end{array}$ & $\begin{array}{c}\text { Manual deve conter } \\
\text { informações } \\
\text { corretas e precisas } \\
\text { bem como } \\
\text { treinamento aos } \\
\text { funcionários da } \\
\text { manutenção. }\end{array}$ & 1 & \\
\hline
\end{tabular}


Em suma, as ações de gerenciamento recomendadas na Tabela 6.6 são:

- correto dimensionamento do engate;

- teste do funcionamento dos sistemas, por exemplo, de acoplamento antes da entrada em operação de cada trem.

- inspeção durante a manufatura, podendo ser realizada pelo controle de qualidade dos componentes fabricados bem como a exigência de certificados disponibilizados pelos fornecedores quanto à qualidade de produto fabricado (mais detalhes em 7.2.2);

- correta manutenção dos sistemas e componentes, fornecendo treinamento aos manutentores e documentação coerente e clara para esta atividade, sendo que para tal pode-se seguir a manutenção centrada em confiabilidade conforme item 7.4.1.

\subsection{4 - COMPONENTES DO SISTEMA DE TRAÇÃO E FRENAGEM}

A árvore de falhas referente ao sistema de tração e frenagem está apresentada na Figura 6.5. Nesta figura são representadas as combinações de falhas referentes ao sistema de tração e frenagem que podem geram um descarrilamento. 


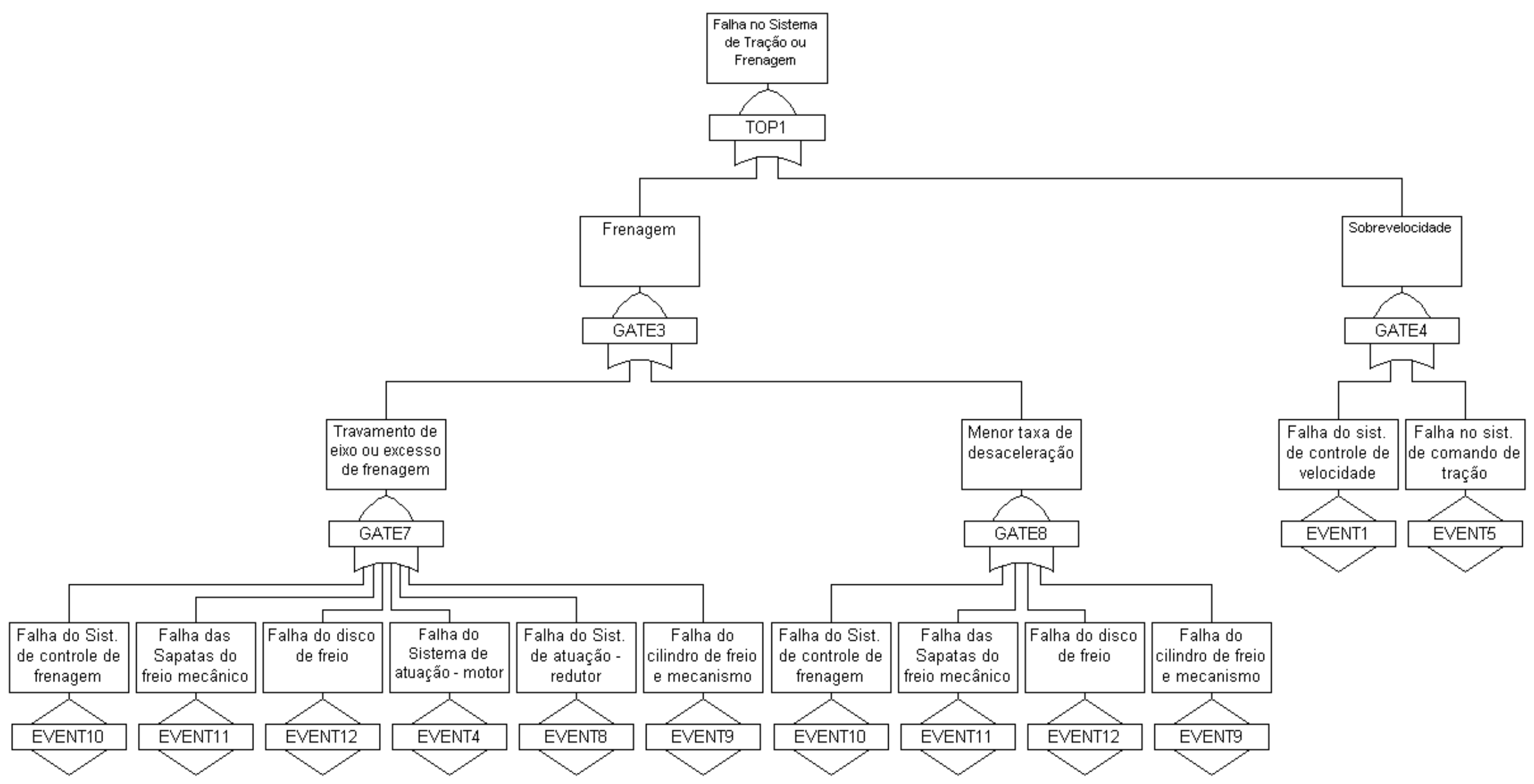

Figura 6.5 - FTA - Falha do Sistema de Tração e Frenagem 
A Tabela 6.7 apresenta os modos de falha para cada item/componente, uma descrição de cada modo de falha e a origem da referência de que foi obtido o respectivo modo de falha. A referência mais utilizada para os modos de falha foi a norma FMD-97 (1997). No APÊNDICE E são descritos os trechos deste banco de dados referentes a componentes contemplados nesta tabela. Além disso, alguns modos de falha apresentados foram agrupados de acordo com o julgamento realizado e explicado no referido anexo. Já uma parte das referências os modos de falha foram provenientes de hipóteses e outras da referência Reliability Toolkit (1995).

Tabela 6.7 - Sistema de Tração e Frenagem - Modos de falha considerados e referências

continua

\begin{tabular}{|c|c|c|c|c|}
\hline Item & Função & Modo de Falha & Descrição & FONTE \\
\hline \multirow{2}{*}{$\begin{array}{l}\text { Sistema de } \\
\text { controle de } \\
\text { velocidade }\end{array}$} & \multirow{2}{*}{$\begin{array}{l}\text { Monitorar e } \\
\text { controlar a } \\
\text { velocidade do } \\
\text { material rodante }\end{array}$} & $\begin{array}{l}\text { Aquisição errada } \\
\text { de velocidade }\end{array}$ & $\begin{array}{l}\text { Aquisição errada de velocidade pelos } \\
\text { sensores ou devido a transmissão errada } \\
\text { da informação para o circuito de } \\
\text { processamento da velocidade. }\end{array}$ & Hipótese \\
\hline & & $\begin{array}{l}\text { Processamento } \\
\text { errado da } \\
\text { velocidade }\end{array}$ & $\begin{array}{l}\text { Processamento errado da informação de } \\
\text { velocidade, enviando informações erradas } \\
\text { para o sistema de tração para o ajuste da } \\
\text { velocidade. }\end{array}$ & Hipótese \\
\hline $\begin{array}{l}\text { Sistema de } \\
\text { comando de } \\
\text { tração }\end{array}$ & $\begin{array}{l}\text { Comandar a } \\
\text { propulsão }\end{array}$ & $\begin{array}{l}\text { Comando } \\
\text { errôneo de } \\
\text { propulsão }\end{array}$ & $\begin{array}{l}\text { Transmissão errada dos parâmetros para } \\
\text { os motores de tração. }\end{array}$ & Hipótese \\
\hline \multirow{4}{*}{$\begin{array}{l}\text { Sistema de } \\
\text { atuação - } \\
\text { motor }\end{array}$} & \multirow{4}{*}{$\begin{array}{l}\text { Converter } \\
\text { energia elétrica } \\
\text { em energia } \\
\text { mecânica }\end{array}$} & $\begin{array}{l}\text { Falha de } \\
\text { ventilação }\end{array}$ & $\begin{array}{l}\text { Falha na ventilação do motor acarretando } \\
\text { elevação de temperatura }\end{array}$ & $\begin{array}{l}\text { Reliability } \\
\text { Toolkit (1995) }\end{array}$ \\
\hline & & $\begin{array}{l}\text { Falha no } \\
\text { rolamento }\end{array}$ & $\begin{array}{l}\text { Rolamento não permite ou dificulta a } \\
\text { rotação. } \\
\text { Rolamento com jogo ou folga excessiva. } \\
\text { Lubrificação do rolamento contaminado, } \\
\text { podendo causar aquecimento e } \\
\text { travamento. }\end{array}$ & $\begin{array}{l}\text { Reliability } \\
\text { Toolkit (1995) }\end{array}$ \\
\hline & & $\begin{array}{l}\text { Falha na } \\
\text { operação depois } \\
\text { da partida }\end{array}$ & $\begin{array}{l}\text { Após a partida do motor, pode ocorrer o } \\
\text { travamento do motor ou alteração da } \\
\text { velocidade de rotação. }\end{array}$ & $\begin{array}{l}\text { Reliability } \\
\text { Toolkit (1995) }\end{array}$ \\
\hline & & Falha de partida & O motor não inicia o movimento. & $\begin{array}{l}\text { Reliability } \\
\text { Toolkit (1995) }\end{array}$ \\
\hline
\end{tabular}


continuação

\begin{tabular}{|c|c|c|c|c|}
\hline Item & Função & Modo de Falha & Descrição & FONTE \\
\hline \multirow{3}{*}{$\begin{array}{l}\text { Sistema de } \\
\text { atuação - } \\
\text { redutor }\end{array}$} & \multirow{3}{*}{$\begin{array}{l}\text { Reduzir o número } \\
\text { de rotações na } \\
\text { saída e aumentar } \\
\text { o torque }\end{array}$} & Perda de lubrificação & Falta de óleo no redutor. & $\begin{array}{l}\text { FMD-97 } \\
(1997)\end{array}$ \\
\hline & & Falha de vedação & $\begin{array}{l}\text { Falha na vedação do redutor, podendo } \\
\text { causar falta de óleo ou acúmulo de } \\
\text { impurezas. }\end{array}$ & $\begin{array}{l}\text { FMD-97 } \\
(1997)\end{array}$ \\
\hline & & Desgaste & Desgaste do redutor. & $\begin{array}{l}\text { FMD-97 } \\
(1997)\end{array}$ \\
\hline \multirow[t]{2}{*}{$\begin{array}{l}\text { Sistema de } \\
\text { controle de } \\
\text { frenagem }\end{array}$} & \multirow{2}{*}{$\begin{array}{l}\text { Monitorar e } \\
\text { controlar a } \\
\text { frenagem do } \\
\text { material rodante }\end{array}$} & $\begin{array}{l}\text { Aquisição errada do } \\
\text { esforço de frenagem }\end{array}$ & $\begin{array}{l}\text { Aquisição errada dos esforços de } \\
\text { frenagem pelos sensores ou devido à } \\
\text { transmissão errada da informação para } \\
\text { o circuito de controle da frenagem. }\end{array}$ & Hipótese \\
\hline & & $\begin{array}{l}\text { Controle errado do } \\
\text { esforço de frenagem }\end{array}$ & $\begin{array}{l}\text { Transmissão errada dos parâmetros } \\
\text { para a aplicação de frenagem. }\end{array}$ & Hipótese \\
\hline \multirow{7}{*}{$\begin{array}{l}\text { Sapatas de } \\
\text { freio do freio } \\
\text { mecânico }\end{array}$} & \multirow{7}{*}{$\begin{array}{l}\text { Em conjunto com } \\
\text { o disco de freio, } \\
\text { garantir a } \\
\text { frenagem do trem }\end{array}$} & Fissura & $\begin{array}{l}\text { Surgimento de fissuras na sapata de } \\
\text { freio. }\end{array}$ & $\begin{array}{l}\text { FMD-97 } \\
(1997)\end{array}$ \\
\hline & & Deteriorado & $\begin{array}{l}\text { Deterioração das propriedades do } \\
\text { material podendo ser causado, por } \\
\text { exemplo, pelo uso em um ambiente } \\
\text { mais severo. }\end{array}$ & $\begin{array}{l}\text { FMD-97 } \\
(1997)\end{array}$ \\
\hline & & Prendendo & $\begin{array}{l}\text { Sapata se aderindo indevidamente ao } \\
\text { disco. }\end{array}$ & $\begin{array}{l}\text { FMD-97 } \\
(1997)\end{array}$ \\
\hline & & Marcada & $\begin{array}{l}\text { Sapata com trincas ou marcas } \\
\text { causadas pela qualidade da sapata ou } \\
\text { algum agente externo. }\end{array}$ & $\begin{array}{l}\text { FMD-97 } \\
(1997)\end{array}$ \\
\hline & & Acúmulo de metais & $\begin{array}{l}\text { Acúmulo de metais na sapata } \\
\text { proveniente do ambiente ou do contato } \\
\text { com o disco de freio. }\end{array}$ & $\begin{array}{l}\text { FMD-97 } \\
(1997)\end{array}$ \\
\hline & & Fora de ajuste & $\begin{array}{l}\text { Desalinhamento da pastilha, pastilha } \\
\text { fora da sua correta posição de } \\
\text { instalação. }\end{array}$ & $\begin{array}{l}\text { FMD-97 } \\
(1997)\end{array}$ \\
\hline & & $\begin{array}{l}\text { Ultrapassando } \\
\text { valores nominais ou } \\
\text { menor valor nominal }\end{array}$ & $\begin{array}{l}\text { Valores nominais errados do coeficiente } \\
\text { de atrito das pastilhas. }\end{array}$ & $\begin{array}{l}\text { FMD-97 } \\
(1997)\end{array}$ \\
\hline
\end{tabular}


conclusão

\begin{tabular}{|c|c|c|c|c|}
\hline Item & Função & Modo de Falha & Descrição & FONTE \\
\hline \multirow{9}{*}{$\begin{array}{l}\text { Cilindro de } \\
\text { freio e } \\
\text { mecanismo } \\
\text { do freio - } \\
\text { freio } \\
\text { mecânico }\end{array}$} & \multirow{9}{*}{$\begin{array}{l}\text { Atuar na } \\
\text { compressão das } \\
\text { pastilhas contra o } \\
\text { disco }\end{array}$} & Vazamento & $\begin{array}{l}\text { Vazamento do cilindro de freio ou de } \\
\text { algum outro elemento do mecanismo. }\end{array}$ & $\begin{array}{l}\text { FMD-97 } \\
(1997)\end{array}$ \\
\hline & & Falha no rolamento & $\begin{array}{l}\text { Rolamento não permite ou dificulta a } \\
\text { rotação; } \\
\text { rolamento com jogo ou folga excessiva; } \\
\text { lubrificação do rolamento contaminado, } \\
\text { podendo causar aquecimento e } \\
\text { travamento. }\end{array}$ & $\begin{array}{l}\text { FMD-97 } \\
(1997)\end{array}$ \\
\hline & & & $\begin{array}{l}\text { Desta forma o mecanismo não atua } \\
\text { corretamente na frenagem. }\end{array}$ & \\
\hline & & $\begin{array}{l}\text { Cilindro de freio } \\
\text { travando }\end{array}$ & $\begin{array}{l}\text { Cilindro de freio travando causando } \\
\text { falha de aplicação ou de alívio de freio. }\end{array}$ & $\begin{array}{l}\text { FMD-97 } \\
(1997)\end{array}$ \\
\hline & & Válvula em falha & $\begin{array}{l}\text { Válvula de acionamento do cilindro } \\
\text { travando causando falha de aplicação } \\
\text { ou de alívio de freio. }\end{array}$ & $\begin{array}{l}\text { FMD-97 } \\
(1997)\end{array}$ \\
\hline & & Falha na mangueira & $\begin{array}{l}\text { Falha na mangueira por ruptura, } \\
\text { bloqueio ou vazamento. }\end{array}$ & $\begin{array}{l}\text { FMD-97 } \\
(1997)\end{array}$ \\
\hline & & $\begin{array}{l}\text { Componentes } \\
\text { internos deteriorados }\end{array}$ & Componentes internos deteriorados. & $\begin{array}{l}\text { FMD-97 } \\
(1997)\end{array}$ \\
\hline & & Falha na vedação & $\begin{array}{l}\text { Vedação não cumpre a sua função, } \\
\text { permitindo, por exemplo, vazamentos. }\end{array}$ & $\begin{array}{l}\text { FMD-97 } \\
(1997)\end{array}$ \\
\hline & & Falha na mola & $\begin{array}{l}\text { Em mecanismos de aplicação ou } \\
\text { desaplicação por mola, pode não } \\
\text { ocorrer a correta aplicação ou } \\
\text { desaplicação. }\end{array}$ & $\begin{array}{l}\text { FMD-97 } \\
(1997)\end{array}$ \\
\hline \multirow{2}{*}{$\begin{array}{l}\text { Disco de } \\
\text { freio - freio } \\
\text { mecânico }\end{array}$} & \multirow{2}{*}{$\begin{array}{l}\text { Em conjunto com } \\
\text { as pinças e } \\
\text { sapatas, garantir } \\
\text { a frenagem do } \\
\text { trem }\end{array}$} & $\begin{array}{l}\text { Coeficiente de atrito } \\
\text { fora dos parâmetros }\end{array}$ & $\begin{array}{l}\text { Coeficiente de atrito fora dos } \\
\text { parâmetros definidos, podendo causar } \\
\text { menor ou maior taxa de frenagem. }\end{array}$ & Hipótese \\
\hline & & Ruptura ou trinca & $\begin{array}{l}\text { Ruptura estrutural devido à quebra do } \\
\text { componente ou trincas que podem } \\
\text { comprometer o componente. }\end{array}$ & Hipótese \\
\hline
\end{tabular}

A Tabela 6.8 apresenta a análise do tipo FMEA para o sistema de tração e frenagem. 
Tabela 6.8 - FMEA Sistema de Tração/Frenagem

continua

\begin{tabular}{|c|c|c|c|c|c|c|c|c|c|c|c|c|}
\hline \multicolumn{13}{|c|}{ Sistema: Tração e Frenagem } \\
\hline \multirow{2}{*}{ 으 } & \multirow{2}{*}{ Item } & \multirow{2}{*}{ Função } & \multirow{2}{*}{$\begin{array}{l}\text { Modo de } \\
\text { Falha }\end{array}$} & \multirow{2}{*}{$\begin{array}{l}\text { Causas } \\
\text { prováveis }\end{array}$} & \multirow{2}{*}{$\begin{array}{c}\text { Modo } \\
\text { Operacional }\end{array}$} & \multicolumn{3}{|c|}{ Efeito das Falhas } & \multirow{2}{*}{$\begin{array}{l}\text { Modo de } \\
\text { Detecção }\end{array}$} & \multirow{2}{*}{ Ação de Gerenciamento } & \multirow{2}{*}{ Sev } & \multirow{2}{*}{ Notas } \\
\hline & & & & & & Item & Sistema & Trem & & & & \\
\hline$\frac{\frac{1}{1}}{\frac{1}{\alpha}}$ & \multirow{4}{*}{ 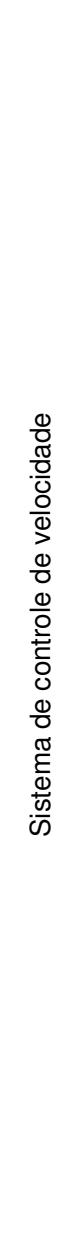 } & \multirow{4}{*}{ 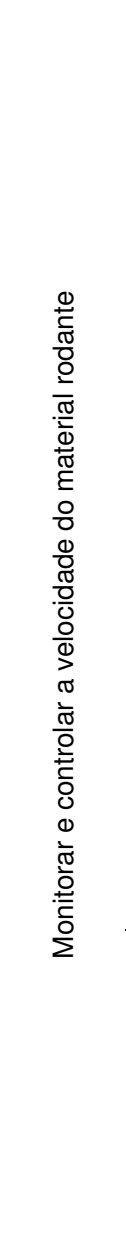 } & \multirow{3}{*}{$\begin{array}{l}\text { Aquisição } \\
\text { errada de } \\
\text { velocidade }\end{array}$} & $\begin{array}{l}\text { Sensores } \\
\text { em falha }\end{array}$ & $\begin{array}{c}\text { Em } \\
\text { movimento }\end{array}$ & $\begin{array}{l}\text { Falha na } \\
\text { aquisição de } \\
\text { velocidade }\end{array}$ & $\begin{array}{l}\text { Sistema não } \\
\text { recebe a } \\
\text { velocidade } \\
\text { correta }\end{array}$ & $\begin{array}{l}\text { Possível sobrevelocidade } \\
\text { no trem e, por exemplo, } \\
\text { em caso de curva pode } \\
\text { ocorrer sobreposição do } \\
\text { flange e descarrilamento. } \\
\text { Pode ainda haver } \\
\text { instabilidade devido a } \\
\text { baixa velocidade em } \\
\text { curva e descarrilamento. }\end{array}$ & $\begin{array}{c}\text { Projeto pode } \\
\text { prever a } \\
\text { sinalização deste } \\
\text { tipo de falha. } \\
\text { Pode-se realizar a } \\
\text { detecção da falha } \\
\text { na manutenção. }\end{array}$ & $\begin{array}{c}\text { Uso de redundâncias na } \\
\text { aquisição de velocidade do } \\
\text { trem associadas a um sistema } \\
\text { votador. } \\
\text { Manutenções periódicas dos } \\
\text { elementos de informação de } \\
\text { velocidade. } \\
\text { Para operação manual, } \\
\text { fornecer correto treinamento } \\
\text { aos operadores. }\end{array}$ & 1 & \\
\hline$\frac{m}{\frac{1}{\alpha}}$ & & & & $\begin{array}{l}\text { Falha no } \\
\text { projeto }\end{array}$ & $\begin{array}{c}\text { Em } \\
\text { movimento }\end{array}$ & $\begin{array}{l}\text { Falha no } \\
\text { Monitoramen } \\
\text { to e/ou } \\
\text { controle da } \\
\text { velocidade } \\
\text { do material } \\
\text { rodante }\end{array}$ & $\begin{array}{l}\text { Sistema não } \\
\text { realiza a sua } \\
\text { função }\end{array}$ & $\begin{array}{l}\text { Possível sobrevelocidade } \\
\text { no trem e, por exemplo, } \\
\text { em caso de curva pode } \\
\text { ocorrer sobreposição do } \\
\text { flange e descarrilamento. } \\
\text { Pode ainda haver } \\
\text { instabilidade devido a } \\
\text { baixa velocidade em } \\
\text { curva e descarrilamento. }\end{array}$ & $\begin{array}{c}\text { Simulação do } \\
\text { movimento. } \\
\text { Testes } \\
\text { operacionais. } \\
\text { Simulações } \\
\text { computacionais. }\end{array}$ & $\begin{array}{c}\text { Estudos e testes para a } \\
\text { averiguação da dinâmica do } \\
\text { movimento. } \\
\text { Elaboração de FMECA e FTA } \\
\text { detalhados dos sistemas para } \\
\text { identificação de falhas dos } \\
\text { componentes. }\end{array}$ & 1 & \\
\hline$\frac{1}{\frac{1}{\alpha}}$ & & & & $\begin{array}{l}\text { Conversão } \\
\text { de } \\
\text { velocidade } \\
\text { em falha }\end{array}$ & $\begin{array}{c}\text { Em } \\
\text { movimento }\end{array}$ & $\begin{array}{c}\text { Falha na } \\
\text { conversão } \\
\text { de } \\
\text { velocidade }\end{array}$ & $\begin{array}{c}\text { Sistema não } \\
\text { converte a } \\
\text { velocidade } \\
\text { correta }\end{array}$ & $\begin{array}{l}\text { Possível sobrevelocidade } \\
\text { no trem e, por exemplo, } \\
\text { em caso de curva pode } \\
\text { ocorrer sobreposição do } \\
\text { flange e descarrilamento. } \\
\text { Pode ainda haver } \\
\text { instabilidade devido a } \\
\text { baixa velocidade em } \\
\text { curva e descarrilamento. }\end{array}$ & $\begin{array}{c}\text { Projeto pode } \\
\text { prever a } \\
\text { sinalização deste } \\
\text { tipo de falha. } \\
\text { Pode-se realizar a } \\
\text { detecção da falha } \\
\text { na manutenção. }\end{array}$ & $\begin{array}{c}\text { Uso de redundâncias na } \\
\text { aquisição de velocidade do } \\
\text { trem associadas a um sistema } \\
\text { votador. } \\
\text { Manutenções periódicas dos } \\
\text { elementos de informação de } \\
\text { velocidade. } \\
\text { Para operação manual, } \\
\text { fornecer correto treinamento } \\
\text { aos operadores. }\end{array}$ & 1 & \\
\hline$\frac{\frac{1}{x}}{\frac{1}{\alpha}}$ & & & $\begin{array}{l}\text { Processame } \\
\text { nto errado } \\
\text { da } \\
\text { velocidade }\end{array}$ & $\begin{array}{l}\text { Processame } \\
\text { nto e/ou } \\
\text { Transmissão } \\
\text { de } \\
\text { informação } \\
\text { em falha }\end{array}$ & $\begin{array}{c}\text { Em } \\
\text { movimento }\end{array}$ & $\begin{array}{c}\text { Falha na } \\
\text { transmissão } \\
\text { da } \\
\text { informação } \\
\text { de } \\
\text { velocidade }\end{array}$ & $\begin{array}{c}\text { Sistema não } \\
\text { realiza } \\
\text { devidamente } \\
\text { a sua função }\end{array}$ & $\begin{array}{l}\text { Possível sobrevelocidade } \\
\text { no trem e, por exemplo, } \\
\text { em caso de curva pode } \\
\text { ocorrer sobreposição do } \\
\text { flange e descarrilamento. } \\
\text { Pode ainda haver } \\
\text { instabilidade devido a } \\
\text { baixa velocidade em } \\
\text { curva e descarrilamento. }\end{array}$ & $\begin{array}{c}\text { Projeto pode } \\
\text { prever a } \\
\text { sinalização deste } \\
\text { tipo de falha. } \\
\text { Pode-se realizar a } \\
\text { detecção da falha } \\
\text { na manutenção. }\end{array}$ & $\begin{array}{c}\text { Uso de redundâncias na } \\
\text { aquisição de velocidade do } \\
\text { trem associadas a um sistema } \\
\text { votador. } \\
\text { Manutenções periódicas dos } \\
\text { elementos de informação de } \\
\text { velocidade. } \\
\text { Para operação manual, } \\
\text { fornecer correto treinamento } \\
\text { aos operadores. }\end{array}$ & 1 & \\
\hline
\end{tabular}


continuação

\begin{tabular}{|c|c|c|c|c|c|c|c|c|c|c|c|c|}
\hline \multicolumn{13}{|c|}{ Sistema: Tração e Frenagem } \\
\hline \multirow{2}{*}{ 으 } & \multirow{2}{*}{ Item } & \multirow{2}{*}{ Função } & \multirow{2}{*}{ Modo de Falha } & \multirow{2}{*}{$\begin{array}{l}\text { Causas } \\
\text { prováveis }\end{array}$} & \multirow{2}{*}{$\begin{array}{c}\text { Modo } \\
\text { Operacional }\end{array}$} & \multicolumn{3}{|c|}{ Efeito das Falhas } & \multirow{2}{*}{$\begin{array}{l}\text { Modo de } \\
\text { Detecção }\end{array}$} & \multirow{2}{*}{ Ação de Gerenciamento } & \multirow{2}{*}{ Sev } & \multirow{2}{*}{ Notas } \\
\hline & & & & & & Item & Sistema & Trem & & & & \\
\hline $\begin{array}{l}\mathbb{1} \\
\underset{\sim}{\dddot{\alpha}} \\
\frac{1}{\alpha}\end{array}$ & \multirow{2}{*}{ 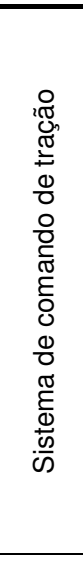 } & \multirow{2}{*}{ 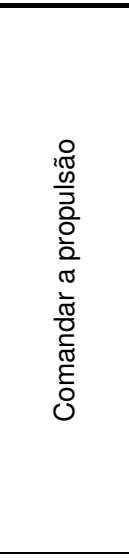 } & \multirow[b]{2}{*}{$\begin{array}{l}\text { Comando } \\
\text { errôneo de } \\
\text { propulsão }\end{array}$} & $\begin{array}{l}\text { Erro de } \\
\text { projeto }\end{array}$ & \multirow[b]{2}{*}{$\begin{array}{c}\text { Em } \\
\text { movimento }\end{array}$} & \multirow[b]{2}{*}{$\begin{array}{c}\text { Falha no } \\
\text { comando da } \\
\text { velocidade de } \\
\text { operação }\end{array}$} & \multirow[b]{2}{*}{$\begin{array}{c}\text { Sistema não } \\
\text { realiza } \\
\text { devidamente } \\
\text { a sua função }\end{array}$} & \multirow{2}{*}{$\begin{array}{c}\text { Possível } \\
\text { sobrevelocidade no } \\
\text { trem e, por exemplo, } \\
\text { em caso de curva } \\
\text { pode ocorrer } \\
\text { sobreposição do } \\
\text { flange e } \\
\text { descarrilamento. } \\
\text { Pode ainda haver } \\
\text { instabilidade devido } \\
\text { a baixa velocidade } \\
\text { em curva e } \\
\text { descarrilamento. }\end{array}$} & $\begin{array}{l}\text { Simulação do } \\
\text { movimento. } \\
\text { Testes } \\
\text { operacionais. } \\
\text { Simulações } \\
\text { computacionais. }\end{array}$ & $\begin{array}{c}\text { Estudos e testes para a } \\
\text { averiguação da dinâmica do } \\
\text { movimento. } \\
\text { Elaboração de FMECA e } \\
\text { FTA detalhados dos } \\
\text { sistemas para identificação } \\
\text { de falhas dos componentes. }\end{array}$ & 1 & \\
\hline $\begin{array}{l}\stackrel{m}{\sim} \\
\underset{\sim}{\alpha}\end{array}$ & & & & $\begin{array}{l}\text { Falha do } \\
\text { sistema }\end{array}$ & & & & & $\begin{array}{c}\text { Projeto pode } \\
\text { prever a } \\
\text { sinalização deste } \\
\text { tipo de falha. } \\
\text { Pode-se realizar a } \\
\text { detecção da falha } \\
\text { na manutenção. }\end{array}$ & $\begin{array}{l}\text { Uso de redundâncias na } \\
\text { aquisição de velocidade do } \\
\text { trem associadas a um } \\
\text { sistema votador. } \\
\text { Manutenções periódicas } \\
\text { dos elementos de } \\
\text { informação de velocidade. } \\
\text { Para operação manual, } \\
\text { fornecer correto treinamento } \\
\text { aos operadores. }\end{array}$ & 1 & \\
\hline 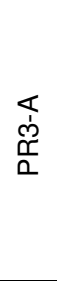 & \multirow{4}{*}{ 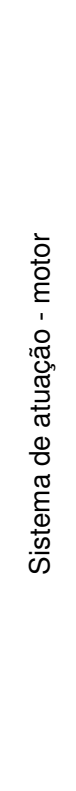 } & \multirow{4}{*}{ 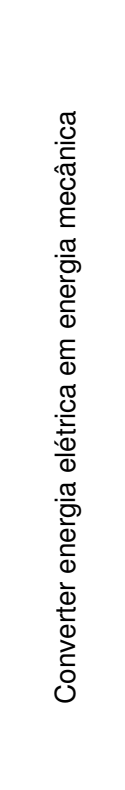 } & $\begin{array}{l}1 \text { - Falha de } \\
\text { ventilação (que } \\
\text { acarrete no } \\
\text { travamento do } \\
\text { motor) } \\
2 \text { - Falha no } \\
\text { rolamento }\end{array}$ & $\begin{array}{l}\text { Manutenç } \\
\text { ão } \\
\text { deficiente }\end{array}$ & $\begin{array}{c}\text { Em } \\
\text { movimento }\end{array}$ & $\begin{array}{c}\text { Motor não se } \\
\text { movimenta }\end{array}$ & $\begin{array}{l}\text { Travamento } \\
\text { do eixo }\end{array}$ & $\begin{array}{c}\text { Em princípio maior } \\
\text { atrito no eixo com } \\
\text { possível } \\
\text { descarrilamento por } \\
\text { possível } \\
\text { sobreposição do } \\
\text { flange ou } \\
\text { instabilidade lateral. }\end{array}$ & $\begin{array}{l}\text { Detectável em } \\
\text { manutenções } \\
\text { periódicas. }\end{array}$ & $\begin{array}{l}\text { Fornecimento de correto } \\
\text { treinamento e determinação } \\
\text { dos corretos intervalos de } \\
\text { manutenção } \\
\text { Pode-se inserir um } \\
\text { monitoramento da } \\
\text { temperatura do motor. }\end{array}$ & 1 & \\
\hline 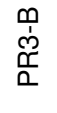 & & & \multirow[b]{2}{*}{$\begin{array}{l}1 \text { - Falha na } \\
\text { operação } \\
\text { depois da } \\
\text { partida }\end{array}$} & $\begin{array}{l}\text { Queima } \\
\text { do motor }\end{array}$ & $\begin{array}{c}\text { Em } \\
\text { movimento }\end{array}$ & - & - & - & - & - & - & $\begin{array}{l}\text { Sem impacto para } \\
\text { o descarrilamento }\end{array}$ \\
\hline 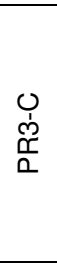 & & & & $\begin{array}{l}\text { Travamen } \\
\text { to do eixo }\end{array}$ & $\begin{array}{c}\text { Em } \\
\text { movimento }\end{array}$ & $\begin{array}{l}\text { Motor não se } \\
\text { movimenta }\end{array}$ & $\begin{array}{l}\text { Travamento } \\
\text { do eixo }\end{array}$ & $\begin{array}{l}\text { Em princípio maior } \\
\text { atrito no eixo com } \\
\text { possível } \\
\text { descarrilamento por } \\
\text { possível } \\
\text { sobreposição do } \\
\text { flange ou } \\
\text { instabilidade lateral. }\end{array}$ & $\begin{array}{l}\text { Detectável em } \\
\text { manutenções } \\
\text { periódicas. }\end{array}$ & $\begin{array}{l}\text { Fornecimento de correto } \\
\text { treinamento e determinação } \\
\text { dos corretos intervalos de } \\
\text { manutenção } \\
\text { Pode-se inserir um } \\
\text { monitoramento da } \\
\text { temperatura do motor. }\end{array}$ & 1 & \\
\hline $\begin{array}{l}\stackrel{p}{1} \\
\stackrel{m}{\dddot{m}} \\
\stackrel{0}{\alpha}\end{array}$ & & & $\begin{array}{l}2 \text { - Falha de } \\
\text { partida }\end{array}$ & - & - & - & - & - & - & - & - & $\begin{array}{l}\text { Sem impacto para } \\
\text { o descarrilamento }\end{array}$ \\
\hline
\end{tabular}


continuação

\begin{tabular}{|c|c|c|c|c|c|c|c|c|c|c|c|c|}
\hline \multicolumn{13}{|c|}{ Sistema: Tração e Frenagem } \\
\hline \multirow{2}{*}{ 으 } & \multirow{2}{*}{ Item } & \multirow{2}{*}{ Função } & \multirow{2}{*}{$\begin{array}{l}\text { Modo de } \\
\text { Falha }\end{array}$} & \multirow{2}{*}{$\begin{array}{l}\text { Causas } \\
\text { prováveis }\end{array}$} & \multirow{2}{*}{$\begin{array}{c}\text { Modo } \\
\text { Operacional }\end{array}$} & \multicolumn{3}{|c|}{ Efeito das Falhas } & \multirow{2}{*}{$\begin{array}{l}\text { Modo de } \\
\text { Detecção }\end{array}$} & \multirow{2}{*}{ Ação de Gerenciamento } & \multirow{2}{*}{ Sev } & \multirow{2}{*}{ Notas } \\
\hline & & & & & & Item & Sistema & Trem & & & & \\
\hline \multirow{2}{*}{ 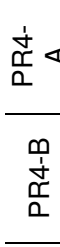 } & \multirow{2}{*}{ 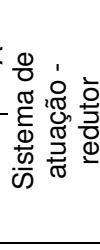 } & \multirow{2}{*}{ 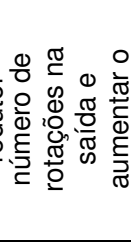 } & \multirow{2}{*}{$\begin{array}{l}\text { Perda de } \\
\text { lubrificação } \\
\text { Falha de } \\
\text { vedação } \\
\text { Desgaste }\end{array}$} & $\begin{array}{l}\text { Manutenção } \\
\text { deficiente }\end{array}$ & \multirow{2}{*}{$\begin{array}{c}\text { Em } \\
\text { movimento }\end{array}$} & \multirow{2}{*}{$\begin{array}{l}\text { Travamento } \\
\text { do redutor }\end{array}$} & \multirow{2}{*}{$\begin{array}{l}\text { Travamento } \\
\text { do eixo }\end{array}$} & \multirow{2}{*}{$\begin{array}{l}\text { Em princípio maior atrito } \\
\text { no eixo com possível } \\
\text { descarrilamento por } \\
\text { possível sobreposição do } \\
\text { flange ou instabilidade } \\
\text { lateral. }\end{array}$} & $\begin{array}{l}\text { Detectável em } \\
\text { manutenções } \\
\text { periódicas. }\end{array}$ & $\begin{array}{l}\text { Fornecimento de correto } \\
\text { treinamento e determinação dos } \\
\text { corretos intervalos de manutenção. }\end{array}$ & 1 & \\
\hline & & & & $\begin{array}{l}\text { Erro de } \\
\text { manufatura }\end{array}$ & & & & & $\begin{array}{c}\text { Detectável em } \\
\text { teste operacional } \\
\text { ou manutenção } \\
\text { periódica. }\end{array}$ & $\begin{array}{l}\text { Determinação dos corretos } \\
\text { intervalos de manutenção e } \\
\text { controle de qualidade. }\end{array}$ & 1 & \\
\hline$\frac{\mathbb{1}}{\frac{1}{\widetilde{r}}}$ & \multirow{4}{*}{ 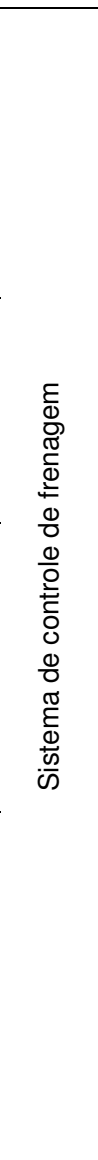 } & \multirow{4}{*}{ 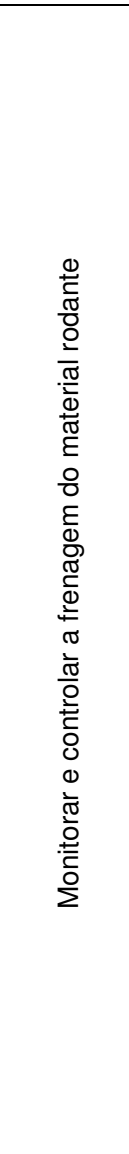 } & \multirow{3}{*}{$\begin{array}{l}\text { Aquisição } \\
\text { errada do } \\
\text { esforço de } \\
\text { frenagem }\end{array}$} & $\begin{array}{l}\text { Sensores } \\
\text { em falha }\end{array}$ & \multirow{3}{*}{$\begin{array}{c}\text { Em } \\
\text { movimento }\end{array}$} & \multirow{3}{*}{$\begin{array}{l}\text { Falha na } \\
\text { aquisição do } \\
\text { esforço de } \\
\text { frenagem }\end{array}$} & \multirow{3}{*}{$\begin{array}{l}\text { Sistema não } \\
\text { recebe a } \\
\text { informação } \\
\text { de esforço } \\
\text { correta }\end{array}$} & \multirow{3}{*}{$\begin{array}{c}\text { Possível sobrevelocidade } \\
\text { no trem e, por exemplo, } \\
\text { em caso de curva pode } \\
\text { ocorrer sobreposição do } \\
\text { flange. } \\
\text { Pode ocorrer ainda } \\
\text { travamento do eixo. } \\
\text { Pode ainda haver } \\
\text { instabilidade devido a } \\
\text { baixa velocidade em } \\
\text { curva e descarrilamento. }\end{array}$} & $\begin{array}{l}\text { Projeto pode } \\
\text { prever a } \\
\text { sinalização deste } \\
\text { tipo de falha. } \\
\text { Pode-se realizar a } \\
\text { detecção da falha } \\
\text { na manutenção. }\end{array}$ & $\begin{array}{c}\text { Uso de redundâncias na aquisição } \\
\text { de velocidade do trem associadas a } \\
\text { um sistema votador. } \\
\text { Manutenções periódicas dos } \\
\text { elementos de informação de } \\
\text { velocidade. } \\
\text { Para operação manual, fornecer } \\
\text { correto treinamento aos } \\
\text { operadores. }\end{array}$ & 1 & \\
\hline$\frac{m}{\frac{1}{\dddot{r}}}$ & & & & $\begin{array}{l}\text { Falha no } \\
\text { projeto }\end{array}$ & & & & & $\begin{array}{c}\text { Simulação } \\
\text { dinâmica do } \\
\text { movimento. } \\
\text { Testes } \\
\text { operacionais. } \\
\text { Simulações } \\
\text { computacionais. } \\
\end{array}$ & $\begin{array}{c}\text { Estudos e testes para a } \\
\text { averiguação da dinâmica do } \\
\text { movimento. } \\
\text { Elaboração de FMECA e FTA } \\
\text { detalhados dos sistemas para } \\
\text { identificação de falhas dos } \\
\text { componentes. } \\
\end{array}$ & 1 & \\
\hline$\frac{0}{\frac{1}{1}}$ & & & & $\begin{array}{l}\text { Conversão } \\
\text { do esforço } \\
\text { em falha }\end{array}$ & & & & & $\begin{array}{c}\text { Projeto pode } \\
\text { prever a } \\
\text { sinalização deste } \\
\text { tipo de falha. } \\
\text { Pode-se realizar a } \\
\text { detecção da falha } \\
\text { na manutenção. }\end{array}$ & $\begin{array}{c}\text { Uso de redundâncias na aquisição } \\
\text { de velocidade do trem associadas a } \\
\text { um sistema votador. } \\
\text { Manutenções periódicas dos } \\
\text { elementos de informação de } \\
\text { velocidade. } \\
\text { Para operação manual, fornecer } \\
\text { correto treinamento aos } \\
\text { operadores. } \\
\end{array}$ & 1 & \\
\hline 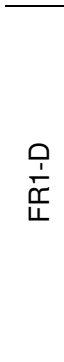 & & & $\begin{array}{l}\text { Controle } \\
\text { errado do } \\
\text { esforço de } \\
\text { frenagem }\end{array}$ & $\begin{array}{l}\text { Processame } \\
\text { nto ou } \\
\text { transmissão } \\
\text { errada da } \\
\text { informação }\end{array}$ & $\begin{array}{c}\text { Em } \\
\text { movimento }\end{array}$ & $\begin{array}{c}\text { Falha na } \\
\text { transmissão } \\
\text { da } \\
\text { informação } \\
\text { de esforço }\end{array}$ & $\begin{array}{l}\text { Sistema não } \\
\text { realiza } \\
\text { devidamente } \\
\text { a sua função }\end{array}$ & $\begin{array}{l}\text { Possível sobrevelocidade } \\
\text { no trem e, por exemplo, } \\
\text { em caso de curva pode } \\
\text { ocorrer sobreposição do } \\
\text { flange. } \\
\text { Pode ocorrer ainda } \\
\text { travamento do eixo. } \\
\text { Pode ainda haver } \\
\text { instabilidade devido a } \\
\text { baixa velocidade em } \\
\text { curva e descarrilamento. }\end{array}$ & $\begin{array}{c}\text { Projeto pode } \\
\text { prever a } \\
\text { sinalização deste } \\
\text { tipo de falha. } \\
\text { Pode-se realizar a } \\
\text { detecção da falha } \\
\text { na manutenção. }\end{array}$ & $\begin{array}{c}\text { Uso de redundâncias na aquisição } \\
\text { de velocidade do trem associadas a } \\
\text { um sistema votador. } \\
\text { Manutenções periódicas dos } \\
\text { elementos de informação de } \\
\text { velocidade. } \\
\text { Para operação manual, fornecer } \\
\text { correto treinamento aos } \\
\text { operadores. }\end{array}$ & 1 & \\
\hline
\end{tabular}


continuação

\begin{tabular}{|c|c|c|c|c|c|c|c|c|c|c|c|c|}
\hline \multicolumn{13}{|c|}{ Sistema: Tração e Frenagem } \\
\hline \multirow{2}{*}{ 으 } & \multirow{2}{*}{ Item } & \multirow{2}{*}{ Função } & \multirow{2}{*}{ Modo de Falha } & \multirow{2}{*}{$\begin{array}{l}\text { Causas } \\
\text { prováveis }\end{array}$} & \multirow{2}{*}{$\begin{array}{c}\text { Modo } \\
\text { Operacional }\end{array}$} & \multicolumn{3}{|c|}{ Efeito das Falhas } & \multirow{2}{*}{$\begin{array}{l}\text { Modo de } \\
\text { Detecção }\end{array}$} & \multirow{2}{*}{ Ação de Gerenciamento } & \multirow{2}{*}{ Sev } & \multirow{2}{*}{ Notas } \\
\hline & & & & & & Item & Sistema & Trem & & & & \\
\hline 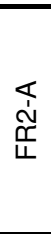 & & $\frac{\varepsilon}{\varrho}$ & $\begin{array}{l}1 \text { - Fissura } \\
2 \text { - Deteriorado }\end{array}$ & $\begin{array}{l}\text { Erro de } \\
\text { manufatura } \\
\text { ou projeto }\end{array}$ & $\begin{array}{c}\text { Em } \\
\text { movimento }\end{array}$ & $\begin{array}{l}\text { Componente } \\
\text { não atua } \\
\text { corretamente }\end{array}$ & $\begin{array}{c}\text { Perda da } \\
\text { capacidade } \\
\text { de frenagem }\end{array}$ & $\begin{array}{c}\text { Possível } \\
\text { sobrevelocidade no } \\
\text { trem e, por exemplo, } \\
\text { em caso de curva } \\
\text { pode ocorrer }\end{array}$ & $\begin{array}{c}\text { Simulação } \\
\text { dinâmica do } \\
\text { movimento. } \\
\text { Testes } \\
\text { operacionais. } \\
\text { Simulações } \\
\text { computacionais. }\end{array}$ & $\begin{array}{c}\text { Estudos e testes para a } \\
\text { averiguação da dinâmica do } \\
\text { movimento. } \\
\text { Correta averiguação das } \\
\text { condições e ambiente de uso. }\end{array}$ & I & \\
\hline $\begin{array}{l}\stackrel{\infty}{1} \\
\stackrel{\sim}{\dddot{\sim}} \\
\stackrel{\sim}{\Psi}\end{array}$ & & 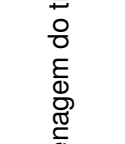 & 3 - Marcada & $\begin{array}{l}\text { Desgaste } \\
\text { excessivo ou } \\
\text { manutenção } \\
\text { incorreta }\end{array}$ & & & & $\begin{array}{l}\text { sobreposição do } \\
\text { flange. }\end{array}$ & $\begin{array}{l}\text { Sinais de } \\
\text { desgaste } \\
\text { detectável em } \\
\text { manutenção. }\end{array}$ & $\begin{array}{l}\text { Manutenção periódica deste } \\
\text { item e fornecimento de } \\
\text { treinamento para manutenção. }\end{array}$ & I & \\
\hline 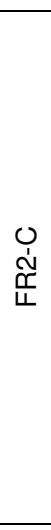 & 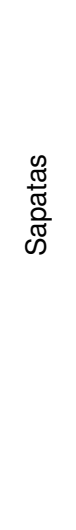 & 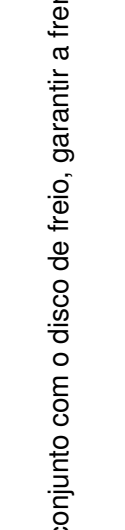 & Prendendo & $\begin{array}{l}\text { Erro de } \\
\text { manufatura } \\
\text { ou projeto }\end{array}$ & $\begin{array}{c}\text { Em } \\
\text { movimento }\end{array}$ & $\begin{array}{l}\text { Componente } \\
\text { não atua } \\
\text { corretamente }\end{array}$ & $\begin{array}{l}\text { Excesso de } \\
\text { frenagem } \\
\text { caso não } \\
\text { haja o } \\
\text { correto alívio } \\
\text { de freio ou } \\
\text { desgaste } \\
\text { prematuro } \\
\text { da pastilha }\end{array}$ & $\begin{array}{c}\text { Possível } \\
\text { sobrevelocidade no } \\
\text { trem e, por exemplo, } \\
\text { em caso de curva } \\
\text { pode ocorrer } \\
\text { sobreposição do } \\
\text { flange em caso de } \\
\text { desgaste } \\
\text { prematuro. } \\
\text { Pode ocorrer ainda } \\
\text { travamento do eixo. } \\
\text { Pode ainda haver } \\
\text { instabilidade devido } \\
\text { a baixa velocidade } \\
\text { em curva e } \\
\text { descarrilamento. } \\
\end{array}$ & $\begin{array}{l}\text { Simulação do } \\
\text { movimento. } \\
\text { Testes } \\
\text { operacionais. } \\
\text { Simulações } \\
\text { computacionais. } \\
\text { Inspeções } \\
\text { periódicas. }\end{array}$ & $\begin{array}{l}\text { Estudos e testes para a } \\
\text { averiguação da dinâmica do } \\
\text { movimento. } \\
\text { Deve-se efetuar a inspeção } \\
\text { periódica do item. } \\
\text { Elaboração de FMECA e FTA } \\
\text { detalhados dos sistemas para } \\
\text { identificação de falhas dos } \\
\text { componentes. }\end{array}$ & I & \\
\hline 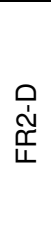 & & 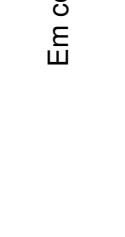 & $\begin{array}{l}\text { Acúmulo de } \\
\text { Metais }\end{array}$ & $\begin{array}{l}\text { Falha de } \\
\text { manutenção }\end{array}$ & $\begin{array}{c}\text { Em } \\
\text { movimento }\end{array}$ & $\begin{array}{l}\text { Componente } \\
\text { não atua } \\
\text { corretamente }\end{array}$ & $\begin{array}{c}\text { Perda da } \\
\text { capacidade } \\
\text { de frenagem }\end{array}$ & $\begin{array}{c}\text { Possível } \\
\text { sobrevelocidade no } \\
\text { trem e, por exemplo, } \\
\text { em caso de curva } \\
\text { pode ocorrer } \\
\text { sobreposição do } \\
\text { flange. }\end{array}$ & $\begin{array}{l}\text { Detectável pela } \\
\text { inspeção visual } \\
\text { das pastilhas. }\end{array}$ & $\begin{array}{l}\text { O manual deve contemplar a } \\
\text { inspeção e os funcionários de } \\
\text { manutenção devem receber } \\
\text { correto treinamento }\end{array}$ & I & \\
\hline
\end{tabular}


continuação

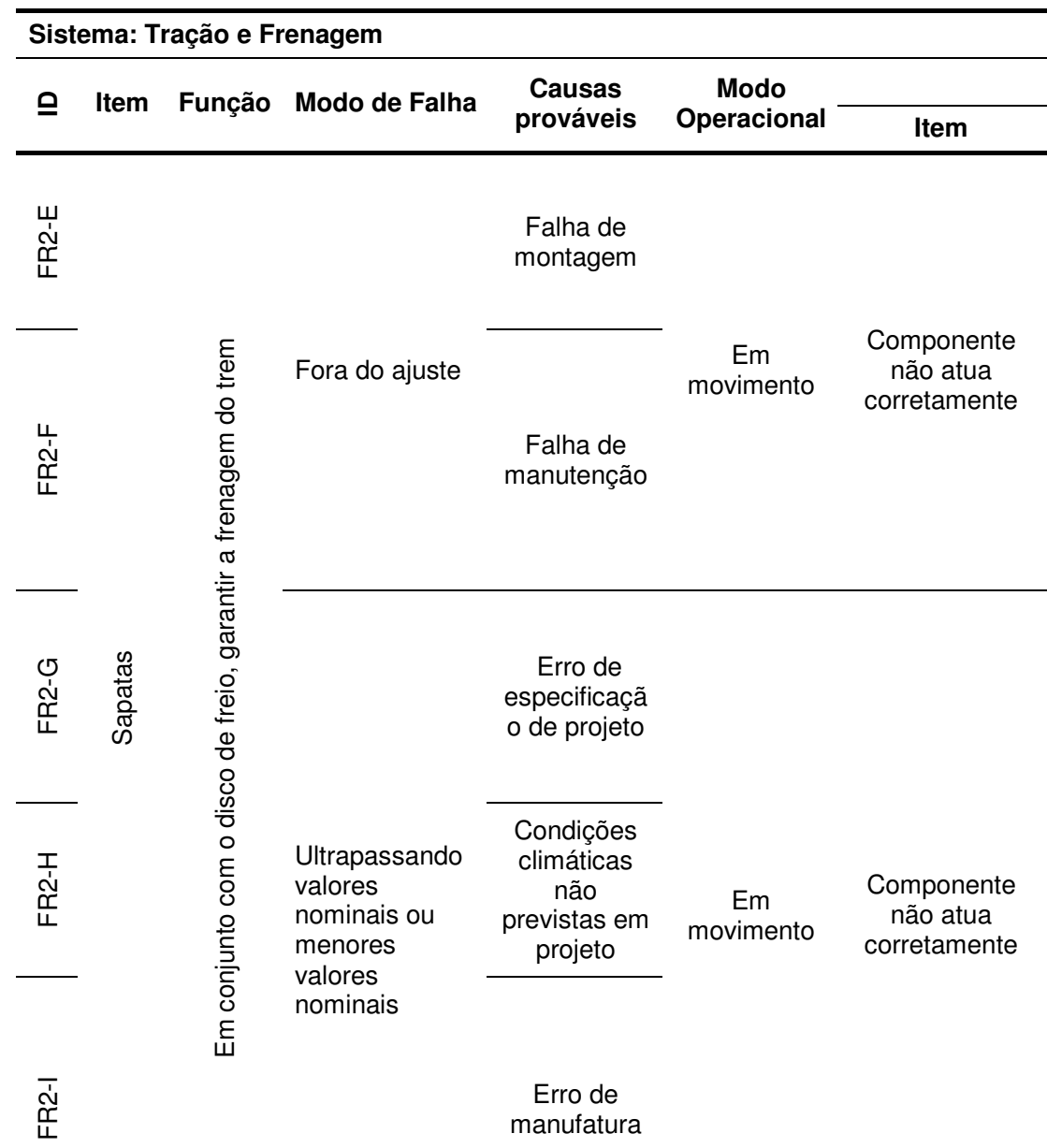

\section{Efeito das Falhas}

Trem

Possível

sobrevelocidade no

trem e, por exemplo,

em caso de curva

$\begin{array}{cc}\text { Perda da } & \text { pode ocorrer } \\ \text { sobreposição do }\end{array}$

capacidade flange.

ou excesso Pode ocorrer ainda

de frenagem travamento do eixo.

Pode ainda haver

instabilidade devido

a baixa velocidade

descarrilamento.

Detectável pela O manual deve contemplar a

inspeção visual inspeção e os funcionários de

das pastilhas. manutenção devem receber

correto treinamento.

manufatura

\begin{tabular}{|c|c|c|c|c|}
\hline \multirow{3}{*}{$\begin{array}{l}\text { Perda da } \\
\text { capacidade } \\
\text { de frenagem } \\
\text { ou excesso } \\
\text { de frenagem }\end{array}$} & \multirow{3}{*}{$\begin{array}{c}\text { Possível } \\
\text { sobrevelocidade no } \\
\text { trem e, por exemplo, } \\
\text { em caso de curva } \\
\text { pode ocorrer } \\
\text { sobreposição do } \\
\text { flange. } \\
\text { Pode ainda haver } \\
\text { instabilidade devido } \\
\text { a baixa velocidade } \\
\text { em curva e } \\
\text { descarrilamento. } \\
\text { Pode ocorrer ainda } \\
\text { travamento do eixo. }\end{array}$} & $\begin{array}{l}\text { Simulação do } \\
\text { movimento. } \\
\text { Testes } \\
\text { operacionais. } \\
\text { Simulações } \\
\text { computacionais. }\end{array}$ & $\begin{array}{l}\text { Estudos e testes para a } \\
\text { averiguação da dinâmica do } \\
\text { movimento. }\end{array}$ & I \\
\hline & & $\begin{array}{l}\text { Sinais de } \\
\text { desgaste } \\
\text { detectável em } \\
\text { manutenção. }\end{array}$ & $\begin{array}{c}\text { Manutenção periódica deste } \\
\text { item } \\
\text { Checagem das condições } \\
\text { climáticas antes de projeto. }\end{array}$ & I \\
\hline & & $\begin{array}{l}\text { Controle de } \\
\text { qualidade dos } \\
\text { itens. } \\
\text { Simulação do } \\
\text { movimento. } \\
\text { Testes } \\
\text { operacionais. }\end{array}$ & $\begin{array}{c}\text { Este item deve ser } \\
\text { inspecionado em controle de } \\
\text { qualidade. } \\
\text { Estudos e testes para a } \\
\text { averiguação da dinâmica do } \\
\text { movimento. }\end{array}$ & I \\
\hline
\end{tabular}


continuação

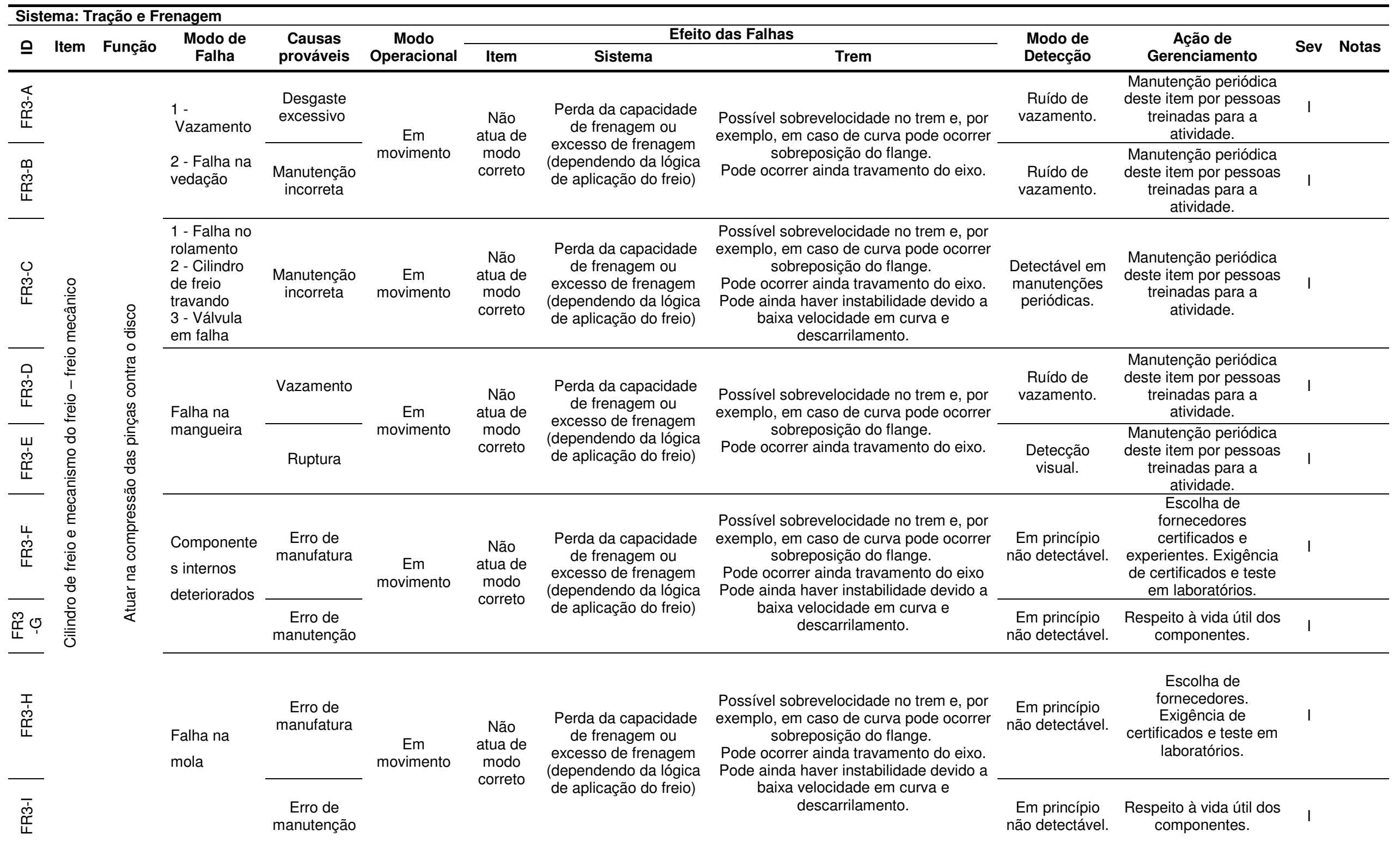


conclusão

\begin{tabular}{|c|c|c|c|c|c|c|c|c|c|c|c|c|}
\hline \multicolumn{13}{|c|}{ Sistema: Tração e Frenagem } \\
\hline \multirow{2}{*}{ 으 } & \multirow{2}{*}{ Item } & \multirow{2}{*}{ Função } & \multirow{2}{*}{ Modo de Falha } & \multirow{2}{*}{$\begin{array}{l}\text { Causas } \\
\text { prováveis }\end{array}$} & \multirow{2}{*}{$\begin{array}{c}\text { Modo } \\
\text { Operacional }\end{array}$} & \multicolumn{3}{|c|}{ Efeito das Falhas } & \multirow{2}{*}{$\begin{array}{l}\text { Modo de } \\
\text { Detecção }\end{array}$} & \multirow{2}{*}{ Ação de Gerenciamento } & \multirow{2}{*}{ Sev } & \multirow{2}{*}{ Notas } \\
\hline & & & & & & Item & Sistema & Trem & & & & \\
\hline 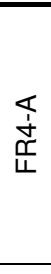 & \multirow{5}{*}{ 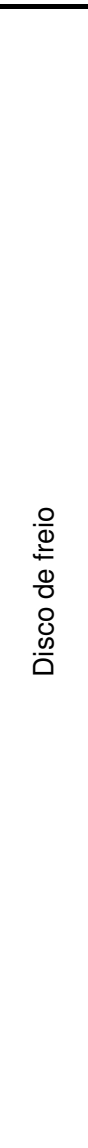 } & \multirow{5}{*}{ 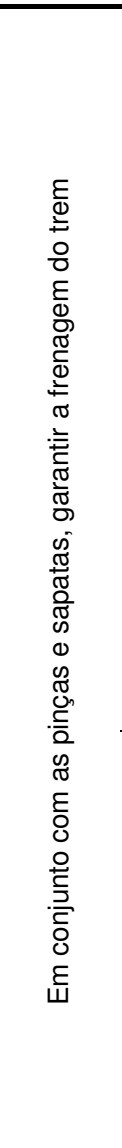 } & \multirow{3}{*}{$\begin{array}{l}\text { Coeficiente de } \\
\text { atrito fora dos } \\
\text { parâmetros }\end{array}$} & $\begin{array}{c}\text { Erro de } \\
\text { especificaçã } \\
\text { o de projeto }\end{array}$ & \multirow{3}{*}{$\begin{array}{c}\text { Em } \\
\text { movimento }\end{array}$} & \multirow{3}{*}{$\begin{array}{l}\text { Componente } \\
\text { não atua } \\
\text { corretamente }\end{array}$} & \multirow{3}{*}{$\begin{array}{l}\text { Perda da } \\
\text { capacidade de } \\
\text { frenagem ou } \\
\text { excesso de } \\
\text { frenagem }\end{array}$} & \multirow{3}{*}{$\begin{array}{l}\text { Possível sobrevelocidade } \\
\text { no trem e, por exemplo, } \\
\text { em caso de curva pode } \\
\text { ocorrer sobreposição do } \\
\text { flange. } \\
\text { Pode ocorrer ainda } \\
\text { travamento do eixo ou } \\
\text { haver instabilidade } \\
\text { devido a baixa } \\
\text { velocidade em curva e } \\
\text { descarrilamento. }\end{array}$} & $\begin{array}{l}\text { Simulação do } \\
\text { movimento. } \\
\text { Testes } \\
\text { operacionais. } \\
\text { Simulações } \\
\text { computacionais }\end{array}$ & $\begin{array}{l}\text { Estudos e testes para a } \\
\text { averiguação da dinâmica } \\
\text { do movimento. } \\
\text { Elaboração de FMECA e } \\
\text { FTA detalhados dos } \\
\text { sistemas para } \\
\text { identificação de falhas } \\
\text { dos componentes. } \\
\end{array}$ & 1 & \\
\hline 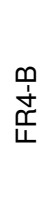 & & & & $\begin{array}{l}\text { Condições } \\
\text { climáticas } \\
\text { não } \\
\text { previstas em } \\
\text { projeto }\end{array}$ & & & & & $\begin{array}{l}\text { Sinais de } \\
\text { desgaste } \\
\text { detectável em } \\
\text { manutenção. }\end{array}$ & $\begin{array}{l}\text { Manutenção periódica } \\
\text { deste item. } \\
\text { Checagem das } \\
\text { condições climáticas } \\
\text { antes de projeto. }\end{array}$ & I & \\
\hline 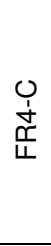 & & & & $\begin{array}{l}\text { Erro de } \\
\text { manufatura }\end{array}$ & & & & & $\begin{array}{c}\text { Controle de } \\
\text { qualidade dos } \\
\text { itens. } \\
\text { Simulação do } \\
\text { movimento. } \\
\text { Testes } \\
\text { operacionais. }\end{array}$ & $\begin{array}{c}\text { Este item deve ser } \\
\text { inspecionado em controle } \\
\text { de qualidade. } \\
\text { Estudos e testes para a } \\
\text { averiguação da dinâmica } \\
\text { do movimento. }\end{array}$ & I & \\
\hline 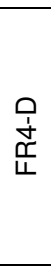 & & & \multirow[t]{2}{*}{$\begin{array}{l}\text { Ruptura ou } \\
\text { trinca }\end{array}$} & $\begin{array}{l}\text { Erro de } \\
\text { manufatura } \\
\text { ou projeto }\end{array}$ & \multirow[t]{2}{*}{$\begin{array}{c}\text { Em } \\
\text { movimento }\end{array}$} & \multirow[t]{2}{*}{$\begin{array}{l}\text { Componente } \\
\text { não atua } \\
\text { corretamente }\end{array}$} & \multirow[t]{2}{*}{$\begin{array}{l}\text { Perda da } \\
\text { capacidade de } \\
\text { frenagem }\end{array}$} & \multirow{2}{*}{$\begin{array}{l}\text { Possível sobrevelocidade } \\
\text { no trem e, por exemplo, } \\
\text { em caso de curva pode } \\
\text { ocorrer sobreposição do } \\
\text { flange. }\end{array}$} & $\begin{array}{c}\text { Simulação } \\
\text { dinâmica do } \\
\text { movimento. } \\
\text { Testes } \\
\text { operacionais. } \\
\text { Simulações } \\
\text { computacionais }\end{array}$ & $\begin{array}{c}\text { Estudos e testes para a } \\
\text { averiguação da dinâmica } \\
\text { do movimento. } \\
\text { Correta averiguação das } \\
\text { condições e ambiente de } \\
\text { uso. } \\
\text { Verificação do processo } \\
\text { de fabricação. }\end{array}$ & I & \\
\hline 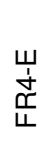 & & & & $\begin{array}{l}\text { Desgaste } \\
\text { excessivo ou } \\
\text { manutenção } \\
\text { incorreta }\end{array}$ & & & & & $\begin{array}{l}\text { Sinais de } \\
\text { desgaste } \\
\text { detectável em } \\
\text { manutenção. }\end{array}$ & $\begin{array}{c}\text { Manutenção periódica } \\
\text { deste item por pessoas } \\
\text { treinadas para a } \\
\text { atividade. }\end{array}$ & I & \\
\hline
\end{tabular}


Em suma, as ações de gerenciamento recomendadas na Tabela 6.8 são:

- correta manutenção dos sistemas e componentes, fornecendo treinamento aos manutentores e documentação coerente e clara para esta atividade, sendo que para tal pode-se seguir a manutenção centrada em confiabilidade conforme item 7.4.1;

- estudos e testes para a averiguação da dinâmica do movimento (mais detalhes já apresentados em 5.1);

- elaboração de FMECA e FTA detalhadas dos sistemas para identificação de falhas dos componentes;

- inspeção durante a manufatura/montagem, podendo ser realizadas pelo controle de qualidade dos componentes fabricados bem como a exigência de certificados disponibilizados pelos fornecedores quanto à qualidade de produto fabricado e quanto à experiência de fornecimento (mais detalhes em 7.2.2);

- uso de sistemas com maior confiabilidade na aquisição, transmissão, conversão e comando da tração e esforço de frenagem do trem;

- é recomendável inserir um monitoramento da temperatura do motor;

- em operação manual, correto treinamento dos operadores/condutores para o respeito das velocidades e outros parâmetros de operação;

- durante projeto, respeito às condições climáticas e de operação e certificação do respeito destas condições durante esta operação;

- respeito à vida útil dos componentes;

- correta determinação do processo de fabricação, por exemplo utilizando-se a ferramenta intitulada FMECA de processo conforme discussão em 7.2.1.

\subsection{5 - FATORES DIVERSOS}

Existem diversas outras falhas que podem causar o descarrilamento do material rodante. Segundo os dados da Tabela 4.3, outras causas podem ser: fatores humanos, sinalização e uma miscelânea de outras causas. Estas demais causas são apresentadas na Tabela 4.3 e não serão aprofundadas nesta dissertação. 


\section{CAPÍTULO 7 - AÇÕES DE REDUÇÃO DO RISCO}

Por se tratar de um problema que pode causar cenários catastróficos, ações de redução de risco podem e devem ser aplicadas para diminuir a severidade ou a probabilidade de ocorrência deste tipo de evento. Estas ações que serão apresentadas neste capítulo, além das já discutidas no item 6.2, podem apresentar maior ou menor efetividade e são baseadas nestes estudos, retornos de experiência, recomendações de fabricantes de componentes ferroviários e no trabalho de Iwnicky (2006).

A implementação de ações de redução de risco se faz necessária pelas vidas envolvidas e devem ser garantidas pelos fabricantes, manutentores e empresas adquirentes do sistema. Assim, algumas ações são discutidas nesta seção e serão divididas em ações de projeto e fabricação, ações de operação e ações de manutenção.

É importante observar que a maior parte das ações indicadas neste capítulo não são novas tecnologias ou novos procedimentos, porém parte da frota de trens do Brasil não apresentam estas medidas implementadas, pois o país apresenta, em muitos casos, frotas projetadas durante uma época em que estas ações não existiam ou ainda frotas que, devido a limitações de investimentos, também não apresentam estas soluções.

Deve-se ressaltar que nem todas as alternativas discutidas na seqüência deste capítulo podem ser aplicadas de maneira simples em sistemas ferroviários já em operação, pois podem representar custos elevados quando comparados a projetos que estão em fases iniciais do ciclo de vida (por exemplo, em fase de concepção).

Além disso, estas ações podem ser consideradas como alternativas a serem propostas aos adquirentes de sistemas para garantir maior segurança em operação 
e muitas delas são de conhecimento dos projetistas, fabricantes e construtoras (no caso específico da via permanente).

Como observação, os custos relativos à correção de uma falha aumentam com a evolução do projeto, por exemplo, os custos para a correção de uma falha de concepção do trem durante o projeto é menor que o custo da correção desta mesma falha após a entrega de todos os trens manufaturados.

\section{1 - AÇÕES PREVENTIVAS E PALIATIVAS DE PROJETO}

As ações de redução de risco a serem implantadas no projeto estão relacionadas com ações que são tomadas antes do início de operação do sistema, ou seja, que surgem durante a concepção do mesmo ou durante a implantação de um novo sistema, estas ações de atenuação são divididas em ações preventivas (que têm por objetivo evitar o descarrilamento) e paliativas (que têm por objetivo atenuar as conseqüências do evento).

\subsection{1- AÇÕES PREVENTIVAS}

\subsubsection{1 - Lubrificador de flange}

O lubrificador de flange de roda é um dispositivo que pode ser utilizado para minimizar o desgaste e o ruído da região do flange da roda e também do trilho conforme indicado na Figura 7.1 pois altera o coeficiente de atrito entre a roda e o trilho. Desta forma pode, por exemplo, diminuir a probabilidade de ocorrência de um descarrilamento em curvas. 


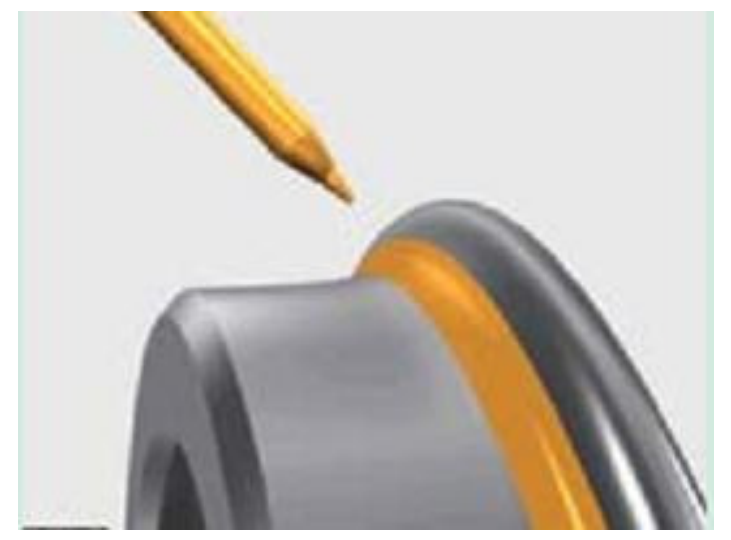

Figura 7.1 - Princípio do Lubrificador de Flange de Roda (REBS, 2009)

O princípio de funcionamento do sistema de lubrificador de flange de roda pode variar entre os diferentes fabricantes. O sistema patenteado da REBS, que teve o seu início de desenvolvimento na década de 80 , funciona da seguinte forma (REBS, 2009): o lubrificante é acondicionado em um reservatório e é forçado contra uma unidade pneumática que mistura o lubrificante com ar; esta mistura percorre tubulações que direcionam a mistura para a roda e, na extremidade desta tubulação, encontram-se bicos que aumentam a aceleração da mistura para que a mesma seja depositada na região do flange.

A Figura 7.2 apresenta a tubulação, o bico ejetor, o reservatório e o sistema de controle do sistema de lubrificação de flange.

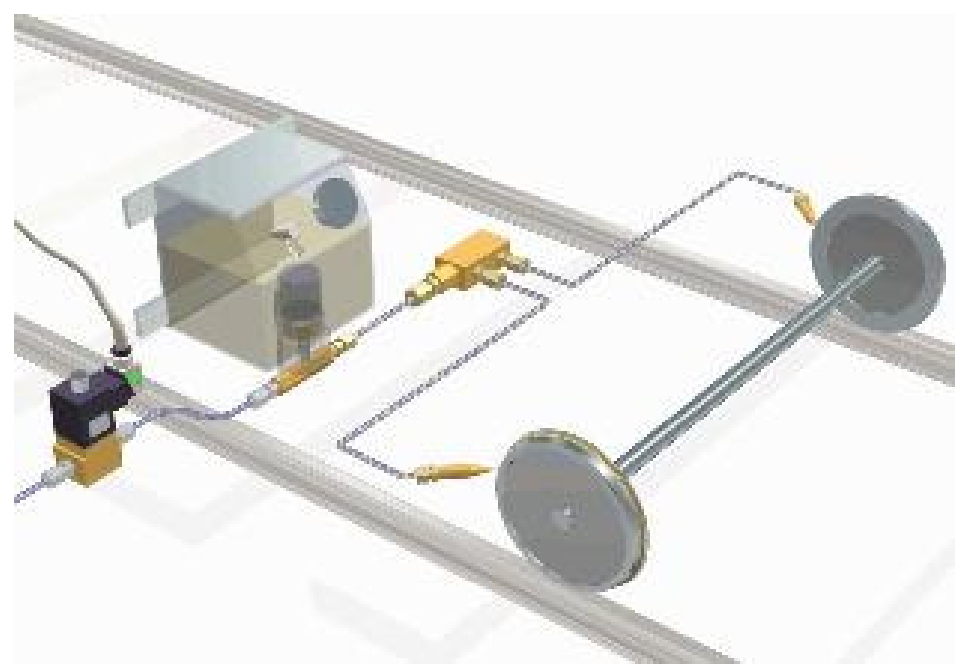

Figura 7.2 - Princípio de Funcionamento do Sistema de Lubrificação de Flange (REBS, 2009) 
Por precaução para que a capacidade de frenagem não seja diminuída, devido a um excesso de lubrificação, algumas ações podem ser realizadas:

- uma lubrificação cíclica da roda deve ser feita ao invés de uma contínua lubrificação da roda. Este tipo de controle pode ser realizado, por exemplo, através de informações de velocidade do trem ou através de períodos prédeterminados;

- a lubrificação é direcionada para o flange e em pequenas quantidades, não atrapalhando as outras regiões de contato roda-trilho.

\subsubsection{2 - Determinação da vida útil dos componentes}

Determinando a vida útil dos componentes, é possível selecionar os itens mais adequados e também estipular as políticas de manutenção dos mesmos. Isso, além de contribuir com o cálculo do custo de vida do sistema, ajudar a definir com maior precisão as necessidades e períodos de manutenção.

Uma ferramenta para a determinação da vida útil pode ser o uso de métodos de confiabilidade como, por exemplo, ensaios acelerados que visam diminuir 0 tempo para a realização de um ensaio de vida de um componente, uso de retorno de experiência, ensaios censuras de confiabilidade etc.

\subsubsection{3 - Detector de obstáculo}

O detector de obstáculo é um dispositivo que detecta a presença de obstáculos na via. Estes obstáculos podem causar instabilidade no movimento, sobreposição do flange e conseqüentemente descarrilamento.

Este sistema pode sinalizar a presença do obstáculo ou aplicar o freio de emergência de maneira a evitar o descarrilamento, podendo, por exemplo, funcionar através de sensores de impacto que sinalizam o objeto indesejado. 


\subsubsection{4 - Deflector de obstáculo - limpa-trilhos}

O deflector de obstáculo, conhecido como limpa-trilhos, age na causa, diferentemente do detector de obstáculo que é uma barreira preventiva ou até mesmo paliativa do descarrilamento.

Este dispositivo, cujo exemplo é apresentado na Figura 7.3, é responsável por evitar que objetos de tamanhos maiores que os pré-determinados atinjam as rodas do truque e desta forma venham a causar um descarrilamento. Além disso, pode ter a função de evitar que objetos colidam com componentes importantes do trem.

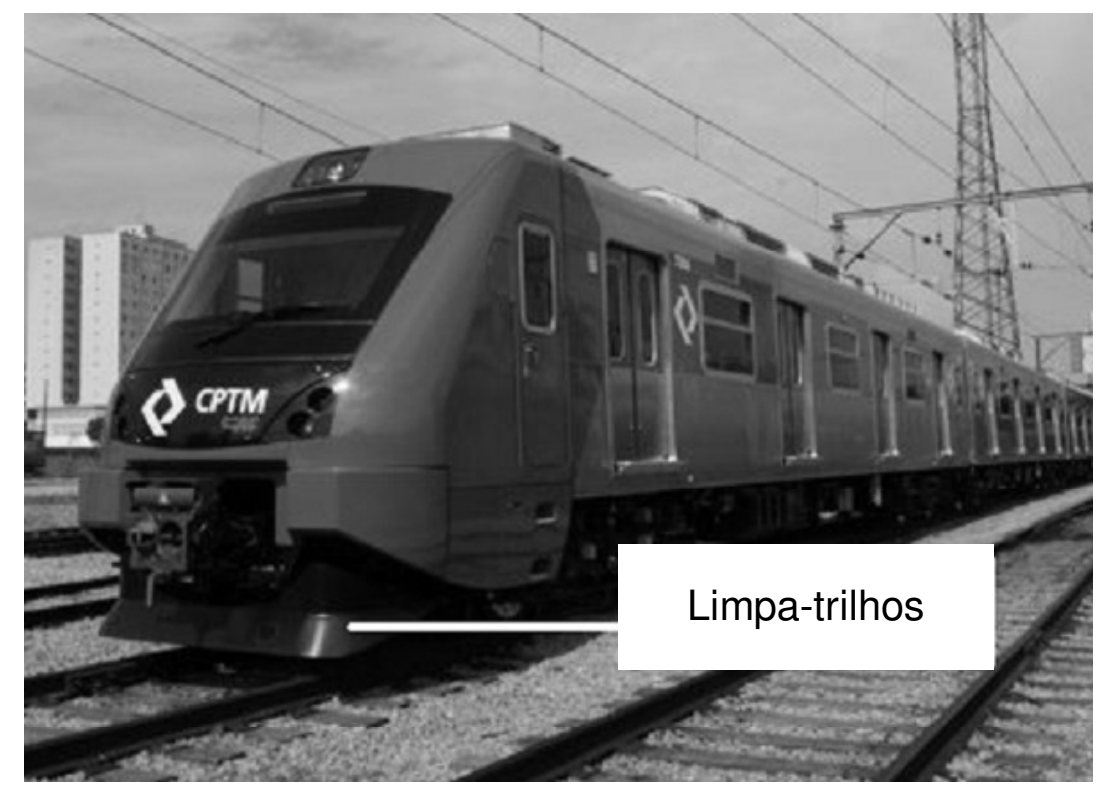

Figura 7.3 - Limpa-trilhos (CPTM, 2010)

\subsubsection{5 - Projeto que respeita os critérios de descarrilamento}

O projeto respeitando os critérios de descarrilamento se faz importante para prevenir a ocorrência deste evento. Estes critérios estabelecem parâmetros limites para as interações de forças de modo a evitar que este problema ocorra. 


\subsubsection{6 - Instalação de contratrilhos em curvas acentuadas}

Os contratrilhos podem ser aplicados para diminuir a probabilidade de ocorrência da sobreposição do flange sobre o trilho ou para reduzir e evitar o aumento da bitola e rotação do trilho. De acordo com Iwnick (2006), este tipo de trilho é normalmente instalado no lado interno do trilho externo à curva. Este tipo de instalação é aplicado em curvas de raio bastante crítico, as quais apresentam maior probabilidade de causar o descarrilamento.

A Figura 7.4 apresenta este tipo de instalação.
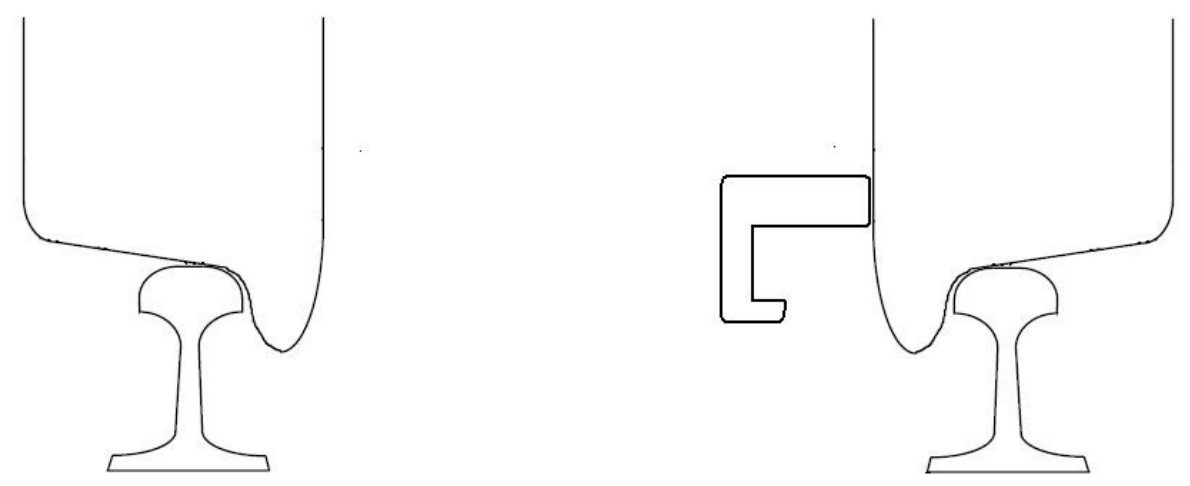

Figura 7.4 - Contratrilho (IWNICK, 2006)

\subsubsection{7 - Otimização da suspensão do truque e resistência do movimento de yaw do truque}

A suspensão do truque apresenta papel fundamental na dinâmica do movimento do material rodante. Suspensões primárias que apresentam menor rigidez permitem uma melhor inscrição em curva que conseqüentemente causam menores forças laterais e menor probabilidade de descarrilamento. Porém desta forma, ocorre uma maior instabilidade em velocidades altas. Assim, a determinação da rigidez da suspensão primária deve ser otimizada de modo a melhor atender à via em que o trem operará. 
A suspensão secundária, que pode apresentar papel de nivelamento do trem, além de suportar as vibrações de baixa freqüência provenientes da armação do truque garantindo estabilidade de movimento e conforto aos passageiros, pode influenciar, por exemplo, nos momentos estabilizadores e instabilizadores definidos no item 3.1.9.2, o que pode aumentar ou diminuir a probabilidade de ocorrência do descarrilamento. Desta forma, este tipo de suspensão também deve ser otimizado de modo à melhor atender a via em que o trem operará.

As características de cada suspensão devem ser escolhidas de acordo com as características da via em que o material rodante operará, desta forma é necessário um estudo da solução a ser implementada que variará conforme as diferentes aplicações.

\subsubsection{8 - Inserção de monitoramento do sistema}

O uso de monitoramento de falhas do sistema pode ser realizado para facilitar a detecção de falhas para os operadores, agilizando a tomada de decisão e evitando, por exemplo, que a operação seja continuada com algum tipo de falha que possa causar uma operação insegura (descarrilamento etc).

Um sistema que está relacionado com o monitoramento de falha é o TCMS, sistema este que pode controlar algumas funções do trem (quando estas são implementadas) ou monitorar falhas pré-estabelecidas, como, a falha de um sistema de detecção de descarrilamento.

Além disso, o monitoramento de falhas do sistema pode facilitar as equipes de manutenção, aumentando assim a disponibilidade e a mantenabilidade do sistema. 


\subsubsection{9 - Inserção de sistemas de proteção (ATP)}

Conforme apresentado na Tabela 4.4 e na Figura 4.3, os erros humanos são responsáveis por $29 \%$ das ocorrências do descarrilamento. Uma das razões da existência do sistema de ATP é justamente minimizar a taxa de ocorrência de falhas humanas durante a operação do material rodante. O sistema de ATP, de uma maneira sucinta, é responsável pela proteção automática do trem através de circuitos de via, sinalização e intertravamentos. Este sistema limita as velocidades máximas de operação nos diferentes trechos; desta forma, a influência humana sobre a magnitude da velocidade é restrita, impedindo assim a sobrevelocidade que poderia vir a causar um descarrilamento.

\subsection{2- AÇÕES PALIATIVAS}

\subsubsection{1 - Detector de Descarrilamento}

Uma ação que pode ser utilizada para diminuir as conseqüências do evento em estudo é o uso de detectores de descarrilamento. Este tipo de dispositivo opera como uma barreira paliativa, ou seja, não atua na causa tampouco na prevenção da ocorrência e tem o intuito de diminuir a severidade do descarrilamento.

Segundo fabricantes, como por exemplo, a Knorr Bremse (2009) ou DM (2010), o detector de descarrilamento pode funcionar com a avaliação das acelerações e de acordo com sua magnitude, pode indicar que o descarrilamento está ocorrendo. Desta forma, dependendo da concepção do sistema, um sinal de alerta é enviado ou até mesmo pode ocorrer a aplicação do freio de emergência.

\section{2 - AÇÕES PREVENTIVAS DE MANUFATURA}

As ações de redução de risco a serem implantadas na manufatura estão relacionadas com a prevenção de ocorrência que podem ser causadas no processo de fabricação e que podem gerar um descarrilamento. 


\subsection{1 - FMEA DE PROCESSO}

A FMEA de processo pode ser uma ferramenta para detectar as causas no processo de fabricação do material rodante que podem gerar um possível descarrilamento. O FMEA de processo, similar ao item 2.1.2, é um método que analisa individualmente as falhas simples de um processo e os efeitos e impactos que podem causar no mesmo incluindo a perda de conformidade nos itens produzidos. Determina assim como cada modo de falha afeta o funcionamento do objeto de estudo.

\subsection{2 - INSPEÇÕES DE QUALIDADE}

As inspeções de qualidade são responsáveis por identificar possíveis problemas e controlar os aspectos e características do produto que será entregue ao cliente. Estas inspeções também podem ser responsáveis por verificar a qualidade dos itens fornecidos pelos parceiros ou fornecedores e devem ter papel fundamental na decisão de escolha de fornecedores. Além disso, as inspeções de qualidade podem detectar pontos críticos no processo ou sistema e promover planos de ações para melhora dos mesmos.

Normas como as pertencentes ao grupo ISO 9000 podem ser utilizadas na gestão da qualidade e melhoria e muitas vezes são exigidas no fornecimento de sistemas ferroviários quanto à garantia da qualidade do produto. Estas normas estabelecem um modelo de gestão de qualidade e é aplicado em diversos seguimentos industriais. Uma norma que foi baseada na ISO 9001, porém voltada para o transporte ferroviário é a norma IRIS (International Railway Industry Standard), que, segundo IRIS Certification (2010), apresenta a estrutura da ISO 9001, adicionando requisitos específicos para o meio ferroviário quanto ao gerenciamento quanto ao projeto, arquitetura, confiabilidade, disponibilidade, mantenabilidade, segurança, ciclo de vida do produto etc. 


\subsection{3 - CONTROLE DA VARIÁVEL HUMANA}

O controle da variável humana durante a manufatura dos componentes, segundo O’Connor (1988), apresenta diversos métodos, por exemplos, métodos motivacionais, métodos estatísticos de controle de qualidade etc. Um dos métodos consiste na inspeção, porém apresenta como defeitos o fato da inspeção não ser perfeita em todos os casos, pode causar desmotivação por parte da pessoa corrigida e em um primeiro momento aparenta que não agrega valor.

Outro método é a inspeção própria (self inspection), em que cada operador é responsável pelo componente que fabrica; desta forma, os operadores necessitam receber treinamentos para que esta inspeção seja bem feita.

Há ainda o método de defeito zero, em que metas são definidas e indicadores são criados de forma a incentivar a ausência de defeitos, porém a motivação para se manter este baixo nível de defeitos é difícil de ser mantido por um longo tempo.

O método de círculos da qualidade divide a organização em pequenos grupos de forma a permitir que os operadores possam transmitir as suas experiências para uma melhora contínua.

Desta forma, apesar de alguns defeitos, com o uso de métodos de controle da variável humana na manufatura, é possível que seja obtido um menor número de falhas no sistema causada pela variável humana.

\section{3 - AÇÕES DE PREVENTIVAS E PALIATIVAS DE OPERAÇÃO}

Conforme Figura 4.3, as falhas humanas são uma das maiores causas para 0 descarrilamento. Desta forma, ações de operação, ou seja, ações que devem ser tomadas pelo próprio condutor do trem ou pelas equipes responsáveis pelo controle das vias e da operação, devem ser consideradas como fatores que podem influenciar no descarrilamento. 
Um dos fatores que tem influencia no evento estudado é a velocidade de operação, ou seja, dependendo da velocidade que o material rodante se encontra, esta pode ser determinante para a ocorrência do descarrilamento, desta forma, caso não haja limitação automática de velocidade (sistema ATP), o condutor deve respeitar os limites de velocidade e os controladores da via devem exigir a instalação de placas de velocidade limites.

Além disso, a condição física dos empregados pode influenciar também neste evento, por exemplo, dependendo do estado de atenção do condutor ou controlador da via, o tempo de reação a uma adversidade pode ser alterado e possivelmente a probabilidade de um descarrilamento também.

Existem ferramentas que podem ser utilizadas para a análise desta variável humana, como as ferramentas de confiabilidade humana bem como a análise de perigos de operação (OHA). Esta última tem como objetivo identificar e analisar os perigos relacionados com pessoas e procedimentos durante manufatura, testes, comissionamento, operação normal e em emergência e manutenções, desta forma é possivel prever medidas para reduzir os riscos relacionados com os mesmos (FEDERAL TRANSIT ADMINISTRATION, 2000).

\section{4 - AÇÕES PREVENTIVAS DE MANUTENÇÃO}

As ações de redução de risco a serem implantadas na manutenção estão relacionadas com a prevenção de ocorrência que podem ser causadas devido a operação do material rodante e que podem gerar um descarrilamento.

\subsection{1 - MANUTENÇÃO CENTRADA EM CONFIABILIDADE}

A manutenção centrada em confiabilidade visa determinar através dos índices de confiabilidade os períodos de manutenção mais adequados. Este tipo de manutenção, deve aliar aspectos de confiabilidade, aspectos econômicos e de segurança quanto à passageiros, meio-ambiente, operadores e funcionários. 
O Reliability Centered Maintenance Guide (1999) define a manutenção centrada em confiabilidade como sendo "uma abordagem de manutenção que combina praticas de manutenção reativa, preventiva, preditiva e pró-ativa e estratégias para maximizar a vida da função requerida de uma peça ou equipamento".

Como observação, a teoria de RCM não têm como objetivo minimizar os custos em oposição à segurança.

Os princípios de RCM são:

a - a preocupação do RCM é de manter a funcionalidade do sistema;

b - a RCM é baseada em confiabilidade, ou seja, se preocupa com a probabilidade de ocorrência das falhas do sistema no período determinado e nas condições determinadas;

c - RCM reconhece as limitações de projeto, já que por mais que uma manutenção pode ser boa, não sobrepõe um projeto ruim, desta forma o projeto e a manutenção devem ser aliadas para o desenvolvimento do produto.

d - RCM se preocupa com a segurança primeiro e não com aspectos econômicos, sendo que a segurança deve ser mantida em detrimento dos aspectos econômicos; e - a definição de falha em RCM é a de uma condição insatisfatória, a falha não é uma opção. Também é definida como a perda da aceitabilidade da qualidade de um produto ou serviço, ou a perda da sua função;

$f$ - as tarefas de RCM devem produzir um resultado tangível, ou seja, os resultados devem ser mensurados pela redução da quantidade de falhas, ou pelo menos do dano causado pela falha;

g - a manutenção centrada em confiabilidade reconhece 4 tipos de manutenção, garantindo consistência na determinação da manutenção nos equipamentos: manutenção corretiva, manutenção preventiva, monitoramento das condições e manutenção pró-ativa.

h - RCM é um processo contínuo, sendo constantemente revisado para propiciar a adequação correta quando à mudança no processo, sucessos e fracassos alcançados. Este retorno na experiência é importante para a melhora contínua. 


\subsubsection{1 - Manutenção corretiva}

A manutenção corretiva, em RCM, é uma decisão consciente de que o sistema perderá sua função momentaneamente. Esta decisão deve ser tomada, considerando a segurança da falha e aspectos econômicos quanto ao ciclo de vida.

Assumindo uma política de manutenção corretiva, é possível que ocorra canibalização de sistemas semelhantes a fim de permitir que o sistema em falha entre em operação, em caso de falta de um determinado componente.

\subsubsection{2 - Manutenção preventiva}

A manutenção preventiva, ou baseada em calendário é comumente usada. Este tipo de manutenção é baseado no tempo transcorrido desde a última manutenção. Itens que apresentam como política a manutenção preventiva, deveriam apresentar uma forte ligação do aumento da taxa de falha com o tempo de operação.

Para a determinação dos corretos períodos de manutenção, podem ser utilizados tanto retorno de experiência, quanto dados estatísticos ou até mesmo uma determinação conservativa do período.

\subsubsection{3 - Monitoramento das condições}

O monitoramento das condições é um tipo de manutenção baseada em inspeções e predições de falha. Nesta manutenção, dados são retirados e analisados para a determinação da necessidade da manutenção, por exemplo, dados de temperatura, pressão e análise de lubrificantes. 


\subsubsection{4 - Manutenção pró-ativa}

A manutenção pró-ativa considera as lições aprendidas em manutenções passadas. Desta forma, inclui ações como melhoria das especificações, análise dos componentes em falha, análise da causa raiz etc.

Este tipo de manutenção é caracterizada pelo retorno e conversas constantes entre responsáveis pelo projeto e responsáveis pela manutenção, revisão dos processos de manutenção com preocupação no ciclo de vida do produto e constante reavaliação para melhoria constante.

\subsubsection{5 - Políticas de manutenção recomendadas}

Dentre os diferentes tipos de manutenção apresentados na manutenção centrada em confiabilidade, a manutenção corretiva é a menos aplicável quando se tem como objetivo diminuir a probabilidade de ocorrência de um descarrilamento, já que a mesma admite que o sistema falhará para que ocorra a intervenção.

Os outros tipos de manutenção (preventiva, monitoramento das condições e pró-ativa) podem ser utilizadas para diminuir a taxa de ocorrência do descarrilamento, sendo que suas eficácias serão variáveis com o sistema, ambiente de uso etc.

\subsection{2 - MONITORAMENTO DOS PARÂMETROS DE VIA}

Os parâmetros de via devem ser inspecionados, pois conforme a Tabela 4.4, são um dos principais causadores do descarrilamento. Desta forma, parâmetros como características do trilho, bitola, sobre-elevação, raio mínimo, desgaste, funcionamento de máquinas de chave, jacarés etc devem ser monitorados a fim de garantir maior segurança na operação do veículo ferroviário. 


\subsection{3 - SISTEMA DE DIAGNÓSTICO DE FALHAS}

Os parâmetros que influenciam o descarrilamento poderiam ser monitorados para permitir uma rápida identificação e manutenção das características de operação a fim de evitar que este evento indesejado ocorra. Para tal, pode-se definir um sistema, podendo ser baseado, por exemplo, no TCMS (Train Control and Monitoring System). Neste sistema de diagnósticos de falhas quanto ao descarrilamento, deve-se considerar os seguintes aspectos:

- elencar os elementos que influenciam no descarrilamento;

- elencar os possíveis monitoramentos considerando os custos e benefícios de cada monitoramento;

- considerar um SIL (nível de integridade de segurança) para o sistema de monitoramento condizente com a aplicação. Este nível de SIL pode ser determinado em normas como a EN 50129 (2002).

Caso uma função demande um THR menor que $10^{-9}$ (por hora e por função), deve ser considerada uma das seguintes alternativas:

- se for possível, dividir a função em diferentes sub-funções de maneira que o THR destas e conseqüentemente o SIL seja alterado;

- se a função não puder ser dividida, as ações e medidas requeridas para um SIL 4 devem ser seguidas e a função deve ser usada em combinação com uma outra ação operacional ou técnica de maneira a alcançar o THR necessário.

Baseado nos resultados constantes nesta dissertação, recomenda-se que o fluxograma apresentado na Figura 7.5 seja seguido para o início da elaboração deste software de monitoramento. 


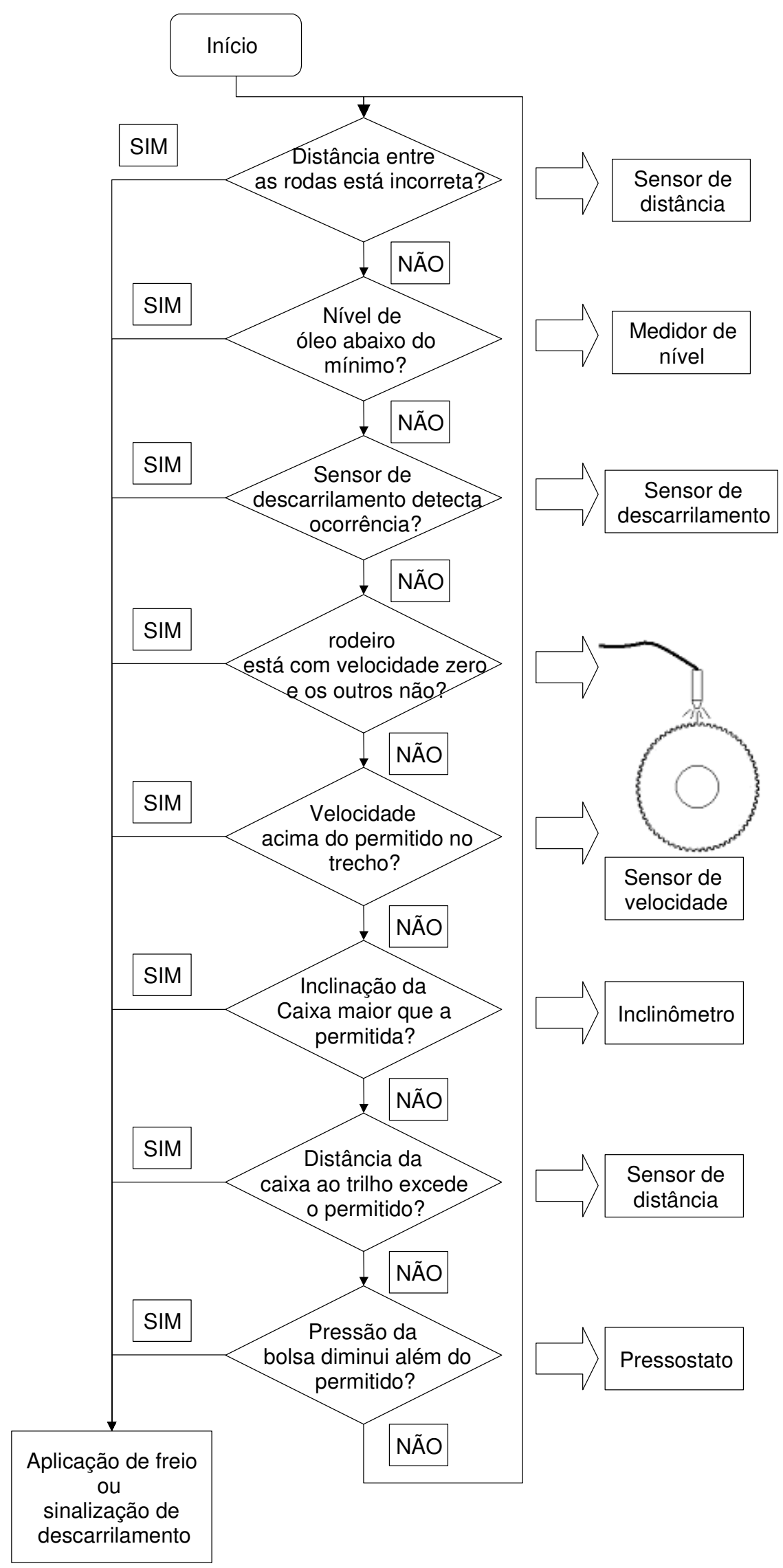

Figura 7.5 - Fluxograma de Monitoramento 
Neste fluxograma, são apresentados alguns parâmetros que poderiam ser monitorados para a determinação de uma provável ocorrência de descarrilamento. Nesta mesma figura, são apresentados alguns dispositivos de monitoramento que auxiliam na determinação dos parâmetros a serem vigiados (como pressostatos e sensores de velocidade).

\section{5 - ANÁLISE DO BENEFÍCIO}

O ideal para a determinação do benefício de cada solução em termos de melhora da confiabilidade seriam testes comparativos em operação para a verificação da real eficácia, porém, conforme apresentado na análise de risco (item 2.2), a estimativa do benefício pode tornar-se difícil pelo tempo acumulado necessário para o ensaio, pois quanto menor a quantidade de ocorrência de falhas, menor seria a confiança quanto a estes valores no calculo da taxa de falha.

Outra alternativa seria se a autoridade ferroviária determinasse o tempo para a comparação entre uma solução e outra, porém, considerando-se por exemplo o tempo de garantia fornecido pelos fabricantes, pode-se não ser possível dentro deste intervalo de tempo determinar com exatidão as taxas de falha e realizar uma comparação quanto à eficácia de cada solução.

Assim, para este trabalho, será proposto estudar a eficácia de uma solução através do método probabilístico condicionado avançado conforme apresentado no item 2.1.4.2 e conforme código computacional desenvolvido em 2.1.4.4.

A solução que será avaliada é a manutenção preventiva para diferentes intervalos de acordo com o item 7.4.1.2 supondo que a mesma restabelece por completo as condições originais de operação.

O benefício que será analisado é a alteração da confiabilidade e dos custos envolvidos. 
Conforme apresentado em 2.1.4.2, o algoritmo deve seguir os seguintes passos:

a) Adotar um valor para o índice de confiabilidade $\beta$;

b) Adotar para todas as variáveis relevantes no sistema que $x_{i}^{*}=m_{i}$, onde $m_{i}$ é o valor esperado da variável básica $x_{i}$

c) Calcular $g_{i}^{\prime}\left(X^{*}\right)$ Para as $n$ variáveis básicas;

d) Calcular o valor da constante de proporcionalidade $\alpha_{i}$ para as $n$ variáveis básicas;

e) Calcular um novo ponto de linearização $X^{*}$

f) Repetir os passos "c" a "e", até que o ponto de linearização se mantenha constante;

g) Calcular o valor da função do estado limite $Z=g\left(X^{*}\right)$ Utilizando-se o ponto de linearização obtido no passo f;

h) Utilizar valores de $\beta$ e repetir os passos "c" a "h" até obter-se um valor nulo para a função de estado limite, ou seja, $Z=0$ e

i) determinar a probabilidade de colapso.

Desta forma, escolhendo como ação de redução de risco a manutenção preventiva apresentada nos conceitos de manutenção centrada em confiabilidade (item 7.4.1.1), pode-se calcular o benefício tanto em termos de confiabilidade através do método probabilístico condicionado avançado quanto em termos de custos.

Pelo critério de Nadal apresentado na equação (4.4) e descrito abaixo,

$$
\frac{L}{V}=\frac{\tan \delta-\mu}{1+\mu \tan \delta}
$$

nota-se que o mesmo pode ser escrito como a diferença entre a solicitação e a resistência, em que a relação L/V torna-se a solicitação e $(\tan \delta-\mu) /(1+\mu \tan \delta)$ torna-se a resistência. Desta forma a função de desempenho $Z$ ou função do estado limite que pode ser expressa pela diferença entre a resistência e a solicitação é representada por: 


$$
Z=\frac{\tan \delta-\mu}{1+\mu \tan \delta}-\frac{L}{V}
$$

Obtida a expressão da variável Z, tem-se o colapso quando $Z$ é menor ou igual à zero, caso contrário, não ocorre o colapso, neste caso, o descarrilamento.

Este mesmo algoritmo para a determinação da probabilidade de falha poderia ser aplicado para outras ações de redução de risco apresentadas nesta dissertação, podendo ser citada a ação de otimização da suspensão, porém para cada ação seria necessária a determinação da função do estado limite que descreve o problema.

\subsection{1- CASO EXEMPLO}

O caso exemplo que será apresentado é resumido na Tabela 7.1.

Tabela 7.1 - Valores das variáveis no caso exemplo

continua

Parâmetro Descrição

Os dados utilizados para a determinação dos resultados foram obtidos

Perfil de da norma UIC 510 - 2 OR (2004) em seu anexo B que apresenta um roda considerado exemplo de perfil de roda UIC-ERRI para rodas com diâmetro entre $1000 \mathrm{~mm}$ e $760 \mathrm{~mm}$ e altura de flange igual a $28 \mathrm{~mm}$. Neste perfil, os valores tan $\delta, \operatorname{Yr}$ (valor em milímetros na direção horizontal), Zr (valor em milímetros na direção vertical) variam conforme 0 .

Segundo Barbosa (1999), em seus ensaios, foram apresentados

Coeficiente valores de coeficiente de atrito que variam de 0,13 a 0,50 dependendo de atrito $\mu$ da condição da pista (seca ou com óleo). Desta forma, para o caso exemplo será adotado um valor médio e constante igual a 0,315. 
conclusão

\begin{tabular}{|c|c|}
\hline Par & $\overline{\operatorname{Des}}$ \\
\hline L & $\begin{array}{l}\text { Pode-se estimar os valores das forças através de equações analíticas. } \\
\text { Por exemplo, TAKAl et al (2002) apresentam uma equação analítica } \\
\text { para estimar a força lateral. } \\
\text { Porém será considerado hipoteticamente que o valor varia seguindo } \\
\text { uma distribuição normal com valor médio calculado pela equação (4.4) } \\
\text { considerando o valor máximo da tangente } \delta \text { (o que corresponde à } \\
\text { região de }-39,5 \mathrm{~mm} \leq \mathrm{Yr} \leq-38,5 \mathrm{~mm} \text { ou ângulo } \delta \text { igual a } 70 \text { ) do perfil } \\
\text { de roda UIC-ERRI considerado, o valor do coeficiente de atrito igual a } \\
0,315 \text { e admitindo que a magnitude média final será igual a } 50 \% \text { do } \\
\text { valor obtido. } \\
\text { Além disso, será considerado que o desvio padrão é de } 0,1304 \text {. } \\
f_{L / V}(L / V)=\frac{1}{\sigma \sqrt{2 \pi}} \text { exp }\left[-\frac{1}{2}\left(\frac{L / V-m e ́ d i a}{\sigma}\right)^{2}\right] \\
\text { É necessário realçar que os valores e distribuições adotados são } \\
\text { hipóteses e que para a determinação da probabilidade de falha de um } \\
\text { caso real, é preciso o estudo prévio e determinação do comportamento } \\
\text { da relação L/V. }\end{array}$ \\
\hline & $\begin{array}{l}\text { A taxa de desgaste para as rodas irá variar, entre outros fatores, com } \\
\text { as características de operação, a massa por eixo, as condições de } \\
\text { conservação da vida e os equipamentos instalados na via e no } \\
\text { material rodante (equipamentos de lubrificação). } \\
\text { Por esta razão, como simplificação e para permitir a exemplificação do } \\
\text { método, será considerado que a taxa de desgaste será de } \\
D^{\star}(1 \% 10.000 \mathrm{~km}) \text {. } \\
\text { Desta forma, manipulando a equação (7.1) e assumindo as } \\
\text { considerações apresentadas nesta tabela: } \\
Z=\frac{\tan \left(70^{\circ}-D\left(\frac{1^{\circ}}{10.000}\right)\right)-0,315}{1+0,315 \cdot \tan \left(70^{\circ}-D\left(\frac{1^{\circ}}{10.000}\right)\right)}-L / V\end{array}$ \\
\hline
\end{tabular}


Os valores obtidos de probabilidade de falha para diferentes quilometragens são apresentados na Tabela 7.2.

Tabela 7.2 - Valor das probabilidade de falhas de acordo com diferentes quilometragens

\begin{tabular}{ccc}
\hline Quilometragem & $\beta$ & $\begin{array}{c}\text { Probabilidade de colapso na } \\
\text { quilometragem considerada }\end{array}$ \\
\hline 0 & 4,87 & $5,58 \times 10^{-7}$ \\
10.000 & 4,62 & $1.92 \times 10^{-6}$ \\
20.000 & 4,31 & $8,16 \times 10^{-6}$ \\
30.000 & 3,99 & $3,30 \times 10^{-5}$ \\
40.000 & 3,68 & $1,17 \times 10^{-4}$ \\
50.000 & 3,38 & $3,62 \times 10^{-4}$ \\
60.000 & 3,09 & $1,00 \times 10^{-3}$ \\
\hline
\end{tabular}

Neste caso, percebe-se que as probabilidades apresentam uma variação considerável para diferentes valores de quilometragens percorridas e neste caso a quilometragem pode guiar os períodos de manutenção das rodas. Ou seja, quanto antes ocorrer a atuação correta, menor a probabilidade de falha.

Os valores de probabilidade de colapso não alcançam o valor zero, pois são obtidos dos índices de confiabilidade $(\beta)$ calculados através da função distribuição acumulada da distribuição normal reduzida e este índice de confiabilidade deveria apresentar determinados valores negativos que não podem ser alcançados com base nas distribuições consideradas para as variáveis básicas no cálculo da probabilidade de colapso. Ou seja, com as variáveis básicas assumidas não é possível alcançar uma probabilidade de colapso igual a zero.

Além da análise em termos de melhora na confiabilidade conforme Tabela 7.2, pode-se estimar os custos envolvidos para cada intervalo de manutenção. Para tal, os seguintes critérios devem ser avaliados: custo do descarrilamento referente à perda de material, custo do descarrilamento referente à perda de vidas, custo da manutenção referente a material e custo de manutenção referente à mão de obra. 
O custo de perda de material considerado será de $R \$ 50.000 .000,00$ e será chamado de $\left(\mathrm{C}_{\mathrm{m}}\right)$.

O custo de perdas de vidas é difícil de ser quantificados em valores monetários pois deve considerar por exemplo o custo de danos morais, porém, considerando apenas o custo devido a indenizações por danos materiais $\left(\mathrm{C}_{\mathrm{in}}\right)$, o mesmo será estimado baseando-se no Art. 948 do Código Civil - Lei 10406/02, que estabelece:

"No caso de homicídio, a indenização consiste, sem excluir outras reparações:

I - no pagamento das despesas com o tratamento da vítima, seu funeral e o luto da família;

II - na prestação de alimentos às pessoas a quem o morto os devia, levando-se em conta a duração provável da vida da vítima." (JUSBRASIL, 2011)

Desta forma, o $C_{\text {in }}$ considerará o valor do salário mínimo de $R \$ 540,00$ (janeiro de 2011) e o número médio de 3,3 pessoas por domicílio na região urbana no Brasil (IBGE,2011), a expectativa de vida à idade de 0 anos de 72,9 anos (IBGE, 2010), 1,9 milhão em média de passageiros transportados em dia útil (CPTM, 2011), 2.265 viagens (CPTM, 2011) e o custo estimado com funeral e luto da família de $R \$ 20.000,00$. Apenas para efeitos de cálculos, a média etária da população que utiliza o transporte ferroviário considerada será de 30 anos e o valor pago de dano material será considerado até a idade média do falecimento destes familiares (expectativa de vida).

$$
C_{i n}=\frac{1.900 .000}{2265} \cdot[20.000+12 \cdot(3,3-1) \cdot(72,9-30) \cdot 540,00]=R \$ 553.123 .638,00
$$

O custo da manutenção referente à mão de obra $\left(\mathrm{C}_{\mathrm{mo}}\right)$ será calculado considerando a remuneração bruta paga pela CPTM em $2009(\mathrm{R} \$ 335.681 .000,00)$ e a quantidade de empregados de 6.720 no final do exercício de 2009 (CPTM, 2011). Será considerada que a manutenção de 1 trem exigirá 24 homem $x$ horas e que a mesma não ocorre em horários comerciais. 


$$
C_{m o}=24 \cdot \frac{335.681 .000}{6.720 \cdot 365 \cdot 8}=R \$ 410,57
$$

Já o custo da manutenção referente a material $\left(\mathrm{C}_{\mathrm{mm}}\right)$ será hipoteticamente estimado como igual a $\mathrm{R} \$ 3.000,00$ por manutenção.

Desta forma, a seguinte expressão será utilizada para determinar o custo anual do risco, considerando a quilometragem anual de $120.000 \mathrm{~km}$ :

$$
C_{a}=\frac{120.000}{Q} \cdot\left[P_{F} \cdot\left(C_{m}+C_{i}\right)+\left(C_{m o}+C_{m m}\right)\right]
$$

Assim, os valores de $C_{a}$ são definidos na Tabela 7.3.

Tabela 7.3 - Valor do custo anual referente ao risco de descarrilamento

\begin{tabular}{ccc}
\hline $\mathrm{Q}(\mathrm{km})$ & $\mathrm{P}_{\mathrm{F}}$ & $\mathrm{C}_{\mathrm{a}}(\mathrm{R} \$)$ \\
\hline 0 & $5,58 \times 10^{-7}$ & - \\
10.000 & $1,92 \times 10^{-6}$ & $48.918,79$ \\
20.000 & $8,16 \times 10^{-6}$ & $49.992,35$ \\
30.000 & $3,30 \times 10^{-5}$ & $93.254,60$ \\
40.000 & $1,17 \times 10^{-4}$ & $221.928,10$ \\
50.000 & $3,62 \times 10^{-4}$ & $532.179,18$ \\
60.000 & $1,00 \times 10^{-3}$ & $1.213 .068,41$ \\
\hline
\end{tabular}

É possível inferir pela Tabela 7.3 que entre os valores, o de $10.000 \mathrm{~km}$ é o melhor valor para a manutenção quando comparado aos outros no caso exemplo pois apresenta menor custo anual referente ao risco de descarrilamento, porém, a estimativa do custo não apresenta grande diferença entre os valores de $10.000 \mathrm{e}$ $20.000 \mathrm{~km}$ e a manutenção a cada $60.000 \mathrm{~km}$ apresenta maior custo anual referente ao risco de descarrilamento.

Os valores apresentados na Tabela 7.1 são, em sua maioria, adotados para possibilitar a aplicação do caso exemplo. Para alguma destas variáveis, é realizada uma análise de benefício com os valores apresentados na Tabela 7.4. 
Tabela 7.4 - Valores das variáveis na análise de sensibilidade

\begin{tabular}{|c|c|c|c|}
\hline Parâmetro & $\begin{array}{l}\text { Valor adotado no } \\
\text { caso exemplo }\end{array}$ & $\begin{array}{l}\text { Valor mínimo utilizado na } \\
\text { análise de sensibilidade }\end{array}$ & $\begin{array}{l}\text { Valor máximo utilizado na } \\
\text { análise de sensibilidade }\end{array}$ \\
\hline $\begin{array}{l}\text { Coeficiente } \\
\text { de atrito } \mu\end{array}$ & 0,315 & 0,13 & 0,50 \\
\hline \multirow{2}{*}{ L / V } & & $f_{L / V}(L / V)=\frac{1}{\sigma \sqrt{2 \pi}} \exp \left[-\frac{1}{2}\left(\frac{L / V}{}\right.\right.$ & $\left.\left.\frac{-m e ́ d i a}{\sigma}\right)^{2}\right]$ \\
\hline & $\begin{array}{l}\text { média }=\frac{1,3040}{2} \\
\sigma=0,1304\end{array}$ & $\begin{array}{l}\text { média }=\frac{1,3040}{2}-0,05 \frac{1,3040}{2} \\
\sigma=0,1304\end{array}$ & $\begin{array}{l}\text { média }=\frac{1,3040}{2}+0,05 \frac{1,3040}{2} \\
\sigma=0,1304\end{array}$ \\
\hline $\begin{array}{l}\text { Taxa de } \\
\text { desgaste }\end{array}$ & $D^{*}(1 \% 10.000 \mathrm{~km})$ & $D^{\star}(0,8 \% 10.000 \mathrm{~km})$ & $D^{*}(1,2 \% 10.000 \mathrm{~km})$ \\
\hline
\end{tabular}

Desta forma, tem-se para o cálculo da probabilidade de falha e do custo:

- Considerando apenas valores diferentes de coeficiente de atrito para o cálculo da probabilidade de falha e custo, tem-se os resultados apresentados na Tabela 7.5.

Tabela 7.5 - Custo anual referente ao risco de descarrilamento para diferentes valores de coeficiente de atrito

\begin{tabular}{ccccc}
\hline \multirow{2}{*}{$Q(\mathrm{~km})$} & \multicolumn{2}{c}{$\mu=0,13$} & \multicolumn{2}{c}{$\mu=0,50$} \\
\cline { 2 - 5 } & $\mathrm{P}_{\mathrm{F}}$ & $\mathrm{C}_{\mathrm{a}}(\mathrm{R} \$)$ & $\mathrm{P}_{\mathrm{F}}$ & $\mathrm{C}_{\mathrm{a}}(\mathrm{R} \$)$ \\
\hline 0 & $2,87 \times 10^{-7}$ & - & $1,16 \times 10^{-2}$ & - \\
10.000 & $2,87 \times 10^{-7}$ & $37.097,45$ & $2,17 \times 10^{-2}$ & $157.088 .418,15$ \\
20.000 & $2,87 \times 10^{-7}$ & $18.548,72$ & $3,84 \times 10^{-2}$ & $138.977 .197,60$ \\
30.000 & $2,87 \times 10^{-7}$ & $12.365,82$ & $6,18 \times 10^{-2}$ & $149.103 .837,58$ \\
40.000 & $2,87 \times 10^{-7}$ & $9.274,36$ & $9,51 \times 10^{-2}$ & $172.079 .929,62$ \\
50.000 & $2,87 \times 10^{-7}$ & $7.419,49$ & $1,38 \times 10^{-1}$ & $199.616 .803,79$ \\
60.000 & $2,87 \times 10^{-7}$ & $6.182,91$ & $1,89 \times 10^{-1}$ & $228.469 .071,20$ \\
\hline
\end{tabular}


Nesta análise de sensibilidade, percebe-se que para pequenos valores de coeficiente de atrito $(0,13)$, a probabilidade de falha não se altera com a mudança dos intervalos de manutenção, uma das explicações poderia ser que dependendo das magnitudes das variáveis, ações de manutenções podem não ser eficientes para alterar a probabilidade de um descarrilamento.

- Considerando apenas valores diferentes de média da razão L / V para o cálculo da probabilidade de falha e custo, tem-se os resultados apresentados na Tabela 7.6.

Tabela 7.6 - Custo anual referente ao risco de descarrilamento para diferentes valores de média da razão $L$ / V

\begin{tabular}{|c|c|c|c|c|}
\hline \multirow[t]{2}{*}{$\mathrm{Q}(\mathrm{km})$} & \multicolumn{2}{|c|}{$\begin{array}{c}\mathrm{L} / \mathrm{V}: \quad \text { média }=\frac{1,3040}{2}-0,05 \frac{1,3040}{2} \\
\sigma=0,1304\end{array}$} & \multicolumn{2}{|c|}{$\begin{array}{c}\mathrm{L} / \mathrm{V}: \quad \text { média }=\frac{1,3040}{2}+0,05 \frac{1,3040}{2} \\
\sigma=0,1304\end{array}$} \\
\hline & $\mathrm{P}_{\mathrm{F}}$ & $\overline{C_{a}(R \$)}$ & $P_{F}$ & $\mathrm{C}_{\mathrm{a}}(\mathrm{R} \$)$ \\
\hline 0 & $1,07 \times 10^{-6}$ & - & $1,07 \times 10^{-6}$ & - \\
\hline 10.000 & $1,43 \times 10^{-6}$ & $45.404,27$ & $5,41 \times 10^{-6}$ & $74.195,71$ \\
\hline 20.000 & $3,56 \times 10^{-6}$ & $30.398,48$ & $2,45 \times 10^{-5}$ & $106.300,86$ \\
\hline 30.000 & $1,22 \times 10^{-5}$ & $41.142,90$ & $9,20 \times 10^{-5}$ & $233.647,90$ \\
\hline 40.000 & $4,43 \times 10^{-5}$ & $88.863,79$ & $3,02 \times 10^{-4}$ & $554.805,75$ \\
\hline 50.000 & $1,42 \times 10^{-4}$ & $212.129,33$ & $8,74 \times 10^{-4}$ & $1.272 .160,13$ \\
\hline 60.000 & $4,19 \times 10^{-4}$ & $511.122,06$ & $2,3 \times 10^{-3}$ & $2.780 .205,87$ \\
\hline
\end{tabular}

- Considerando apenas valores diferentes de taxa de desgaste para o cálculo da probabilidade de falha e custo, tem-se os resultados apresentados na Tabela 7.7. 
Tabela 7.7 - Custo anual referente ao risco de descarrilamento para diferentes valores de taxa de desgaste

\begin{tabular}{ccccc}
\hline \multirow{2}{*}{$Q(\mathrm{~km})$} & \multicolumn{2}{c}{ Taxa de desgaste: } & \multicolumn{2}{c}{ Taxa de desgaste: } \\
& \multicolumn{2}{c}{$\mathrm{D}^{*}(0,8 \% 10.000 \mathrm{~km})$} & \multicolumn{2}{c}{$\mathrm{D}^{*}(1,2 \% 10.000 \mathrm{~km})$} \\
\cline { 2 - 5 } & $\mathrm{P}_{\mathrm{F}}$ & $\mathrm{C}_{\mathrm{a}}(\mathrm{R} \$)$ & $\mathrm{P}_{\mathrm{F}}$ & $\mathrm{C}_{\mathrm{a}}(\mathrm{R} \$)$ \\
\hline 0 & $5,58 \times 10^{-7}$ & - & $5,58 \times 10^{-7}$ & - \\
10.000 & $1,43 \times 10^{-6}$ & $45.404,27$ & $2,56 \times 10^{-6}$ & $53.534,14$ \\
20.000 & $4,71 \times 10^{-6}$ & $34.561,84$ & $1,46 \times 10^{-5}$ & $70.254,57$ \\
30.000 & $1,46 \times 10^{-5}$ & $46.836,38$ & $7,23 \times 10^{-5}$ & $186.213,43$ \\
40.000 & $4,43 \times 10^{-5}$ & $88.863,79$ & $2,91 \times 10^{-4}$ & $535.029,33$ \\
50.000 & $1,17 \times 10^{-4}$ & $175.811,63$ & $1,00 \times 10^{-3}$ & $1.454 .501,30$ \\
60.000 & $2,91 \times 10^{-4}$ & $356.686,22$ & $2,90 \times 10^{-3}$ & $3.503 .954,24$ \\
\hline
\end{tabular}

Nestas análises de sensibilidades, percebe-se que para pequenas variações da razão $L / V$ ou da taxa de desgaste, o custo anual referente ao risco de descarrilamento altera-se consideravelmente, porém em termos de probabilidade de falha, a alteração do cenário de menor valor para o de maior valor apresentou menor variação quando comparado ao cenário de variação do coeficiente de atrito.

Além disso, durante a operação, as variáveis $L$ / V e coeficiente de atrito são mais difíceis de serem determinadas quando comparadas a taxa de desgaste, pois 0 perfil da roda e conseqüentemente 0 desgaste pode ser monitorado por equipamentos específicos enquanto que o coeficiente de atrito varia com as condições climáticas (por exemplo dias chuvosos ou secos) e a razão $L$ / V varia por exemplo com a massa do veículo e número de passageiros. 


\section{CAPÍTULO 8 - CONCLUSÕES E RECOMENDAÇÕES}

\section{1- CONCLUSÕES}

Conforme discutido em 2.2, como no Brasil não existe a figura da autoridade ferroviária, é comum transferir as responsabilidades de aceitação para as empresas que estão adquirindo o material rodante. Ademais, cada empresa que adquire o material rodante ou é responsável pela operação dos mesmos pode definir seus próprios critérios de aceitação quando da ausência desta figura ferroviária.

Para tal, normas como EN 50126 (2000), MIL-STD-882C (1993) e IEC 62278 (2002) que se baseou na norma EN 50126, apresentam formas de gerenciamento e condução de estudos de segurança que podem ser considerados, cabendo à autoridade ferroviária estipular se as mesmas serão aceitas.

Neste trabalho foi proposto um método de análise de risco aplicada ao descarrilamento que complementa as simulações computacionais e simulações dinâmicas de forma a tornar mais seguro o transporte ferroviário, que não apresenta diminuição da taxa de acidentes conforme demonstrado na Figura 4.1. Esta metodologia foi apresentada na seção 5.2. E conforme apresentado na seção 2.2, a análise de risco deve ser pautada pela:

- descrição da metodologia;

- hipóteses, limitações e justificativas quanto ao uso da metodologia;

- identificação dos resultados estudo do perigo;

- estimativa do risco e nível de confiança;

- resultados de estudos;

- discussão sobre fonte de dados e

- referências.

A descrição da metodologia proposta aplicada ao descarrilamento considerou as seguintes etapas: entendimento do problema e identificação dos elementos sob 
análise, análise de causa e conseqüência, elaboração de FTA, elaboração de FMEA e proposta de cálculo da probabilidade de ocorrência do evento. O fluxograma que descreve este método foi apresentado na Figura 5.1.

Pela introdução dos conceitos das ferramentas utilizadas, foi possível a sua aplicação no caso exemplo considerando como limitações para 0 uso da metodologia a dificuldade da determinação quantitativa dos parâmetros que influenciam o descarrilamento, diferentemente da abordagem pelos critérios de descarrilamento que permitem maior facilidade na quantificação, entretanto o método proposto complementa as simulações computacionais e dinâmicas para tornar mais seguro o transporte ferroviário, por exemplo, através da identificação de elementos críticos quanto ao descarrilamento e priorização de ações de redução de risco.

A análise de causa e conseqüência elaborada permitiu a identificação da conseqüência dos eventos iniciais, ou seja, o descarrilamento, bem como a combinação de falhas que podem gerar um descarrilamento, isto é, a falha de um sistema aliada a falha na detecção deste evento.

Já a análise por árvore de falhas permite uma rápida identificação visual dos eventos que causam o evento topo analisado, identificando os eventos básicos que foram submetidos a análises do tipo FMEA. Esta, por sua vez, permitiu a identificação de deficiências no projeto e priorização das ações de gerenciamento para diminuição do risco.

Percebe-se ainda que as análises do tipo FTA apresentaram o seu evento topo formado por elementos "não desenvolvidos" combinados por portas lógicas do tipo "ou". Isto ocorre pois não há um detalhamento quanto a um projeto específico e desta forma não é possível, neste trabalho, o aprofundamento dos eventos "não desenvolvidos”. Já em um estudo aplicado a um projeto específico, seria possível o detalhamento deste eventos e haveria a presença de portas lógicas do tipo "e".

Para a estimativa da melhora de confiabilidade e do custo, foi proposto uma metodologia baseada no método probabilístico condicionado avançado, que é um 
ponto de equilíbrio entre o método semi probabilístico (que utiliza fatores de segurança parciais para as variáveis empregadas no modelo) e o método probabilístico puro (que considera todas as possíveis configurações de colapso). A eficácia deste método depende da coleta de informações quanto ao comportamento das variáveis básicas.

Ressalta-se que os dados utilizados para estimativa da contribuição de cada causa do descarrilamento foi baseada na Railway Safety Statistics (2005), que é um banco de dados americano, pois a mesma possui um maior detalhamento quanto aos acidentes quando comparado ao banco de dados brasileiro consultado (ANTT, 2007). Esta opção pode causar uma distorção quanto às informações apresentadas, pois o banco de dados utilizado pode não refletir o cenário brasileiro das causas dos acidentes e das causas dos descarrilamentos.

Assim, a metodologia proposta tem o intuito de auxiliar na identificação de problemas relacionados ao descarrilamento e facilitar o gerenciamento quanto aos problemas de segurança de modo a agregar maior nível de confiança à operação ferroviária e diminuição do número de acidentes. Esta metodologia não tem a ambição de substituir os estudos desenvolvidos mas tem o objetivo de auxiliar no estudo deste evento, que conforme a Figura 4.1, não tem apresentado diminuição em sua taxa de ocorrência.

\subsection{RECOMENDAÇÕES PARA TRABALHOS FUTUROS}

Através das conclusões anteriores e com 0 intuito de melhorar a determinação das causas e prevenções do descarrilamento bem como promover o desenvolvimento da análise de risco, algumas recomendações para trabalhos futuros podem ser apresentadas:

- Aplicação da mesma metodologia para o estudo de eventos críticos relacionadas ao material rodante e à operação ferroviária.

- Determinação da vida útil de componentes como, por exemplo, a vida útil do eixo do rodeiro através de ferramentas de confiabilidade e métodos probabilísticos, podendo ainda utilizar dados de retorno em garantia bem como histórico de 
intervenções e trocas. Desta forma, há a possibilidade de determinação do correto período de troca dos componentes em função dos diferentes parâmetros encontrados para cada aplicação, evitando custos desnecessários associados à troca desnecessária de componentes e estoque de material.

- Simulação das recomendações apresentadas neste trabalho, quantificando a eficácia de cada recomendação através do uso do método probabilístico condicionado avançado.

- Segundo Railway Safety Statistics (2005), pelo menos $29 \%$ das falhas que geram o descarrilamento estão relacionadas a fatores humanos, desta forma, uma recomendação para trabalho futuro seria o estudo da influência da variável humana no estudo do descarrilamento que não foi analisada neste trabalho devido a uma opção de metodologia. Esta pesquisa sobre a variável humana no descarrilamento poderia, por exemplo, utilizar a metodologia de confiabilidade humana.

- Detalhamento da análise de benefício realizada no item 7.5.1, pois conforme apresentado, alguns parâmetros ou comportamentos foram assumidos como o comportamento da razão L/V, o custo de manutenção referente a material, o valor do coeficiente de atrito etc. Desta forma, o caso exemplo poderia sofrer uma análise mais profunda.

Como ressalva, muita das recomendações para pesquisas enfrentam deficiências quando a qualidade e quantidade de dados de acidentes e de ações de manutenções executadas pelas operadoras atuantes no transporte ferroviário brasileiro, ou seja, as informações consultadas que estão em domínio público não apresentam a riqueza de detalhes necessária para o aprofundamento do estudo elaborado. Desta forma os trabalhos futuros também podem ser prejudicados por esta carência de informações. 


\section{CAPÍTULO 9 REFERÊNCIAS BIBLIOGRÁFICAS}

ALMEIDA, Fabio Cardoso. Análise das Forças de Contato e Comportamento

Dinâmico de Rodeiro Ferroviário. 2006. 132p. Dissertação (Mestrado) - Escola Politécnica da Universidade de São Paulo. São Paulo. São Paulo, 2006.

ANTT. Apresenta a evolução recente do transporte ferroviário. Disponível em $<$ http://www.antt.gov.br/concessaofer/EvolucaoFerroviaria20080707.pdf>. Acesso em 6 de julho de 2009.

ASSOCIAÇÃO BRASILEIRA DE NORMAS TÉCNICAS. NBR 9321: Cálculo de Estimativas por Ponto e Limites de Confiança Resultante de Ensaios de Determinação da Confiabilidade de Equipamentos. 1986. 34 p.

BARBOSA, Roberto Spinola. Aplicação de Sistemas Multicorpos na Dinâmica de Veículos Guiados. 1999. 273p. Tese (Doutorado) - Escola de Engenharia de São Carlos da Universidade de São Paulo. São Carlos. São Carlos, 1999.

BARBOSA, Roberto Spinola. A 3D Contact Force Safety Criterion for Flange Climb Derailment of a Railway Wheel. Vehicle System Dynamics - Taylor \& Francis Group, 12.p., 2004, v.42, no 5, pp $289-300$.

BARBOSA, Roberto Spinola. Safety criterion for railway vehicle derailment. 8th International Heavy Haul Conference - Safety, Environment and Productivity, Rio de Janeiro, Brasil, 8.p., 2005, pp 477 - 484.

BRINA, Helvécio Lapertosa. Estradas de Ferro. $2^{3}$ ed. Minas Gerais: Editora UFMG, 1988. v.1.

BUL.GARIN, Miguel Rodríguez; DÍAZ-DE-VILLEGAS, José-Manuel García. Desvíos Ferroviários. Editora Ingenieria cántabra, 1995. 
CENELEC. EN 50126: Applications ferroviaires - Spécification et demonstration de la fiabilité, de la disponibilité, de la maintenabilité et de la securité (FDMS) Part 1: Exigences de base et procédés génériques. 2000. 76 p.

CENELEC. EN 50126: Railway applications - The specification and demonstration of reliability, availability, maintainability and safety (RAMS) Part 2: Guide to the application of EN 50126-1 for safety. 2007. $131 \mathrm{p}$.

CENELEC. EN 50126: Railway applications - The specification and demonstration of reliability, availability, maintainability and safety (RAMS) Part 3: Guide to the application of EN 50126-1 for rolling stock RAMS. 2006. 62 p.

CENELEC. EN 50129: Railway applications - Communication, signaling and processing systems - Safety related electronic systems for signaling. 2002. 44 p.

CPTM. Apresenta fotos de trens. Disponível em < http://www.cptm.sp.gov.br/e frota/frota/default.asp $>$. Acesso em 27 de dezembro de 2010.

CPTM. Apresenta balanço patrimonial. Disponível em $<$ http://www.cptm.sp.gov.br/e contabeis/Balanco Patrimonial 2009.PDF>. Acesso em 03 de janeiro de 2011.

COLPAERT, Hubertus. Metalografia dos Produtos Siderúrgicos Comuns. $2^{\mathrm{a}}$ ed. São Paulo: Edgard Blücher, 1959. 412p.

CONSOLI, Luciano Ribeiro Pinto. Análise do Comportamento Dinâmico Lateral de um Veículo Ferroviário. 2007. 158p. Dissertação (Mestrado) - Escola Politécnica da Universidade de São Paulo. São Paulo. São Paulo, 2007.

DEPARTMENT OF DEFENSE. MIL-STD-882C: System Safety Program Requirements. DOD, 1993. 
DEPARTMENT OF DEFENSE. MIL-STD-1629A: Procedures for performing a failure mode, effects and criticality analysis. DOD, 1984.

DM Sistemas de Medição. Apresenta a empresa e características dos produtos. Disponível em <http://dmsistemas.ind.br>. Acesso em 07 de agosto de 2010.

FACINI DOS SANTOS, Alexandre. Gerenciamento da Confiabilidade em Projetos de Material Rodante Ferroviário. 2007. 256p. Dissertação (Mestrado) - Escola Politécnica da Universidade de São Paulo. São Paulo. São Paulo, 2007.

FEDERAL RAILROAD ADMINISTRATION. Fracture and Fatigue Damage Tolerance of Bainitic and Pearlitic Rail Steels. U.S. Department Of Transportation, 4p., 2006.

FEDERAL TRANSIT ADMINISTRATION. Hazard Analysis Guidelines for Transit projects. Cambridge, FTA, 2000, 35p.

IBGE. Apresenta informações a pirâmide etária brasileira. Disponível em <http://www.ibge.gov.br/home/estatistica/populacao/tabuadevida/2008/default.shtm>. Acesso em 30 de dezembro de 2010.

IBGE. Apresenta informações a pirâmide etária brasileira. Disponível em <http://www.ibge.gov.br/censo2010/piramide etaria/index.php $>$. Acesso em 3 de janeiro de 2011.

INTERNATIONAL ELECTROTECHNICAL COMMISSION. IEC-61124: Reliability testing - Compliance tests for constant failure rate and constant failure intensity. Geneva, IEC, 2006. 249 p.

INTERNATIONAL ELECTROTECHNICAL COMMISSION. IEC-62278: Railway Applications - Specification and Demonstration of Reliability, Availability, Maintainability and Safety (RAMS). Geneva, IEC, 2002. 159 p. 
IRIS Certification. Apresenta informações sobre a norma International Railway Industry Standard. Disponível em <http://www.iris-rail.org >. Acesso em 9 de outubro de 2010.

ISOGRAPH. FaultTree+. Version 7.0.1, 1996.

IWNICKI, Simon. Handbook of Railway Vehicle Dynamics. $1^{\text {st }}$ ed. New York: taylor \& Francis, 2006. 535p.

JUSBRASIL. Apresenta o código civil brasileiro. Disponível em <http://www.jusbrasil.com.br/legislacao/103257/codigo-civil-lei-10406-02\#art948> Acesso em 03 de janeiro de 2011.

Knorr-Bremse Brasil. Apresenta a empresa e características dos produtos. Disponível em <http://www.knorr-bremse.com.br>. Acesso em 15 de dezembro de 2009.

LAUERMAN, Elvis Diógenes. Ferrovia - Via Permanente. 2008. 68p. Trabalho de Conclusão de Curso - Universidade Federal de Santa Maria. Santa Maria. Rio Grande do Sul, 2008.

M.I.M.F. Apresenta produtos de materiais ferroviários. Disponível em $<$ http://www.mimf.com.br>. Acesso em 28 de dezembro de 2009.

MONTGOMERY, Douglas C. Design and Analysis of Experiments. $4^{\text {th }}$ ed. New York: John Wiley \& Sons, 1997. 704p.

O'CONNOR, Patric D. T. Practical Reliability Engineering. $2^{\text {nd }}$ ed. New York: John Wiley \& Sons, 1988. 398p.

PIRES, Cassiano Lobo. Simulação do Sistema de Tração Elétrica MetroFerroviária. 2006. 424 p. Tese (Doutorado) - Escola Politécnica, Universidade de São Paulo, São Paulo, 2006. 
PORTO, Telmo Giolito. A Infra-estrutura da Via Férrea. 1984. 122 p + apêndice. Dissertação (Mestrado) - Escola Politécnica, Universidade de São Paulo, São Paulo, 1984.

QUANTERION SOLUTION INCORPORATED. Apresenta as datas de publicação de documentos e guias referentes a Confiabilidade. Disponível em: $<$ http://www.quanterion.com/Publications/Toolkit/index.asp $>$. Acesso em: 16 de julho de 2010.

Railroad Safety Statistics 2005 Annual Report. Apresenta relatório anual de estatísticas dos trens em operação nos EUA. Disponível em: $<$ http://safetydata.fra.dot.gov/publicobjects/bull2005-book.pdf>. Acesso em: 06 de julho de 2009.

REBS Wheel Flange Lubrication for Rail Vehicles. Apresenta características do lubrificador de flange. Disponível em $<$ http://www.rebs.de/english/products/spurkranzschmierung.php $>$. Acesso em $25 \mathrm{de}$ dezembro de 2009.

RELIABILITY ANALYSIS CENTER. FMD-97: Failure Mode / Mechanism Distribution 1997. New York. RAC, 1997. 440p.

RELIABILITY ANALYSIS CENTER. NPRD-95: Nonelectronic parts reliability data. New York. RAC, 1995. 1020p.

RELIABILITY ANALYSIS CENTER. Reliability Toolkit: Commercial Practices Edition. A Practical Guide for Commercial Products and Military Systems Under Acquisition Reform. RAC, 1995 ${ }^{1}$. 508p

SILVA, Ricardo Martins. PTR 2501 - Ferrovias. São Paulo: Escola Politécnica da Universidade de São Paulo, 2004. 80p. Apostila para a disciplina PTR 2501 Ferrovias.

${ }^{1}$ Dado proveniente de QUANTERION SOLUTIONS INCORPORATED (2010) 
SIMPÓSIO INTERNACIONAL DE CONFIABILIDADE, 2008, Florianópolis. Confiabilidade Humana: nova metodologia de análise qualitativa e quantitativa.

SOUZA, Gilberto Francisco Martha. Análise de Confiabilidade Estrutural a Fadiga de Risers Rígidos. 1994. 295 p + apêndice. Tese (Doutorado) - Escola Politécnica, Universidade de São Paulo, São Paulo, 1994.

SOUZA, Gilberto Francisco Martha. Desenvolvimento de Metodologia para a Análise Probabilística do Processo de Fadiga de Estruturas Soldadas. 2001. 216 p. Tese (Livre Docência) - Escola Politécnica, Universidade de São Paulo, São Paulo, 2001.

SUNDARARAJAN, C. Guide to Reliability Engineering - Data, Analysis, Applications, Implementation, and Management. $1^{\text {st }}$ ed. New York: Van Nostrand Reinhold, 1991. $414 p$.

STEFANI, Celia Regina Baider. O Sistema Ferroviário Paulista: Um Estudo Sobre a Evolução do Transporte de Passageiros Sobre Trilhos. 2007. 304p. Dissertação (Mestrado) - Faculdade de Filosofia, Letras e Ciências da Universidade de São Paulo. São Paulo. São Paulo, 2007.

STOPATTO, Sérgio. Via Permanente Ferroviária. São Paulo: Editora da Universidade de São Paulo, 1987. v.3.

TAKAI, Hideyuki; UCHIDA, Masao; MURAMATSU, Hironari; ISHIDA, Hiroaki. Derailment Safety Evaluation by Analytic Equations. QR of RTRI, Vol.43, No.3, Sep. 2002, pp $119-124$.

THE MATHWORKS. Matlab - The Language of Technical Computing. Version 7.9.0.529 (R2009b), 2009.

TRENSURB. Apresenta a característica da via permanente. Disponível em $<$ http://www.trensurb.gov.br/php/metro/trem.php\#via> Acesso em 27 de dezembro de 2010. 
UNION INTERNATIONALE DES CHEMIS DE FER. UIC 510-2 OR: Trailing Stock: wheels and wheelsets. Conditions concerning the use of wheels of various diameters. UIC, 2004. $71 \mathrm{p}$.

UNION INTERNATIONALE DES CHEMIS DE FER. UIC 518 OR: Testing and approval of railway vehicles from the point of view of their dynamic behaviour - Safety - Track fatigue - Ride quality. UIC, 2005. 518 p.

UNION INTERNATIONALE DES CHEMIS DE FER. UIC 541-1 OR: Brakes regulations concerning the design of brake components. UIC, 2003. $48 \mathrm{p}$.

UNION INTERNATIONALE DES CHEMIS DE FER. UIC 541-3 OR: Brakes - Disc brakes and their application - General conditions for the approval of brake pads. UIC, 2004. $63 \mathrm{p}$.

UNION INTERNATIONALE DES CHEMIS DE FER. UIC 541-4 OR: Brakes Regulations concerning the manufacture of brake components - Self-adjusting load-proportional braking system and automatic "empty-loaded" control device. UIC, 2004. 21 p.

UNION INTERNATIONALE DES CHEMIS DE FER. UIC 541-5 OR: Brakes Electropneumatic brake (ep brake) Electropneumatic emergency brake override (EBO). UIC, 2006. 57 p.

UNION INTERNATIONALE DES CHEMIS DE FER. UIC 544-1 O: Freins performance de freinage. UIC, 2004. $111 \mathrm{p}$.

UNION INTERNATIONALE DES CHEMIS DE FER. UIC 544-2 OR: Conditions To Be Observed by the Dynamic Brake of Locomotives and Motor Coaches so that the Extra Braking Effort Produced can be taken into Account for the Calculation of the Brake-weight. UIC, 1983. $10 \mathrm{p}$. 
UNION INTERNATIONALE DES CHEMIS DE FER. UIC 813 O: Technical specification for the supply of wheelsets for tractive and trailing stock Tolerances and assembly. UIC, 2003. 35 p.

USA CONSTRUCTION ENGINEERING RESEARCH LABORATORIES. Reliability Centered Maintenance (RCM) Guide. Estados Unidos, USACERL, 1999, 97p.

VILLEMEUR, Alain. Reliability, Availability, Maintainability and Safety Assessment. $1^{\text {st }}$ ed. New York: John Willey \& Sons, 1991. 363p + anexos. v.1.

WAGNER, Simon. Derailment Risk Assessment. 2004. 154p. Dissertação (Mestrado) - Central Queensland University. Austrália. Austrália, 2004.

WICKENS, A. H. Fundamentals of Rail Vehicle Dynamics: Guidance and Stability. $1^{\text {st }}$ ed. Netherlands: Swets \& Zeitlinger, 2003. 286p. 


\section{APÊNDICE A - EXEMPLO DE PARÂMETROS DIMENSIONAIS DA RODA}

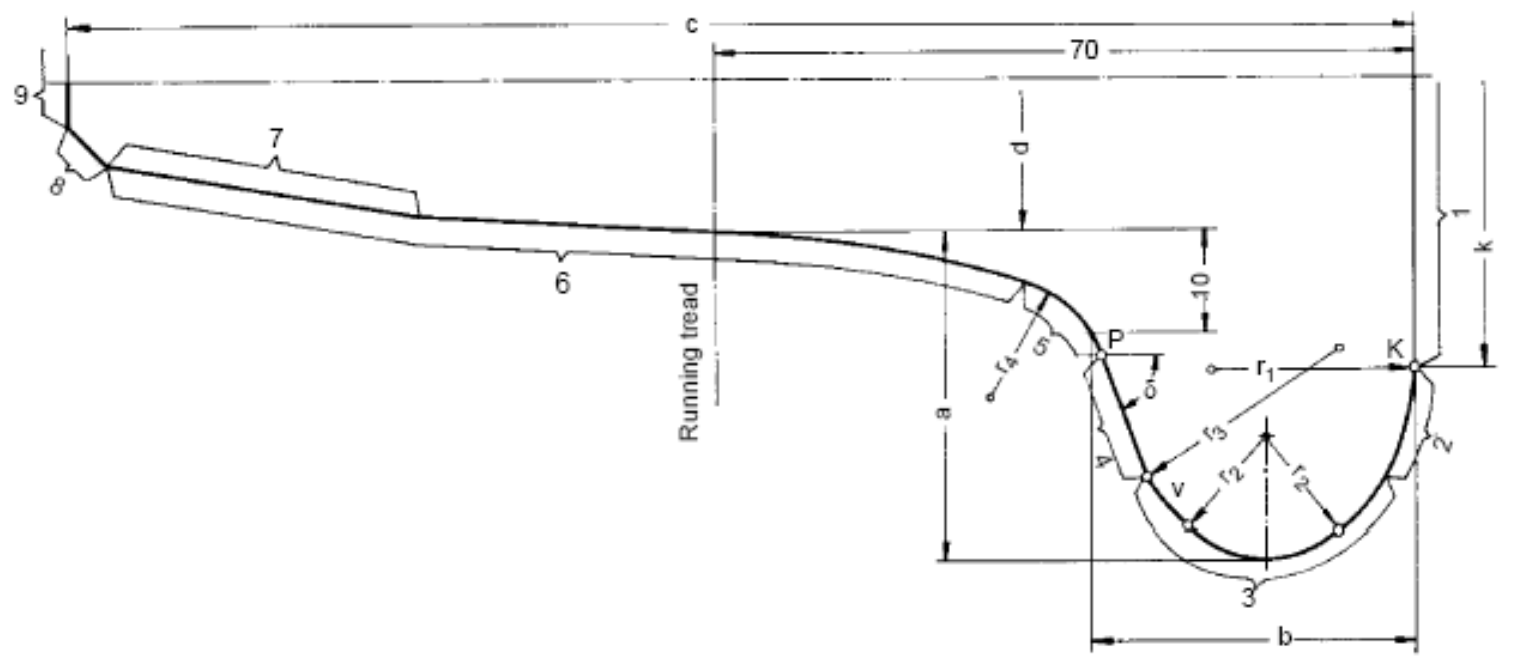

Fig. 1 - Wheel running profile

Table 1 : Descriptions concerning the wheel running profile

\begin{tabular}{|c|c|c|c|}
\hline $\begin{array}{l}\text { Reference } \\
\text { figure }\end{array}$ & $\begin{array}{l}\text { Description of wheel-profile } \\
\text { zone }\end{array}$ & $\begin{array}{l}\text { Reference } \\
\text { letter }\end{array}$ & \\
\hline \multirow{2}{*}{1} & Internal surface of rim-tyre & a & Flange height \\
\hline & Internal surface of tyre & & \\
\hline 2 & Internal surface of flange & $\mathrm{b}$ & Flange thickness \\
\hline \multirow{2}{*}{3} & \multirow{2}{*}{ Top of flange } & \multirow{2}{*}{ c } & Width of rim-tyre \\
\hline & & & Width of tyre \\
\hline 4 & External surface of flange & $d$ & Diameter of running tread \\
\hline 5 & Running profile fillet & $r_{1}, r_{2}, r_{3}$ & Radii of rounded end of flange \\
\hline 6 & Running surface & $\mathrm{r}_{4}$ & Radius of running profile fillet \\
\hline 7 & $\begin{array}{l}\text { Slope of external section of } \\
\text { running surface }\end{array}$ & $\delta$ & $\begin{array}{l}\text { Angle of external surface of } \\
\text { flange }\end{array}$ \\
\hline 8 & External bevel of running profile & & \\
\hline \multirow{2}{*}{9} & External surface of rim-tyre & & \\
\hline & External surface of tyre & & \\
\hline
\end{tabular}

Figura ( A-1 ) - Parâmetros do perfil da roda definidos em norma (UIC 510 - 2, 2004) 


\section{APÊNDICE B- TOLERÂNCIAS DAS DIMENSÕES EIXO-FURO}

\begin{tabular}{|c|c|c|c|c|c|c|c|c|c|c|c|c|c|c|c|c|c|c|}
\hline 1 & \multicolumn{3}{|c|}{2} & 3 & & \multicolumn{5}{|c|}{4} & \multicolumn{5}{|c|}{5} & 6 & 7 & 8 \\
\hline $\begin{array}{c}\text { Nominal and } \\
\text { minimum } \\
\text { bore }\end{array}$ & \multicolumn{3}{|c|}{$\begin{array}{c}\text { Maximum } \\
\text { bore diameter }\end{array}$} & \multicolumn{7}{|c|}{ Limit of seat diameter $^{3}$} & \multicolumn{6}{|c|}{ Tightening between bore ${ }^{a}$ and seat ${ }^{a}$} & \multicolumn{2}{|c|}{$\begin{array}{l}\text { Wheel seat } \\
\text { diameter }^{\mathrm{a}}\end{array}$} \\
\hline$D_{\text {Bnom }}$ & \multirow{2}{*}{\multicolumn{3}{|c|}{$D_{\text {Bmax }}=D_{\text {Bnom }}+\ldots$}} & \multirow{2}{*}{\multicolumn{2}{|c|}{ Lower }} & \multicolumn{5}{|c|}{ Upper } & \multirow{2}{*}{\multicolumn{5}{|c|}{ Min. }} & \multirow{3}{*}{$\begin{array}{l}\text { Max. } \\
J_{\max } \\
=\text { es }\end{array}$} & \multirow{3}{*}{$\begin{array}{l}\text { Min. } \\
\mathrm{ds}_{\min }\end{array}$} & \multirow{3}{*}{$\begin{array}{l}\text { Max. } \\
\mathrm{ds}_{\text {max }}\end{array}$} \\
\hline $\mathrm{D}_{\mathrm{Bmin}}$ & & & & & & & & $\mathrm{s}=\mathrm{J}_{\mathrm{ma}}$ & & & & & & & & & & \\
\hline $\mathrm{mm}$ & $\mathrm{H} 6$ & $\mathrm{H} 7$ & $\mathrm{H} 8$ & $u^{b}$ & $v^{b}$ & u6 & u7 & u8 & v6 & v7 & $\mathrm{H} 6 / \mathrm{u}^{\mathrm{b}}$ & $\mathrm{H} 7 / \mathrm{u}^{\mathrm{b}}$ & $\mathrm{H} 6 / \mathrm{v}^{\mathrm{b}}$ & $\mathrm{H} 7 / \mathrm{v}^{\mathrm{b}}$ & $\mathrm{H} 8 / \mathrm{v}^{\mathrm{b}}$ & & & \\
\hline$>100$ to 120 & 0,022 & 0,035 & 0,054 & 0,144 & 0,172 & 0,166 & 0,179 & 0,198 & 0,194 & 0,207 & 0,122 & 0,109 & 0,150 & 0,137 & 0,188 & & & $f$ \\
\hline$>120$ to 140 & 0,025 & 0,040 & 0,063 & 0,170 & 0,202 & 0,195 & 0,210 & 0,233 & 0,227 & 0,242 & 0,145 & 0,130 & 0,177 & 0,162 & 0,139 & & $\frac{\mathrm{g}}{\tilde{\sigma}}$ & $\frac{9}{5}$ \\
\hline$>140$ to 160 & 0,025 & 0,040 & 0,063 & 0,190 & 0,228 & 0,215 & 0,230 & 0,253 & 0,253 & 0,268 & 0,165 & 0,150 & 0,203 & 0,188 & 0,165 & $\widehat{\vec{\tau}}$ & $\stackrel{g}{=}$ & 总 \\
\hline$>160$ to 180 & 0,025 & 0,040 & 0,063 & 0,210 & 0,252 & 0,235 & 0,250 & 0,273 & 0,277 & 0,292 & 0,185 & 0,170 & 0,227 & 0,212 & 0,189 & 뭉 & 8 & \\
\hline$>180$ to 200 & 0,029 & 0,046 & 0,072 & 0,236 & 0,284 & 0,265 & 0,282 & 0,308 & 0,313 & 0,330 & 0,207 & 0,190 & 0,255 & 0,238 & 0,212 & $\begin{array}{l}8 \\
\$ \\
\infty\end{array}$ & $\stackrel{\Phi}{\Phi}$ & 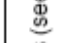 \\
\hline$>200$ to 225 & 0,029 & 0,046 & 0,072 & 0,258 & 0,310 & 0,287 & 0,304 & 0,330 & 0,339 & 0,356 & 0,229 & 0,212 & 0,281 & 0,264 & 0,238 & 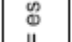 & + & $\stackrel{\oplus}{+}$ \\
\hline$>225$ to 250 & 0,029 & 0,046 & 0,072 & 0,284 & 0,340 & 0,313 & 0,330 & 0,356 & 0,369 & 0,386 & 0,255 & 0,238 & 0,311 & 0,294 & 0,268 & है & 占 & 怘 \\
\hline$>250$ to 280 & 0,032 & 0,052 & 0,081 & 0,315 & 0,385 & 0,347 & 0,367 & 0,396 & 0,417 & 0,437 & 0,283 & 0,263 & 0,353 & 0,333 & 0,304 & & $\bar{E}$ & 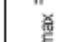 \\
\hline$>280$ to 315 & 0,032 & 0,052 & 0,081 & 0,350 & 0,425 & 0,382 & 0,402 & 0,431 & 0,457 & 0,477 & 0,318 & 0,298 & 0,393 & 0,373 & 0,344 & & & \\
\hline
\end{tabular}

a. The terms "bore" and "seat" used in this technical specification apply respectively to the wheel, gear and brake-disc bores and the wheel, gear and brake-disc seats.

b. For all tolerance ranges.

c. $J_{\max }-\mathrm{ei}+I \mathrm{~T}_{\mathrm{v}}\left(I \mathrm{~T}_{\mathrm{v}}\right.$ - international tolerances $\mathrm{v}$, $\mathrm{v}$ being equal to 6,7 or 8 ; see Fig. 3 ).

d. $v$ can be equal to 6,7 or 8 (see Fig. 1, 2 and 3 ).

Figura ( B-1 ) - Valores Limite das dimensões Eixo-furo (UIC 813 O, 2003) 


\section{APÊNDICE C - APROVAÇÃO DE UM VEÍCULO FERROVIÁRIO QUANTO AOS TESTES}

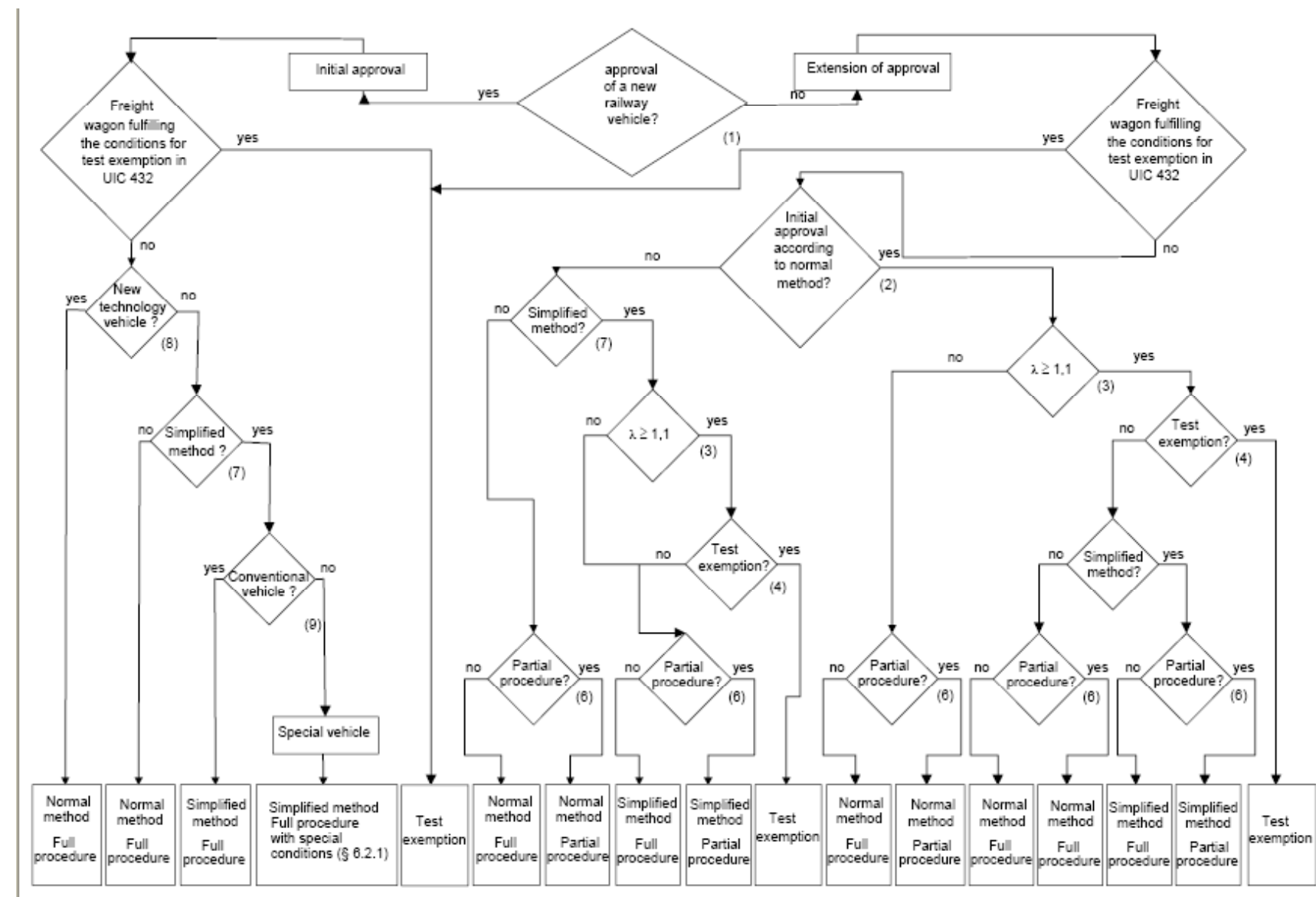

Explanatory notes to the flowchart

(1) Does the matter concern approval of a new railway vehicle ? (2) (Was the initial acceptance made using the normal measurement
method (forces $Y, Q$...)?

(3) Was the $\lambda$ factor calculated during the initial approval greater than or equal to 1,1

(4) Are the conditions for waiving the tests (first column of the centre part of the table corresponding to the type of vehicle) met?

(5) Are the specific conditions for applying a simplified method (2nd and 3 rod columns of the centre part of the table corresponding to the type
of tractive vehicle) met ?

(8) The test cases marked in the right-hand part of the corresponding table must be carried out.

(7) Are the conditions for apolying a simplified method met ?

(8) Is the vehicle a new-technology design ?

(8) Is the vehicle a conventional one ?

Figura ( C-1 ) - Fluxograma Geral de Aprovação de um Veículo ferroviário Quanto aos Testes (UIC 518 OR, 2005) 


\section{APÊNDICE D - HETEROGENEIDADES NO TRILHO E FIXAÇÃO}

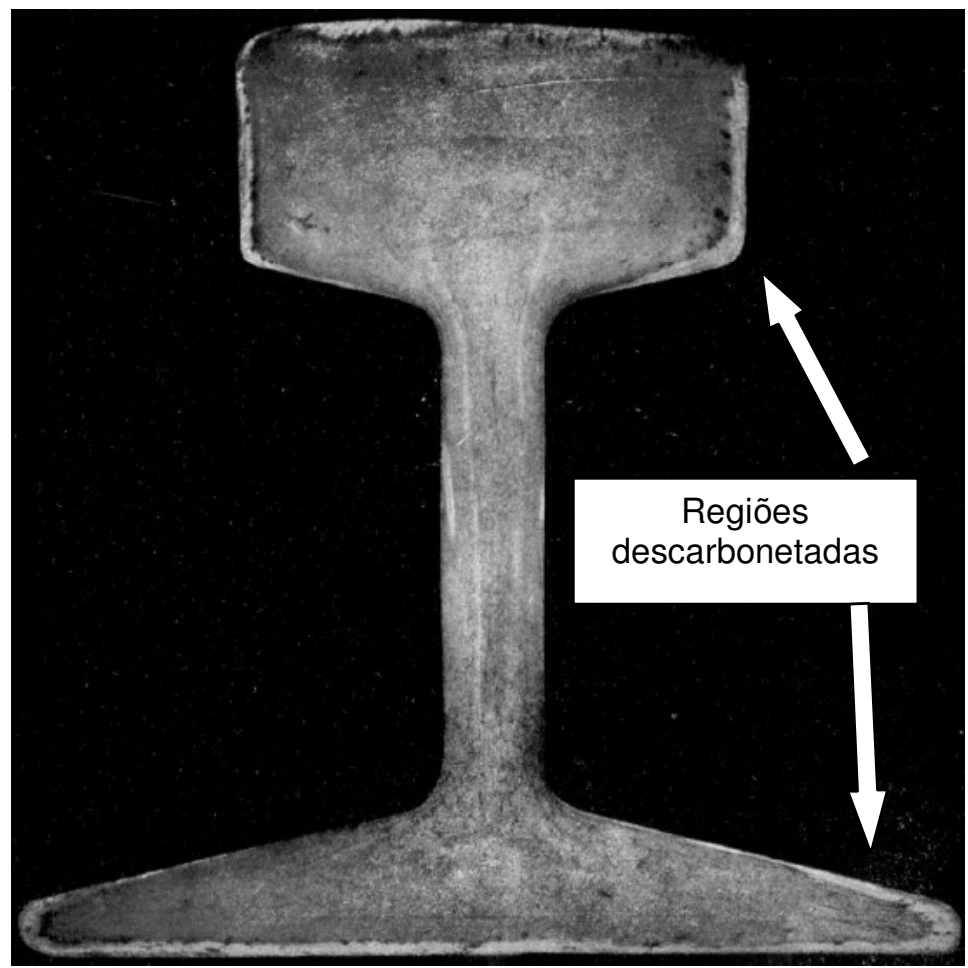

Figura ( D-1 ) - Trilho com regiões descarbonetadas (COLPAERT, 1959)

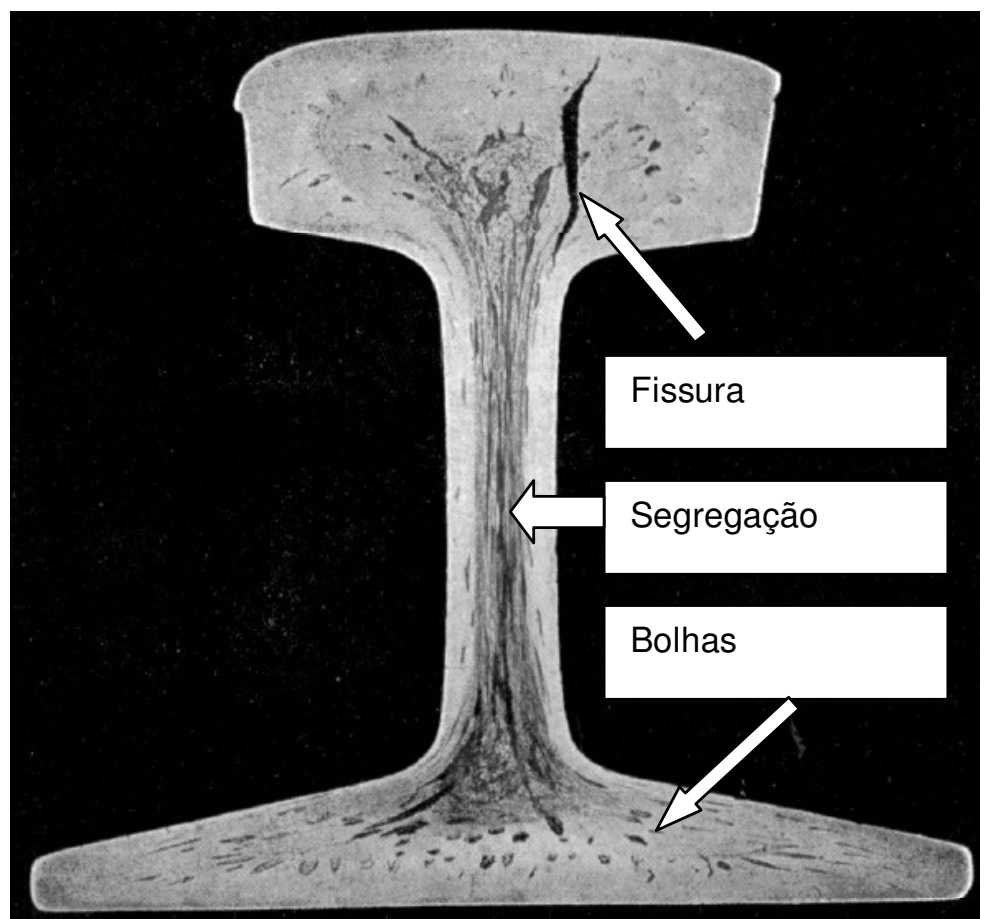

Figura ( D-2 ) - Trilho com segregação, bolhas e fissura interna (COLPAERT, 1959) 


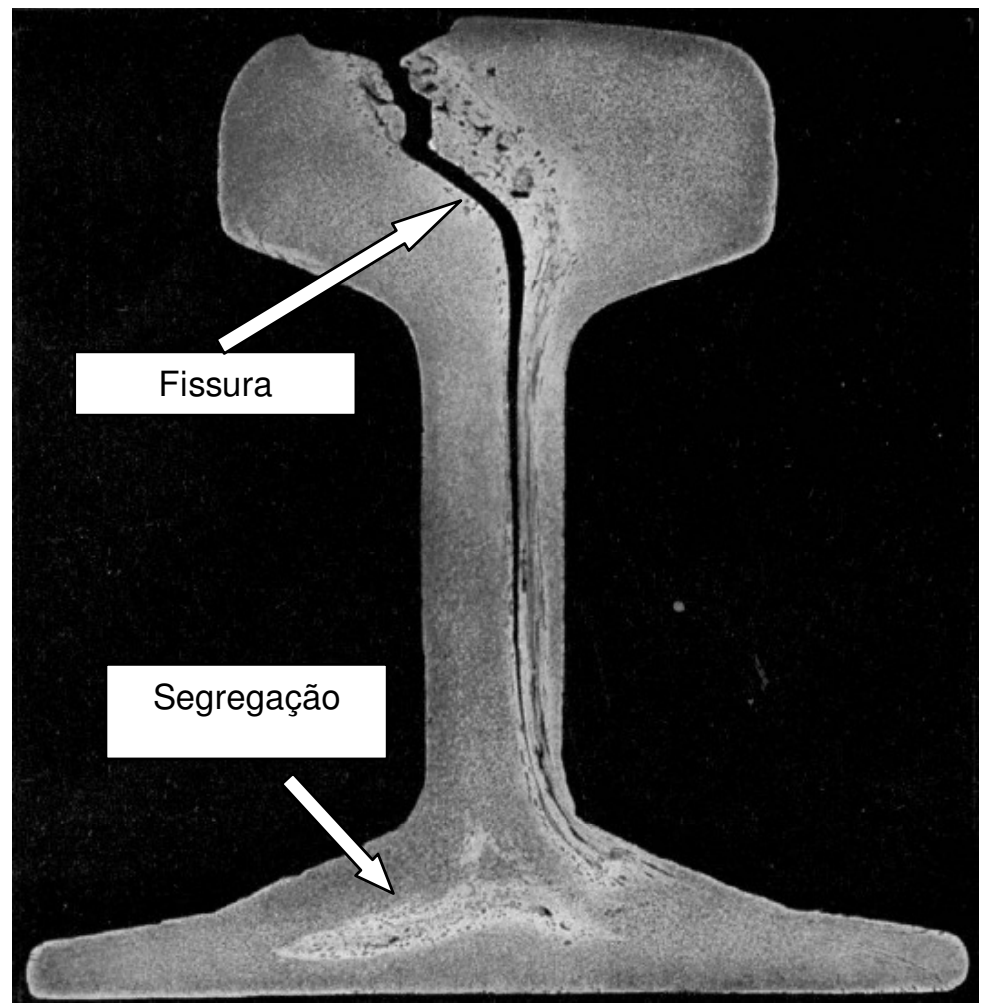

Figura ( D-3 ) - Trilho com segregação e fissura (COLPAERT, 1959)

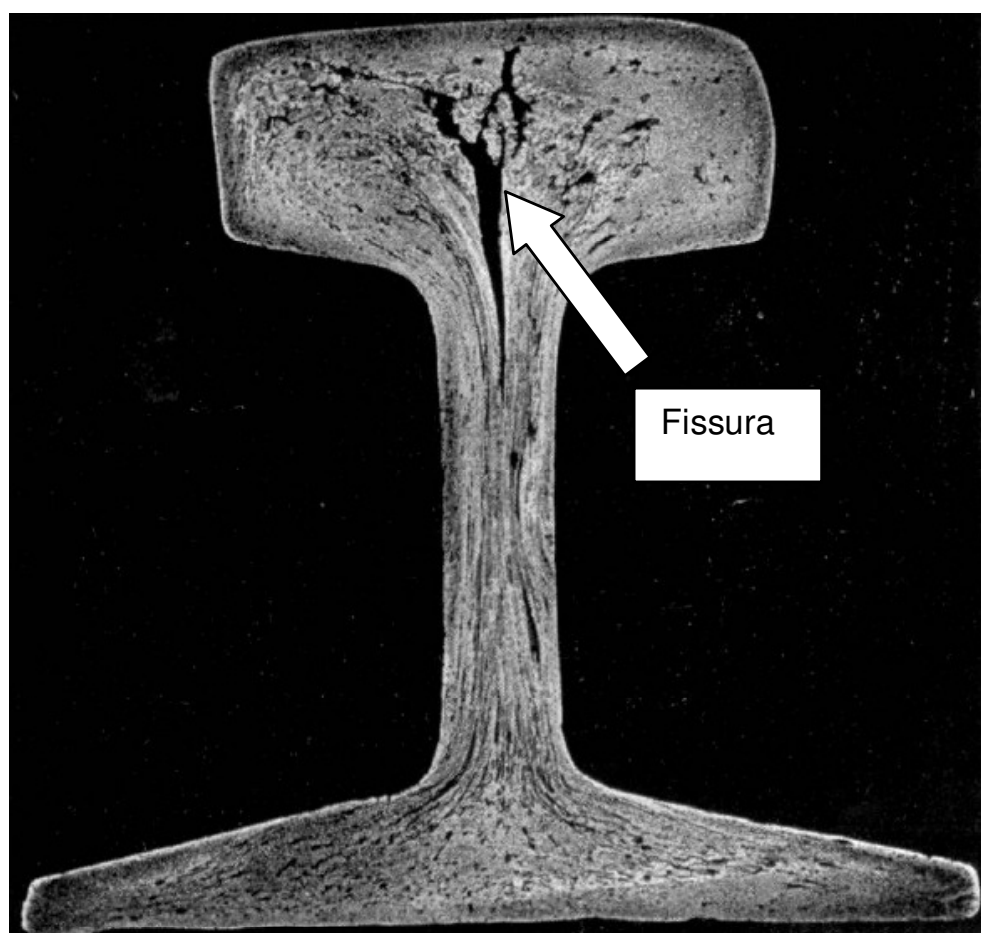

Figura ( D-4 ) - Trilho fissurado devido a trincas de fadiga (COLPAERT, 1959) 


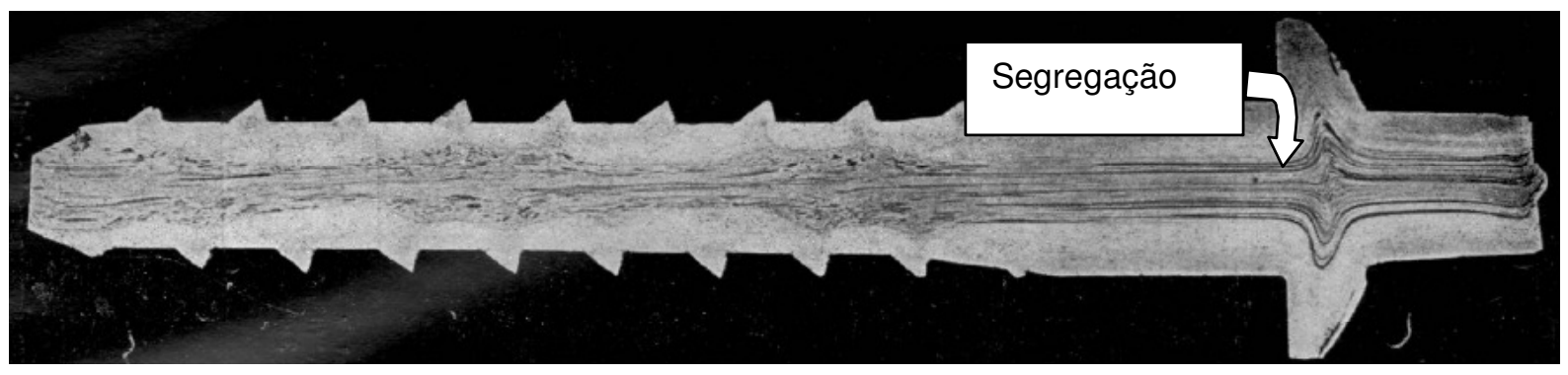

Figura ( D-5 ) - Tirefão com segregação (COLPAERT, 1959)

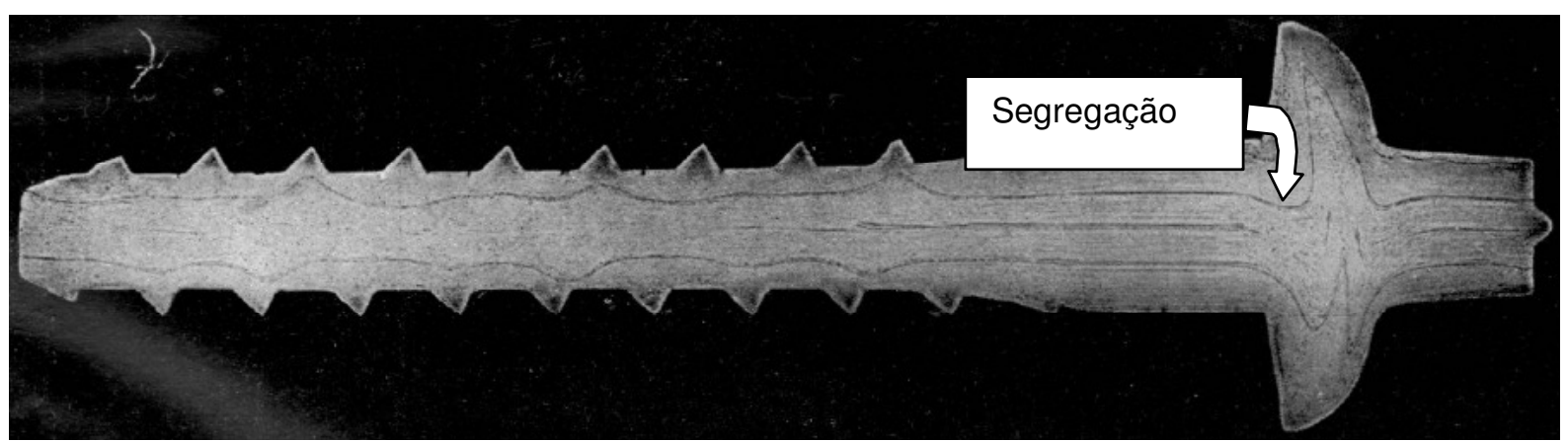

Figura ( D-6 ) - Tirefão com segregação (COLPAERT, 1959) 


\section{APÊNDICE E - MODOS DE FALHA SEGUNDO FMD-97 (1997)}

A referência FMD-97 (1997) apresenta as informações quanto ao modo de falha conforme Figura ( E-1 ). Os campos principais para este trabalho são o campo de componentes e o de modo de falha.

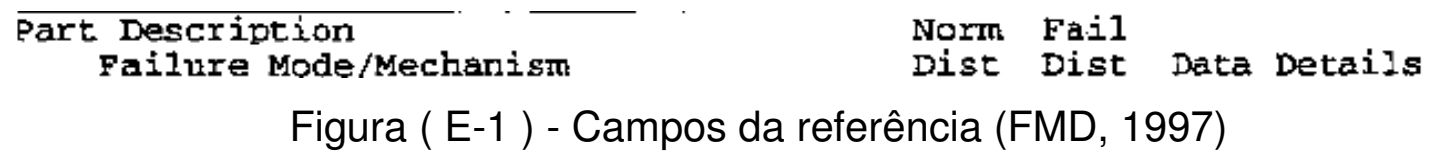

Na Figura ( E-2 ) são apresentadas as falhas referentes à roda. Como nota, no presente trabalho, não são consideradas as falhas classificadas como desconhecidas pois não é possível a determinação dos efeitos no respectivo FMEA. Também não são consideradas as falhas classificadas como Induced, pois se julga que as mesmas são relacionadas com a causa do modo de falha e não ao modo de falha propriamente dito, além disso, é considerado que este modo de falha já está englobado nos outros modos de falha,.

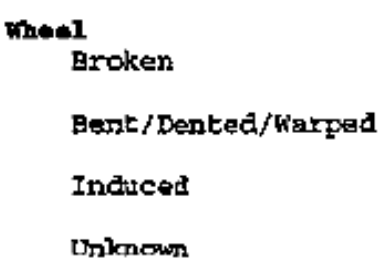

Figura ( E-2 ) - Falhas referentes à roda (FMD-97, 1997)

Na Figura ( E-3) são apresentadas as falhas referentes ao eixo. Como nota, no presente trabalho, não são consideradas as falhas classificadas como desconhecidas, pois não é possível a determinação dos efeitos no respectivo FMEA. 
Axle

\section{Chaffed}

Bent /Dented/Warped

WecharleaI Damzige

Unknown
$77.88 \quad 70.08$ Chatfed

11.1810 .08 Distorted

$11.18 \quad 20.0 \%$ Dopnaged

10.08 Doknown

Figura ( E-3 ) - Falhas referentes ao eixo (FMD-97, 1997)

Na Figura ( E-4 ) são apresentadas as falhas referentes à mola. Foram desconsiderados os seguintes modos de falha:

- Falhas classificadas como desconhecidas não são consideradas, pois não é possível a determinação dos efeitos no respectivo FMEA.

- Falhas classificadas como binding/sticking, excessive play foram consideradas no modo de falha weakened. No presente trabalho foi chamado de "inoperante por enfraquecimento", que apesar de não ser a tradução correta, permite um melhor entendimento.

- Falhas classificadas como aged/deteriored foram consideradas no modo de falha worn. No presente trabalho foi chamado de "uso além da vida útil", que apesar de não ser a tradução correta, permite um melhor entendimento.

- Não são consideradas as falhas classificadas como Induced, pois se julga que as mesmas são relacionadas com a causa do modo de falha e não ao modo de falha propriamente dito, além disso, é considerado que este modo de falha já está englobado nos outros modos de falha. 

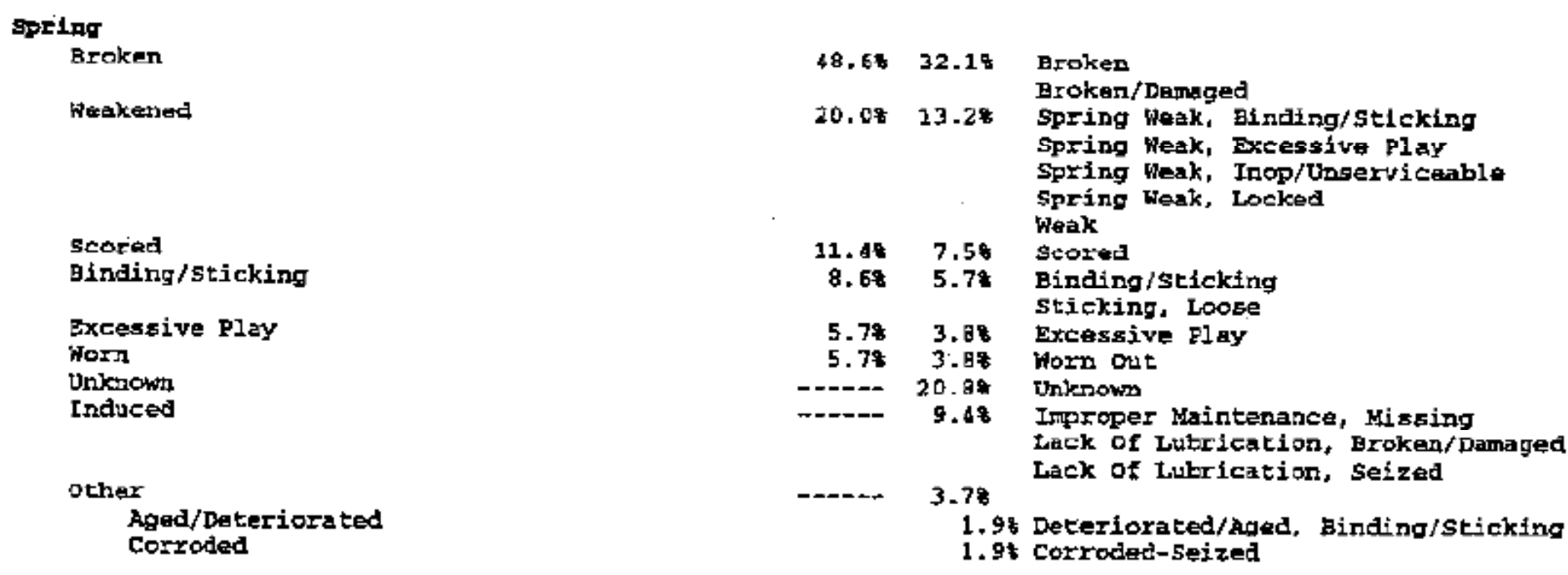

1.98 Deteriorated/Aged, Binding/Sticking 1. . Corrodet-Seized

Figura ( E-4 ) - Falhas referentes à mola (FMD-97, 1997)

Na Figura ( E-5 ) são apresentadas as falhas referentes ao redutor.

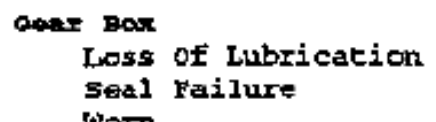

Figura ( E-5 ) - Falhas referentes ao redutor (FMD-97, 1997)

Na Figura ( E-6 ) e na Figura ( E-7 ) são apresentadas as falhas referentes as sapatas de freio. No presente trabalho, foram desconsiderados os seguintes modos de falha:

- O modo de falha hot spotting foi considerado no modo de falha scored, que foi traduzido como marcado.

- Falhas classificadas como desconhecidas não são consideradas pois não é possível a determinação dos efeitos no respectivo FMEA. 
- O modo de falha fade foi considerado no modo de falha worn, que foi traduzido como deteriorado.

- Não são consideradas as falhas classificadas como Induced, pois se julga que as mesmas são relacionadas com a causa do modo de falha e não ao modo de falha propriamente dito, além disso, é considerado que este modo de falha já está englobado nos outros modos de falha.

Brake, Frietion, rinteriel

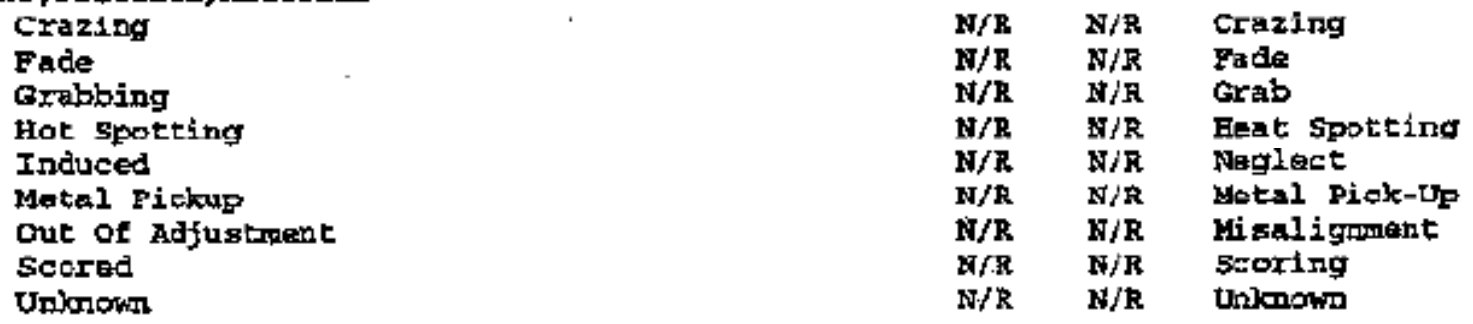

Figura ( E-6 ) - Falhas referentes às sapatas de freio (FMD-97, 1997)

Brake, show, Linting

worn

out of Adfustruent

Unknown
66.7840 .09 worn out

33.38 20.04 Brakes Not Adjusted

- 40.01 Daknown

Figura ( E-7 ) - Falhas referentes às sapatas de freio (FMD-97, 1997)

Na Figura ( E-8 ) são apresentadas as falhas referentes ao cilindro de freio e ao mecanismo do freio. No presente trabalho, os dois modos de falha leaking foram agrupados em apenas um. 


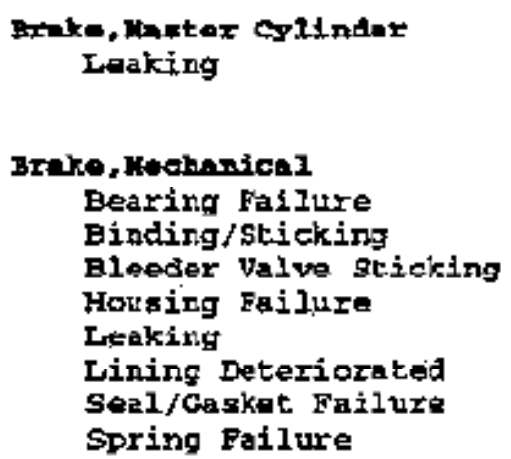

100.08 100.08 Leaking

Figura ( E-8 ) - Falhas referentes ao cilindro de freio e ao mecanismo (FMD-97, 1997)

Na Figura ( E-9 ) são apresentadas as falhas referentes ao trilho. Como nota, não são consideradas as falhas classificadas como Induced, pois se julga que as mesmas são relacionadas com a causa do modo de falha e não ao modo de falha propriamente dito, além disso, é considerado que este modo de falha já está englobado nos outros modos de falha.

\section{And1 Aespmbzy \\ Broker}

Induced

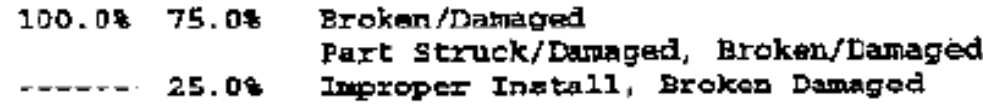

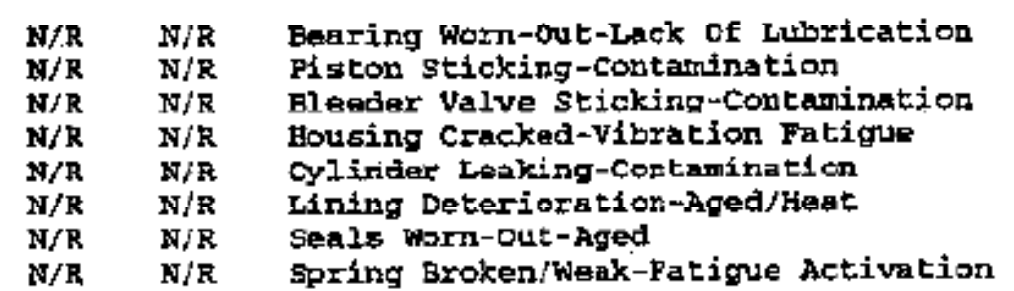

spring Broken/Weak-Patigue Activation

Figura ( E-9 ) - Falhas referentes ao trilho (FMD-97, 1997)

Na Figura ( E-10 ) são apresentadas as falhas referentes às talas de junção e fixação. Como nota, não são consideradas as falhas classificadas como Induced, pois se julga que as mesmas são relacionadas com a causa do modo de falha e não ao modo de falha propriamente dito, além disso, é considerado que este modo de falha já está englobado nos outros. Outro modo de falha que não é considerado é o de falha na manufatura, já que também se considera como a causa e não ao modo de falha propriamente dito. 
Solit, Ond rexanl

Broken

Horn

Cracked/Fractured

Brcessive Vibration

Induced

Worknanship

\author{
$69.0341 .4 \%$ Hroken/Damaged \\ Broken/Seperated, Broken/Damaged \\ 23.8814 .38 Worn, Excessive Play \\ Wom, Inop/Doserviceable \\ Word, Loose \\ A.85 2.98 Cracked \\ 2.4 1.44 Vracket/split-Inop/0nserviceable \\ Caused By Other Failure-Broken/Darnaged \\ Fell off or Lost \\ Inpropax Installation, Bicken/Damaged \\ Intropar Mainterance, Broken/Dameged \\ Iack of haintenance, Binding/Sticking \\ Lack of hainterarce, corroded

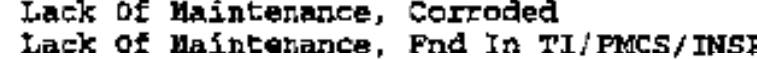 \\ Fell off or Lost, Missing \\ hIong Fart, Broken/Damaged
}

Figura ( E-10 ) - Falhas referentes às talas de junção e fixações (FMD-97, 1997) 


\section{APÊNDICE F- EXEMPLO DE PERFIL DE RODA UIC-ERRI}

Figura ( F-1 )- Perfil de Roda UIC-ERRI para roda com diâmetro entre 1000 mm e $760 \mathrm{~mm}$ e altura de flange igual a $28 \mathrm{~mm}$ (UIC 510 - 2 OR, 2004)

continua

\begin{tabular}{|c|c|c|c|c|c|c|c|}
\hline NR & $\mathrm{Yr}(\mathrm{mm})$ & $\mathrm{Zr}(\mathrm{mm})$ & $\tan \delta$ & NR & $\mathrm{Yr}(\mathrm{mm})$ & $\mathrm{Zr}(\mathrm{mm})$ & $\operatorname{Tan} \delta$ \\
\hline 1 & $-70,0$ & $-9,519$ & & 131 & $-5,0$ & $-0,211$ & 0,0514 \\
\hline 2 & $-69,5$ & $-14,019$ & $-4,4444$ & 132 & $-4,5$ & $-0,185$ & 0,0494 \\
\hline 3 & $-69,0$ & $-15,844$ & $-3,0832$ & 133 & $-4,0$ & $-0,161$ & 0,0475 \\
\hline 4 & $-68,5$ & $-17,217$ & $-2,4684$ & 134 & $-3,5$ & $-0,138$ & 0,0456 \\
\hline 5 & $-68,0$ & $-18,351$ & $-2,0947$ & 135 & $-3,0$ & $-0,116$ & 0,0438 \\
\hline 6 & $-67,5$ & $-19,330$ & $-1,8347$ & 136 & $-2,5$ & $-0,094$ & 0,0419 \\
\hline 7 & $-67,0$ & $-20,196$ & $-1,6390$ & 137 & $-2,0$ & $-0,074$ & 0,0402 \\
\hline 8 & $-66,5$ & $-20,976$ & $-1,4339$ & 138 & $-1,5$ & $-0,054$ & 0,0385 \\
\hline 9 & $-66,0$ & $-21,685$ & $-1,3563$ & 139 & $-1,0$ & $-0,035$ & 0,0368 \\
\hline 10 & $-65,5$ & $-22,335$ & $-1,2484$ & 140 & $-0,5$ & $-0,017$ & 0,0352 \\
\hline 11 & $-65,0$ & $-22,936$ & $-1,1553$ & 141 & 0,0 & 0,000 & 0,0336 \\
\hline 12 & $-64,5$ & $-23,492$ & $-1,0735$ & 142 & 0,5 & 0,016 & 0,0320 \\
\hline 13 & $-64,0$ & $-24,011$ & $-1,0006$ & 143 & 1,0 & 0,032 & 0,0305 \\
\hline 14 & $-63,5$ & $-24,494$ & $-0,9349$ & 144 & 1,5 & 0,047 & 0,0291 \\
\hline 15 & $-63,0$ & $-24,947$ & $-0,8751$ & 145 & 2,0 & 0,061 & 0,0277 \\
\hline 16 & $-62,5$ & $-25,367$ & $-0,8006$ & 146 & 2,5 & 0,075 & 0,0263 \\
\hline 17 & $-62,0$ & $-25,747$ & $-0,7182$ & 147 & 3,0 & 0,087 & 0,0250 \\
\hline 18 & $-61,5$ & $-26,087$ & $-0,6444$ & 148 & 3,5 & 0,100 & 0,0237 \\
\hline 19 & $-61,0$ & $-26,392$ & $-0,5774$ & 149 & 4,0 & 0,111 & 0,0224 \\
\hline 20 & $-60,5$ & $-26,665$ & $-0,5157$ & 150 & 4,5 & 0,122 & 0,0212 \\
\hline 21 & $-60,0$ & $-26,909$ & $-0,4583$ & 151 & 5,0 & 0,132 & 0,0201 \\
\hline 22 & $-59,5$ & $-27,124$ & $-0,4045$ & 152 & 5,5 & 0,142 & 0,0139 \\
\hline 23 & $-59,0$ & $-27,314$ & $-0,3536$ & 153 & 6,0 & 0,151 & 0,0179 \\
\hline 24 & $-58,5$ & $-27,478$ & $-0,3049$ & 154 & 6,5 & 0,160 & 0,0169 \\
\hline 25 & $-58,0$ & $-27,619$ & $-0,2582$ & 155 & 7,0 & 0,168 & 0,0159 \\
\hline 26 & $-57,5$ & $-27,737$ & $-0,2130$ & 156 & 7,5 & 0,176 & 0,0150 \\
\hline 27 & $-57,0$ & $-27,832$ & $-0,1690$ & 157 & 8,0 & 0,183 & 0,0141 \\
\hline 28 & $-56,5$ & $-27,906$ & $-0,1260$ & 158 & 8,5 & 0,190 & 0,0133 \\
\hline 29 & $-56,0$ & $-27,958$ & $-0,0836$ & 159 & 9,0 & 0,196 & 0,0126 \\
\hline 30 & $-55,5$ & $-27,990$ & $-0,0417$ & 160 & 9,5 & 0,203 & 0,0119 \\
\hline 31 & $-55,0$ & $-28,000$ & 0,0000 & 161 & 10,0 & 0,208 & 0,0113 \\
\hline 32 & $-54,5$ & $-27,990$ & 0,0417 & 162 & 10,5 & 0,214 & 0,0107 \\
\hline 33 & $-54,0$ & $-27,958$ & 0,0836 & 163 & 11,0 & 0,219 & 0,0102 \\
\hline 34 & $-53,5$ & $-27,906$ & 0,1260 & 164 & 11,5 & 0,224 & 0,0098 \\
\hline 35 & $-53,0$ & $-27,832$ & 0,1690 & 165 & 12,0 & 0,229 & 0,0094 \\
\hline 36 & $-52,5$ & $-27,737$ & 0,2130 & 166 & 12,5 & 0,234 & 0,0091 \\
\hline 37 & $-52,0$ & $-27,619$ & 0,2582 & 167 & 13,0 & 0,238 & 0,0089 \\
\hline 38 & $-51,5$ & $-27,478$ & 0,3049 & $16 \mathrm{~B}$ & 13,5 & 0,242 & 0,0038 \\
\hline
\end{tabular}


continuação

\begin{tabular}{|c|c|c|c|c|c|c|c|}
\hline NR & $\operatorname{Yr}(\mathrm{mm})$ & $\mathrm{Zr}(\mathrm{mm})$ & $\tan \delta$ & $\mathrm{NR}$ & $\operatorname{Yr}(\mathrm{mm})$ & $\mathrm{Zr}(\mathrm{mm})$ & $\operatorname{Tan} \delta$ \\
\hline 39 & $-51,0$ & $-27,314$ & 0,3536 & 169 & 14,0 & 0,247 & 0,0037 \\
\hline 40 & $-50,5$ & $-27,124$ & 0,4045 & 170 & 14,5 & 0,251 & 0,0038 \\
\hline 41 & $-50,0$ & $-26,909$ & 0,4583 & 171 & 15,0 & 0,256 & 0,0039 \\
\hline 42 & $-49,5$ & $-26,666$ & 0,5080 & 172 & 15,5 & 0,260 & 0,0091 \\
\hline 43 & $-49,0$ & $-26,403$ & 0,5441 & 173 & 16,0 & 0,265 & 0,0094 \\
\hline 44 & $-48,5$ & $-26,122$ & 0,5819 & 174 & 16,5 & 0,269 & 0,0097 \\
\hline 45 & $-48,0$ & $-25,821$ & 0,6216 & 175 & 17,0 & 0,274 & 0,0102 \\
\hline 46 & $-47,5$ & $-25,500$ & 0,6636 & 176 & 17,5 & 0,280 & 0,0108 \\
\hline 47 & $-47,0$ & $-25,157$ & 0,7081 & 177 & 18,0 & 0,285 & 0,0115 \\
\hline 48 & $-46,5$ & $-24,791$ & 0,7557 & 178 & 18,5 & 0,291 & 0,0123 \\
\hline 49 & $-46,0$ & $-24,401$ & 0,8068 & 179 & 19,0 & 0,298 & 0,0132 \\
\hline 50 & $-45,5$ & $-23,984$ & 1,8620 & 180 & 19,5 & 0,304 & 0,0142 \\
\hline 51 & $-45,0$ & $-23,538$ & 1,9222 & 181 & 20,0 & 0,312 & 0,0153 \\
\hline 52 & $-44,5$ & $-23,060$ & 1,9883 & 182 & 20,5 & 0,320 & 0,0165 \\
\hline 53 & $-44,0$ & $-22,548$ & 1,0616 & 183 & 21,0 & 0,328 & 0,0178 \\
\hline 54 & $-43,5$ & $-21,997$ & 1,1440 & 184 & 21,5 & 0,338 & 0,0192 \\
\hline 55 & $-43,0$ & $-21,402$ & 1,2380 & 185 & 22,0 & 0,348 & 0,0208 \\
\hline 56 & $-42,5$ & $-20,757$ & 1,3470 & 186 & 22,5 & 0,358 & 0,0224 \\
\hline 57 & $-42,0$ & $-20,052$ & 1,4762 & 187 & 23,0 & 0,370 & 0,0241 \\
\hline 58 & $-41,5$ & $-19,276$ & 1,6338 & 188 & 23,5 & 0,382 & 0,0260 \\
\hline 59 & $-41,0$ & $-18,411$ & 1,8335 & 189 & 24,0 & 0,396 & 0,0279 \\
\hline 60 & $-40,5$ & $-17,431$ & 2,1007 & 190 & 24,5 & 0,410 & 0,0300 \\
\hline 61 & $-40,0$ & $-16,291$ & 2,4891 & 191 & 25,0 & 0,426 & 0,0321 \\
\hline 62 & $-39,5$ & $-14,949$ & 2,7475 & 192 & 25,5 & 0,443 & 0,0343 \\
\hline 63 & $-39,0$ & $-13,575$ & 2,7475 & 193 & 26,0 & 0,460 & 0,0366 \\
\hline 64 & $-33,5$ & $-12,201$ & 2,7475 & 194 & 26,5 & 0,479 & 0,0390 \\
\hline 65 & $-38,0$ & $-10,968$ & 2,1520 & 195 & 27,0 & 0,499 & 0,0414 \\
\hline 66 & $-37,5$ & $-10,000$ & 1,7514 & 196 & 27,5 & 0,521 & 0,0439 \\
\hline 67 & $-37,0$ & $-9,194$ & 1,4878 & 197 & 28,0 & 0,543 & 0,0464 \\
\hline 68 & $-36,5$ & $-8,501$ & 1,2950 & 198 & 28,5 & 0,567 & 0,0490 \\
\hline 69 & $-36,0$ & $-7,892$ & 1,1444 & 199 & 29,0 & 0,592 & 0,0515 \\
\hline 70 & $-35,5$ & $-7,352$ & 1,0214 & 200 & 29,5 & 0,619 & 0,0541 \\
\hline 71 & $-35,0$ & $-6,867$ & 0,9176 & 201 & 30,0 & 0,646 & 0,0566 \\
\hline 72 & $-34,5$ & $-6,432$ & 0,8279 & 202 & 30,5 & 0,675 & 0,0591 \\
\hline 73 & $-34,0$ & $-6,038$ & 0,7493 & 203 & 31,0 & 0,705 & 0,0615 \\
\hline 74 & $-33,5$ & $-5,681$ & 0,6798 & 204 & 31,5 & 0,737 & 0,0638 \\
\hline 75 & $-33,0$ & $-5,357$ & 0,6181 & 205 & 32,0 & 0,769 & 0,0660 \\
\hline 76 & $-32,5$ & $-5,062$ & 0,5630 & 206 & 32,5 & 0,802 & 0,0667 \\
\hline 77 & $-32,0$ & $-4,793$ & 0,5140 & 207 & 33,0 & 0,836 & 0,0667 \\
\hline 78 & $-31,5$ & $-4,547$ & 0,4706 & 208 & 33,5 & 0,869 & 0,0667 \\
\hline 79 & $-31,0$ & $-4,321$ & 0,4322 & 209 & 34,0 & 0,902 & 0,0667 \\
\hline 80 & $-30,5$ & $-4,114$ & 0,3988 & 210 & 34,5 & 0,936 & 0,0667 \\
\hline 81 & $-30,0$ & $-3,922$ & 0,3698 & 211 & 35,0 & 0,969 & 0,0667 \\
\hline 82 & $-29,5$ & $-3,743$ & 0,3449 & 212 & 35,5 & 1,002 & 0,0667 \\
\hline 83 & $-29,0$ & $-3,576$ & 0,3237 & 213 & 36,0 & 1,036 & 0,0667 \\
\hline 84 & $-28,5$ & $-3,419$ & 0,3055 & 214 & 36,5 & 1,069 & 0,0667 \\
\hline
\end{tabular}


conclusão

\begin{tabular}{|c|c|c|c|c|c|c|c|}
\hline NR & $\mathrm{Yr}(\mathrm{mm})$ & $\mathrm{Zr}(\mathrm{mm})$ & $\tan \delta$ & $\mathrm{NR}$ & $\mathrm{Yr}(\mathrm{mm})$ & $\mathrm{Zr}(\mathrm{mm})$ & $\operatorname{Tan} \delta$ \\
\hline 85 & $-28,0$ & $-3,270$ & 0,2899 & 215 & 37,0 & 1,102 & 0,0667 \\
\hline 86 & $-27,5$ & $-3,129$ & 0,2763 & 216 & 37,5 & 1,136 & 0,0667 \\
\hline 87 & $-27,0$ & $-2,994$ & 0,2639 & 217 & 38,0 & 1,169 & 0,0667 \\
\hline 88 & $-26,5$ & $-2,365$ & 0,2525 & 218 & 38,5 & 1,202 & 0,0667 \\
\hline 89 & $-26,0$ & $-2,741$ & 0,2417 & 219 & 39,0 & 1,236 & 0,0667 \\
\hline 90 & $-25,5$ & $-2,623$ & 0,2315 & 220 & 39,5 & 1,269 & 0,0667 \\
\hline 91 & $-25,0$ & $-2,509$ & 0,2218 & 221 & 40,0 & 1,302 & 0,0667 \\
\hline 92 & $-24,5$ & $-2,401$ & 0,2127 & 222 & 40,5 & 1,336 & 0,0667 \\
\hline 93 & $-24,0$ & $-2,297$ & 0,2041 & 223 & 41,0 & 1,369 & 0,0667 \\
\hline 94 & $-23,5$ & $-2,197$ & 0,1960 & 224 & 41,5 & 1,402 & 0,0667 \\
\hline 95 & $-23,0$ & $-2,101$ & 0,1883 & 225 & 42,0 & 1,436 & 0,0667 \\
\hline 96 & $-22,5$ & $-2,008$ & 0,1810 & 226 & 42,5 & 1,469 & 0,0667 \\
\hline 97 & $-22,0$ & $-1,920$ & 0,1741 & 227 & 43,0 & 1,502 & 0,0667 \\
\hline 98 & $-21,5$ & $-1,834$ & 0,1675 & 228 & 43,5 & 1,536 & 0,0667 \\
\hline 99 & $-21,0$ & $-1,752$ & 0,1613 & 229 & 44,0 & 1,569 & 0,0667 \\
\hline 100 & $-20,5$ & $-1,673$ & 0,1553 & 230 & 44,5 & 1,602 & 0,0667 \\
\hline 101 & $-20,0$ & $-1,597$ & 0,1497 & 231 & 45,0 & 1,636 & 0,0667 \\
\hline 102 & $-19,5$ & $-1,523$ & 0,1443 & 232 & 45,5 & 1,669 & 0,0667 \\
\hline 103 & $-19,0$ & $-1,452$ & 0,1392 & 233 & 46,0 & 1,702 & 0,0667 \\
\hline 104 & $-18,5$ & $-1,384$ & 0,1342 & 234 & 46,5 & 1,736 & 0,0667 \\
\hline 105 & $-18,0$ & $-1,318$ & 0,1295 & 235 & 47,0 & 1,769 & 0,0667 \\
\hline 106 & $-17,5$ & $-1,254$ & 0,1250 & 236 & 47,5 & 1,802 & 0,0667 \\
\hline 107 & $-17,0$ & $-1,193$ & 0,1207 & 237 & 48,0 & 1,836 & 0,0667 \\
\hline 108 & $-16,5$ & $-1,134$ & 0,1166 & 238 & 48,5 & 1,869 & 0,0667 \\
\hline 109 & $-16,0$ & $-1,076$ & 0,1126 & 239 & 49,0 & 1,902 & 0,0667 \\
\hline 110 & $-15,5$ & $-1,021$ & 0,1088 & 240 & 49,5 & 1,936 & 0,0667 \\
\hline 111 & $-15,0$ & $-0,967$ & 0,1051 & 241 & 50,0 & 1,969 & 0,0667 \\
\hline 112 & $-14,5$ & $-0,916$ & 0,1016 & 242 & 50,5 & 2,002 & 0,0667 \\
\hline 113 & $-14,0$ & $-0,866$ & 0,0981 & 243 & 51,0 & 2,036 & 0,0667 \\
\hline 114 & $-13,5$ & $-0,818$ & 0,0948 & 244 & 51,5 & 2,069 & 0,0667 \\
\hline 115 & $-13,0$ & $-0,771$ & 0,0916 & 245 & 52,0 & 2,102 & 0,0667 \\
\hline 116 & $-12,5$ & $-0,726$ & 0,0885 & 246 & 52,5 & 2,136 & 0,0667 \\
\hline 117 & $-12,0$ & $-0,682$ & 0,0855 & 247 & 53,0 & 2,169 & 0,0667 \\
\hline 118 & $-11,5$ & $-0,640$ & 0,0826 & 248 & 53,5 & 2,202 & 0,0667 \\
\hline 119 & $-11,0$ & $-0,600$ & 0,0798 & 249 & 54,0 & 2,236 & 0,0667 \\
\hline 120 & $-10,5$ & $-0,561$ & 0,0771 & 250 & 54,5 & 2,269 & 0,0667 \\
\hline 121 & $-10,0$ & $-0,523$ & 0,0744 & 251 & 55,0 & 2,302 & 0,0667 \\
\hline 122 & $-9,5$ & $-0,486$ & 0,0718 & 252 & 55,5 & 2,336 & 0,0667 \\
\hline 123 & $-9,0$ & $-0,451$ & 0,0693 & 253 & 56,0 & 2,369 & 0,0667 \\
\hline 124 & $-8,5$ & $-0,417$ & 0,0669 & 254 & 56,5 & 2,402 & 0,0667 \\
\hline 125 & $-3,0$ & $-0,384$ & 0,0645 & 255 & 57,0 & 2,436 & 0,0667 \\
\hline 126 & $-7,5$ & $-0,352$ & 0,0622 & 256 & 57,5 & 2,469 & 0,0667 \\
\hline 127 & $-7,0$ & $-0,322$ & 0,0599 & 257 & 58,0 & 2,502 & 0,0667 \\
\hline 128 & $-6,5$ & $-0,292$ & 0,0577 & 258 & 58,5 & 2,536 & 0,0667 \\
\hline 129 & $-6,0$ & $-0,264$ & 0,0556 & 259 & 59,0 & 2,569 & 0,0667 \\
\hline 130 & $-5,5$ & $-0,237$ & 0,0535 & 260 & 59,5 & 2,602 & 0,0667 \\
\hline
\end{tabular}

